\author{
UNIVERSIDADE DE SÃO PAULO \\ ESCOLA DE ENGENHARIA DE SÃO CARLOS
}

ANA LAURA RAYMUNDO PAVAN

AVALIAÇÃO DE IMPACTOS DO CICLO DE VIDA NO BRASIL: DESENVOLVIMENTO DE FATORES DE CARACTERIZAÇÃO REGIONAIS PARA SERVIÇOS ECOSSISTÊMICOS RELACIONADOS À QUALIDADE DO SOLO

SÃO CARLOS 



\title{
AVALIAÇÃO DE IMPACTOS DO CICLO DE VIDA NO BRASIL: DESENVOLVIMENTO DE FATORES DE CARACTERIZAÇÃO REGIONAIS PARA SERVIÇOS ECOSSISTEMMICOS RELACIONADOS À QUALIDADE DO SOLO
}

\author{
Tese apresentada à Escola de Engenharia de \\ São Carlos da Universidade de São Paulo, \\ como requisito para a obtenção do Título de \\ Doutora em Ciências da Engenharia \\ Ambiental. \\ Área de Concentração: Ecologia Industrial \\ Orientador: Prof. Associado Aldo Roberto \\ Ometto
}

São Carlos 
AUTORIZO A REPRODUÇÃO TOTAL OU PARCIAL DESTE TRABALHO, POR QUALQUER MEIO CONVENCIONAL OU ELETRÔNICO, PARA FINS DE ESTUDO E PESQUISA, DESDE QUE CITADA A FONTE.

Ficha catalográfica elaborada pela Biblioteca Prof. Dr. Sérgio Rodrigues Fontes da EESC/USP com os dados inseridos pelo(a) autor(a).

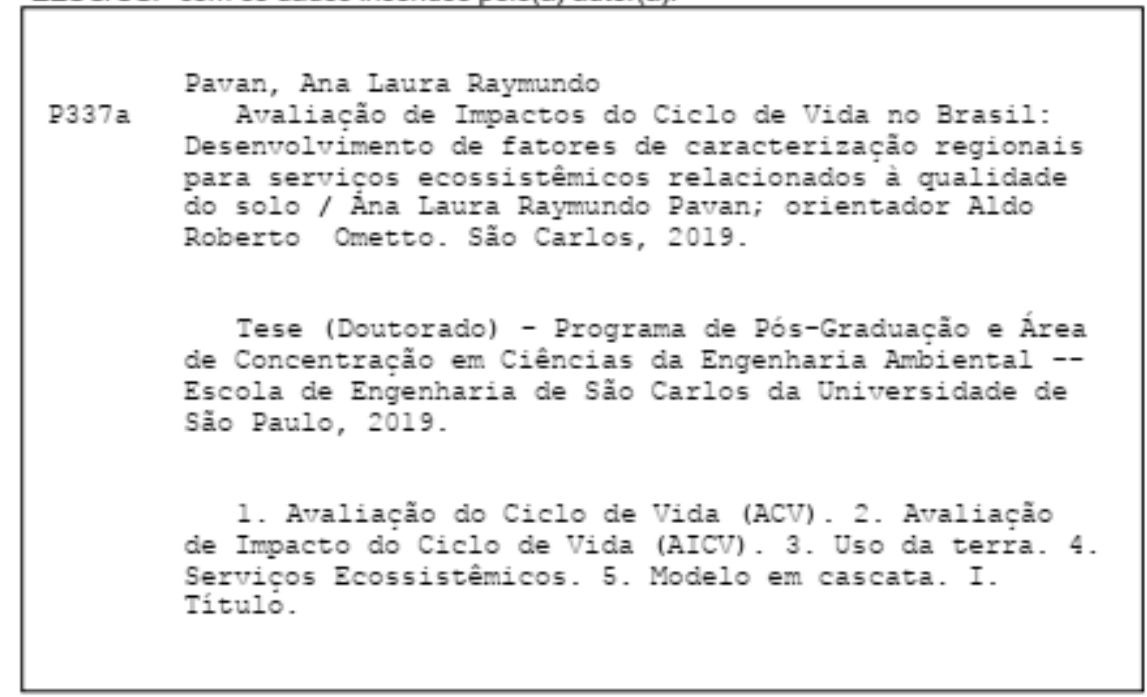




\section{FOLHA DE JULGAMENTO}

Candidata: ANA LAURA RAYMUNDO PAVAN

Título da tese: "Avaliação de impactos do ciclo de vida no Brasil: desenvolvimento de fatores de caracterização regionais para serviços ecossistêmicos relacionados à qualidade do solo"

Data da defesa: 24/01/2019

Comissão Julgadora:

Prof. Associado Aldo Roberto Ometto

(Orientador)

(Escola de Engenharia de São Carlos/EESC)

Prof. Associado Victor Eduardo Lima Ranieri

(Escola de Engenharia de São Carlos/EESC)

Prof ${ }^{\circ}$. Dr ${ }^{\circ}$. Cássia Maria Lie Ugaya

(Universidade Tecnológica Federal do Paraná/UTFPR)

$\mathrm{Dr}^{\circ}$. Maria Cléa Brito de Figueirêdo

(Empresa Brasileira de Pesquisa Agropecuária/Embrapa)

Profa. Dr ${ }^{\circ}$. Cinthia Rubio Urbano da Silva

(Centro Universitário Claretiano)

\section{Resultado:}
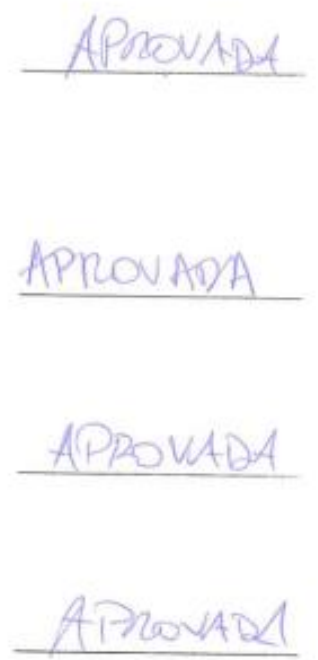

APRONADA

Coordenador do Programa de Pós-Graduação em Ciências da Engenharia Ambiental: Prof. Associado Frederico Fabio Mauad

Presidente da Comissāo de Pós-Graduação:

Prof. Titular Luís Fernando Costa Alberto 

Cada aprendiz em sua lição. Cada trabalhador na tarefa que lhe foi competida. Cada vaso em sua utilidade. Cada lutador com a prova necessária. Assim, cada um de nós tem o testemunho individual no caminho da vida.

Francisco Cândido Xavier (ditado por Emmanuel) 



\section{AGRADECIMENTOS}

Agradeço em primeiro lugar a Deus, pelo dom da vida e por todo o aprendizado e bênçãos que me concede.

Agradeço a minha família, em especial meus pais, Luiz Roberto Pavan e Maria Inês Raymundo, por todo apoio e por mais essa oportunidade reencarnatória, e minha irmã Ana Carolina R. Veloso pelo apoio e carinho em todos os momentos.

Ao Prof. Aldo Roberto Ometto, todo meu respeito, admiração e gratidão pelo apoio e suporte ao longo destes seis anos de Pós-Graduação.

Agradeço também todos os professores e funcionários tanto do Programa de Pós-Graduação em Ciências da Engenharia Ambiental, quanto da Engenharia de Produção, pelos valiosos ensinamentos e auxílio ao longo do caminho.

Aos professores que participaram da banca de qualificação e defesa, pelas contribuições.

A todos meus amigos de São Carlos, com quem compartilhei momentos de alegrias, cafés, risadas, mas que também me apoiaram nas horas de preocupações e aflições. Toda minha gratidão e carinho à Ana Carolina, Carol, Ana Carvalho, Lucas Calache, Lucas Zanon, Júlia, Camilinha, Brayan, Rafael, Giovana, Diego, Diogo, Zé, Renata, Efigênia, Daiane, André, Camila, Yovanna, Fernanda, Isa e Danielle.

À Natalia pela amizade, ajuda e incontáveis risadas.

A todos os amigos e trabalhadores da Casa do Caminho - Instituição Espírita, por realizarem tão belo trabalho. Obrigada por todo auxílio, aprendizagem e por fazerem com que minhas percepções mudassem e expandissem tanto.

Às amigas queridas que fazem parte da minha história: Aline, Flávia, Raíssa, Carô, Noelly, Karla, Bárbara, Ana Paula e Elisa.

À Coordenação de Aperfeiçoamento de Pessoal de Nível Superior (Capes) e ao Conselho Nacional de Desenvolvimento Científico e Tecnológico (CNPq) pelo apoio financeiro.

Sou muito grata a todos que de alguma forma fizeram parte desta jornada. 



\section{RESUMO}

PAVAN, A. L. R. Avaliação de Impactos do Ciclo de Vida no Brasil: Desenvolvimento de fatores de caracterização regionais para serviços ecossistêmicos relacionados à qualidade do solo. 2019. 190f. Tese (Doutorado) - Escola de Engenharia de São Carlos, Universidade de São Paulo, São Carlos, 2019.

A Avaliação de Ciclo de Vida (ACV) é um método estruturado, compreensivo e padronizado a nível internacional que quantifica informações sobre emissões, recursos consumidos e impactos ambientais potenciais de produtos através do seu ciclo de vida. Uma das fases do estudo, a Avaliação de Impacto do Ciclo de Vida (AICV), refere-se ao processo quantitativo e/ou qualitativo aplicado na avaliação dos impactos associados ao inventário do ciclo de vida. Dentre os impactos ambientais abordados na AICV estão aqueles relacionados ao uso da terra, sendo avaliados segundo duas vertentes: impactos sobre a biodiversidade e impactos sobre Serviços Ecossistêmicos. A modelagem dos impactos dos serviços ecossistêmicos na ACV ainda apresenta limitações e alguns erros conceituais como, por exemplo, não avaliar de fato os benefícios fornecidos ao homem. Além disso, um dos grandes desafios na ACV refere-se à diferenciação espacial nos procedimentos metodológicos de AICV, sobretudo para impactos devido ao uso da terra. Assim, o principal objetivo desde estudo é discutir a inserção do conceito de serviços ecossistêmicos na ACV e obter fatores de caracterização de impactos em serviços ecossistêmicos relacionados ao solo para a AICV, aplicáveis de maneira regionalizada para o Brasil. A revisão de literatura e comparação do mecanismo ambiental para os impactos do uso da terra na AICV com o modelo em cascata de serviços ecossistêmicos possibilitou o desenvolvimento de um novo modelo conceitual para serviços ecossistêmicos relacionados solo. Cada uma das etapas do modelo de cascata foi alinhada à terminologia da ACV para coincidir com os níveis de modelagem de ponto intermediário e de danos ao mesmo tempo considerando os principais processos, funções, serviços, benefícios e valores relacionados ao solo. Além disso, foram calculados fatores de caracterização para impactos aos serviços ecossistêmicos relacionados à fertilidade do solo através da aplicação de um modelo de caracterização de AICV espacialmente diferenciado. O procedimento metodológico envolveu (i) a definição do mecanismo ambiental, tendo como indicador o teor de Carbono Orgânico do Solo (COS), (ii) a definição da Vegetação Natural Potencial como situação de referência e (iii) a definição das unidades biogeográficas de análise denominadas Associação Solo-Vegetação (ASV). Com base nestes parâmetros, foram calculados os estoques de COS para 32 classes diferentes de uso da terra e os estoques de COS para as situações referência, necessários para o cálculo dos impactos resultantes do uso da terra. Foram calculados e disponibilizados mais de três mil fatores de caracterização aos usuários de ACV, aplicáveis em 32 classes diferentes de uso da terra para 74 unidades biogeográficas (ASV). Além desses, foram obtidos fatores de caracterização também para as 27 unidades federativas do país, que apesar de estarem agregados em divisões políticas, levam em consideração dados regionais de COS. Por fim, os resultados e discussões deste trabalho contribuem na integração de dois campos de estudo e podem auxiliar ao melhor entendimento do sistema de produtos, não apenas focando em danos ambientais, mas também possibilitando a identificação de impactos positivos e agregação de valor.

Palavras-chave: Avaliação do Ciclo de Vida (ACV); Avaliação de Impacto do Ciclo de Vida (AICV); Uso da terra; Serviços Ecossistêmicos; Modelo em cascata. 


\begin{abstract}
PAVAN, A. L. R. Land use Life Cycle Impact Assessment in Brazil: Development of regional characterization factors for ecosystem services related to soil quality. 2019. 190p. Thesis (Doctoral Degree in Environmental Engineering Sciences) - Engineering School of Sao Carlos, University of Sao Paulo, Sao Carlos, 2019.
\end{abstract}

Life Cycle Assessment (LCA) is a structured, comprehensive and standardized method at international level that quantifies information on emissions, resources consumed and potential environmental impacts of products through their life cycle. One of it phases, the Life Cycle Impact Assessment (LCIA), refers to the quantitative and / or qualitative process applied in assessing the impacts associated with the life cycle inventory. Among the environmental impacts addressed in LCIA are those related to land use, being evaluated according to two pathways: impacts on biodiversity and impacts on ecosystem services. The ecosystem services impact modelling on LCA still presents limitations and some conceptual errors, such as not actually evaluating the benefits provided to humans. In addition, one of the major challenges in LCA relates to the spatial differentiation in LCIA methodological procedures, especially for impacts due to land use. Thus, the main goal of the present study is to discuss the ecosystem services concept integration in LCA and obtain characterization factors of soilrelated ecosystem services impacts, regionally applicable to Brazil. The literature review and the LCA environmental mechanism of land use impacts and the cascade model of ecosystem services comparison allowed the development of a new conceptual model for soil-related ecosystem services. Each one of these steps in the cascade model was aligned with the LCA's terminology to match the midpoint and endpoint modelling levels while considering the key processes, functions, services, benefits, and values related to the soil. In addition, characterization factors for ecosystem services related to soil fertility were calculated applying a spatially differentiated characterization model. The methodological procedure involved the (i) environmental mechanism definition, establishing the Soil Organic Carbon content (SOC) as an indicator, (ii) the definition of Potential Natural Vegetation as a reference situation and (iii) the definition of the biogeographic analysis units denominated Soil Vegetation Association (SVA). Based on these parameters, SOC stocks were calculated for 32 different land use classes and SOC stocks for reference situations allowing the calculation of impacts resulting from land use. More than two thousand characterization factors were calculated, being available to LCA users, applicable in 32 different land use classes to 74 biogeographic units (SVA). In addition, characterization factors were also obtained for the 27 Brazilian federative units, which, although aggregated in political divisions, consider SOC regional data. Finally, the results and discussions of this study contribute to the integration of two scientific domains and help to better understand the product system, not only focusing on environmental damages, but also enabling the identification of positive impacts and value aggregation.

Key-words: Life Cycle Assessment (LCA); Life Cycle Impact Assessment (LCIA); Land use; Ecosystem Services; Cascade model. 


\section{LISTA DE FIGURAS}

Figura 1: Modelo cascata e as relações entre as funções dos ecossistemas e bem-estar humano..........22

Figura 2: Exemplos de organizações relacionadas ao conceito de ciclo de vida e ACV. .....................29

Figura 3: Principais resultados da Iniciativa do Ciclo de Vida ao longo dos anos. ..............................30

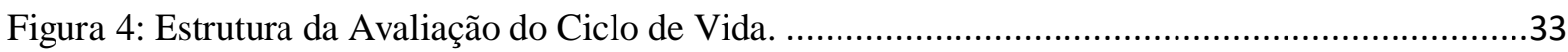

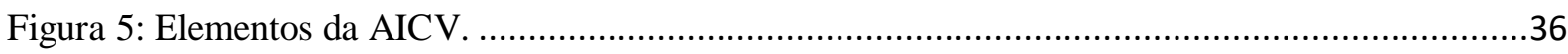

Figura 6: Cadeia de causa e efeito dos impactos do uso da terra.....................................................

Figura 7: Classificação dos serviços ecossistêmicos e seus exemplos, segundo a Avaliação

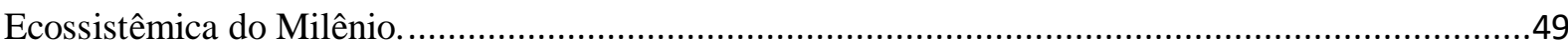

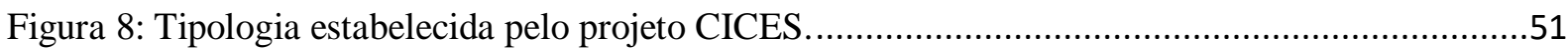

Figura 9: Objetivos, etapas do trabalho e resultados esperados........................................................

Figura 10: Detalhamento da primeira etapa do estudo de revisão bibliográfica exploratória. ..............71

Figura 11: Representação dos impactos decorrentes da ocupação e transformação da terra.................79

Figura 12: Elementos e exemplos da estrutura em cascata dos serviços ecossistêmicos relacionados ao

solo.

Figura 13: Mecanismo ambiental dos serviços ecossistêmicos relacionados ao solo de acordo com o

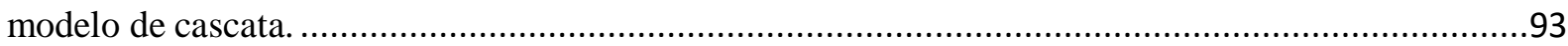

Figura 14: Exemplo detalhado da estrutura conceitual para o serviço de regulação da qualidade do

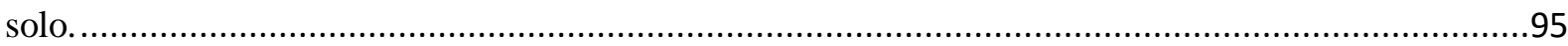

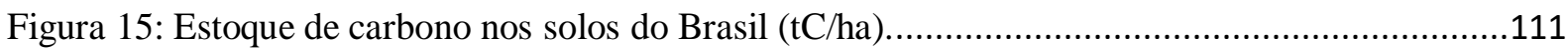

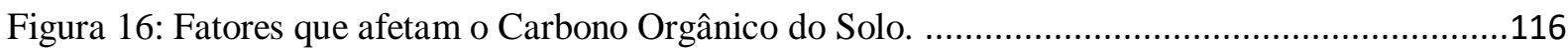

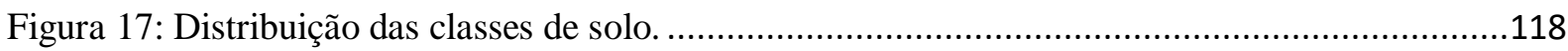

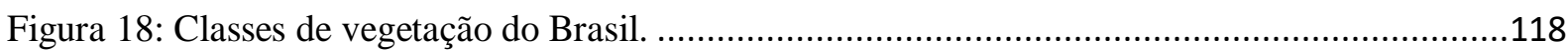

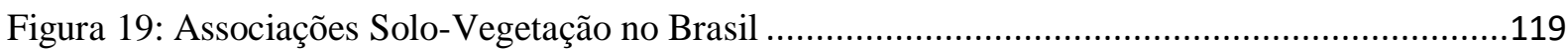

Figura 20: Distribuição dos resultados dos fatores de caracterização para culturas anuais..................125

Figura 21: Distribuição dos resultados dos fatores de caracterização para culturas perenes...............129

Figura 22: Distribuição dos resultados dos fatores de caracterização para pastagens. .......................134

Figura 23: Distribuição dos fatores de caracterização para culturas anuais de acordo com os estados

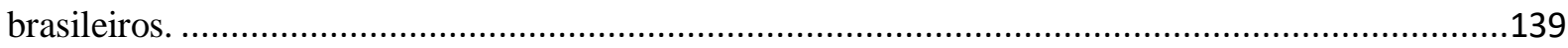

Figura 24: Distribuição dos fatores de caracterização para culturas perenes de acordo com os estados

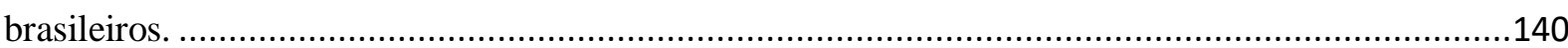

Figura 25: Distribuição dos fatores de caracterização para pastagens de acordo com os estados brasileiros.

Figura 26: Variação dos fatores de caracterização para culturas anuais de preparo convencional e média entrada de matéria orgânica.

Figura 27: Variação dos fatores de caracterização para culturas perenes de preparo convencional e

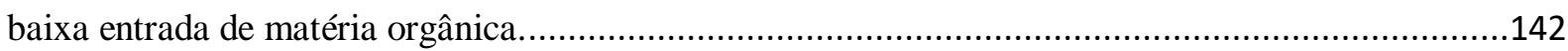

Figura 28: Variação dos fatores de caracterização para pastagens moderadamente degradadas.........143

Figura 29: Evolução das culturas temporárias, permanentes e pastagens no território brasileiro. ......147 


\section{LISTA DE QUADROS}

Quadro 1: Definições de serviços ecossistêmicos disponíveis na literatura........................................46

Quadro 2: Comparativo das classificações dos Serviços Ecossistêmicos............................................53

Quadro 3: Exemplos de soluções relacionadas à economia circular no contexto de serviços

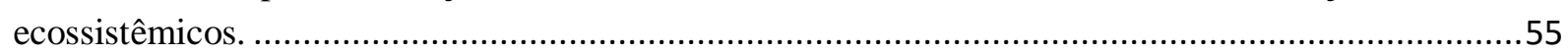

Quadro 4: Relação entre os Objetivos de Desenvolvimento Sustentável da ONU e serviços

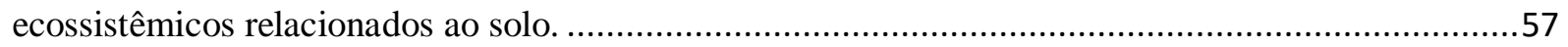

Quadro 6: Descrição e exemplificação dos elementos do modelo de cascata. ......................................60

Quadro 8: Classificação de modelos de caracterização disponíveis para AICV, incluindo a medida usada para expressar os serviços ecossistêmicos e a etapa do modelo de cascata que ela representa. ..67

Quadro 5: Critérios para análise da viabilidade de regionalização dos modelos de caracterização. .....74

Quadro 7: Processos, funções, serviços, benefícios e valor relacionados ao solo identificados na

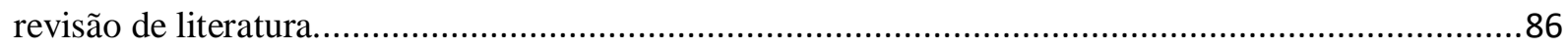

Quadro 9: Resultado da análise de viabilidade de regionalização. ....................................................98

Quadro 10: Síntese dos termos e parâmetros adotados na adaptação do modelo de caracterização....104

Quadro 11: Classes de solo e vegetação a serem combinadas para constituir as unidades

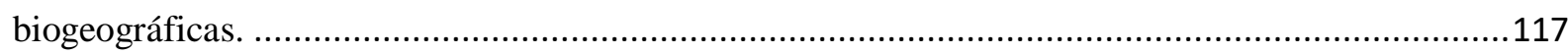

Quadro 12: Estados brasileiros e unidades biogeográficas presentes. ..........................................178 


\section{LISTA DE TABELAS}

Tabela 1: Fatores relativos de mudança de estoque para diferentes atividades e manejo em terras agrícolas.

Tabela 2: Fatores relativos de mudança de estoque para diferentes atividades e manejo em pastagens.

Tabela 3: Fatores de caracterização para impactos de ocupação causados por culturas anuais (tC/ha) (Continua)

Tabela 4: Fatores de caracterização para impactos de ocupação causados por culturas perenes $(\mathrm{tC} / \mathrm{ha})$ (Continua)

Tabela 5: Fatores de caracterização para impactos de ocupação causados por atividades de pastagem (tC/ha) (Continua)

Tabela 6: Fatores de caracterização para culturas anuais agregados por estados brasileiros (tC/ha)...136 Tabela 7: Fatores de caracterização para usos da terra com culturas perenes e áreas de pousio, agregados em estados brasileiros ( $\mathrm{tC} / \mathrm{ha})$.

Tabela 8: Fatores de caracterização para atividades de pastagem, agregados por estados brasileiros (tC/ha).

Tabela 9: Valores de COSpot utilizados na aplicação do modelo de caracterização de acordo com tipo de clima, solo e vegetação (tC/ha) (Continua).

Tabela 10: Valores de COS para culturas perenes (Continua). .......................................................179

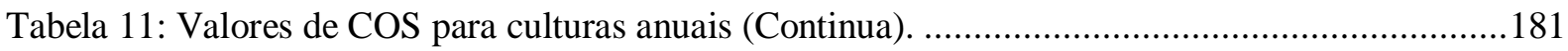

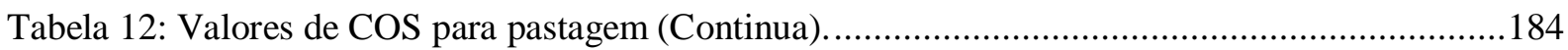

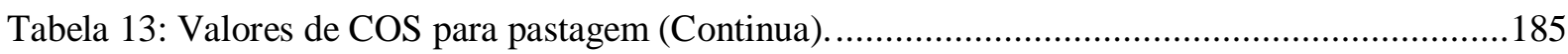

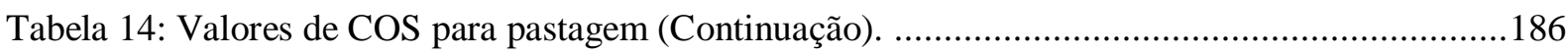

Tabela 15: Valores de COS para a situação de referência, por estados. .............................................187

Tabela 16: Valores calculados para COS de culturas anuais, por estados........................................188

Tabela 17: Valores calculados de COS para culturas perenes, por estados .......................................189

Tabela 18: Valores calculados para COS para pastagens, por estado. …..........................................190 


\section{LISTA DE SIGLAS}

\begin{tabular}{ll} 
ABNT & Associação Brasileira de Normas Técnicas \\
ACV & Avaliação do Ciclo de Vida \\
AFM & Análise de Fluxo de Materiais \\
AIA & Avaliação de Impacto Ambiental \\
AICV & Avaliação de Impacto do Ciclo de Vida \\
ASV & Associação Solo-Vegetação \\
CICES & Common International Classification of Ecosystem Services \\
CNPq & Conselho Nacional de Desenvolvimento Científico e Tecnológico \\
COS & Carbono Orgânico do Solo \\
EMBRAPA & Empresa Brasileira de Pesquisa Agropecuária \\
FC & Fator de caracterização \\
IBAMA & Instituto Brasileiro do Meio Ambiente e dos Recursos Naturais Renováveis \\
IBGE & Instituto Brasileiro de Geografia e Estatística \\
IBICT & Instituto Brasileiro de Informação em Ciência e Tecnologia \\
ICV & Inventário de Ciclo de Vida \\
ILCD & International Reference Life Cycle Data System \\
INMETRO & Instituto Nacional de Metrologia, Qualidade e Tecnologia \\
ISO & International Organization for Standardization \\
JRC & Joint Research Council \\
MEA & Millennium Ecosystem Assessment \\
PBACV & Programa Brasileiro de Avaliação do Ciclo de Vida \\
PPB & Potencial de Produção Biótica \\
SETAC & Society for Environmental Toxicology and Chemistry \\
SIG & Sistema de Informação Geográfica \\
UNEP & United Nations Environment Programme \\
VNP & Vegetação Natural Potencial \\
\hline
\end{tabular}

\section{LISTA DE SÍMBOLOS}

$\begin{array}{ll}\mathrm{A} & \text { Área } \\ \Delta \mathrm{Q} & \text { Diferença de qualidade do ecossistema } \\ \mathrm{COS}_{\mathrm{pot}} & \text { Nível potencial de carbono orgânico do solo } \\ \mathrm{COS}_{\mathrm{UT} 2} & \text { Carbono Orgânico durante o uso da terra } \\ \mathrm{FC}_{\mathrm{oc}} & \text { Fator de caracterização para ocupação } \\ \mathrm{FC}_{\text {trans }} & \text { Fator de caracterização para transformação } \\ \mathrm{IO} & \text { Impacto da transformação da terra } \\ \mathrm{IT} & \text { Impacto da ocupação da terra }\end{array}$




\section{SUMÁRIO}

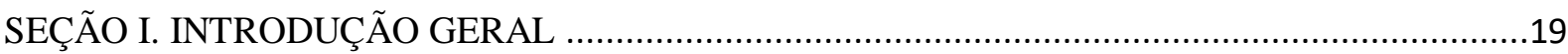

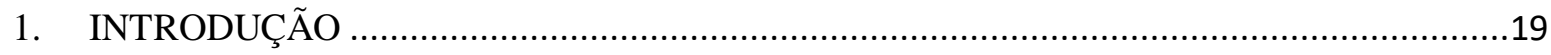

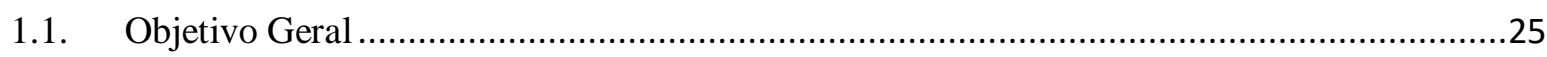

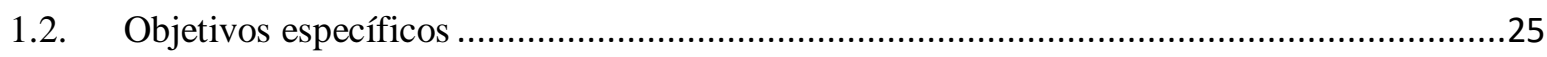

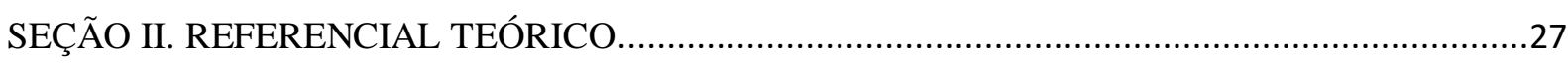

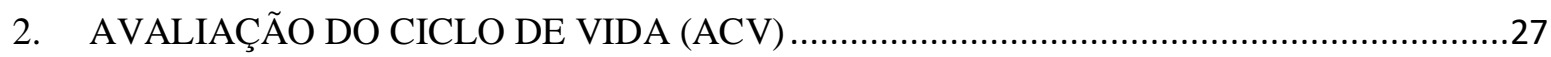

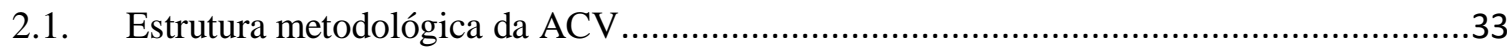

2.2. Avaliação de Impacto do Ciclo de Vida..........................................................................

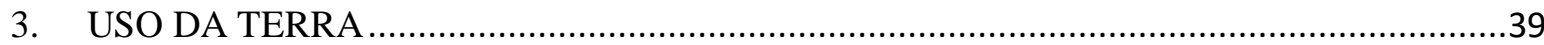

3.1. Uso da terra na Avaliação do Ciclo de Vida ......................................................................41

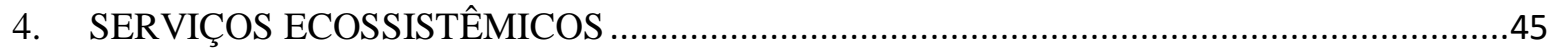

4.1. Serviços Ecossistêmicos relacionados a políticas e estratégias globais ................................54

4.2. Modelo de cascata dos serviços ecossistêmicos ................................................................58

4.3. Serviços Ecossistêmicos na Avaliação do Ciclo de Vida ....................................................63

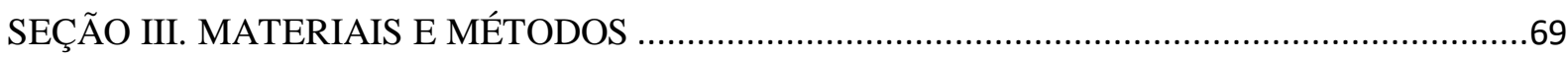

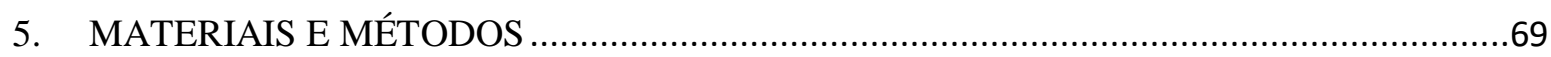

5.1. Análise e correlação do mecanismo ambiental e o modelo de cascata de Serviços

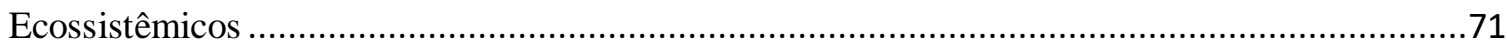

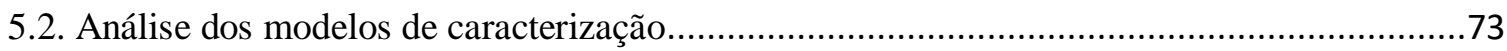

5.3. Aplicação do modelo de caracterização espacialmente diferenciado ...................................75

5.4. Cálculo e obtenção dos fatores de caracterização ..........................................................78

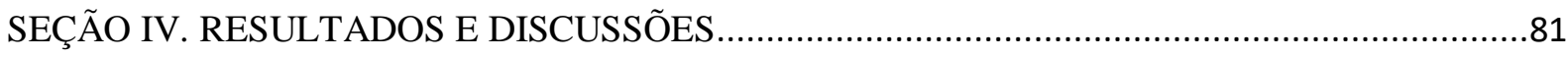

6. MODELO CONCEITUAL DE SERVIÇOS ECOSSISTÊMICOS NA ACV .........................81

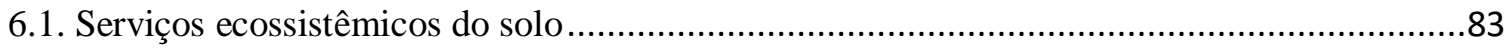

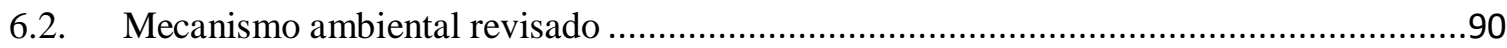

7. ANÁLISE DE MODELOS DE CARACTERIZAÇÃO RELACIONADOS AO USO DA

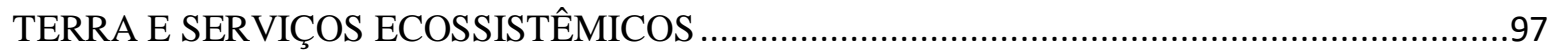

8. DESENVOLVIMENTO DOS FATORES DE CARACTERIZAÇÃO ESPACIALMENTE

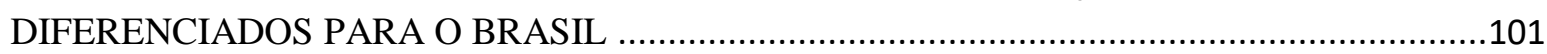

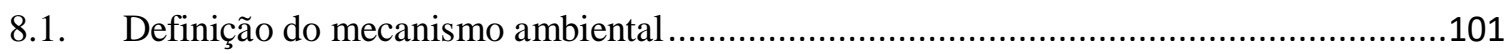

8.2. Definição da situação de referência ...........................................................................104

8.3. Estoques de carbono por tipos de uso da terra.........................................................111

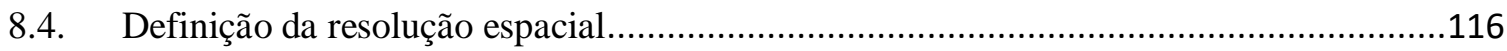

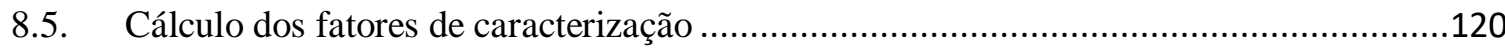




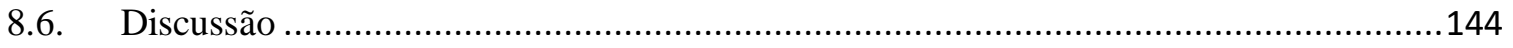

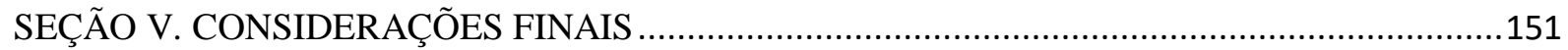

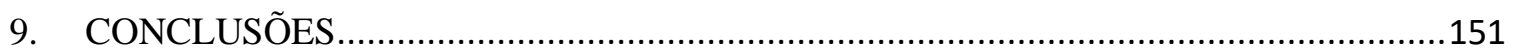

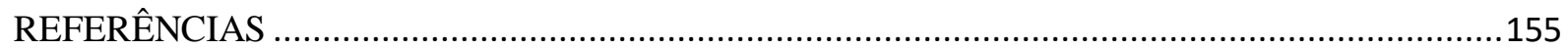

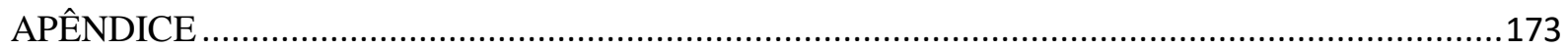




\section{SEÇÃO I. INTRODUÇÃO GERAL}

\section{INTRODUÇÃO}

Questões relacionadas ao meio ambiente, preservação da natureza e desenvolvimento sustentável vêm se tornando o foco de muitas discussões e decisões nacionais e internacionais, influenciando políticas públicas e questionando hábitos de consumo. Diante da necessidade de ações para preservar os recursos naturais e para a condução do desenvolvimento e das atividades econômicas dentro dos padrões de sustentabilidade são necessárias informações sobre os aspectos ambientais ${ }^{1}$, além de instrumentos e técnicas para melhor compreender e lidar com os consequentes impactos gerados.

Não obstante, o esgotamento dos recursos globais, o aumento da quantidade de resíduos e o aumento das emissões de gases de efeito estufa (GEEs) são o resultado dos atuais modelos lineares da economia de produção-consumo-descarte (ZAMAN; LEHMANN, 2013). Assim, o conceito de Economia Circular surgiu como modelo econômico, que associa o crescimento econômico a um ciclo de desenvolvimento positivo contínuo, que preserva e aprimora o capital natural, otimiza o uso de recursos naturais e minimiza riscos sistêmicos, com a administração de estoques finitos e fluxos renováveis (ELLEN MACARTHUR FOUNDATION, 2017). A Economia Circular integra diversas escolas e linhas de pensamento, tais como: Ecologia Industrial, Engenharia do Ciclo de Vida, Gestão do Ciclo de Vida, Economia de Performance, entre outros.

Neste sentido, estudos de Avaliação do Ciclo de Vida (ACV) são importantes instrumentos de avaliação quantitativa dos efeitos ambientais provenientes de todo o ciclo de vida de produtos $^{2}$, facilitando a definição de estratégias para a melhoria do desempenho ambiental dos mesmos. Além disso, a ACV, como técnica para mensuração dos possíveis impactos ambientais causados ao longo do sistema de produto, pode incrementar o nível de informação dos tomadores de decisão na indústria e nas organizações governamentais ou não governamentais.

Os princípios para conduzir os estudos de ACV e a padronização de sua metodologia são descritos pela Organização Internacional de Normalização (International Organization for Standardization - ISO), sendo dividida em quatro etapas: (1) Definição do objetivo e escopo,

\footnotetext{
${ }^{1}$ Elementos das atividades, produtos ou serviços que possam interagir com o meio ambiente (ABNT, 2009a)

${ }^{2}$ Estágios consecutivos de um sistema de produto, desde a aquisição da matéria-prima ou de sua geração a partir de recursos naturais até a disposição final.
} 
(2) Análise de inventário do Ciclo de Vida (ICV), (3) Avaliação de Impacto do Ciclo de Vida (AICV), e (4) Interpretação (ABNT, 2009a,b).

A terceira fase (AICV) é o foco do presente estudo e visa ao entendimento e à avaliação da magnitude e significância dos impactos ambientais potenciais de um sistema de produto ao longo do ciclo de vida do produto (ABNT, 2009b). Em linhas gerais, durante a AICV, o impacto potencial é modelado quantitativamente de acordo com o mecanismo ambiental $^{3}$, por categoria de impacto, utilizando um modelo de caracterização previamente selecionado. Através deste modelo são calculados fatores de caracterização ${ }^{4}$ específicos que expressam o impacto potencial em termos da unidade comum do indicador de categoria (ABNT, 2009b).

Dentre os impactos quantificados na AICV estão aqueles relacionados ao uso da terra (land use, em inglês), os quais vêm sendo alvo de grandes discussões na comunidade científica. $\mathrm{Na} \mathrm{ACV}$, o termo uso da terra é definido como um tipo específico de intervenção ambiental, definido nos resultados do inventário do ciclo de vida, o qual ocasionará modificações na aptidão da terra em realizar suas funções (MILÀ i CANALS et al. 2007a).

Um dos motivos da ampla discussão acerca do uso da terra na ACV é o desafio de trabalhar com a diversidade de consequências ambientais do uso da terra. Desta forma grandes projetos internacionais inseriram o tema em sua agenda, como por exemplo, o programa Iniciativa do Ciclo de Vida da ONU Meio Ambiente e da Sociedade de Toxicologia e Química Ambiental (SETAC). Um dos objetivos deste programa é a construção de um consenso global na maneira como o uso da terra é tratado na $\mathrm{ACV}$, principalmente quanto ao mecanismo ambiental destes impactos (KOELLNER et al., 2013a,b). Assim, os estudos conduzidos pela Iniciativa do Ciclo de Vida concluem que os impactos do uso da terra e danos à qualidade do ecossistema devido às atividades de transformação e ocupação podem ser medidos com diferentes indicadores que expressam o valor intrínseco da biodiversidade ou os efeitos nos serviços ecossistêmicos (KOELLNER et al., 2013b).

Esta tese tem como objeto de estudo os impactos sobre serviços ecossistêmicos, visto que enquanto a pesquisa sobre os impactos do uso da terra sobre a biodiversidade é um campo bem estabelecido, a avaliação dos serviços ecossistêmicos ainda necessita de aprimoramento (KOELLNER et al., 2013a; CAO et al., 2015; OTHONIEL et al.,2016; BRUEL et al., 2016; VIDAL LEGAZ et al., 2016). Além disso, a avaliação dos impactos aos serviços

\footnotetext{
${ }^{3}$ Sistema de processos físicos, químicos e biológicos para uma dada categoria de impacto, vinculando os resultados do inventário aos indicadores de categoria e aos pontos finais da categoria (ABNT, 2009b).

${ }^{4}$ Fator aplicado para converter o resultado da análise do inventário do ciclo de vida na unidade comum do indicador de categoria.
} 
ecossistêmicos é recomendada para a AICV relacionada ao uso da terra, pois coletivamente eles são cruciais para a manutenção do equilíbrio da vida no planeta, e, consequentemente, aos seres humanos (BARE, 2011).

No entanto, quando se trata da avaliação de impactos aos serviços ecossistêmicos, algumas lacunas são evidentes. Por definição, serviços ecossistêmicos são contribuições diretas ou indiretas dos ecossistemas para o bem-estar humano (TEEB, 2010). Outras definições foram propostas e encontram-se sintetizadas no Quadro 1 do Capítulo 4. Logo, considerando esta definição é possível dizer que os modelos disponíveis atualmente não estão de fato avaliando estes serviços, pois os indicadores escolhidos na AICV geralmente não abrangem os benefícios reais oferecidos à sociedade (OTHONIEL et al., 2016).

A criação de um framework conceitual tem sido considerada um passo inicial chave em muitas iniciativas referente aos serviços ecossistêmicos. Sabe-se que a maioria destes frameworks conceituais tenta ilustrar de alguma forma a natureza transdisciplinar do paradigma, usando o conceito de serviço para vincular representações de estruturas e processos biofísicos a valores humanos, benefícios e, finalmente, bem-estar humano. HainesYoung; Potschin (2010) resumem a lógica que sustenta o paradigma dos serviços ecossistêmicos ao criarem o modelo em cascata. O modelo, que também foi adaptado e discutido por outros autores (por exemplo, De Groot et al., 2010b; Salles, 2011), tenta capturar a lógica que existe uma "cadeia de produção" e que vincula as estruturas e processos ecológicos e biofísicos a valores humanos, benefícios e, finalmente, bem-estar humano (Figura 1). 
Figura 1: Modelo cascata e as relações entre as funções dos ecossistemas e bem-estar humano.

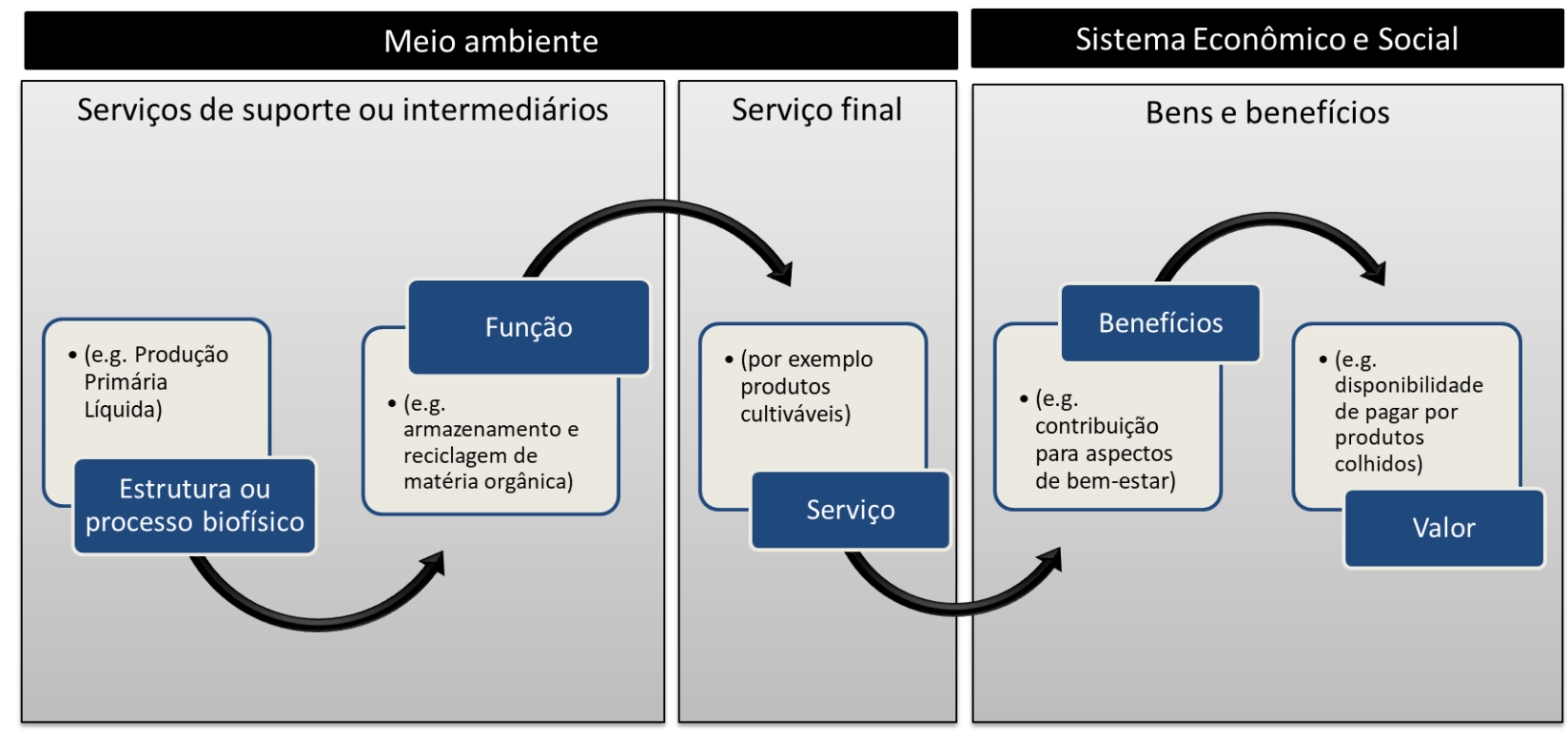

Fonte: Adaptado de Potschin-Young et al. (2017).

Assim, a modelagem da provisão de serviços ecossistêmicos envolve a compreensão da relação dos serviços ecossistêmicos, com as propriedades do ecossistema e processos ecológicos (como visto no modelo de cascata), identificando e valorando sua importância qualitativa e ou/quantitativa nesse processo (COSTANZA, 2000; VAN OUDENHOVEN et al. 2012). Neste contexto, outra lacuna explícita na literatura relacionada aos serviços ecossistêmicos na ACV evidencia-se pela ausência de uma hierarquia e melhor compreensão da inter-relação entre os serviços bem como a falta da integração do modelo de cascata na modelagem.

Assim como o próprio conceito de serviços ecossistêmicos, sua tipologia também gera divergências na literatura. Nesse sentido, a Classificação Internacional Comum dos Serviços Ecossistêmicos (The Common International Classification of Ecosystem Services - CICES) foi desenvolvida para alcançar uma classificação padrão para os serviços ecossistêmicos, permitindo uma tradução fácil de informações entre diferentes tipologias e aplicações. $\mathrm{O}$ modelo de classificação CICES estipula uma estrutura hierarquizada, sendo os serviços ecossistêmicos divididos em três temas (HAINES-YOUNG; POTSCHIN, 2013):

1. Serviços de provisão - serviços obtidos de ecossistemas naturais, seminaturais, agrícolas, florestais, marinhos, fluviais, etc., e incluem alimentos, matérias-primas como a madeira, produtos silvestres, água e materiais energéticos. 
2. Serviços de regulação e manutenção - serviços ecológicos prestados pelos ecossistemas como a regulação da erosão, polinização, produção primária (fotossíntese), formação do solo, ciclo da água e dos nutrientes.

3. Serviços culturais - estão associados a usos espirituais ou intelectuais, incluem recreação e lazer, benefícios estéticos, bem-estar físico e espiritual, serviços educacionais, patrimoniais e até religiosos.

Logo, é possível afirmar que o espectro de serviços ecossistêmicos considerado na ACV ainda está incompleto. Segundo Othoniel et al. (2016), isto pode estar relacionado à escassez de conhecimento sobre processos ecológicos subjacentes à disposição de alguns serviços, mas é possível relacionar à própria complexidade envolvida na temática.

Outro importante desafio que vem gerando discussões nos últimos anos dentro do campo da ACV refere-se à questão da regionalização, ou seja, a consideração das variações nos impactos entre diferentes regiões geográficas (BARE, 2010; POTTING; HAUSCHILD, 2006). Segundo Potting; Hauschild (2006), a diferenciação espacial em métodos de AICV se dá em três níveis: i) métodos genéricos, ou seja, não é realizada a diferenciação espacial em relação às fontes emissoras e ao ambiente receptor; ii) método dependentes do local (ou locodependentes) quando existe alguma diferenciação espacial, mesmo que pouco refinada; e iii) métodos específicos para o local (ou loco-específico), quando há uma diferenciação espacial muito detalhada, incluindo informações precisas com relação às fontes emissoras.

A regionalização em ACV e adequação da avaliação dos impactos ambientais frente ao contexto brasileiro também ganhou atenção recentemente na comunidade científica nacional. O Programa Brasileiro de Avaliação do Ciclo de Vida (PBACV), coordenado pelo Instituto Brasileiro de Informação em Ciência e Tecnologia (IBICT) e pelo Inmetro, tem entre seus objetivos identificar as principais categorias de impactos ambientais para o Brasil (BRASIL, 2010). Ademais, dentro das ações do programa, definiu-se como um dos temas estratégicos: "avaliar as categorias de impacto existentes e identificar aquelas relevantes para a realidade brasileira para, posteriormente, identificar dados necessários para adaptação e, por fim, a elaboração de um método de AICV para o Brasil” (CHERUBINI, 2015).

A regionalização dos modelos de AICV visa melhorar a identificação de pontos críticos de impacto ambiental (hotspots) no território brasileiro e reduzir a incerteza nos resultados, bem como apresentar fatores de caracterização para regiões políticas e ambientais significativas no Brasil (MAIA DE SOUZA et al., 2016). Nesse sentido, destaca-se também a criação da Rede de Pesquisa em Avaliação de Impacto do Ciclo de Vida (Rede AICV), com o objetivo avançar nas pesquisas para regionalização de metodologias de AICV para o Brasil 
(CHERUBINI, 2015), envolvendo instituições como Instituto Federal Sul Riograndense (IFSUL), Universidade do Estado de Santa Catarina (UDESC), Universidade de São Paulo (EESC-USP), Universidade Tecnológica Federal do Paraná (UTFPR), Universidade Estadual de Santa Cruz (UESC), Laboratório Nacional de Ciência e Tecnologia do Bioetanol (CTBE), Embrapa e colaboradores internacionais.

Quando se trata de impactos do uso da terra, é possível notar que são altamente influenciados pelas condições locais e dependem de muitos fatores biogeográficos como paisagem, clima, padrões da vegetação e propriedades do solo (MILÀ i CANALS et al., 2007a). Além disso, considera-se aqui que a transformação e ocupação em determinado espaço geográfico, bem como a gestão dos impactos ambientais derivados, devem se basear no reconhecimento das potencialidades e fragilidades dos fatores físicos, biológicos e antrópicos que compõem esse meio frente às características das atividades ali instaladas. Nesse sentido, uma avaliação em nível genérico pode levar a resultados que não refletem adequadamente a magnitude destes impactos, resultando em grandes incertezas ligadas à variabilidade espacial (SAAD et al., 2011).

Diante disso, cada vez mais se reconhece a necessidade do desenvolvimento de fatores de caracterização (FC) que levem em conta a diferenciação espacial para impactos derivados do uso da terra e que diferencie a intensidade das intervenções humanas (MÜLLER-WENK; BRANDÃO, 2010; POTTING; HAUSCHILD, 2006; SAAD et al., 2011; TOFFOLETTO, 2007). Ressalta-se, porém, que isto implica em novos desafios e discussões, pois apesar das avaliações regionalizadas aumentarem a acurácia do estudo, estes avanços devem ocorrer sem tornar a aplicação excessivamente complexa e comprometer a aplicabilidade da técnica (HELLWEG; MILÀ i CANALS, 2014).

Este projeto visa colaborar nos desafios e discussões apresentados anteriormente, visto que ainda é necessário o aperfeiçoamento de metodologias de avaliação de impactos do uso da terra nos serviços ecossistêmicos (KOELLNER; GEYER, 2013) e que o desenvolvimento da AICV regionalizada é um desafio científico no Brasil (CONMETRO, 2010; DE SOUZA et al., 2017).

Logo, além das lacunas de cunho teórico relacionadas à avaliação dos serviços ecossistêmicos na $\mathrm{ACV}$, o problema de pesquisa aqui abordado também se refere às limitações práticas de uma avaliação de impacto genérica e a necessidade de fatores de caracterização loco-dependentes baseados em unidades de escala espacial regionais, que expressem a diversidade ambiental brasileira e as diferentes tipologias de uso da terra. 
Por fim, ressalta-se o ineditismo da proposta aqui descrita e evidenciada através da análise de produções cientificas (dissertações, teses e artigos). Primeiramente trata-se da primeira proposta de revisão dos preceitos e modelagem da AICV utilizando-se explicitamente o modelo de cascata de provisão de Serviços Ecossistêmicos. Observa-se também que há poucas pesquisas aplicadas ao Brasil voltadas à modelagem dos impactos do uso da terra na AICV, sendo muitas vezes focadas apenas na biodiversidade (SOUZA, 2010) ou limitadas a um recorte territorial específico, como por exemplo, em Marroquín (2013), no qual o foco foi o Bioma Amazônico.

\subsection{Objetivo Geral}

O principal objetivo deste estudo é contribuir de maneira teórica e aplicada para a inserção da categoria de serviços ecossistêmicos na AICV, desenvolvendo fatores de caracterização, para o Brasil, relacionados ao solo.

\subsection{Objetivos específicos}

Considerando as lacunas apresentadas anteriormente, os objetivos específicos deste trabalho são:

1. Analisar as principais categorias de impacto do uso da terra sobre serviços ecossistêmicos.

2. Comparar o modelo de cascata de provisão de serviços ecossistêmicos com o mecanismo ambiental relacionado ao uso da terra aplicado na AICV.

3. Elaborar um novo modelo conceitual para o mecanismo ambiental dos impactos aos serviços ecossistêmicos relacionados ao solo de acordo com o modelo de cascata.

4. Avaliar os métodos com melhor potencial de uso e/ou adaptação para o Brasil pela robustez científica ou disponibilidade de dados.

5. Calcular fatores de caracterização de impactos regionalizados para serviços ecossistêmicos devido ao uso da terra, para o Brasil.

A partir destes objetivos, estruturou-se o texto da tese em cinco seções e 10 capítulos. Na presente seção é apresentada a contextualização no que diz respeito à utilização da ACV 
para avaliação dos impactos relacionados aos serviços ecossistêmicos, além das lacunas e justificativas para elaboração da pesquisa e seus objetivos. A Seção II do trabalho apresenta aspectos conceituais pertinentes aos objetos de estudo (ACV, uso da terra e serviços ecossistêmicos). Desta forma, no Capítulo 2 a técnica de ACV é descrita, bem como sua metodologia e evolução histórica. Já no Capítulo 3 é apresentada uma revisão bibliográfica acerca do uso da terra e como se deu sua inclusão na ACV. O último tema revisado nesta seção são os Serviços Ecossistêmicos (Capítulo 4), suas diferentes definições e classificações bem como o modelo de cascata usado na compreensão da provisão destes benefícios ao homem. Na terceira seção são apresentados e detalhados os procedimentos metodológicos adotados para a condução da pesquisa. Os resultados e discussões são apresentados ao longo da Seção IV, sendo descrito no Capítulo 6 o novo modelo conceitual de serviços ecossistêmicos relacionados ao solo para AICV e no Capítulo 7 a análise realizada dos modelos de caracterização. O Capítulo 8 traz a aplicação do modelo de caracterização regionalizado para unidades biogeográficas e estados brasileiros. As conclusões, limitações e recomendações futuras são sintetizados no Capítulo 9, apresentado na Seção V. 


\section{SEÇÃO II. REFERENCIAL TEÓRICO}

Nos próximos capítulos é apresentada a sistematização da literatura acerca dos temas que esta tese abrange. No capítulo 2 encontra-se uma revisão de literatura da Avaliação do Ciclo de Vida (ACV), seus princípios, características-chave e estrutura metodológica.

O capítulo 3 trata, portanto, das definiçõos de termos fundamentais ao desenvolvimento do trabalho como uso da terra e os impactos ambientais resultantes bem como sua inclusão da ACV.

Por fim, no Capítulo 4 encontra-se uma revisão do estado da arte no que diz respeito aos Serviços Ecossistêmicos, abrangendo não só suas diferentes definições e classificação, mas também sua evolução dentro da técnica de ACV.

\section{AVALIAÇÃO DO CICLO DE VIDA (ACV)}

A dimensão ambiental passou a ser uma variável estratégica para organizações devido ao aumento de exigências das legislações, pressão da opinião pública e de clientes, oportunidades econômicas associadas ao custo de materiais e energia, dentre outros motivadores (MORIOKA, 2014). Nesse sentido, informações sobre aspectos ambientais são necessárias sendo que muitas técnicas e indicadores de avaliação de impactos ambientais foram desenvolvidos, como por exemplo: Avaliação Ambiental Estratégica (AAE), Avaliação de Impacto Ambiental (AIA), Avaliação de Risco Ambiental, Análise de Fluxo de Materiais (AFM), Pegada Ecológica e Avaliação do Ciclo de Vida (ACV) (FINNVEDEN et al., 2009).

A ACV tem sua origem histórica centrada na busca por uma técnica adequada para a comparação de desempenho ambiental de produtos. Os primeiros estudos reconhecidos como sendo de alguma forma estudos de ACV datam do final da década de 60 e derivam das análises energéticas conduzidas nessa época, sendo ampliado para abranger outros recursos e emissões (CHERUBINI, 2015). Logo, desde a sua origem, a ACV tem sido amplamente utilizada como uma ferramenta robusta para avaliação de impactos ambientais atribuíveis a um produto específico (bens ou serviços) em muitos campos, por exemplo, na gestão ambiental, produção industrial, agências governamentais e outras organizações (CHEN et al., 2014).

Durante o período de 1970-1990, houve pouca atenção do público e muito pouco foi publicado sobre ACV (HUNT; FRANKLIN, 1996). Já a década de 1990 pode ser considerada um período de concepção e normalização da ACV, tendo um crescimento científico notável e 
atividades a nível mundial, como por exemplo, pela Sociedade de Toxicologia e Química Ambiental (SETAC), e Organização Internacional de Normalização (ISO). Assim, publicações como "Code of Practice”, de 1993 da SETAC e a norma ISO 14040 são exemplos destes avanços (CHEN et al., 2014). A definição de ACV dada pela norma ISO 14040 e traduzida para o Brasil pela Associação Brasileira de Normas Técnicas (ABNT) constitui a "compilação e avaliação das entradas, saídas e dos impactos ambientais potenciais de um sistema de produto ao longo do ciclo de vida do produto". Ainda segundo a norma NBR ISO 14040 (ABNT, 2009a) a ACV enfoca os aspectos ambientais e os impactos ambientais potenciais ao longo de todo o ciclo de vida de um produto, desde a aquisição das matérias-primas, produção, uso, tratamento, pós-uso, reciclagem até a disposição final.

A ACV pode ser utilizada para diversos propósitos e em diferentes estágios do ciclo de vida sendo que suas aplicações incluem (ABNT, 2009a; GIANNETTI; ALMEIDA, 2006):

- Identificação dos processos, materiais e sistemas que mais contribuem para o potencial impacto ambiental ao longo do ciclo de vida e oportunidades de melhoria;

- Comparação das diversas opções, em um processo particular, a fim de minimizar potenciais impactos;

- Seleção de indicadores ambientais relevantes.

A utilização da $\mathrm{ACV}$ em empresas permite também a produção de informação ambiental para efeitos de marketing, relacionando-se ao conceito de declarações ambientais de produto (CHERUBINI, 2015). Portanto, para Schatsky (2011) os principais benefícios do uso da ACV referem-se ao desenvolvimento de melhores produtos; resposta a questões colocadas pelos consumidores; consistência científica à sustentabilidade; melhorar a imagem corporativa; e auxiliar as empresas a se tornarem mais eficientes. Além disso, governos utilizam a ACV para análise de decisões com impacto na sociedade, como fonte analítica das Políticas Integradas de Produto, na rotulagem ambiental e em licitações públicas (GAVA et al., 2019; NOTARNICOLA et al., 2017; HAUSCHILD; JESWIET; ALTING, 2005).

Tendo em vista os benefícios da ACV, diversas iniciativas e organizações surgiram ao longo dos anos com o objetivo de aprimorar a técnica e promover o conceito de ciclo de vida (Life Cycle Thinking) a nível global, europeu e até mesmo no Brasil. Dentre elas, destaca-se a Iniciativa do Ciclo de Vida (UNEP, 2002), Plataforma Europeia sobre ACV e o Sistema Internacional de Referência de Dados do Ciclo de Vida de Produtos e Processos (International Reference Life Cycle Data System - ILCD), as quais serão abordadas a seguir. 
No levantamento realizado por Bjørn et al. (2013) foram identificadas cerca de 100 redes/plataformas internacionais, regionais, nacionais e locais relacionadas com o conceito do ciclo de vida e o uso da ACV, sendo alguns deles apresentados a seguir (Figura 2).

Figura 2: Exemplos de organizações relacionadas ao conceito de ciclo de vida e ACV.

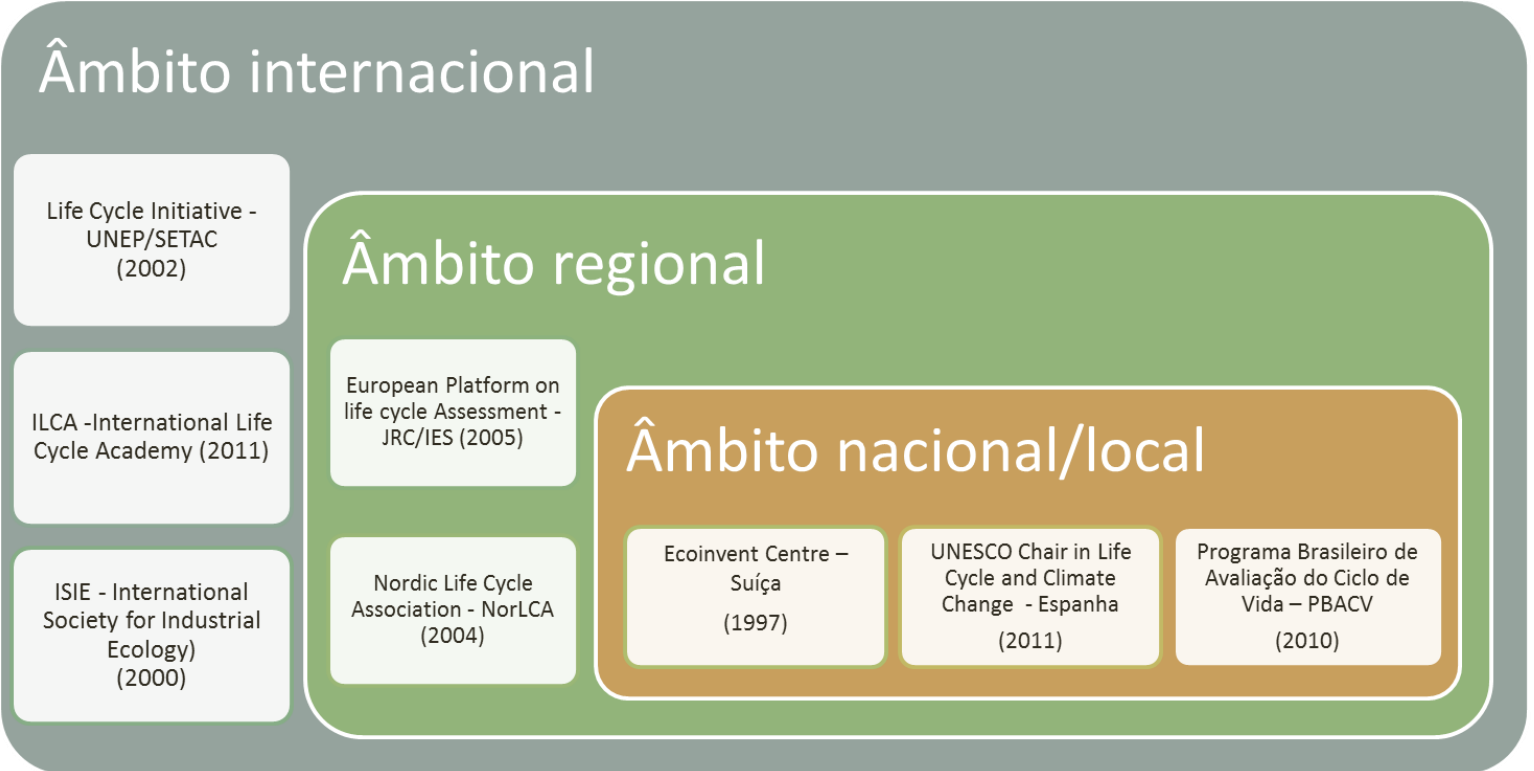

Fonte: Elaborado pela autora.

A Iniciativa do Ciclo de Vida (Life Cycle Initiative é um dos programas mais notáveis e constitui uma parceria da ONU Meio Ambiente e da Society for Environmental Toxicology and Chemistry (SETAC) com objetivo de promover o conceito de ciclo de vida a nível global $^{5}$. É composta pelo International Life Cycle Board (ILCB), suportado por um secretariado sediado em Paris, nos escritórios da ONU Meio Ambiente além de um setor responsável por seguir a implementação das atividades definidas (Project Management Office - PMO) e por um comitê responsável pela revisão dos documentos produzidos (Technical Review Committee). Desde sua criação em 2002, as atividades promovidas pela Iniciativa do Ciclo de Vida foram organizadas em três diferentes fases. A primeira fase (entre 2002 e 2006) foi concentrada na promoção do conceito de ciclo de vida a nível global enquanto a segunda fase (entre 2007 e 2011) teve objetivos de promover o conceito de ciclo de vida em empresas, governos e público em geral, alcançar um consenso global sobre abordagens metodológicas além de promover a capacitação para o melhor uso das abordagens de ciclo de vida. Nesta segunda fase cinco áreas de trabalho foram definidas:

${ }^{5}$ Disponível em: http://www.lifecycleinitiative.org/ 
- Metodologias e dados (métodos, casos de estudo, dados, etc.);

- Recursos e impactos (incluindo recursos naturais, produtos químicos, água, energia, etc.);

- Grupos de consumo (habitação, mobilidade, alimentos e produtos de grande consumo);

- Capacitação (formação, desenvolvimento curricular, capacitação institucional, etc.);

- Gestão do ciclo de vida em empresas e indústrias.

Destas duas primeiras fases resultou um conjunto de documentos e métodos de extrema relevância para o desenvolvimento de Gestão do Ciclo de Vida de produtos, processos e serviços, como: Jolliet et al. (2004), Rosenbaum et al. (2008), UNEP/SETAC (2009), UNEP/SETAC (2011a) e UNEP/SETAC (2011b) (Figura 3).

Figura 3: Principais resultados da Iniciativa do Ciclo de Vida ao longo dos anos.

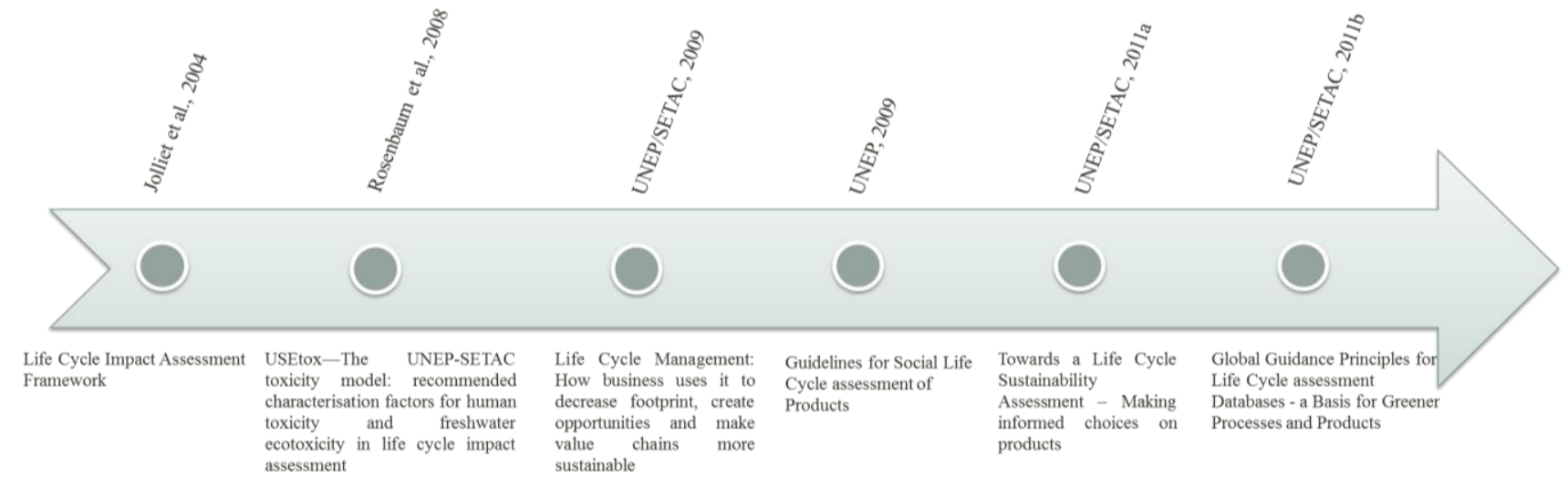

Fonte: Elaborado pela autora.

A terceira fase (2012-2016) visa promover a utilização global do conhecimento do ciclo de vida a fim de alcançar sociedades mais sustentáveis. Dentre os objetivos traçados para esta fase estão:

- Aperfeiçoar o consenso e a relevância da gestão de dados e metodologias de ciclo de vida existentes e emergentes.

- Comunicar o conhecimento atual e constituir-se como a voz global da comunidade de ciclo de vida para influenciar e criar parcerias com stakeholders.

- Expandir a capacidade para aplicar e melhorar as abordagens de ciclo de vida, tornando-as operacionais para as organizações. 
Também de âmbito internacional, a International Society for Industrial Ecology promove globalmente a ecologia industrial como uma forma de encontrar soluções inovadoras para os problemas ambientais, facilitando a comunicação entre cientistas, engenheiros, políticos e administradores ${ }^{6}$. Além dela, a International Life Cycle Academy (ILCA) foi fundada em 2011 e visa dar suporte à avaliação da sustentabilidade por métodos quantitativos, através de formação de alta qualidade, contando com um conjunto de profissionais do meio acadêmico e profissional ${ }^{7}$.

Já na Europa, a ACV é frequentemente utilizada em políticas públicas, especialmente para questões ambientais e saúde humana (CHERUBINI, 2015). Um dos exemplos de redes ligadas ao conceito de ciclo de vida é a European Platform on Life Cycle Assessment (EPLCA), estabelecida pelo Joint Research Council (JRC) - Institute for Environment and Sustainability (IES). Esta plataforma visa melhorar a credibilidade e a prática da ACV em empresas, assegurar a qualidade dos dados de estudos de ACV bem como dar suporte à decisão no âmbito de um conjunto de instrumentos de negócio e de políticas ambientais (CHERUBINI, 2015).

Em nível nacional, uma das principais organizações é o Ecoinvent Center, fundada em 1997 com sede em Zurique na Suíça. Desde 2013 é uma associação independente sem fins lucrativos, visando estabelecer e fornecer dados e serviços para indústrias, entidades públicas e instituições, de forma a subsidiar um melhor desempenho ambiental de produtos, processos e serviços ${ }^{8}$. A principal atividade da associação é o desenvolvimento da base de dados Ecoinvent, internacionalmente conhecida e uma das bases de dados mais utilizadas em estudos de ACV.

No Brasil, os esforços voltados para aprimoramento e divulgação do pensamento do ciclo de vida se iniciaram em 2002, quando foi criada a Associação Brasileira de Ciclo de Vida (ABCV), com finalidade de viabilizar a difusão e a consolidação da Gestão do Ciclo de Vida, atuando junto às empresas e instituições acadêmicas de ensino e pesquisa, órgãos governamentais e sociedade organizada (CHERUBINI, 2015). No ano seguinte o Instituto Brasileiro de Informação em Tecnologia (IBICT) lançou um portal a fim de integrar parceiros da indústria, governo, instituições de pesquisa e academia, e demais interessados em desenvolver e aprimorar a metodologia de ACV no país. Dois anos mais tarde, em 2006, foi lançado o projeto Inventário do Ciclo de Vida para a competitividade Ambiental da Indústria

\footnotetext{
${ }^{6}$ Disponível em: http://www.is4ie.org/ (Acesso em 10 set. 2016)

${ }^{7}$ Disponível em: http://ilca.es/ (Acesso em 10 set. 2016)

${ }^{8}$ Disponível em: http://www.ecoinvent.ch/ (Acesso em 10 set. 2016)
} 
Brasileira - SICV Brasil, com o objetivo de desenvolver a infraestrutura necessária para a implantação da metodologia no Brasil, com o respaldo da Financiadora de Estudos e Projetos (FINEP).

Destaca-se também a criação do Programa Brasileiro de Avaliação do Ciclo de Vida (PBACV), em 2010, por meio da Resolução 04/2010 do Conselho Nacional de Metrologia, Normalização e Qualidade Industrial, cuja principal finalidade é apoiar o desenvolvimento sustentável e a competitividade ambiental da produção industrial brasileira e promover o acesso aos mercados interno e externo (BRASIL, 2010). Criou-se também o Grupo de Trabalho sobre Avaliação do Ciclo de Vida (GT-ACV) pelo Comitê Brasileiro de Avaliação de Conformidade para a proposta do PBACV (BRASIL, 2010), composto de representantes do setor governamental (e.g. Ministério do Meio Ambiente e Agência Brasileira de Desenvolvimento Industrial; do setor produtivo (e.g. SEBRAE e Bracelpa); da academia (e.g. especialistas da UnB, UTFPR e USP); de institutos de tecnologia (e.g. CTI, CNPEM-CTBE e Embrapa); e de outras partes interessadas, como Associação Brasileira do Ciclo de Vida, Associação Brasileira de Normas Técnicas/Comitê Brasileiro de Gestão Ambiental/ Subcomitê de Avaliação do Ciclo de Vida (BRASIL, 2010b).

Recentemente o IBICT coletou e sintetizou informações sobre o desenvolvimento do campo da ACV no país, concluindo que atualmente o tema é abordado principalmente pelo PBACV, pela $\mathrm{ABCV}$ e por mais de 27 grupos e/ou laboratórios de pesquisa, 18 empresas de consultoria, além de 64 empresas/ indústrias que usam a ACV como prática de gestão ambiental, e iniciativas voluntárias como a Rede Empresarial Brasileira de Avaliação de Ciclo de Vida (CHERUBINI, 2015). Neste panorama também foi concluído que a ACV é mais disseminada em nível europeu, sobretudo em aspectos de ordem mais prática e ao nível de suporte a políticas integradas de produto. O Brasil, por sua vez, ainda necessita lidar com limitações como: escassez de inventários do ciclo de vida para consolidação de bases nacionais; aspectos metodológicos ligados às incertezas intrínsecas da modelagem; e necessidade de regionalização de ICV e fatores de caracterização. Apesar disso, a ACV é objeto de estudo em diversas instituições de pesquisa e universidades, podendo também ser considerada como uma fonte de negócios que vem ganhando cada vez mais destaque e importância para diferentes organizações. 


\subsection{Estrutura metodológica da ACV}

Dentre as características relevantes da ACV, listadas pela norma ISO 14040, ressaltase que sua metodologia é aberta à inclusão de novas descobertas científicas e melhorias e que não existe um método único para se conduzir uma ACV. No entanto, a estrutura metodológica mais empregada é a apresentada na norma, composta de quatro fases iterativas: a) Definição de objetivo e escopo; b) Análise de inventário; c) Avaliação de impacto; d) Interpretação (Figura 4).

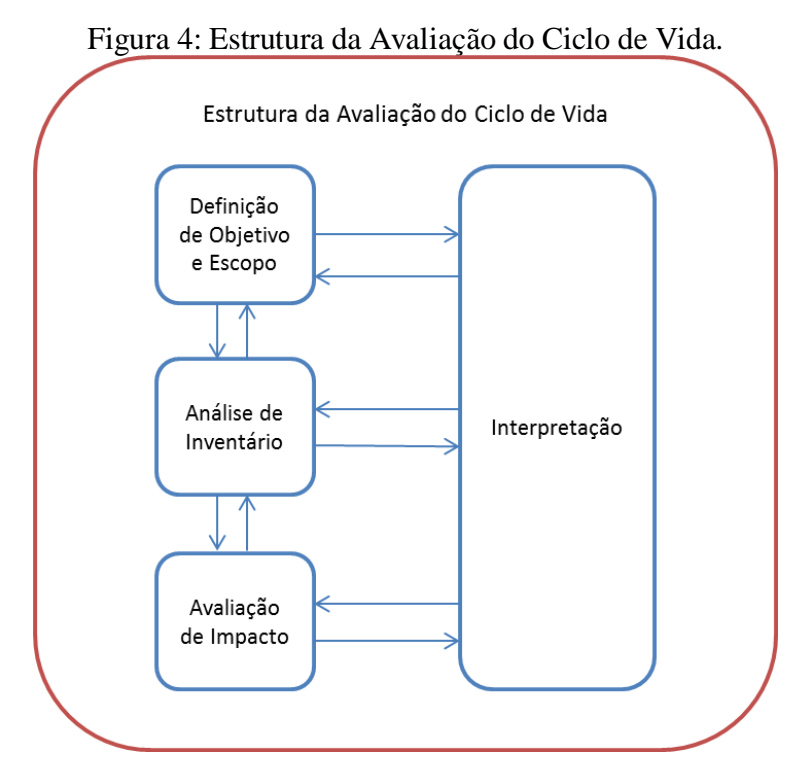

Fonte: ABNT (2009a).

A definição de objetivo é a primeira fase de qualquer ACV e alguns aspectos devem ser abordados e documentados durante esta fase, como: aplicação pretendida dos produtos/resultados; limitações e premissas; razões para a realização do estudo; e público-alvo dos produtos / resultados do estudo. Durante a definição de escopo, o objeto do estudo da ACV (ou seja, o produto ou outros sistemas a serem analisados) é identificado e definido detalhadamente. É fundamental que isso seja feito em consonância com a definição do objetivo. Além disso, na definição do escopo são definidos os requisitos de metodologia, qualidade, geração de relatórios e revisão com base no objetivo do estudo, no contexto decisório, nas aplicações previstas e nos destinatários dos resultados (EC-JRC, 2010b).

$\mathrm{Na}$ fase de análise de inventário do ciclo de vida (ICV) ocorre a coleta de dados e procedimentos de cálculo para quantificar entradas e saídas relevantes de um sistema de produto (ABNT, 2009a). Dois princípios relevantes de modelagem de ICV são utilizados na 
prática de ACV: atribucional e consequencial. A modelagem atribucional faz uso de dados históricos, mensuráveis, com incerteza conhecida (ou passível de ser conhecida), e inclui todos os processos identificados como de contribuição relevante para o sistema que está sendo estudado (EC-JRC, 2010b). Já na modelagem consequencial o objetivo é identificar as consequências que uma decisão no sistema de primeiro plano acarreta em outros processos e sistemas da economia. O sistema interage com os mercados e são representadas as alterações que uma demanda adicional pelo sistema analisado pode produzir em uma tecnosfera dinâmica, que está reagindo a essa demanda adicional (EC-JRC, 2010b).

Já na terceira fase, de Avaliação de Impactos do Ciclo de Vida (AICV), o objetivo é avaliar a magnitude e significância dos impactos ambientais potenciais de um sistema de produto. Assim, a AICV associa os resultados da fase anterior (ICV) a categorias de impacto e o conjunto dos resultados dos indicadores de categoria fornece informações sobre as questões ambientais associadas às entradas e saídas do sistema de produto (ABNT, 2009a). Este estudo enfoca diretamente esta fase da $\mathrm{ACV}$, portanto, seus elementos e procedimentos metodológicos serão detalhados separadamente a seguir.

A quarta fase de uma ACV, a fase de interpretação do ciclo de vida, ocorre após a análise do inventário e avaliação de impacto a fim de considerar todas as informações em conjunto e seu resultado está relacionado ao objetivo do estudo, podendo ser recomendações para tomadores de decisão, que normalmente consideram os impactos ao meio ambiente e recursos juntos com outros critérios de decisão, como aspectos econômicos e sociais (ABNT, 2009b; HAUSCHILD; JESWIET; ALTING, 2005). Assim, a interpretação visa responder questões previstas no estudo de ACV e desenvolver recomendações de maneira compreensível para que o usuário avalie as conclusões e limitações em potencial da ACV.

\subsection{Avaliação de Impacto do Ciclo de Vida}

Segundo a Norma NBR ISO 14044, a AICV envolve a coleta de resultados dos indicadores para diferentes categorias de impacto, que em conjunto, representam o perfil de AICV para o sistema de produto. Ainda segundo a norma, a AICV possui elementos obrigatórios e opcionais. As três etapas obrigatórias são: a) seleção das categorias de impacto, indicadores, e modelos de caracterização; b) correlação dos resultados do ICV às categorias de impacto (classificação); c) cálculo dos resultados dos indicadores de categoria (caracterização). 
Desta forma, a primeira etapa da AICV consiste na seleção das categorias de impacto, indicadores de categoria e modelos de caracterização, devendo ser justificada e consistente com o objetivo do estudo. Não obstante, a seleção das categorias de impacto deve refletir um conjunto abrangente da problemática ambiental e tanto o mecanismo ambiental quanto os modelos de caracterização devem ser descritos. Estes modelos descrevem a relação entre os resultados ICV, os indicadores de categoria e é através deles que são calculados fatores de caracterização. Ainda sobre a seleção das categorias e indicadores, a norma NBR ISO 14044 recomenda que dependendo do mecanismo ambiental e do objetivo e escopo, deve-se também considerar a diferenciação espacial e temporal no modelo de caracterização.

$\mathrm{Na}$ fase de classificação é feita a correlação dos resultados do ICV às categorias selecionadas. Deve ser levada em consideração a identificação dos resultados do ICV que se correlacionam a mais de uma categoria de impacto, incluindo distinção entre mecanismos paralelos correlação a mecanismos seriais, a fim de não haver dupla contagem.

$\mathrm{Na}$ terceira etapa, conhecida como caracterização, dá-se o cálculo dos resultados dos indicadores pela conversão dos resultados em unidades comuns e agregação em uma mesma categoria de impacto. Este processo de conversão faz uso de fatores de caracterização (derivados dos modelos de caracterização) e seu resultado é um valor numérico do indicador. Há várias abordagens de modelagem de impacto, mas as duas principais são: midpoint e endpoint. Na abordagem midpoint a caracterização usa indicadores localizados ao longo do mecanismo ambiental (pontos intermediários) com resultados em geral mais precisos comparados com a modelagem endpoint na qual a caracterização considera todo o mecanismo ambiental até o seu ponto final (pontos finais). A avaliação endpoint refere-se, portanto, a um dano específico relacionado com uma área mais ampla de proteção que pode ser saúde humana, ambiente natural ou recursos naturais.

A Figura 5 a seguir ilustra o conceito de indicadores de categoria, sendo que cada categoria de impacto tem seu mecanismo ambiental próprio. Os modelos de caracterização refletem o mecanismo ambiental, descrevendo a relação entre os resultados do ICV, indicadores de categoria e, em alguns casos, o ponto final da categoria (ABNT, 2009b). 
Figura 5: Elementos da AICV.

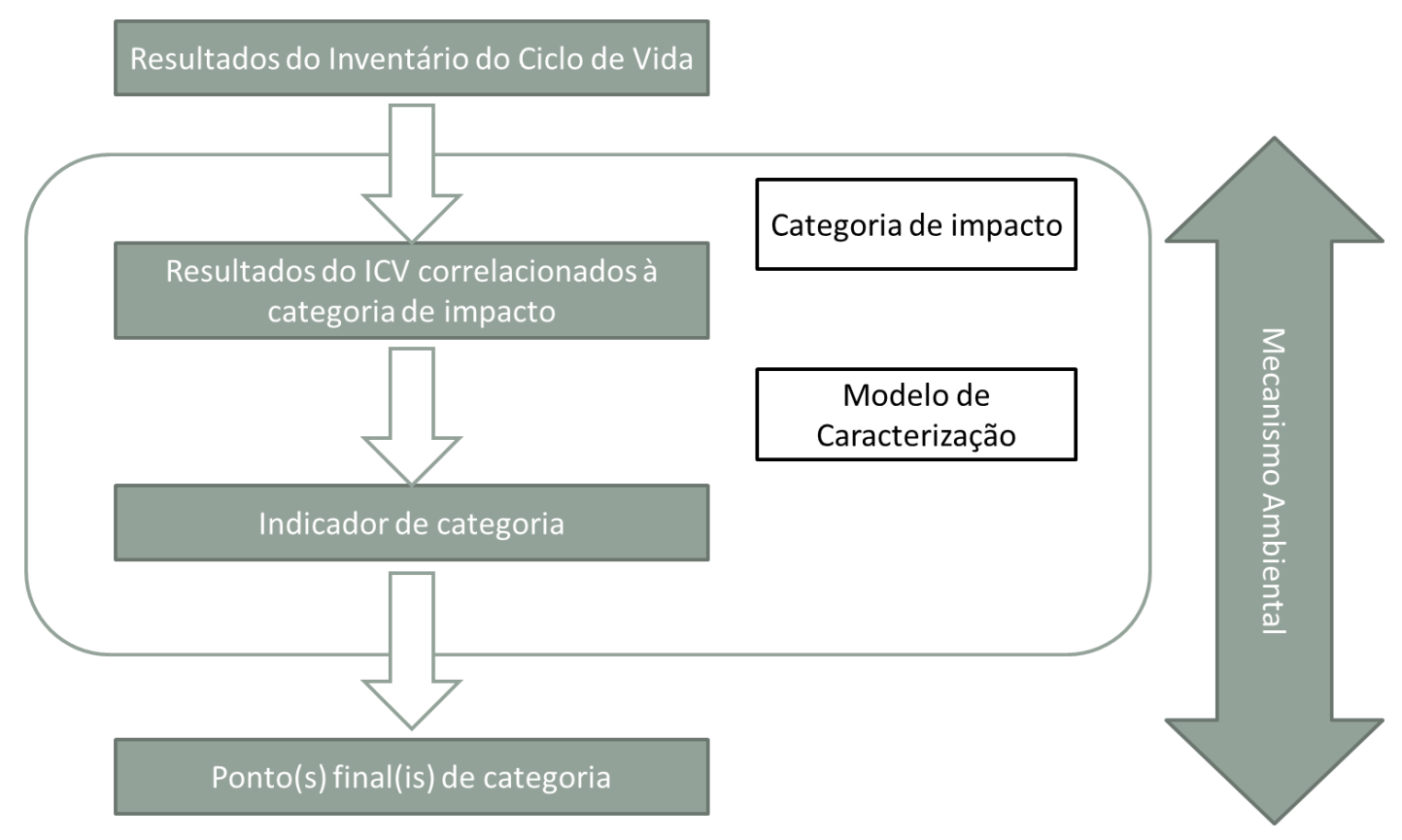

Fonte: Adaptado de ABNT (2009b).

Os elementos opcionais da AICV, segundo a norma NBR ISO 14044, são: a) normalização, que consiste no cálculo da magnitude dos resultados dos indicadores de categoria com relação à informação de referência e tem por objetivo verificar inconsistências, fornece informações sobre a significância dos resultados, entre outras; b) agrupamento, que é a agregação e possível hierarquização das categorias de impacto; c) ponderação, na qual é realizada a conversão e possível agregação dos resultados dos indicadores entre as diferentes categorias de impacto utilizando fatores numéricos baseados em escolhas de valores, sendo necessária a disponibilidade dos dados anteriores a essa etapa; d) análise da qualidade dos dados para melhor entendimento da confiabilidade da coleção de resultados dos indicadores (ABNT, 2009b).

Apesar das normas NBR ISO 14040 e 14044 (ABNT, 2009 a,b) indicarem a estrutura metodológica geral das fases para a realização de um estudo de $\mathrm{ACV}$, não há recomendações de métodos para a realização do estudo. Desta forma, ao longo dos anos diversos métodos de AICV foram desenvolvidos e hoje se estima que existem mais de 50 métodos disponíveis (EPLCA, 2010). Destes, é possível identificar os principais métodos amplamente utilizados na AICV, sendo: EcoIndicator 99, EDIP 2003, CML 2002, TRACI, EPS 2000, Impact 2002+, ReCiPe, MEEuP, LIME e Swiss Ecoscarcity. Ressalta-se, entretanto, a ausência de um método sul americano, ou mesmo brasileiro, que possibilite estudos de ACV mais precisos e com resultados mais confiáveis. 
A escolha do método de AICV a ser usado muitas vezes não é clara e os resultados obtidos pela utilização desses métodos podem ser bastante distintos para o mesmo ICV (HAUSCHILD et al., 2013). Assim, alguns requisitos foram traçados em EC-JRC (2010b) para auxiliar e guiar a condução da AICV, por exemplo: devem ser priorizados métodos internacionalmente aceitos e recomendados por um organismo governamental relevante; devem ser cientificamente e tecnicamente válidos; devem ser baseados em um mecanismo ambiental identificável ou observações empíricas reprodutíveis; e devem evitar a dupla contagem de impactos.

Como visto, os métodos de AICV e seus modelos de caracterização avaliam diversas categorias de impacto; dentre elas, podem-se citar algumas comumente avaliadas: aquecimento global, depleção da camada de ozônio, eutrofização, ecotoxicidade, toxidade humana, depleção de recursos bióticos e abióticos, acidificação e uso da terra, a qual será abordada nas próximas seções deste capítulo. 


\section{USO DA TERRA}

Tendo em vista o objeto de estudo desta tese, inicialmente é preciso que sejam definidos alguns termos utilizados ao longo do trabalho. Assim, terra é conceituada como:

"segmento da superfície do globo terrestre definido no espaço e reconhecido em função de características e propriedades compreendidas pelos atributos da biosfera, que sejam razoavelmente estáveis ou ciclicamente previsíveis, incluindo aquelas de atmosfera, solo, substrato geológico, hidrologia e resultado da atividade do homem". (FAO, 1976)

O solo, por sua vez, é uma coleção de corpos naturais, constituídos por partes sólidas, líquidas e gasosas, tridimensionais, dinâmicos, formados por materiais minerais e orgânicos, contendo matéria viva e ocupando a maior porção do manto superficial das extensões continentais do planeta (EMBRAPA, 1999). O Brasil se caracteriza por uma grande diversidade de tipos de solos, diferentes formas e tipos de relevo, clima, material de origem, vegetação e organismos associados, influenciando em diferentes processos formadores dos solos. Tal diversidade explica diferenças regionais no que se refere às diversas formas de ocupação, uso e desenvolvimento do território (COELHO et al., 2002).

O termo uso da terra pode ser definido como "uma expressão das relações socioeconômicas que indica a apropriação da natureza pela sociedade" (IBAMA, 2013, p.93). Segundo Choudhury; Jansen (1999) consiste principalmente nas intervenções humanas em um determinado tipo de cobertura terrestre para nele realizar modificações, produzir ou manter seu estado. Portanto, o uso da terra está relacionado à função socioeconômica (agricultura, habitação, proteção ambiental) da superfície (CORINE, 2000).

Já a cobertura da terra pode ser definida como os elementos da natureza - como a vegetação (natural e plantada), água, gelo, rocha, areia e superfícies similares - além das construções artificiais criadas pelo homem, que recobrem a superfície da terra. (BIE; LEEUWEN; ZUIDEMA, 1996). A cobertura da terra pode mudar devido a fenômenos naturais como intempéries, sucessão vegetal, ou por atividades humanas (USGS, 2013).

A capacidade da agricultura, pecuária e silvicultura de satisfazer a crescente demanda por alimentos, recursos energéticos e matérias-primas de origem animal e vegetal é incerta sendo fundamental acompanhar as variações da pressão sobre o recurso solo e as crescentes disputas entre os diferentes tipos de uso desse recurso (IBGE, 2015). Embora as práticas de 
uso da terra variem muito em todo o mundo, o seu resultado final é geralmente o mesmo: a aquisição de recursos naturais para as necessidades humanas imediatas, muitas vezes em detrimento da degradação ambiental (FOLEY et al., 2005). Em termos gerais, as consequências incluem a alteração dos fluxos de água, nutrientes, energia e espécies presentes na área (KNOESTER, 2015).

O desmatamento, por exemplo, pode provocar uma série de danos e desequilíbrio ambiental, como a fragmentação de habitats, a extinção de espécies da fauna e da flora, a interferência nos fluxos e processos biológicos e de polinização, dentre outros danos à biodiversidade. Além de ser apontado como uma das grandes ameaças à qualidade e à quantidade disponível de água, o desmatamento é também historicamente responsável por grande parte das emissões líquidas de gás carbônico $\left(\mathrm{CO}_{2}\right)$ na atmosfera (IBGE, 2015).

A degradação do solo é resultado de um ou mais processos que diminuem a capacidade produtiva do solo (atual e/ou potencial) em produzir bens ou serviços (MEA, 2005). Gregorich; Carter (1997) complementam a definição de degradação do solo como efeitos relacionados à capacidade de cumprir uma função específica, podendo ser determinada em diferentes escalas (em campo, propriedade agrícola, ecossistema e região). Portanto, o grau de degradação do solo é um indicador da sustentabilidade dos ecossistemas, sendo que terras degradadas são tipicamente caracterizadas por solos empobrecidos e erodidos, pela instabilidade geológica, produtividade primária reduzida e diversidade biológica diminuída (KOBIYAMA et al., 1993).

Segundo Hernani et al. (2002, p.47), os tipos de degradação dos solos podem ser:

- "Erosão hídrica: perda de horizontes superficiais, deformação do terreno, movimentos de massa, deposição.

- Erosão eólica: perda de horizontes superficiais, deformação do terreno, movimentos de massa, deposição.

- Química: perda de nutrientes e/ou matéria orgânica, desequilíbrio de nutrientes, salinização, acidificação, poluição.

- Física: compactação, selamento, inundação, aeração deficiente, excesso ou falta de água.

- Biológica: redução da biomassa, redução da biodiversidade.”

Além disso, as propriedades biogeoquímicas e ecológicas da terra determinam o provisionamento dos serviços dos ecossistemas que suportam as necessidades humanas, 
sendo, portanto, diretamente afetados pelo uso da terra e indiretamente por meio de todos os outros impactos (RICKETTS et al., 2004).

Tendo em vista todas as consequências ambientais, a compreensão e a quantificação dos impactos do uso da terra são fundamentais no desenvolvimento de sistemas agrícolas sustentáveis (DEXTER; YOUNGS, 1992). Contudo, transformar a natureza complexa e específica de cada solo em atributos mensuráveis que possibilitem avaliações sistemáticas independentes de seus usos é um grande desafio (SOJKA; UPCHURCH, 1999; WANDER; DRINKWATER, 2000 ).

Dados do uso e transformação da terra devem ser espacialmente explícitos com resolução adequada e precisão para realizar seu pleno potencial de gestão e planejamento ambiental. No entanto, muitas incertezas e suposições surgem na coleta de dados, incluindo erros de medição, erros de classificação, e erros de comunicação (ECOLOGIC INSTITUTE; SERI, 2010).

Apesar das limitações, análises sistemáticas dos impactos ambientais relacionados ao uso da terra podem ajudar a melhorar o planejamento ambiental e garantir que responsáveis pela tomada de decisão não só estabeleçam medidas mitigadoras conforme os impactos, mas também alcancem soluções adequadas com vistas ao desenvolvimento sustentável.

\subsection{Uso da terra na Avaliação do Ciclo de Vida}

A transformação e ocupação da terra tem atenção especial no planejamento territorial, sendo relevante no domínio da Avaliação de Impacto Ambiental (AIA), mas também na $\mathrm{ACV}$, sempre levando em consideração o objetivo do estudo. No campo da AIA e de ordenamento do território de áreas urbanas e rurais, é relevante para a identificação de impactos potenciais na instalação futura de um empreendimento além do estudo da expansão de áreas construídas com um mínimo de degradação da natureza (VOGTLÄNDER et al., 2004) enquanto no campo da ACV, é relevante na incorporação dos efeitos negativos do uso da terra, devido ao papel essencial dos solos no funcionamento dos ecossistemas e de forma que a metodologia contemple o respectivo princípio de completeza, o qual salienta que a ACV deve considerar todos os atributos ou aspectos do ambiente natural, da saúde humana e dos recursos (ABNT, 2009a).

No campo da ACV, o termo uso da terra refere-se a um tipo específico de intervenção ambiental, definido nos resultados do inventário do ciclo de vida, o qual ocasionará modificações na aptidão do solo em realizar suas funções (MILÀ i CANALS et al. 2007a). 
Segundo Milà i Canals et al. (2007a), dois tipos de intervenção são usualmente considerados em ICV e AICV: a transformação e a ocupação da terra. Durante a transformação da terra (fase relativamente curta), as propriedades da área são modificadas para torná-la adequada para a utilização pretendida. Na AICV, a dimensão temporal desta intervenção é negligenciada e o processo é medido em unidades de área transformada (geralmente em hectares) (SOUZA, 2010). Já durante a ocupação da terra, que é a utilização de uma área por determinada atividade em certo tempo, considera-se que as propriedades da área são mantidas constantes de acordo com a atividade estabelecida. Este processo é mensurado em unidades de área-tempo (hectares*ano) por unidade funcional (SOUZA, 2010).

Ambas as intervenções têm um impacto sobre a qualidade do ecossistema $(Q)$, podendo esta ser definida como a capacidade de um ecossistema de sustentar a biodiversidade e prestar serviços à sociedade humana, i.e., serviços ecossistêmicos (KOELLNER, 2013b). A Figura 6 sintetiza o mecanismo ambiental dos impactos do uso da terra, evidenciando estas duas vertentes. De modo geral, os impactos são então calculados proporcionalmente à diferença de qualidade entre o sistema estudado e uma situação de referência (KOELLNER et al. 2013b). 
Figura 6: Cadeia de causa e efeito dos impactos do uso da terra.

INVENTÁRIO

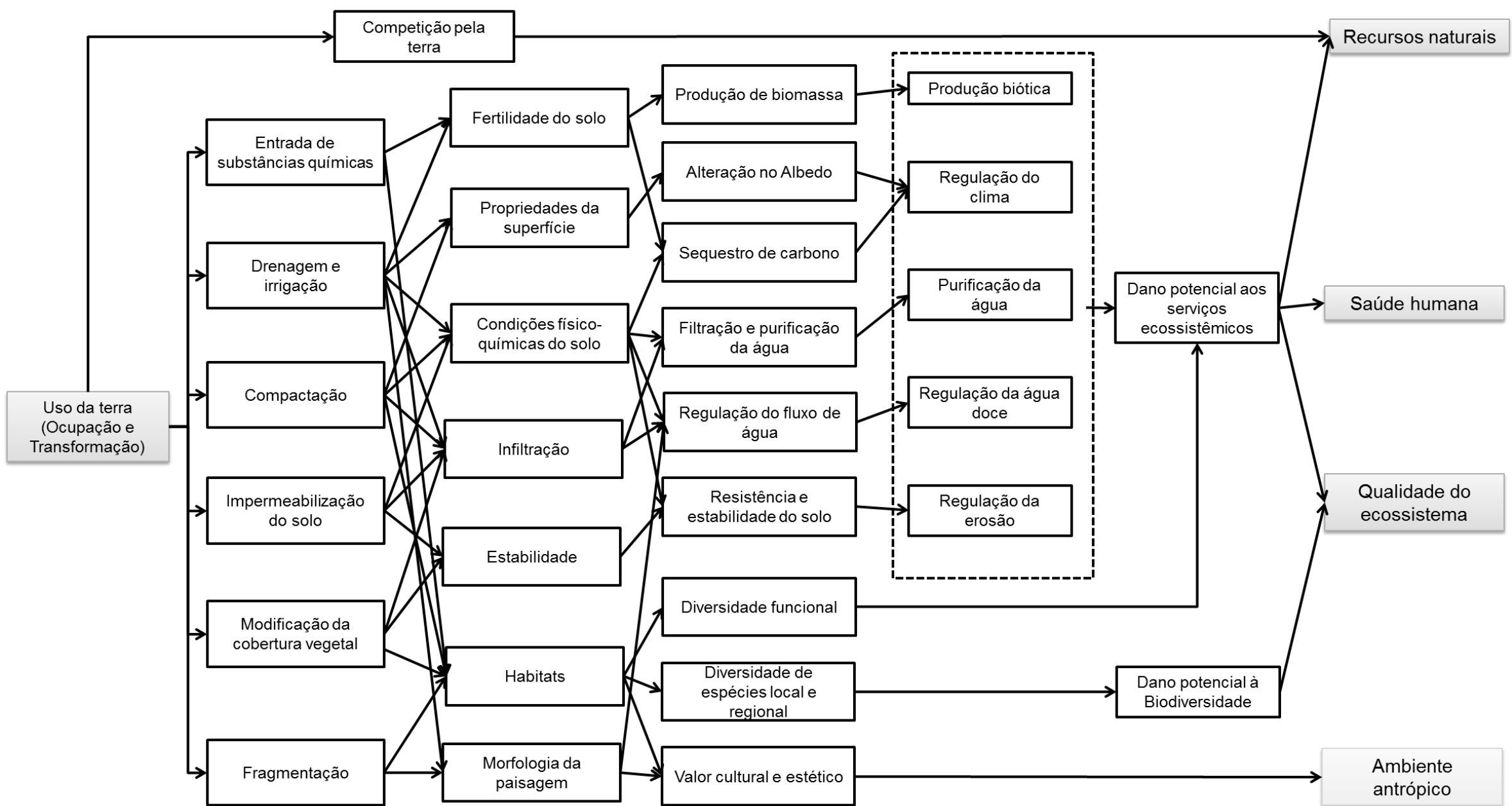

Fonte: adaptado de Koellner et al. (2013b). 
Ao longo dos últimos 15 anos diversas pesquisas foram desenvolvidas com o objetivo de propor indicadores de biodiversidade para expressar impactos do uso da terra na ACV. A maioria destas pesquisas usa indicadores baseados na riqueza de espécies e modelos ecológicos de relação espécie-área (Species-Area Relationship - SAR). Outros utilizam metaanálise ou aplicam modelos de distribuição de espécies (Species Distribution Model - SDM) para avaliar impactos ambientais locais (SOUZA et al., 2015).

Paralelamente, o conceito de serviços ecossistêmicos foi inserido nos estudos de ACV recentemente (KOELLNER; GEYER, 2013; ZHANG et al., 2010a,b) sobrepondo o que antes era denominado de funções de suporte a vida (UDO de HAES et al., 2002; MILÀ I CANALS et al., 2007b). Definido como benefícios relevantes para a sociedade gerados pelos ecossistemas, este conceito teve difusão no meio acadêmico e empresarial a partir da Avaliação Ecossistêmica do Milênio (Millennium Ecosystem Assessment) (MEA, 2005), como oportunidade de conciliar interesses econômicos e ambientais. 


\section{SERVIÇOS ECOSSISTÊMICOS}

Um ecossistema é "um complexo dinâmico de comunidades vegetais, animais, microrganismos, e seu respectivo meio, que interagem como uma unidade funcional" (MEA, 2005). Desta forma, incluem não apenas as interações entre os organismos, mas entre a totalidade dos fatores físicos do ambiente (TANSLEY, 1935). A abundância e variedade dos elementos abióticos, plantas, animais e microrganismos representa a composição do ecossistema, sendo que de acordo com McGarigal et al. (1994) a distribuição física dos elementos é chamada de estrutura do ecossistema.

As primeiras menções ao termo "serviços ecossistêmicos" na literatura científica datam do final da década de 1970 e início da década de 1980, surgindo com o objetivo de aumentar o interesse público na conservação da biodiversidade e evoluiu rapidamente para o desenvolvimento de métodos para estimar seus valores econômicos. Nesse sentido, podem ser destacados os estudos pioneiros como de Ehrlich; Mooney (1983) mas também o de Costanza et al. (1997) que foi um dos primeiros estudos que tentou valorar os serviços ecossistêmicos. Desde então o conceito tem sido usado para representar os benefícios da natureza para os seres humanos, seja para a conservação, gestão, ou fins econômicos (MEA, 2005; VAN OUDENHOVEN et al., 2012; DE GROOT et al., 2012).

As últimas duas décadas foram marcadas por intenso debate sobre a definição e classificação dos serviços ecossistêmicos (WALLACE, 2007; FISHER; TURNER; MORLING, 2009; DE GROOT et al., 2010a; NAHLIK et al., 2012). No Quadro 1 são apresentadas dez diferentes definições encontradas na literatura exemplificando tamanha variedade. 
Quadro 1: Definições de serviços ecossistêmicos disponíveis na literatura.

\begin{tabular}{|c|c|}
\hline Definição & Referência \\
\hline $\begin{array}{l}\text { Capacidade de processos naturais e componentes para fornecer bens e } \\
\text { serviços que satisfaçam as necessidades humanas, direta ou indiretamente. }\end{array}$ & De Groot (1992) \\
\hline $\begin{array}{l}\text { São condições e processos provenientes dos ecossistemas naturais e das } \\
\text { espécies que os compõem que sustentam e mantém a vida humana. }\end{array}$ & Daily (1997) \\
\hline $\begin{array}{l}\text { São os benefícios para populações humanas que derivam, direta ou } \\
\text { indiretamente, das funções dos ecossistemas. }\end{array}$ & Costanza et al. (1997) \\
\hline $\begin{array}{c}\text { São processos naturais que garantem a sobrevivência das espécies no planeta } \\
\text { e têm a capacidade de prover bens e serviços que satisfazem as necessidades } \\
\text { humanas. }\end{array}$ & De Groot et al. (2002) \\
\hline $\begin{array}{l}\text { São produtos de funções ecológicas ou processos que direta ou indiretamente } \\
\text { contribuem para o bem-estar humano, ou têm potencial para fazê-lo no futuro. } \\
\text { Representam os processos ecológicos e os recursos expressos em termos de } \\
\text { bens e serviços que fornecem. }\end{array}$ & Daily; Farley (2004) \\
\hline São os benefícios que as pessoas obtêm do ecossistema. & $\begin{array}{c}\text { Millennium } \\
\text { Ecosystem } \\
\text { Assessment - MEA } \\
(2005)\end{array}$ \\
\hline $\begin{array}{c}\text { Benefícios da natureza para famílias, comunidades e economias. São } \\
\text { componentes da natureza, diretamente aproveitados, consumidos ou } \\
\text { usufruídos para o bem-estar humano. }\end{array}$ & $\begin{array}{l}\text { Boyd; Banzhaf } \\
\quad \text { (2007) }\end{array}$ \\
\hline $\begin{array}{c}\text { Benefícios que as pessoas obtêm dos ecossistemas, obtidos de elementos } \\
\text { naturais de ecossistemas (ou também de elementos culturais), incluindo bens } \\
\text { e serviços. }\end{array}$ & Wallace (2007) \\
\hline $\begin{array}{l}\text { São os aspectos dos ecossistemas utilizados, ativa ou passivamente, para } \\
\text { produzir bem-estar humano. }\end{array}$ & Fisher et al. (2009) \\
\hline $\begin{array}{l}\text { Contribuições das estruturas e funções do ecossistema (em combinação com } \\
\text { outros insumos) para o bem-estar humano. }\end{array}$ & Burkhard et al. (2012) \\
\hline $\begin{array}{c}\text { Considera a estrutura, processos e fluxos, consumidos ou utilizados direta ou } \\
\text { indiretamente para produzir bem-estar humano. }\end{array}$ & Farley (2012) \\
\hline
\end{tabular}

Fonte: elaboração própria.

Além disso, existem outros debates e discussões a cerca do conceito de serviços ecossistêmicos, com diversas críticas e respectivos contra-argumentos. Schröter et al. (2014) citam os principais pontos críticos, como por exemplo, o fato do conceito ser criticado por ser antropocêntrico, ao mesmo tempo que outros argumentam que vai além dos valores instrumentais. Segundo, existem argumentações de que o conceito promove uma relação de exploração entre homem e natureza, enquanto outros afirmam que possibilita reconectar a sociedade aos ecossistemas, enfatizando a dependência da humanidade em relação à natureza. O conceito também é questionado por causa de seu suposto foco na avaliação econômica e 
por promover a mercantilização da natureza, enquanto outros argumentam que a ciência dos serviços ecossistêmicos inclui muitos valores e que a maioria dos serviços ecossistêmicos não está conectada a instrumentos baseados no mercado (SCHRÖTER et al., 2014). Estes debates críticos, apesar de serem essenciais para o desenvolvimento do conceito na teoria e na prática, não são o foco do presente estudo.

Quanto a classificação, vale destacar que se procurou neste trabalho uma definição que permite a separação do potencial de um ecossistema de fornecer serviços (função), os serviços ecossistêmicos em si, e os benefícios que eles fornecem aos seres humanos (os quais podem ser expressos em unidades monetárias, por exemplo). As funções do ecossistema são consideradas nesta pesquisa como intermediárias entre os processos e serviços do ecossistema e podem ser definidas como a "capacidade dos ecossistemas para fornecer bens e serviços que satisfaçam as necessidades humanas, direta e indiretamente" (de Groot, 1992). Assim, resume-se em um subconjunto das interações entre estruturas biofísicas, biodiversidade e processos que sustentam a capacidade de um ecossistema para fornecer serviços ecossistêmicos. DALY; FARLEY (2004) complementam a definição ao referir como constantes interações existentes entre os elementos estruturais de um ecossistema, o que inclui transferências de energia, ciclagem de nutrientes, regulação de gás, regulação climática e do ciclo da água.

Como sugere de Groot; Wilson; Boumans (2002), o primeiro passo para uma avaliação abrangente de serviços ecossistêmicos envolve a tradução da complexidade da estrutura e processos do ecossistema em um número mais limitado de funções. Assim, de acordo com De Groot et al. (2000), as funções ecossistêmicas podem ser agrupadas em quatro categorias primárias:

1) Funções de regulação: relacionadas à capacidade de ecossistemas (naturais ou seminaturais) regularem processos ecológicos essenciais através de ciclos biogeoquímicos e outros processos da biosfera.

2) Funções de habitat: ecossistemas naturais fornecem habitat para refúgio e reprodução de espécies de plantas e animais, contribuindo para a conservação da biodiversidade.

3) Funções de produção: relacionadas aos processos de fotossíntese e sequestro de nutrientes por seres autótrofos.

4) Funções de informação: relacionadas à capacidade de ecossistemas naturais contribuírem para a manutenção da saúde humana, fornecendo desenvolvimento cognitivo, recreação e estética. 
Consequente a essas funções, o uso de um bem ou serviço oferece benefícios (nutrição, saúde, lazer, etc.) que, por sua vez, podem ser valorados em termos econômicos e monetários, caracterizando assim os serviços ecossistêmicos (de Groot et al., 2010a), englobando assim fluxos de materiais, energia e informações de ações de capital natural (COSTANZA et al., 1997).

Conforme destacado por Turner; Daily (2008), os serviços ecossistêmicos expressam o papel ao longo prazo que os ecossistemas desempenham para proporcionar bem-estar humano, benefícios sustentáveis e desenvolvimento econômico. Com isso, é uma maneira compreensível e abrangente de integrar as relações humanas e a necessidade de sistemas ecológicos de suporte (GÓMEZ-BAGGETHUN et al., 2010).

Reconhecendo a diversidade de definições e suas implicações nas classificações dos serviços ecossistêmicos, o projeto Avaliação Ecossistêmica do Milênio (MEA, 2005) teve como objetivo estabelecer base científica das ações necessárias para melhorar a contribuição dos ecossistemas para o bem-estar humano e avaliar as consequências das mudanças nos ecossistemas para o bem-estar humano.

O projeto, realizado entre 2001 e 2005, foi um marco significativo na área, difundindo o conceito fora do meio acadêmico e consolidando-o na agenda política e na comunidade empresarial. Dentre os resultados publicados em MEA (2005), foi sistematizada uma classificação dos tipos de serviços ecossistêmicos como descritos abaixo (Figura 7):

- Serviços de provisão: fornecem diretamente bens ou produtos ambientais utilizados pelo ser humano para consumo ou comercialização, tais como água, alimentos, madeira, fibras, entre outros. Normalmente podem existir trade-offs na geração desses serviços, sendo que o uso ou consumo de um serviço pode afetar outros serviços de provisão.

- Serviços de suporte: mantêm o habitat dos seres vivos e sua diversidade genética, tais como a manutenção ou a renovação da fertilidade do solo, produção primária, polinização e a dispersão de sementes. Os impactos dos serviços de suporte sobre os seres humanos são principalmente indiretos e/ou ocorrem ao longo prazo.

- Serviços de regulação: se relacionam às características regulatórias dos processos ecossistêmicos, como a manutenção dos processos ecológicos essenciais e dos sistemas de suporte à vida. Como exemplo pode-se citar a manutenção da qualidade do ar, a regulação climática, regulação de doenças, regulação biológicas, regulação e 
purificação de água, regulação de danos naturais, polinização. Ao contrário dos serviços de provisão, não dependem da "quantidade" de produção, mas da capacidade de os ecossistemas regularem determinados processos.

- Serviços culturais: são bens não materiais que a sociedade adquire da natureza, tais como lazer, turismo, espirituais, entre outros. Estes serviços estão ligados a valores e comportamentos humanos, e a percepção dos mesmos pode ser diferente dependendo de cada indivíduo.

Figura 7: Classificação dos serviços ecossistêmicos e seus exemplos, segundo a Avaliação Ecossistêmica do Milênio.

\section{Serviços Ecossistêmicos}
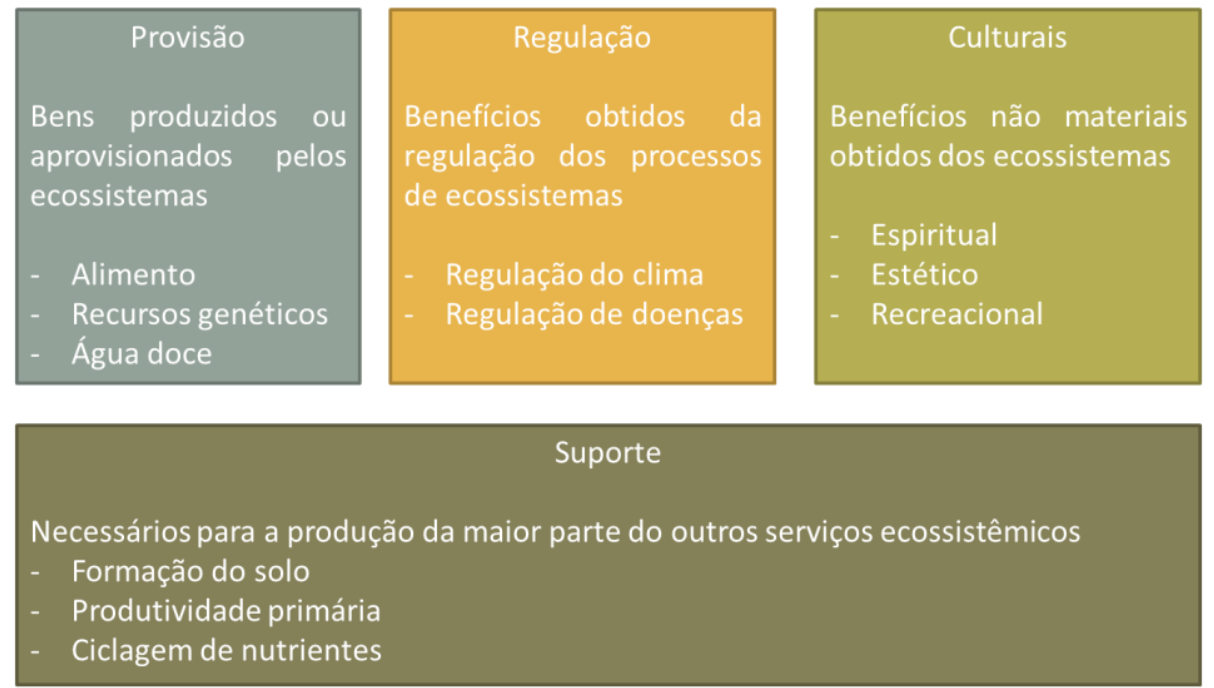

Fonte: Elaborado pela autora.

No entanto, algumas críticas a essa publicação são encontradas na literatura, principalmente no que tange à confusão entre os processos do ecossistema e os serviços em si. Boyd e Banzhaf (2007), por exemplo, salientam que muitos dos serviços de regulação correspondem melhor às funções ecossistêmicas do que aos serviços (por exemplo, regulação de pragas, regulação de doenças). Além disso, eles argumentam que os serviços culturais, incluindo valores espirituais e religiosos, valores estéticos, recreação e ecoturismo, devem ser caracterizados como benefícios e não como serviços.

Uma das atividades seguintes e estimulada a partir da Avaliação dos Ecossistemas do Milênio é o projeto The Economics of Ecosystems and Biodiversity (TEEB, 2010) que visa analisar os caminhos das estruturas e processos do ecossistema ao bem-estar humano (de 
acordo com benefícios e valores ecológicos, socioculturais e econômicos). Outra iniciativa, a Classificação Internacional Comum dos Serviços de Ecossistemas (The Common International Classification of Ecosystem Services - CICES) foi desenvolvida para alcançar uma classificação padrão para os serviços ecossistêmicos, permitindo uma tradução fácil de informações entre diferentes tipologias e aplicações. Entre as definições que alicerçam o projeto CICES, tem-se que os serviços ecossistêmicos são considerados como resultado da interação de processos bióticos e abióticos, referente aos resultados (ou produtos) finais dos ecossistemas. Como resultado deste projeto, foi proposta uma estrutura hierárquica em que o mais alto nível abrange três "temas" (provisão; regulação e manutenção; e serviços culturais), oito divisões e 20 grupos subsequentes de serviços ecossistêmicos (Figura 8). 
Figura 8: Tipologia estabelecida pelo projeto CICES.

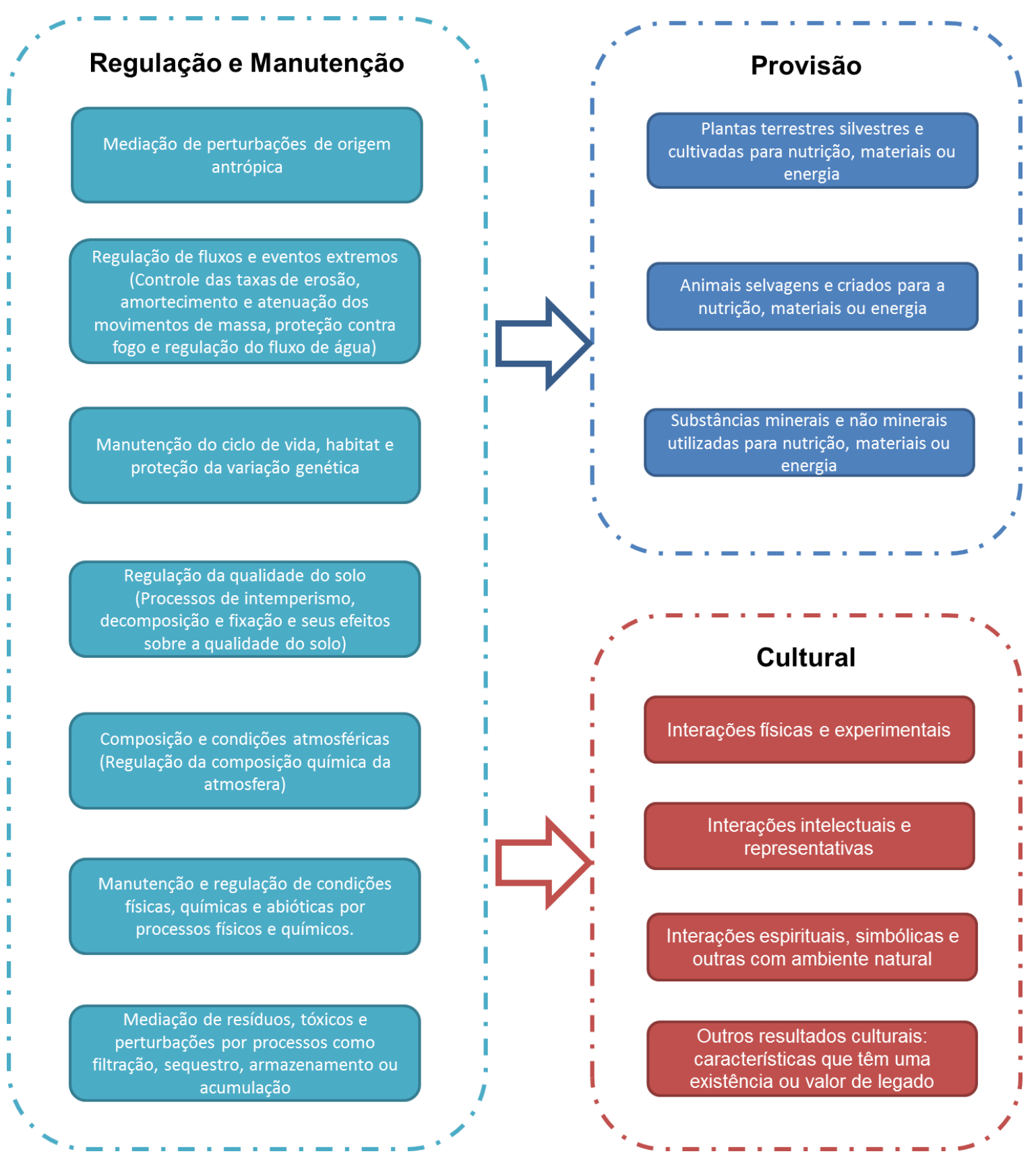

Fonte: Elaboração própria.

Assim, os serviços de suporte originalmente definidos no MEA não são incluídos pelo CICES, mas sim tratados como parte das estruturas, processos e funções subjacentes que caracterizam os ecossistemas, o que será discutido posteriormente. Além disso, os serviços de regulação e manutenção podem ser descritos como serviços intermediários, uma vez que considera os resultados do ecossistema que não são consumidos, mas que afetam o desempenho de indivíduos, comunidades e populações. Trata-se de todas as maneiras pelas quais os organismos vivos podem mediar ou moderar o ambiente que afeta a saúde humana, 
segurança ou conforto. Esta divisão cobre, portanto, (i) a "transformação de insumos bioquímicos ou físicos para os ecossistemas", sob a forma de resíduos e substâncias tóxicas; e (ii) a "regulação das condições físicas, químicas e biológicas, que categoriza as várias maneiras pelas quais os sistemas vivos podem mediar o meio físico-químico e biológico das pessoas de forma benéfica (HAINES-YOUNG, POTSCHIN, 2018, p.15).

Os serviços de provisão incluem resultados tangíveis (materiais e energéticos) de ecossistemas que podem ser trocados ou comercializados, bem como consumidos ou utilizados diretamente pelas pessoas. Assim, esta divisão abrange todos os materiais nutricionais, não nutricionais e saídas energéticas dos sistemas vivos, bem como saídas abióticas (incluindo água) (HAINES-YOUNG, R. POTSCHIN, 2018).

Finalmente, os serviços culturais incluem resultados não materiais que têm significado simbólico, cultural ou intelectual (HAINES; POTSCHIN, 2011). São, portanto, todas as saídas não-materiais e normalmente não consumíveis dos ecossistemas (bióticos e abióticos) que afetam os estados físicos e mentais das pessoas. Os serviços culturais são considerados por Haines-Young, Potschin (2018) como as configurações ambientais, locais ou situações que dão origem a mudanças nos estados físicos ou mentais das pessoas, onde o caráter dessas configurações é fundamentalmente dependente de processos vivos; eles podem envolver espécies individuais, habitats e ecossistemas inteiros.

O sistema de classificação desenvolvido no âmbito do CICES adapta e expande a abordagem do MA para fornecer um sistema de classificação mais sistemático e detalhado, que inclui mais atenção à diferenciação entre serviços ecossistêmicos intermediários e finais. No entanto, existem críticas de que esta abordagem de classificação não cria categorias que distinguem completamente entre o que é fornecido por sistemas naturais; como esses sistemas e saídas naturais são usados pelo homem; e o que é produzido por sistemas humanos (USEPA, 2015).

O Quadro 2 a seguir apresenta uma comparação entre as tipologias citadas acima. 
Quadro 2: Comparativo das classificações dos Serviços Ecossistêmicos.

\begin{tabular}{|c|c|c|c|}
\hline $\begin{array}{c}\text { Serviços } \\
\text { Ecossistêmicos }\end{array}$ & MA & TEEB & CICES \\
\hline $\begin{array}{c}\text { Serviços de } \\
\text { provisão }\end{array}$ & $\begin{array}{c}\text { Alimentação } \\
\text { Água doce } \\
\text { Fibra e madeira } \\
\text { Bioquímicos } \\
\text { Recursos genéticos } \\
\text { Recursos } \\
\text { ornamentais }\end{array}$ & $\begin{array}{c}\text { Alimento } \\
\text { Água } \\
\text { Matéria-prima } \\
\text { Recursos medicinais } \\
\text { Recursos genéticos } \\
\text { Recursos ornamentais }\end{array}$ & $\begin{array}{c}\text { Biomassa (nutrição, materiais para } \\
\text { uso na agricultura) } \\
\text { Água (nutrição, dessedentação e } \\
\text { outros usos) } \\
\text { Biomassa (materiais derivados de } \\
\text { plantas e animais para uso e } \\
\text { processamento direto) } \\
\text { Biomassa (material genético } \\
\text { derivado da biota) } \\
\text { Fontes de energia oriunda de } \\
\text { biomassa } \\
\text { Energia mecânica (tração animal) }\end{array}$ \\
\hline $\begin{array}{c}\text { Serviços de } \\
\text { suporte e } \\
\text { regulação (MA) } \\
\text { Serviços de } \\
\text { regulação } \\
\text { (TEEB) } \\
\text { Serviços de } \\
\text { regulação e } \\
\text { manutenção } \\
\text { (CICES) }\end{array}$ & $\begin{array}{c}\text { Regulação de gases } \\
\text { e qualidade do ar } \\
\text { Purificação e } \\
\text { tratamento da água } \\
\text { Regulação da água } \\
\text { Regulação da } \\
\text { erosão } \\
\text { Regulação do clima } \\
\text { Polinização } \\
\text { Regulação de } \\
\text { doenças e pragas } \\
\text { Produção primária } \\
\text { Ciclagem de } \\
\text { nutrientes }\end{array}$ & $\begin{array}{l}\text { Regulação de gases e } \\
\text { qualidade do ar } \\
\text { Tratamento de } \\
\text { resíduos (purificação } \\
\text { da água) } \\
\text { Regulação dos fluxos } \\
\text { de água } \\
\text { Prevenção de erosões } \\
\text { Regulação do clima } \\
\text { Polinização } \\
\text { Controle biológico } \\
\text { Regulação de eventos } \\
\text { extremos } \\
\text { Manutenção do ciclo } \\
\text { de vida } \\
\text { Manutenção da } \\
\text { diversidade genética }\end{array}$ & $\begin{array}{c}\text { Mediação de fluxos de ar e gases } \\
\text { Mediação de resíduos, tóxicos e } \\
\text { outras perturbações pela biota e } \\
\text { ecossistema } \\
\text { Mediação de fluxos líquidos } \\
\text { Mediação de fluxos de massa } \\
\text { Regulação do clima e composição } \\
\text { atmosférica } \\
\text { Manutenção do ciclo de vida, } \\
\text { habitat e proteção da diversidade } \\
\text { genética } \\
\text { Controle de doenças e pragas } \\
\text { Manutenção do ciclo de vida, } \\
\text { habitat e proteção da diversidade } \\
\text { genética } \\
\text { Formação e composição do solo, } \\
\text { manutenção das condições da água }\end{array}$ \\
\hline $\begin{array}{c}\text { Serviços } \\
\text { culturais (MA, } \\
\text { TEEB e } \\
\text { CICES) }\end{array}$ & $\begin{array}{c}\text { Valores religiosos e } \\
\text { espirituais } \\
\text { Valores estéticos } \\
\text { Diversidade cultural } \\
\text { Recreação e } \\
\text { ecoturismo } \\
\text { Conhecimento e } \\
\text { valores } \\
\text { educacionais }\end{array}$ & $\begin{array}{c}\text { Experiência espiritual } \\
\text { Informação estética } \\
\text { Inspiração cultural, } \\
\text { artística e de design } \\
\text { Recreação e turismo } \\
\text { Informação para } \\
\text { desenvolvimento } \\
\text { cognitivo }\end{array}$ & $\begin{array}{c}\text { Serviços de cunho espiritual e/ou } \\
\text { emblemáticos } \\
\text { Interações intelectuais e } \\
\text { representacionais } \\
\text { Interações intelectuais e } \\
\text { representacionais } \\
\text { Serviços de cunho espiritual e/ou } \\
\text { emblemáticos } \\
\text { Interações físicas e experimentais } \\
\text { Interações intelectuais e } \\
\text { representacionais } \\
\text { Outros serviços culturais } \\
\text { (existência) }\end{array}$ \\
\hline
\end{tabular}

Fonte: Traduzido de Adhikari, Hartemink 2016. 


\subsection{Serviços Ecossistêmicos relacionados a políticas e estratégias globais}

Quando se trata de objetivos de melhorar a geração de serviços ecossistêmicos, e fortalecer o monitoramento e a pesquisa de ecossistemas é possível considerar um alinhamento com objetivos de políticas de conservação de recursos, como por exemplo, a Economia Circular (ALI et al., 2018).

A Economia Circular visa preservar e melhorar o capital natural através do controle de estoques finitos e balanceamento de fluxos de recursos renováveis; otimizar o rendimento de recursos circulando produtos, componentes e materiais na mais alta utilidade em todos os momentos, em ciclos técnicos e biológicos, e promover a efetividade do sistema, revelando e projetando externalidades negativas (ELLEN MACARTHUR FOUNDATION, 2017).

Além disso, uma das premissas básicas da Economia Circular é a restauração contínua e a reposição de recursos através do princípio 3R de reduzir, reutilizar e reciclar (MURRAY et al., 2017). Para Ali et al. (2018), visto que as operações de produção e desenvolvimento envolvem uso de recursos naturais, e serviços ecossistêmicos, a Economia Circular deve não só conciliar estas atividades à conservação, mas também incluir sua restauração para sustentar estoques adequados de capital natural. Assim, é possível vislumbrar caminhos para a integração dos conceitos de serviços ecossistêmicos e capital natural na Economia Circular e que o funcionamento dos ecossistemas é um exemplo para processos e sistemas industriais (WOJTACH, 2016).

Segundo Ali et al. (2018), embora a preservação da biodiversidade esteja integrada ao conceito de Economia Circular, faltam exemplos que demonstrem uma ligação clara entre os dois. Além disso, a literatura existente sobre Economia Circular se concentra muito na avaliação de questões operacionais, como a minimização de resíduos por meio da eficiência da cadeia de suprimentos e simbiose industrial, por exemplo. Assim, novas soluções para melhorar a conservação da biodiversidade e serviços ecossistêmicos devem ser exploradas. Exemplos incluem áreas úmidas construídas que podem ser usadas para recuperação de terras ou tratamento de águas residuais, preservando a biodiversidade (ZEDLER, 2003), compostagem de lixo usada para disposição de resíduos, proporcionando serviços ecossistêmicos de controle de erosão do solo e manutenção de ciclos naturais (BASTA et al. 2016), ou mesmo a preservação da biodiversidade para turismo (MARTIN-LOPEZ et al., 2008). 
Além destes, Wojtach (2016) também listam exemplos de soluções para Economia Circular no contexto de serviços ecossistêmicos e associados à soluções de efeitos ambientais e econômicos. (Quadro 3).

Quadro 3: Exemplos de soluções relacionadas à economia circular no contexto de serviços ecossistêmicos.

\begin{tabular}{|c|c|c|}
\hline Serviços Ecossistêmicos & Soluções da Economia Circular & $\begin{array}{l}\text { Efeitos ambientais e } \\
\text { econômicos }\end{array}$ \\
\hline $\begin{array}{l}\text { Provisão: alimentos e } \\
\text { matérias-primas }\end{array}$ & $\begin{array}{l}\text { - } \text { Redução da quantidade de materiais } \\
\text { necessários para a entrega de bens / } \\
\text { serviços; } \\
\text { - } \quad \text { Redução do consumo de energia e } \\
\text { materiais na produção e uso de } \\
\text { produtos; } \\
\text { - } \quad \text { Extensão do tempo de uso de } \\
\text { - } \quad \text { Redução do uso de materiais perigosos } \\
\text { - } \quad \text { Design de produtos mais fáceis de } \\
\text { - } \quad \text { reparar, recuperar e reciclar; } \\
\text { - Criação de mercados para matérias- } \\
\text { - } \text { primas secundárias; } \\
\text { - Incentivar e apoiar a redução de } \\
\text { resíduos e a separação de alta } \\
\text { qualidade pelos consumidores; } \\
\text { Incentivo à separação e sistemas de } \\
\text { coleta que minimizam os custos de } \\
\text { reciclagem e reutilização. }\end{array}$ & $\begin{array}{ll}\text { - } & \text { Eficiência do uso de } \\
\text { recursos } \\
\text { - } \\
\text { Menores custos de } \\
\text { transporte } \\
\text { - } & \text { Durabilidade dos produtos } \\
\text { - } & \text { Redução da quantidade de } \\
\text { resíduos (incluindo } \\
\text { resíduos perigosos) e o } \\
\text { custo de recuperação e } \\
\text { reciclagem }\end{array}$ \\
\hline $\begin{array}{c}\text { Regulação térmica e de } \\
\text { umidade; Melhoria da } \\
\text { qualidade do ar }\end{array}$ & $\begin{array}{l}\text { Processo de regulação das condições bio- } \\
\text { climáticas e a absorção da liberação de } \\
\mathrm{CO}_{2} \text { e } \mathrm{O}_{2} \text { pela vegetação na construção e } \\
\text { no desenho de espaços urbanos. }\end{array}$ & $\begin{array}{l}\text { - } \quad \text { Redução do consumo de } \\
\text { recursos não renováveis; } \\
\text { - } \text { Redução dos custos de } \\
\text { refrigeração e } \\
\text { aquecimento. }\end{array}$ \\
\hline $\begin{array}{l}\text { Regulação: neutralização } \\
\text { de degradação água } \\
\text { (filtração, autodepuração } \\
\text { em reservatórios) }\end{array}$ & $\begin{array}{l}\text { Filtragem, purificação de água em } \\
\text { processos e serviços de produção. }\end{array}$ & 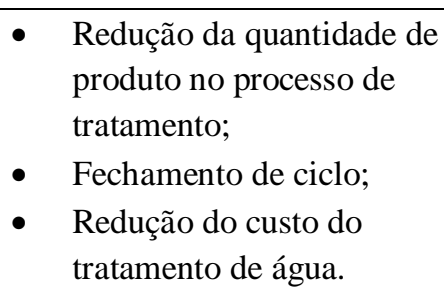 \\
\hline
\end{tabular}

Fonte: Adaptado de Wojtach (2016).

Para Wojtach (2016) o conceito de Economia Circular tem um valor importante para o estado de conservação dos ecossistemas e para o aumento do potencial de serviços ecossistêmicos, ajudando a criar formas mais eficientes de produzir e consumir. Ao mesmo tempo, economiza energia e ajuda a evitar os danos irreversíveis causados pelo uso de 
recursos a uma taxa que excede a capacidade da Terra de renová-los em termos de clima e biodiversidade, poluição do ar, do solo e da água.

Logo, a valorização do capital natural e dos fluxos de serviços ecossistêmicos fornece um relevante impulsionador econômico para preservar ecossistemas e usar soluções baseadas na natureza para enfrentar os desafios econômicos atuais.

Outro marco importante se deu em 2015, com a definição dos 17 Objetivos de Desenvolvimento Sustentável como uma nova agenda de ação até 2030 pela ONU. Resultante do trabalho conjunto de governos e cidadãos de todo o mundo, esta agenda pretende criar um novo modelo global para acabar com a pobreza, promover a prosperidade e o bem-estar, proteger o meio ambiente e combater as alterações climáticas.

Muitos dos objetivos definidos têm uma forte ligação e gestão do uso da terra e da água e reivindicam por um uso sustentável de recursos, restauração de ecossistemas, biodiversidade, sequestro de carbono e manejo sustentável de bacias hidrográficas. Alguns deles são principalmente de caráter socioeconômico (e.g. objetivos 1, 4, 5, 8-11, 16, 17), enquanto outros se concentram claramente no sistema biofísico (e.g. objetivos 2, 3, 6, 7, 12 15). Contudo, para alcançar os objetivos com um enfoque socioeconômico, é necessário considerar o comportamento dinâmico associado dos ecossistemas, enquanto que, para alcançar objetivos com um foco no ecossistema, é necessário considerar os aspectos socioeconômicos (KEESSTRA et al., 2018). Neste contexto, é possível dizer que o conceito dos serviços ecossistêmicos se encontra alinhado à esta agenda global e seus objetivos. No Quadro 4 a seguir encontram-se algumas das relações entre os temas, encontradas por Keesstra et al. (2016). 
Quadro 4: Relação entre os Objetivos de Desenvolvimento Sustentável da ONU e serviços ecossistêmicos relacionados ao solo.

Objetivos de Desenvolvimento Sustentável (ODS)

Serviços Ecossistêmicos

\begin{tabular}{|c|c|c|c|c|c|c|c|c|c|c|c|c|}
\hline \multirow[b]{2}{*}{ Objetivos de Desenvolvimento Sustentável (ODS) } & \multicolumn{12}{|c|}{ Serviços Ecossistêmicos } \\
\hline & 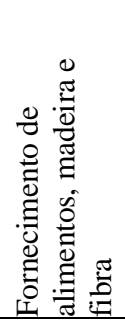 & 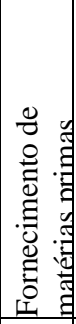 & 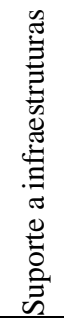 & 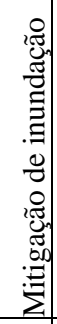 & 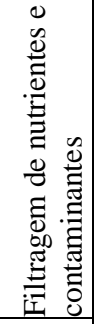 & 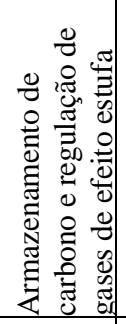 & 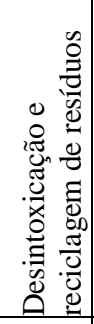 & 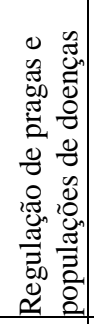 & 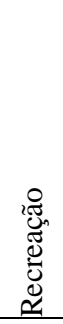 & 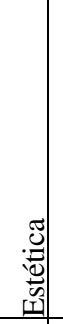 & 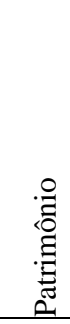 & 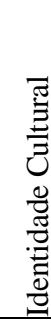 \\
\hline 1 Acabar com a pobreza em todas as suas formas, em todos os lugares & $\mathrm{x}$ & $\mathrm{x}$ & $\mathrm{x}$ & $\mathrm{x}$ & & & & & & & & \\
\hline $\begin{array}{l}2 \text { Acabar com a fome, alcançar a segurança alimentar e melhoria da nutrição e promover a } \\
\text { agricultura sustentável }\end{array}$ & $\mathrm{x}$ & & $\mathrm{x}$ & & & & & & & & & \\
\hline 3 Assegurar uma vida saudável e promover o bem-estar para todos, em todas as idades & $\mathrm{x}$ & & & & & & & $\mathrm{x}$ & $\mathrm{x}$ & $\mathrm{x}$ & $\mathrm{x}$ & $\mathrm{x}$ \\
\hline $\begin{array}{l}4 \text { Assegurar a educação inclusiva e equitativa e de qualidade, e promover oportunidades de } \\
\text { aprendizagem ao longo da vida para todos }\end{array}$ & & & & & & & & & & & & $\mathrm{x}$ \\
\hline \multicolumn{13}{|l|}{5 Alcançar a igualdade de gênero e empoderar todas as mulheres e meninas } \\
\hline 6 Assegurar a disponibilidade e gestão sustentável da água e saneamento para todos & & & & $\mathrm{x}$ & $\mathrm{x}$ & & $\mathrm{x}$ & & $\mathrm{x}$ & & & \\
\hline 7 Assegurar o acesso confiável, sustentável, moderno e a preço acessível à energia para todos & $\mathrm{x}$ & $\mathrm{x}$ & & & & & & & & & & \\
\hline $\begin{array}{l}8 \text { Promover o crescimento econômico sustentado, inclusivo e sustentável, emprego pleno e } \\
\text { produtivo e trabalho decente para todos }\end{array}$ & $\mathrm{x}$ & $\mathrm{x}$ & $\mathrm{x}$ & & & & & & & & & \\
\hline $\begin{array}{l}9 \text { Construir infraestruturas resilientes, promover a industrialização inclusiva e sustentável e } \\
\text { fomentar a inovação }\end{array}$ & & $\mathrm{x}$ & $\mathrm{x}$ & & & & & & & & & \\
\hline \multicolumn{13}{|l|}{10 Reduzir a desigualdade dentro dos países e entre eles } \\
\hline 11 Tornar as cidades e os assentamentos humanos inclusivos, seguros, resilientes e sustentáveis & & $\mathrm{x}$ & $\mathrm{x}$ & & & & & & & & & \\
\hline 12 Assegurar padrões de produção e de consumo sustentáveis & $\mathrm{x}$ & $\mathrm{x}$ & & & $\mathrm{x}$ & $\mathrm{x}$ & $\mathrm{x}$ & & & & & \\
\hline 13 Tomar medidas urgentes para combater a mudança do clima e seus impactos & & & & $\mathrm{x}$ & & $\mathrm{x}$ & & & & & & \\
\hline \multicolumn{13}{|l|}{$\begin{array}{l}14 \text { Conservação e uso sustentável dos oceanos, dos mares e dos recursos marinhos para o } \\
\text { desenvolvimento sustentável }\end{array}$} \\
\hline $\begin{array}{l}15 \text { Proteger, recuperar e promover o uso sustentável dos ecossistemas terrestres, gerir de forma } \\
\text { sustentável as florestas, combater a desertificação, deter e reverter a degradação da terra e deter } \\
\text { a perda de biodiversidade }\end{array}$ & $\mathrm{x}$ & $\mathrm{x}$ & $\mathrm{x}$ & $\mathrm{x}$ & $\mathrm{x}$ & $\mathrm{x}$ & $\mathrm{x}$ & $\mathrm{x}$ & $\mathrm{x}$ & & $\mathrm{x}$ & $\mathrm{x}$ \\
\hline $\begin{array}{l}16 \text { Promover sociedades pacíficas e inclusivas para o desenvolvimento sustentável, proporcionar } \\
\text { o acesso à justiça para todos e construir instituições eficazes, responsáveis e inclusivas em todos } \\
\text { os níveis }\end{array}$ & & & $\mathrm{x}$ & & & & & & $\mathrm{x}$ & & $\mathrm{x}$ & $\mathrm{x}$ \\
\hline $\begin{array}{l}17 \text { Fortalecer os meios de implementação e revitalizar a parceria global para o desenvolvimento } \\
\text { sustentável }\end{array}$ & & & & & & & & & & & & \\
\hline
\end{tabular}

Fonte: Keesstra et al. (2016). 


\subsection{Modelo de cascata dos serviços ecossistêmicos}

O modelo de cascata da provisão de Serviços Ecossistêmicos (Figura 1), desenvolvido por HAINES-YOUNG; POTSCHIN (2010) é uma estrutura conceitual bem conhecida para operacionalizar os elos entre propriedades do ecossistema (estrutura ou processo biofísico), funções do ecossistema (fluxos), serviços ecossistêmicos, benefícios e, finalmente, um valor (POTSCHIN; HAINES-YOUNG, 2011).

\section{- $\quad$ Processos do ecossistema}

O ponto de partida do modelo em cascata são estruturas e processos biofísicos que Kandziora; Burkhard; Müller, (2013) definem como aspectos ecológicos únicos, e então as funções ecológicas decorrem dessas estruturas. La Notte et al. (2017) definem a estrutura biofísica como a conformação de componentes do ecossistema (biótico e abiótico), enquanto os processos se referem à interação ecológica entre os componentes de um ecossistema ao longo do tempo. São vistos como as interações complexas entre os elementos bióticos e abióticos dos ecossistemas, abrangendo, em termos gerais, ciclos de materiais e fluxo de energia (LYONS et al., 2005).

\section{- $\quad$ Funções do ecossistema}

Como já abordado, existem diferentes denominações de funções do ecossistema, mas pelo identificado na literatura a maioria dos autores concorda que bens e serviços são gerados por funções ecológicos (por exemplo, COSTANZA et al., 1997; DAILY, 1997; FARBER et al., 2006). No entanto, de Groot (1992, p.17) as define como "a capacidade de processos e componentes naturais para fornecer bens e serviços que satisfaçam as necessidades humanas, direta ou indiretamente". As funções são, portanto, o subconjunto de estruturas e processos biofísicos que fornecem serviços (de Groot et al., 2010). Assim, observa-se que o termo é considerado como "capacidade". No entanto, muito frequentemente o termo é usado como sinônimo de processos ecossistêmicos, segundo (JAX, 2005) geralmente ele é usado de maneira mais geral para se referir a processos que operam dentro de um ecossistema (e.g., ciclagem de nutrientes).

\section{- $\quad$ Serviços ecossistêmicos}

Assim como as funções do ecossistema, o conceito de serviços ecossistêmicos já foi alvo de diversos estudos, logo existem várias classes semânticas do termo, dependendo do objetivo ou do contexto específico (FISHER; TURNER; MORLING, 2009). O Quadro 1 
anteriormente apresentado na página 46 sintetiza diferentes visões e definições para serviços ecossistêmicos.

\section{- Benefícios}

Um benefício é algo que afeta diretamente o bem-estar das pessoas (FISHER; TURNER, 2008). Como o bem-estar é dependente da situação, das circunstâncias culturais e ecológicas, os benefícios são espacialmente explícitos (BOYD; BANZHAF, 2007). Os benefícios podem ser vistos, portanto, como o vínculo entre o bem-estar humano e os ecossistemas, nos quais, teoricamente, um valor econômico pode ser aplicado. Alguns autores podem questionar a diferença entre serviços e benefícios do ecossistema. Para responder este questionamento, Potschin; Haines-Young (2017) citam que a diferença entre um serviço e um benefício no modelo em cascata é que os benefícios são algo que as pessoas atribuem valor. Geralmente, os benefícios se referem ao que é gerado pelo serviço e leva a uma mudança no bem-estar humano (LA NOTTE et al., 2017). No caso dos serviços de regulação e manutenção, o conceito de benefício pode ser de difícil compreensão, pois não há consumo de "produtos" do ecossistema, mas se relaciona com o quanto e como os serviços ecossistêmicos melhoram a qualidade do ecossistema, afetando o desempenho de indivíduos, comunidades, populações, e suas atividades (MAES et al., 2013).

\section{- Valor}

O termo valor gera discussões e definições diferentes: conforme indicado por Spangenberg et al. (2014), os serviços são fluxos, sendo possível medir-se fisicamente e o valor atribuído a eles é subjetivo. O valor pode ser definido como o "valor econômico da mudança no bem-estar" (BOEREMA et al., 2017, p.360). Além disso, de acordo com Groot; Wilson; Boumans (2002) existem três tipos de "valores" do ecossistema: valor ecológico, sociocultural e econômico.

Vale ressaltar que o modelo de cascata foca no fluxo do ecossistema para a sociedade, mas a direção inversa do fluxo também existe, ou seja, a sociedade tem uma demanda que impulsiona as ações humanas para mudar o ambiente a fim de obter e utilizar os serviços ecossistêmicos desejados (SPANGENBERG et al., 2014). De fato, o gerenciamento do ecossistema é uma questão antropogênica que parte de uma demanda da sociedade, mas também precisa considerar o potencial do ecossistema para fornecer serviços e benefícios.

De acordo com de Groot et al. (2010), apesar da aceitação desta estrutura em cascata, a distinção entre os conceitos de função, serviço e benefício, bem como o uso de tal modelo 
ainda suscita discussão. Kandziora; Burkhard; Müller (2013) argumentam que vários processos podem contribuir para diferentes serviços e um serviço pode contribuir para vários aspectos do bem-estar humano, portanto, a cascata não deve ser vista como um sistema unidimensional.

No contexto dos estudos de ACV, que é o foco do presente trabalho, pode ser definido como aspectos que a sociedade considera alvo de proteção (VERONES et al., 2017). O Quadro 6 abaixo fornece descrições de cada nível do modelo de cascata.

Quadro 5: Descrição e exemplificação dos elementos do modelo de cascata.

\begin{tabular}{|c|c|c|}
\hline Categoria & Definição & Exemplos \\
\hline Estrutura & $\begin{array}{c}\text { Indicadores neste nível definem as } \\
\text { características biofísicas que os ecossistemas } \\
\text { precisam para poder funcionar e fornecer } \\
\text { serviços ecossistêmicos. }\end{array}$ & $\begin{array}{l}\text { Cobertura vegetal intacta } \\
\text { Diversidade funcional de } \\
\text { organismos do solo }\end{array}$ \\
\hline Função & $\begin{array}{c}\text { Os indicadores de função definem a } \\
\text { capacidade do ecossistema para produzir } \\
\text { serviços ecossistêmicos em um determinado } \\
\text { período de tempo. }\end{array}$ & $\begin{array}{l}\text { Ciclagem de nutrientes } \\
\text { Produção primária líquida }\end{array}$ \\
\hline Serviço & $\begin{array}{l}\text { Um fluxo gerado pelo ecossistema, incluindo } \\
\text { interações ecológicas e informações que são } \\
\text { úteis aos seres humanos. }\end{array}$ & $\begin{array}{l}\text { Serviço de provisionamento de } \\
\text { madeira } \\
\text { Sequestro de carbono } \\
\text { Purificação de água } \\
\end{array}$ \\
\hline Benefício & $\begin{array}{l}\text { Gerados pelos serviços, levam a mudanças no } \\
\text { bem-estar humano. Os benefícios são } \\
\text { considerados como a parcela utilizada do } \\
\text { rendimento total dos serviços ecossistêmicos. }\end{array}$ & $\begin{array}{l}\text { Colheita anual de madeira em } \\
\text { metros cúbicos por hectare por ano }\end{array}$ \\
\hline Valor & $\begin{array}{l}\text { Podem ser valores econômicos, sociais, de } \\
\text { saúde e intrínsecos. } \\
\text { Indicadores neste nível visam apresentar } \\
\text { completamente a importância dos serviços } \\
\text { ecossistêmicos a partir de diferentes } \\
\text { perspectivas (podendo ser econômico, sociais, } \\
\text { de saúde e valores intrínsecos). }\end{array}$ & $\begin{array}{l}\text { Valor econômico: rendimentos para } \\
\text { proprietários. } \\
\text { Valor social: número de empregos } \\
\text { regulares na cadeia de valor da } \\
\text { madeira. }\end{array}$ \\
\hline
\end{tabular}

Fonte: Adaptado de Berghöfer; Schneider (2015) e La Notte et al. (2017).

Segundo De Groot et al. (2010), apesar da aceitação dessa estrutura em cascata, a distinção entre os conceitos de função, serviço e benefício, bem como o uso de tal modelo, ainda levanta discussões. Kandziora et al. (2013) argumentam que vários processos podem contribuir para diferentes serviços e um serviço pode contribuir para vários aspectos do bemestar humano, portanto a cascata não deve ser vista como um sistema unidimensional. Maes et al. (2012, p.35) são favoráveis ao uso do modelo de cascata, argumentando que é "um conceito útil para enquadrar avaliações quantitativas, espacialmente explícitas, de ecossistemas, serviços ecossistêmicos e beneficios". Da mesma forma, Spangenberg et al. 
(2014), que procuraram mostrar como a cascata pode ser usada para estruturar o planejamento do uso da terra, consideram um framework útil para classificar diversas etapas de geração e alocação de serviços ecossistêmicos, pois permite mapear diferentes fluxos entre a ecosfera e a antroposfera e entender a atribuição de valor. Esse esquema de cinco níveis permite uma visão mais estruturada da variabilidade espacial e das escalas nas quais serviços ecossistêmicos são fornecidos e os benefícios e valores gerados (DE SOUZA et al., 2018).

Segundo Apitz (2013), todos os estudos práticos de avaliação dos serviços ecossistêmicos seguem esta cascata até certo ponto, mas em muitos casos, os cinco níveis são assumidos e não abordados explicitamente. Por exemplo, Boerema et al. (2017) realizaram uma extensa revisão quantitativa sobre estudos de serviços ecossistêmicos e não encontraram medidas específicas para quantificar o nível de serviços da cascata. Os autores constataram que as medidas estavam mais ligadas à quantificação do funcionamento do ecossistema (lado ecológico da cascata) ou à quantificação dos benefícios (lado socioeconômico).

Quanto a pertinência do modelo, Maes et al. (2012, p.35) são favoráveis à aplicação do modelo de cascata, argumentando que é "um conceito útil para enquadrar avaliações espacialmente explícitas e quantitativas de ecossistemas, SE e benefícios". Da mesma forma, Spangenberg; Von Haaren; Settele (2014), que visava mostrar como o modelo de cascata pode ser usado para estruturar o planejamento público do uso da terra, considera uma estrutura útil para classificar diversas etapas de geração e alocação de SE.

No presente estudo, o modelo de cascata de serviços ecossistêmicos é considerado uma orientação valiosa para o mapeamento de fluxos e valores biofísicos derivados de ecossistemas, o que também é visto em de Souza et al. (2018) por exemplo. Consequentemente, considera-se que o modelo em cascata pode ajudar a reformulação de um quadro para integrar serviços ecossistêmicos e ACV, evitando duplas contagens e distinguindo indicadores.

Para impedir o uso excessivo e a deterioração dos ecossistemas, é crucial compreender e avaliar o impacto das atividades e decisões humanas sobre o funcionamento dos ecossistemas (KREMEN; OSTFELD, 2005; BROUWER et al., 2013). A aplicação de uma avaliação de serviços ecossistêmicos é uma ferramenta que permite integrar os benefícios da natureza nas decisões políticas e comparar as implicações das opções políticas em uma abordagem ampla e integrada (GHALEY et al., 2014, HÄYḦ̈; FRANZESE, 2014). Contudo, para isso é necessário conhecimento ecológico, social e econômico, o que gera ainda muitos desafios. Por exemplo, o conhecimento para quantificar as relações entre a biodiversidade, as funções do ecossistema e a provisão de serviços ecossistêmicos ainda é 
limitado (KREMEN; OSTFELD 2005, DE GROOT et al., 2010, RING et al., 2010). Para ecologistas, um desafio importante é melhorar a compreensão sobre como os ecossistemas funcionam, estimar como as ações humanas afetam a estrutura e o funcionamento do ecossistema e como isso afetará a entrega de serviços ecossistêmicos (DAILY et al., 2000, HAINES-YOUNG; POTSCHIN, 2010).

Já avaliações de impactos do uso da terra sobre serviços ecossistêmicos são feitas para fins diferentes e em várias escalas espaciais: para uma determinada área ou globalmente, para fins de conservação ou econômicos, e para um, vários ou todos estes tipos de serviços ecossistêmicos (KNOESTER, 2015). Para tanto, não apenas um único indicador é necessário, mas um conjunto de indicadores (VAN OUDENHOVEN et al., 2012). Contudo, devido às dificuldades com a classificação dos serviços ecossistêmicos e sua complexa relação com o uso da terra, ainda não há um consenso sobre tais indicadores (DE GROOT et al., 2010). Dentre as publicações que sugerem indicadores de serviços ecossistêmicos podem-se citar os estudos de Maes; Paracchini; Zulian (2011); Van Oudenhoven et al. (2012); De Groot et al. (2010); Kandziora; Burkhard; Müller (2013); e Tsonkova et al. (2014). Estes indicadores são frequentemente classificados como indicadores de capacidade (integridade ou função), os quais representam o potencial de prestação de serviços; ou indicadores de fluxo (processo ou serviço), que representam a prestação efetiva de um serviço trazendo benefícios aos homens (TSONKOVA et al., 2014).

Alguns serviços ecossistêmicos podem ser medidos diretamente, principalmente os serviços de provisão (por exemplo, colheitas, madeira ou fibra, número de animais) (KANDZIORA; BURKHARD; MÜLLER, 2013). Já os serviços culturais dependem de valores humanos e só podem ser estimados indiretamente (por exemplo, número de visitantes, número de espécies ou habitats protegidos) (KANDZIORA; BURKHARD; MÜLLER, 2013; DE GROOT et al., 2010). Segundo Knoester (2015), serviços de regulação e de suporte são mais difíceis de quantificar, pois muitas vezes são resultados de interações complexas de propriedades do ecossistema, ou ocorrem em diferentes escalas espaciais da escala da paisagem observada (por exemplo, regulação do clima). 


\subsection{Serviços Ecossistêmicos na Avaliação do Ciclo de Vida}

A primeira menção explícita sobre a contabilização do consumo de serviços ecossistêmicos na ACV aparece em SINGH; BAKSHI (2009), que descreve brevemente a ferramenta de Eco-LCA (Eco-Based Cycle Assessment), baseada na implementação do modelo Economic Input-Output (EIO). De acordo com os autores, a regulação do clima (sequestro de dióxido de carbono), regulação da qualidade do ar, regulação da erosão e polinização, formação de solo, ciclagem de nutrientes (mineralização de nitrogênio e fósforo), ciclagem de água e produção primária são abordados na metodologia.

Já Zhang; Singh; Bakshi (2010) realizaram uma revisão dos métodos existentes focados em serviços ecossistêmicos e os desafios envolvidos na inclusão na ACV. A análise dos autores enfatiza que os métodos existentes não são capazes de considerar a diversidade total de serviços ecossistêmicos. Além disso, os autores fornecem algumas recomendações para superar tal limitação, por exemplo, usando uma hierarquia de unidades além de desenvolver modelos integrados de sistemas tecnológicos e ecológicos.

O estudo posterior dos autores (ZHANG, BARAL, BAKSHI, 2010) apresenta um passo adiante, para incluir as funções diretas e indiretas dos ecossistemas na ACV. A abordagem descrita por Zhang, Baral, Bakshi (2010) foi usada para desenvolver o modelo Eco-LCA para os EUA em 1997 e um software público. Esta nova abordagem tem vantagens ao considerar diferentes tipos de serviços ecossistêmicos como, por exemplo: serviços de provisão como combustíveis fósseis e minerais, energia renovável, terra e água doce, além de serviços de suporte de formação do solo e fotossíntese. Ademais, combina teorias e dados de muitos métodos existentes como, por exemplo, emergia e exergia. Diferente dos estudos convencionais de ACV, a Eco- $L C A$ foca em insumos da natureza em vez das emissões para a natureza, usando uma estrutura de agregação hierárquica que ajuda a identificar a escassez ou a vulnerabilidade dos recursos. Apesar dos avanços mencionados acima, a escala econômica aplicada pelos autores nem sempre é viável para avaliar os impactos em um nível de produto / processo, como geralmente acontece nos estudos de ACV.

Anos mais tarde, Rugani et al. (2013), reconhecendo que a avaliação de SE na ACV tem sido focada apenas em alguns serviços de provisão ou bens do ecossistema, negligenciando serviços de regulação, suporte e cultura, investigou a possibilidade de utilização da emergia na AICV. Segundo os autores, emergia é capaz de distinguir e comparar o trabalho realizado pelos humanos com o trabalho da natureza, sendo contabilizado em joules de energia solar equivalente (RUGANI et al., 2013 p.254). Além disso, emergia mede a 
quantidade de energia solar incorporada em insumos e serviços pelo trabalho do ecossistema durante suas formações. Alguns anos antes disso, Ometto; Roma; Ortega (2004) concluíram que a emergia é indicada como uma forma de avaliar o consumo de recursos durante todo o ciclo de vida de produtos e serviços. Uma vez que subsidia a avaliação e valoração do recurso na sua cadeia produtiva, sua aplicação para estudos de ACV é compatível (OMETTO, 2005). No entanto, há necessidade de uma investigação mais aprofundada sobre como expressar categorias de regulação e culturais usando o procedimento de cálculo de emergia.

$\mathrm{O}$ estudo de maior visibilidade no campo foi provavelmente o desenvolvido por Koellner et al. (2013). O documento compõe uma edição especial sobre os impactos do uso da terra na biodiversidade e serviços ecossistêmicos na ACV e resume as diretrizes desenvolvidas no âmbito da Iniciativa do Ciclo de Vida criada pela ONU Meio Ambiente e SETAC. Essas diretrizes incluem discussões e recomendações sobre modelagem espacial, coleta de dados de inventário e cálculo de impactos de uso da terra. Koellner et al. (2013) consolidaram as duas principais vias de impacto para os impactos do uso da terra em uma nova cadeia de causa-efeito: potencial de danos à biodiversidade e potencial de danos aos serviços ecossistêmicos (usando a classificação da Avaliação Ecossistêmica do Milênio).

Assim, segundo os autores a avaliação é focada nos seguintes impactos resultantes do uso da terra: i) impacto no potencial do ecossistema em produzir biomassa (Potencial de Produção Biótica), ii) impacto no clima devido ao sequestro de carbono (Potencial de Regulação Climática), iii) impactos na quantidade e qualidade da água (Potencial de Regulação da água doce e Potencial de Purificação da água), iv) impactos na quantidade e qualidade do solo (Potencial de regulação da Erosão) (KOELLNER et al., 2013b).

No entanto, nota-se que alguns serviços ainda não estão contemplados, por exemplo, regulação de doenças, polinização, proteção contra inundações e tempestades, e serviços culturais. Além disso, com o desenvolvimento de fatores de caracterização de cada um dos serviços separadamente, as interdependências são negligenciadas, podendo ocorrer dupla contagem.

Embora a publicação não resolva os problemas envolvidos na avaliação dos impactos em serviços ecossistêmicos, os autores forneceram discussões e recomendações cruciais sobre tipologia de uso e cobertura da terra, diferenciação biogeográfica, situação de referência, tempo de regeneração e alocação de impactos de transformação de terras.

Uma abordagem alternativa para contabilizar danos em serviços ecossistêmicos usando modelagem dinâmica de sistema de terra integrada foi desenvolvida por Arbault et al. (2014). Os autores reconhecem a necessidade de modelos integrados e dinâmicos como 
suporte para modelos de caracterização, demonstrando a viabilidade de usar a perspectiva de modelagem dinâmica de sistemas terrestres para obter fatores de caracterização para cenários específicos e temporalmente dependentes. Para conseguir isso, os autores escolheram o Metamodelo Unificado Global da Biosfera (GUMBO), que simula cadeias de causa-efeito dependentes do contexto entre a esfera natural e a esfera humana. No entanto, observa-se que, apesar da relevância da adoção de uma avaliação dinâmica e integrada, ainda é uma nova abordagem conceitual que não está pronta para implementação na AICV.

Outro estudo, desenvolvido por Cao et al. (2015), deu um passo adiante desenvolvendo uma metodologia para converter indicadores biofísicos de impacto nas funções ecológicas do solo em serviços ecossistêmicos usando avaliação econômica para enquadrar indicadores intermediários (em inglês midpoint) de uso da terra em uma única área de proteção (AoP). Os autores usaram os fatores de caracterização publicados por Koellner et al., 2013 como ponto de partida e o framework proposto considera que o valor econômico representa o custo para a sociedade devido à perda de serviços ecossistêmicos. As vantagens do método desenvolvido por Cao et al. (2015) são a agregação em um único indicador baseado em unidades econômicas, facilitando comparações com estudos de SE, além de auxiliar o processo de tomada de decisão do usuário de ACV. O método também considera as especificidades regionais e expressa o custo social para compensar o uso dos serviços ecossistêmicos. No entanto, ainda é observada a mesma limitação discutida anteriormente que os serviços ecossistêmicos são principalmente relacionados aos impactos do uso da terra.

Bruel et al. (2016) desenvolveram uma nova abordagem para avaliar externalidades ambientais a nível de produto para apoiar a tomada de decisão, fornecendo um indicador monetário de mudanças no fornecimento de SE. Os autores propuseram o uso das saídas do Inventário do Ciclo de Vida (LCI) em modelos bio-econômicos para avaliar mudanças no fornecimento de SE e aplicação de técnicas de monetização para obter os indicadores monetários que expressam a perda de benefícios. Uma vantagem deste método é a hierarquização dos SE, ou seja, a diferenciação entre serviços "intermediários" e "finais". O primeiro corresponde às estruturas e funções dos ecossistemas que produzem o serviço final, que por sua vez são diretamente utilizados ou consumidos pelos beneficiários. Apesar da inovação, o método desenvolvido por Bruel et al. (2016) precisa de mais refinamento para realmente ser implementado em estudos de ACV pois os fatores de caracterização calculados pelos autores são específicos para um único caso e apenas um serviço ecossistêmico é modelado. 
Othoniel et al. (2016) publicaram uma revisão completa do estado da arte da AICV na provisão de SE. Nesta revisão crítica, não só foram identificadas lacunas metodológicas e de conhecimento, mas também os limites das cadeias de causa-efeito adotadas em modelos de caracterização da AICV. Outra contribuição foi a comparação feita entre os tipos de SE modelados na ACV e a classificação dada pelo projeto CICES, destacando a deficiência de métodos para avaliar serviços de regulação e manutenção e culturais. Além das discussões pertinentes, que inclusive alimentaram o desenvolvimento do presente trabalho, Othoniel et al. (2016) concluíram que o uso de modelos integrados dinâmicos multi-escalas são opções promissoras e que podem ser usadas como base para melhoraria dos modelos de caracterização na AICV.

Outra revisão inovadora foi publicada por Crenna et al. (2017) apresentando e discutindo as lacunas conceituais e metodológicas existentes entre AICV e a avaliação da provisão de serviços de polinização. Como esperado, os autores concluíram que o quadro atual da AICV não cobre efetivamente o papel funcional dos polinizadores na prestação de serviços de polinização. Com isso, Crenna et al. (2017) elaboraram recomendações para melhorar os modelos de AICV, através de pesquisas adicionais sobre: perda de habitats relevantes de polinizadores nos atuais modelos de uso da terra, exposição e efeitos dos produtos químicos que afetam os polinizadores em modelos de ecotoxicidade e, finalmente, o desenvolvimento de novas categorias de impacto.

Finalmente, Verones et al. (2017) reconheceram os serviços ecossistêmicos como uma Área de Proteção (AoP) conjuntamente com recursos naturais, relacionado a valores instrumentais (ou seja, valores que têm uma utilidade clara para a humanidade e são definidos a partir de um ponto de vista antropocêntrico). Nas discussões dos autores, é apontado que serviços ecossistêmicos podem ser vistos como parte da categoria de recursos naturais. Essa afirmação deve ser cuidadosamente discutida, uma vez que também incluem valores culturais, abrangendo interações intelectuais, espirituais e simbólicas com os ecossistemas, que não podem ser avaliados como recursos naturais. Esta questão precisa ser abordada em futuras pesquisas, a fim de evitar interpretações equivocadas ou duplas contagem.

Além disso, foi também realizada uma classificação semelhante à de Adhikari; Hartemink (2016) e Boerema (2016) com modelos de caracterização de AICV de acordo com o tipo de medida utilizada e o nível da estrutura em cascata que o modelo engloba (Quadro 8). 
Quadro 6: Classificação de modelos de caracterização disponíveis para AICV, incluindo a medida usada para expressar os serviços ecossistêmicos e a etapa do modelo de cascata que ela representa.

\begin{tabular}{|c|c|c|}
\hline Referência & Medida & Nível da cascata \\
\hline Arbault et al. (2014) & B+M & SE/V \\
\hline Brandão; Milà i Canals (2013) & B & SE \\
\hline Bruel et al. (2016) & M & V \\
\hline Cao et al. (2015) & M & FE \\
\hline Muller-Wenk; Brandão (2010) & B & FE \\
\hline Saad et al. (2013) & B & SE \\
\hline Zhang, Baral, Bakshi (2010) & B & \\
\hline
\end{tabular}

B: Medida biofísica; M: Medida monetária; B+M: Medida biofísica e monetária. PE: Propriedade do ecossistema; FE: Função ecossistêmica; SE: Serviço ecossistêmico; Bn: Benefícios; e V: Valor.

Essa classificação aponta que muitos dos modelos de caracterização se concentram em indicadores biofísicos, o que era esperado, uma vez que este é o foco da ACV ambiental. Também é evidente que os níveis de benefício e valor ainda são a minoria, comprovando a necessidade de maior desenvolvimento na integração total do conceito na AICV. 


\section{SEÇÃO III. MATERIAIS E MÉTODOS}

\section{MATERIAIS E MÉTODOS}

Neste capítulo são apresentados os procedimentos metodológicos utilizados e as etapas necessárias ao desenvolvimento do projeto. A estrutura proposta de pesquisa é composta de três etapas de acordo com os objetivos específicos, sendo ilustrada na Figura 9, juntamente com as atividades que as compõem, as relações entre as atividades e os resultados esperados.

Ressalta-se que o estudo seguiu as diretrizes estabelecidas em publicações internacionais, guias e documentos normativos; especificamente as publicações do Sistema Internacional de Referência para Dados de Ciclo de Vida (International Reference Life Cycle Data System - ILCD) (EC-JRC, 2010a,b) e da Iniciativa do Ciclo de Vida (KOELLNER et al., 2013a, 2013b). 
Figura 9: Objetivos, etapas do trabalho e resultados esperados

Objetivos 1 a 3: Analisar o mecanismo ambiental de impactos do uso da terra $\mathrm{e}$ as principais categorias de impacto relacionados aos serviços ecossistềmicos compara-los ao modelo de cascata de provisão de serviços cossistêmicos.

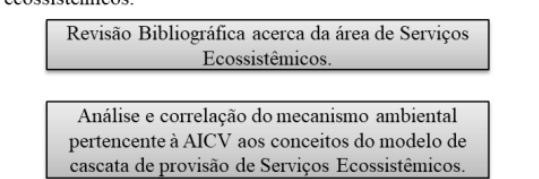

Te provisão de Serviços Ecossistemicos.

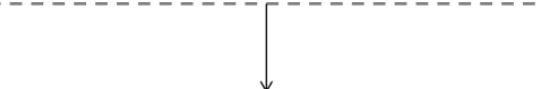

Novo modelo conceitual para impactos em Serviços Ecossistêmicos em ACV.

Objetivo 4: Avaliar os métodos com melhor potencial de Brasil pela robustez cientifica ou disponibilidade de dados.

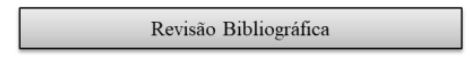

Análise dos modelos de caracterização frente a

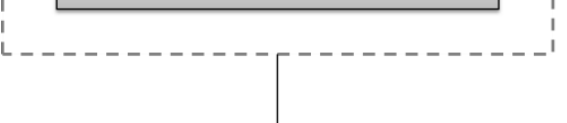

Modelo de caracterização selecionado

Fonte: elaboração própria.

Objetivo 5: Calcular fatores de caracterização de impactos nos serviços ecossistêmicos devido ao uso da ação de AICV espacialmente diferenciado para serviços ecossistêmicos relacionados à fertilidade do solo.

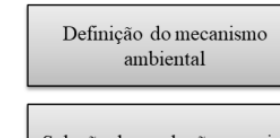

Seleção da resolução espacial

Seleção da situação de referência Classificação dos tipos de uso
da terra 


\subsection{Análise e correlação do mecanismo ambiental e o modelo de cascata de Serviços Ecossistêmicos}

A primeira etapa deste estudo teve como objetivo realizar uma revisão crítica sobre as principais proposições teóricas sobre serviços ecossistêmicos existentes na literatura e os métodos atuais utilizados para estudar seus aspectos biofísicos, especificamente aqueles relacionados ao solo (Figura 10).

Figura 10: Detalhamento da primeira etapa do estudo de revisão bibliográfica exploratória.

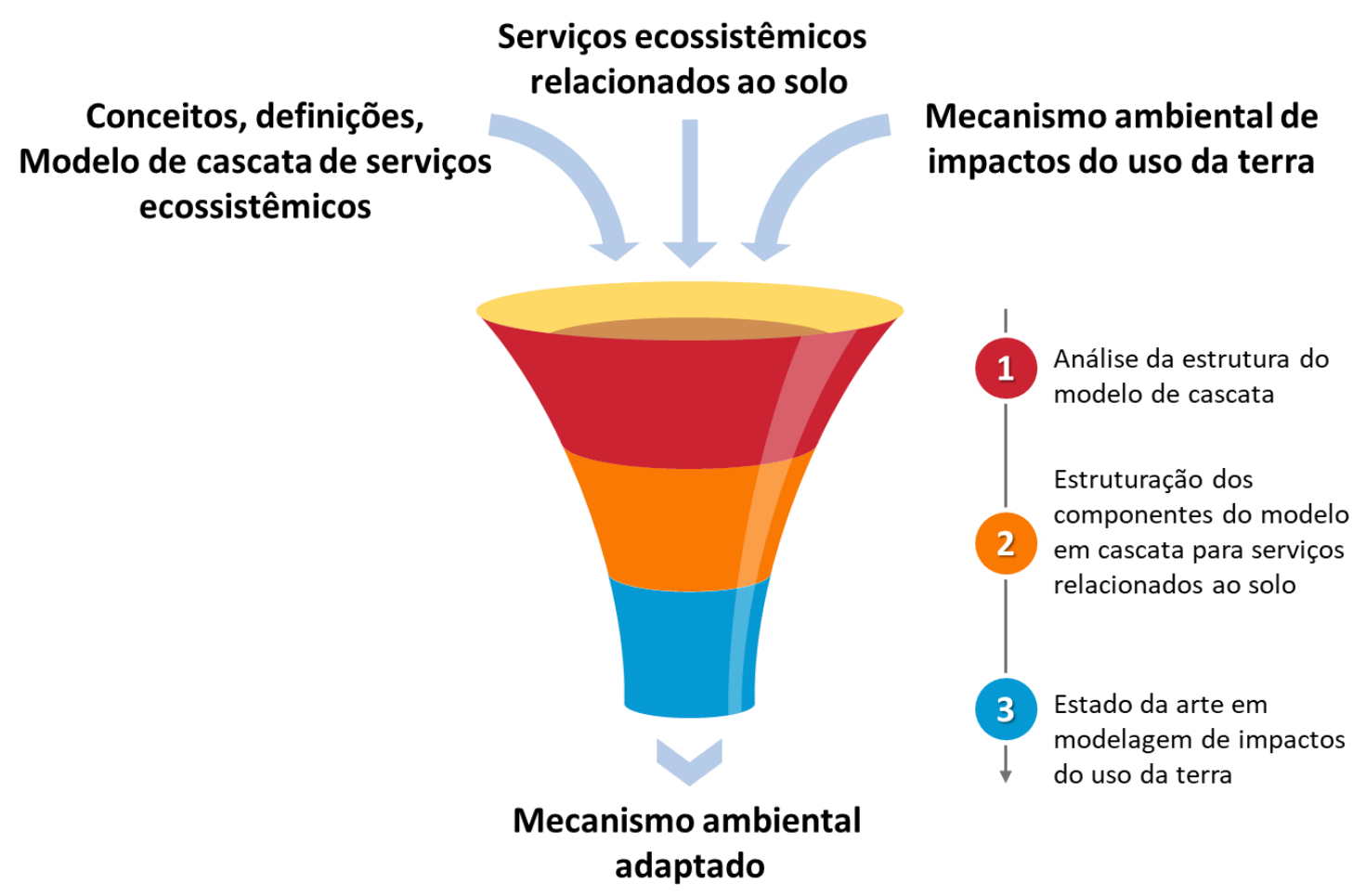

Fonte: elaboração própria.

Na primeira atividade, a abordagem adotada para consultar a literatura consistiu em uma busca por termos e palavras-chave como "Ecosystem Services", "Ecological Services" e "Environmental Service” na base de dados Web of Knowledge. A pesquisa incluiu resultados até o ano de 2017 e seguiu o seguinte conjunto de critérios de inclusão:

- A literatura deve abordar os serviços ecossistêmicos como assunto principal.

- As palavras-chave predefinidas devem aparecer completas em pelo menos um dos campos: título, palavras-chave ou resumo.

- $\quad$ artigo deve ser publicado em um periódico científico revisado por pares.

- $\quad \mathrm{O}$ artigo deve ser escrito em língua inglesa. 
Contudo, como essa etapa visou compilar as princiais definições de conceitos, classes e frameworks de avaliação de serviços ecossistêmicos foram também consultados livros, teses e dissertações, relatórios e websites. Esta revisão inicial permitiu a construção de uma contextualização para o problema e subsidiou a compreensão das diferentes tipologias de serviços ecossistêmicos, adoção de um sistema para utilização bem como a análise do modelo de cascata de provisão dos serviços ecossistêmicos.

Feito isso, a segunda atividade consistiu em um refinamento específico acerca dos serviços ecossistêmicos providos pelo solo a fim de fomentar a estruturação dos componentes do modelo de cascata para esta categoria. Para tanto, novas buscas foram realizadas utilizando os seguintes termos: ("ecosystem service*" OR "ecossystem good*" OR "ecossystem benefit" OR "environmental service*" OR "ecological service*") AND ("soil processes*" OR "soil function*" OR "soil service" OR "soil value").

Vale ressaltar que a temática dos serviços ecossistêmicos é ampla e está atrelado a diversas atividades humanas. No entanto, na ACV esta categoria de impacto está, até então, ligada às intervenções de uso e ocupação da terra. Sendo estas o objeto de pesquisa do presente trabalho, o foco da comparação do modelo de cascata se deu nestas intervenções, especificamente no que tange aos serviços ecossistêmicos providos pelo solo.

A terceira atividade inclui o estado da arte em modelagem de impactos do uso da terra, sendo realizada a análise e correlação dos conceitos e estrutura do modelo de cascata de provisão de serviços ecossistêmicos ao mecanismo ambiental (cadeia de causa-e-efeito), elemento que integra a AICV. Assim, as informações acerca dos elementos componentes do modelo de cascata relacionados ao solo foram comparadas à estudos concentrados na modelagem dos impactos na qualidade do solo derivados do uso da terra na ACV.

Ao fim da análise comparativa elaborou-se um mecanismo ambiental adaptado com base nos componentes do modelo de cascata, ilustrando um novo framework conceitual para estudos de ACV com intuito de viabilizar uma integração dos assuntos de maneira mais fiel e estruturada. 


\subsection{Análise dos modelos de caracterização}

Esta etapa tem como objetivo analisar as principais categorias de impacto do uso da terra sobre serviços ecossistêmicos e selecionar um modelo de caracterização a ser regionalizado para o Brasil. Para tanto foi realizada a coleta e o levantamento de estudos existentes e previamente desenvolvidos para a área de interesse através de uma revisão bibliográfica exploratória.

Para a organização das informações contidas nas publicações encontradas foi feita uma leitura prévia dos títulos e resumos dos trabalhos, identificando-se os objetivos do estudo e seus resultados. Em seguida, os estudos que se enquadraram ao escopo dessa pesquisa foram lidos na íntegra, possibilitando a identificação de orientações para a avaliação dos impactos sobre serviços ecossistêmicos na ACV.

Em seguida, a fim de selecionar um modelo de caracterização para a adaptação à realidade brasileira, as metodologias disponíveis na literatura foram analisadas quanto à viabilidade de regionalização. Inicialmente foi feita uma análise da relevância científica dos modelos, de forma a complementar o estudo já realizado em Pavan; Ometto (2016), abordando critérios relacionados à "Documentação e Transparência" e "Disponibilidade de dados e Reprodutibilidade" (Quadro 5).

Por fim, o modelo que apresentou a maior pontuação nas análises foi considerado como base para o desenvolvimento das próximas etapas do projeto. 
Quadro 7: Critérios para análise da viabilidade de regionalização dos modelos de caracterização.

\begin{tabular}{|c|c|c|c|c|}
\hline TEMA & SUBCATEGORIA & $\begin{array}{l}\text { CRITÉRIO DE } \\
\text { AVALIAÇÃO }\end{array}$ & DESCRIÇÃO & PONTUAÇÃO \\
\hline \multirow{2}{*}{ 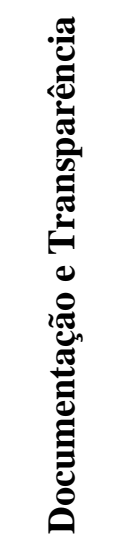 } & \multirow[b]{2}{*}{$\begin{array}{c}\text { Transparência do } \\
\text { modelo }\end{array}$} & $\begin{array}{l}\text { Acessibilidade do } \\
\text { modelo e fatores de } \\
\text { caracterização }\end{array}$ & $\begin{array}{l}\text { O modelo e os produtos (fatores de caracterização) } \\
\text { são acessíveis? A documentação (incluindo a } \\
\text { descrição do mecanismo, o modelo, a escala } \\
\text { temporal e espacial e fatores de caracterização) são } \\
\text { facilmente acessíveis? }\end{array}$ & $\begin{array}{l}1 \text { = não, dados não disponíveis } \\
3 \text { = parcialmente, informação resumida está disponível, mas } \\
\text { sem detalhamento } \\
5=\text { sim, todas as informações estão disponíveis incluindo } \\
\text { fatores de caracterização }\end{array}$ \\
\hline & & $\begin{array}{l}\text { Possibilidade de } \\
\text { desenvolvimento por } \\
\text { terceiros }\end{array}$ & $\begin{array}{l}\text { É possível aprimorar o modelo e gerar fatores } \\
\text { adicionais (por exemplo, incorporando mais } \\
\text { unidades geográficas ou classes de uso da terra)? }\end{array}$ & $\begin{array}{l}1 \text { = não, dados essenciais brasileiros não estão descritos / } \\
\text { publicados } \\
3=\text { parcialmente, o método é claro e os dados são } \\
\text { apresentados, porém não totalmente disponível para replicação } \\
5=\text { sim, os dados estão disponíveis e o método pode ser } \\
\text { replicado }\end{array}$ \\
\hline \multirow{2}{*}{ 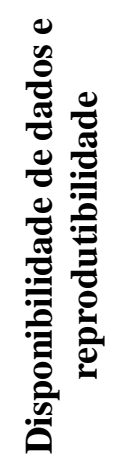 } & $\begin{array}{l}\text { Existência de } \\
\text { dados }\end{array}$ & $\begin{array}{l}\text { Disponibilidade de } \\
\text { dados }\end{array}$ & $\begin{array}{l}\text { Os dados brasileiros necessários para regionalização } \\
\text { estão disponíveis em bases de dados ou na } \\
\text { literatura? }\end{array}$ & $\begin{array}{l}1=\text { não } \\
3=\text { parcialmente } \\
5=\text { sim }\end{array}$ \\
\hline & $\begin{array}{l}\text { Existência de } \\
\text { aplicações } \\
\text { anteriores }\end{array}$ & Aplicações anteriores & $\begin{array}{l}\text { Existem publicações de estudos de caso utilizando o } \\
\text { modelo de caracterização em sua metodologia? } \\
\text { Existem aplicações bem-sucedidas do modelo de } \\
\text { caracterização? }\end{array}$ & $\begin{array}{l}\text { 1= não } \\
3=\text { não existem aplicações, porém existe estudo de adaptação } \\
\text { da metodologia } \\
5=\operatorname{sim}\end{array}$ \\
\hline
\end{tabular}

Fonte: elaboração própria. 


\subsection{Aplicação do modelo de caracterização espacialmente diferenciado}

A fase de adaptação do modelo de caracterização para o Brasil envolve quatro atividades, descritas a seguir.

\subsubsection{Definição do mecanismo ambiental}

Esta atividade está intimamente relacionada à etapa descrita anteriormente no item 5.2 uma vez que a definição da estrutura fundamental do modelo, as premissas e definição do mecanismo ambiental (incluindo o indicador empregado) dependem do estudo selecionado para a adaptação. Além desses itens, neste tópico se definem as intervenções avaliadas: ocupação da terra (utilização de uma área, por uma atividade, em um determinado tempo) e/ou transformação da terra (mudanças na qualidade da terra, decorrentes da alteração do tipo de ocupação). Ressalta-se que a definição do mecanismo ambiental seguiu as diretrizes publicadas pela Iniciativa do Ciclo de Vida (KOELLNER et al., 2013b).

\subsubsection{Seleção da situação de referência}

Como visto, os impactos do uso da terra são avaliados proporcionalmente à diferença de qualidade entre o sistema estudado e uma situação de referência. O estado de referência da qualidade da terra é alvo de inúmeras discussões e de acordo com Koellner; Geyer (2013) é uma das questões mais relevantes para pesquisas futuras no campo do desenvolvimento de metodologias de avaliação de impactos do uso da terra na ACV.

As mais recentes publicações acerca da avaliação do uso da terra na AICV apontam três opções principais para descrever a situação de referência na ACV:

1. Adotar o conceito de Vegetação Natural Potencial (VNP), o qual descreve a vegetação que se desenvolveria se acabasse toda a influência humana no local e em seu entorno (CHIARUCCI et al., 2010; SAAD et al., 2011).

2. Tomar como referência o estado (quase) natural da terra em cada bioma/ região, como por exemplo, um mosaico de florestas, zonas húmidas, lagos e rios. Este termo é utilizado porque esta situação não representa, necessariamente, habitats naturais e isentas de intervenções humanas, mas sim habitats em estágio de fim de sucessão (de BAAN; ALKEMADE; KOELLNER; 2013). 
3. Adotar o uso atual do solo como referência, ou seja, o uso anterior à modificação, utilizando um mosaico de tipos de uso da terra, como já proposto para a Europa (KOELLNER; SCHOLZ, 2008).

A escolha entre uma dessas três se deu a partir de uma revisão dos conceitos e sobretudo, a verificação da disponibilidade dos dados.

\subsubsection{Classificação dos tipos de uso da terra no Brasil}

A classificação das atividades antrópicas que ocupam uma determinada superfície da terra define os diferentes tipos ou classes de uso da terra (SOUZA, 2010). Ademais, estas tipologias de uso da terra desempenham importante papel nas características e no funcionamento dos ambientes (IBAMA, 2013).

De acordo com Koellner et al. (2013a), a classificação de uso da terra na ACV deve preferencialmente (i) ser derivada de um sistema de classificação da cobertura terrestre amplamente aceito, (ii) distinguir os tipos da cobertura da terra em classes ambientalmente relevantes (indicando também informações sobre a intensidade do uso da terra), e (iii) classificar casos individuais de uso da terra de tal forma que os impactos ambientais causados sejam semelhantes sob determinadas condições biogeográficas.

Além dos critérios acima citados, esta etapa do trabalho levou em consideração a dinâmica espacial recente no uso e ocupação das terras brasileiras através do Mapa da Cobertura e Uso da Terra no Brasil (IBGE, 2010) em escala de 1:5.000.000, o qual apresenta um retrato simplificado dos arranjos espaciais e permite destacar padrões de utilização associados em razão da escala original (IBAMA, 2013).

\subsubsection{Definição da resolução espacial (diferenciação biogeográfica)}

O desenvolvimento de modelos de caracterização regionalizados requer a definição dos limites de avaliação e divisão da região determinada e, segundo Mutel et al. (2018), convém que sejam explicitamente definidos quais os parâmetros regionalizados e em qual resolução espacial. Unidades biogeográficas são consideradas apropriadas, pois fornecem informações importantes sobre a integridade dos recursos naturais, sua gestão e análise ambiental (SAAD et al., 2011). De acordo com Koellner et al. (2013a), existem quatro níveis de detalhamento das áreas consideradas para o cálculo dos fatores de caracterização: 
- Nível 1: divisão em biomas terrestres, biomas de água doce, águas costeiras e oceanos.

- Nível 2: refinamento das categorias do nível 1, em regiões climáticas: tropical / subtropical, Temperado, boreal e polar.

- Nível 3: classificação em dezesseis biomas terrestres e de água doce por Olson et al. (2001) e três biomas marinhos com base em Spalding et al. (2007).

- Nível 4: classificação em 867 ecorregiões terrestres e de água doce por Olson et al. (2001) e 232 ecorregiões costeiras de Spalding et al. (2007).

Neste estudo a diferenciação espacial priorizou os seguintes direcionamentos:

- Relevância científica e representatividade: ser baseada em padrões ambientais similares relevantes para estudo da qualidade do solo; e considerar as repetições de padrões bióticos e abióticos dos ecossistemas.

- Disponibilidade de dados: a resolução espacial deverá preferencialmente já ser utilizada em estudo prévios; os dados das unidades geográficas brasileiras deverão estar disponíveis em bases de dados geográficos; e os dados deverão ser compatíveis ao uso em Sistemas de Informação Geográfica (SIG).

Observa-se que em estudos relacionados à qualidade do solo, fatores como clima, vegetação e tipo de solo são fundamentais nas observações de padrões. Assim, outras possibilidades de unidade espacial, não listadas em Koellner et al. (2013a) não serão descartadas.

Ressalta-se também que em estudos de ACV os fatores de caracterização são aplicados aos dados de inventário usualmente pertencentes à banco de dados e tais fluxos elementares são registrados por divisões políticas e não em regiões biogeográficas. Desta forma, considerou-se que a adaptação do modelo deve ser espacialmente regionalizada, mas convém que os dados sejam agregados de forma a facilitar a aplicação na ACV. Portanto, baseando-se em Bernoux et al. (2001), os resultados também foram apresentados por estados brasileiros. 


\subsection{Cálculo e obtenção dos fatores de caracterização}

Nesta etapa se deu a compilação e a associação de dados espaciais aos dados de usos da terra para cada unidade de escala espacial. Para tanto, são utilizados exclusivamente dados secundários, obtidos de base de dados como ISRIC - World Soil Information, Instituto Brasileiro de Geografia e Estatística (IBGE) e Painel Intergovernamental sobre Mudanças Climática (IPCC).

O gerenciamento e processamento dos dados espacialmente diferenciados se deu com auxílio de um Sistema de Informação Geográfica (SIG), subsidiando a sobreposição dos parâmetros ambientais. Sabe-se que o SIG pode ser uma ferramenta bastante útil para a ACV, principalmente quando se trata de intervenções como uso da terra, que são inerentemente espaciais, e seus impactos não dependem somente do tipo de atividade desenvolvida na ocupação ou após a transformação, mas também das características da área (LANGE, 2012).

Para esta etapa do trabalho foram utilizados o software ArcGIS 10 que é amplamente utilizado na adquisição, armazenamento, recuperação e manipulação de informações digitais, georreferenciadas, proveniente de imagens e mapas, gerando dados na forma de mapas, tabelas, gráficos. O uso do SIG se fez necessário para cruzar as variáveis e dados geográficos, como por exemplo: mapa político do Brasil, mapa do território brasilieiro dividido nas unidades biogeográficas previamente definidas e mapas dos atributos utilizados como indicador da categoria de impacto.

Assim, a projeção de trabalho adotada foi GCS WGS 1984, Datum WGS 1984 e os mapas administrativos do território brasileiro foram obtidos da GADM database, enquanto os mapas de tipos de solo e zonas climáticas foram obtidos nos dados do IPCC.

Segundo Koellner et al. (2013b), o impacto da transformação da terra (IT) é calculado com base na diferença de qualidade do ecossistema $(\Delta Q)$ entre uma situação de uso da terra e uma situação de referência apropriada ao longo do tempo, multiplicada pela área $(A)$ transformada. Como a dinâmica temporal da qualidade do ecossistema é na sua maioria desconhecidas, uma trajetória linear de recuperação do ecossistema é assumida (Figura 11). Assim, os impactos da transformação são calculados segundo Koellner et al. (2013b) usando a Equação 1, sendo $t_{\text {reg }} \mathrm{o}$ tempo necessário para a recuperação total da qualidade do ecossistema. 
Figura 11: Representação dos impactos decorrentes da ocupação e transformação da terra.

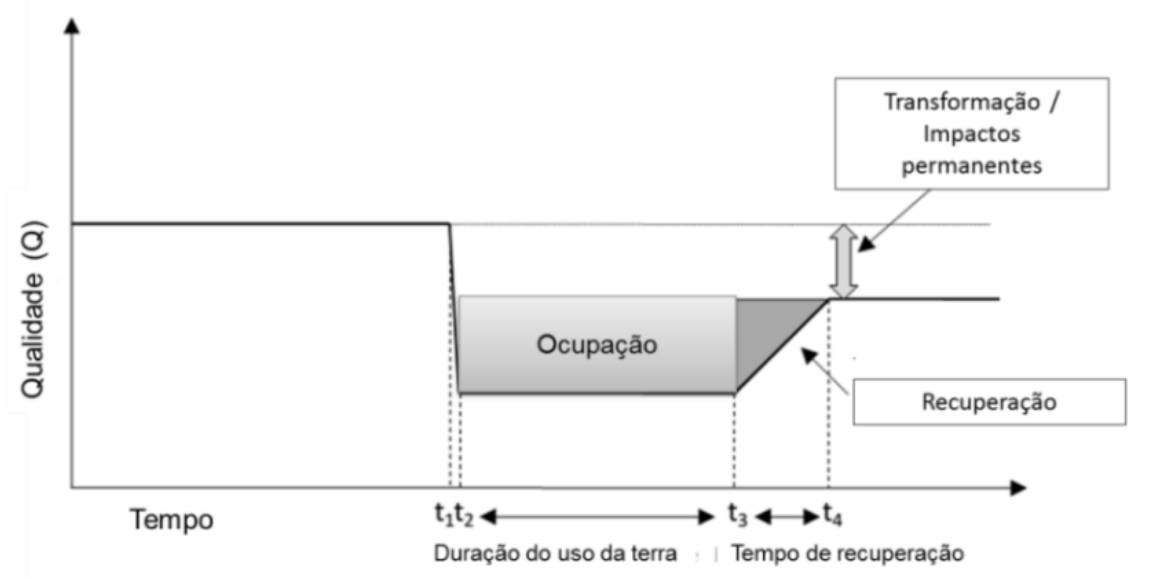

Fonte: Adaptado de Beck et al. (2010)

$$
I T=0.5 \times \Delta Q \times t_{\text {reg }} \times A
$$

Para o cálculo final do impacto, os dados da área transformada são registrados na etapa de inventário, enquanto que o fator de caracterização da transformação ( $\left.\mathrm{FC}_{\text {trans }}\right)$ é dado pela Equação 2 a seguir.

$$
F C_{\text {trans }}=0.5 \times \Delta Q \times t_{\text {reg }}
$$

Já o impacto da ocupação da terra (IO), é calculado com base na diferença de qualidade $(\Delta Q)$ em um período de tempo $(\mathrm{T})$, multiplicada pela área $(A)$ ocupada (Eq. 3). Assume-se que $\Delta \mathrm{Q}$ é constante durante a fase de ocupação. Além disso, no caso da ocupação da terra, o fator de caracterização ( $\mathrm{FC}_{\mathrm{oc}}$ ) será igual ao valor de $\Delta \mathrm{Q}$.

$$
I O=\Delta Q \times T \times A
$$

A definição e cálculo de Q se dará de acordo com o modelo de caracterização adotado como base na atividade de definição do mecanismo ambiental (item 5.3.1). Os resultados dos cálculos dos fatores de caracterização serão listados em tabelas de acordo com o tipo de uso da terra e a diferenciação biogeográfica adotada. 


\section{SEÇÃO IV. RESULTADOS E DISCUSSÕES}

\section{MODELO CONCEITUAL DE SERVIÇOS ECOSSISTÊMICOS NA ACV}

A revisão bibliográfica exploratória permitiu identificar os principais conceitos envolvidos na avaliação de serviços ecossistêmicos bem como as discussões que permeiam este campo de pesquisa. Além da sistematização já apresentada na Seção II, item 4, aqui são apresentadas outras discussões acerca do modelo de cascata bem como a estruturação de um diagrama que represente a provisão dos serviços ecossistêmicos relacionados ao solo sob a ótica desse modelo. O resultado apresentado neste capítulo encontra-se publicado em Pavan; Ometto (2018).

É importante destacar que após a revisão das diferentes tipologias dos serviços ecossistêmicos, adotou-se neste estudo o sistema de classificação publicado por CICES ${ }^{9}$ (HAINES-YOUNG; POTSCHIN, 2013) já descrito no Capítulo 4. Tal framework vem sendo utilizado em estudos atuais e importantes na área como, por exemplo: Maes et al. (2016), Sousa et al. (2016) e Cook; Davíðsdóttir; Kristófersson (2017). No presente estudo foi adotado a classificação de CICES, pois considerou-se um sistema robusto e de fácil compreensão, de maior abrangência se comparado com sistemas anteriores e que diferencia serviços ecossistêmicos intermediários e finais, resultando em um sistema de classificação mais sistemático e hierarquizado.

Pode-se encontrar na literatura que os serviços ecossistêmicos intermediários são considerados sinônimos de serviços de suporte (de acordo com a tipologia MEA) ou definidos como estruturas e processos ecossistêmicos que não são produtos finais (BOYD; BANZHAF, 2007). Os serviços ecossistêmicos finais, por sua vez, constituem contribuições diretas ao bem-estar humano (diretamente utilizados ou consumidos pelos beneficiários) e são o foco do sistema de classificação CICES (HAINES-YOUNG; POTSCHIN, 2018).

Além disso, esta classificação é pautada no modelo de cascata, desenvolvido por Haines-Young; Potschin (2010) com o objetivo de ilustrar o caminho dos serviços ecossistêmicos, desde estruturas e processos ecológicos até o bem-estar humano. Este modelo retrata os serviços ecossistêmicos na interface entre o sistema biofísico e social, mostrando que vários aspectos podem ser examinados e utilizados como indicadores. Trata-se, portanto, de uma estrutura que representa a lógica subjacente ao paradigma dos serviços ecossistêmicos

\footnotetext{
${ }^{9}$ http://cices.eu
} 
e ajuda a operacionalizar as ligações entre propriedades do ecossistema (estrutura ou processo biofísico), funções do ecossistema, serviços e finalmente um valor (HAINES-YOUNG; POTSCHIN, 2010). É fundamental ressaltar que as conexões entre o ecossistema, processos, funções e benefícios para os seres humanos são complexos, não-lineares e dinâmicos (COSTANZA et al., 2017), mas esse quadro é útil para saber quais relações são produzidas e, consequentemente, planejar melhor as atividades humanas.

Conforme mencionado anteriormente, quando se trata de AICV, a avaliação dos serviços ecossistêmicos é relacionada principalmente às intervenções de uso da terra (ver item 4.2). Van Oudenhoven et al. (2012) definem o manejo da terra como as atividades humanas que podem afetar as propriedades e a função do ecossistema, bem como os serviços ecossistêmicos que podem ser fornecidos. O uso da terra pode, portanto, influenciar diferentes níveis da cascata: alterando as propriedades do ecossistema, influenciando o funcionamento do ecossistema e determinando a finalidade da terra.

Assim, os impactos sobre o uso da terra já estão sob o desenvolvimento teórico de integração do conceito serviços ecossistêmicos na ACV, geralmente através do uso de indicadores de qualidade do solo para alcançar este objetivo. Tomando esta categoria de impacto e o progresso metodológico nessa área como ponto de partida, foi feita uma revisão da cadeia de causa e efeito para superar algumas limitações existentes. Além disso, como o solo é um sistema complexo, exigindo uma abordagem holística para entender o processo do ecossistema e os serviços que oferece à sociedade (ADHIKARI; HARTEMINK, 2016), optou-se por concentrar os esforços na melhoria desse mecanismo de impacto. 


\subsection{Serviços ecossistêmicos do solo}

Nesta seção, exemplifica-se a aplicação da estrutura em cascata dos serviços ecossistêmicos relacionada ao solo. O solo pode ser basicamente definido como o meio natural para o crescimento das plantas (SOIL SURVEY STAFF, 1999), ou, mais especificamente, como um corpo natural contínuo formado por constituintes minerais e orgânicos, organizados em estruturas e em constante evolução (FAO, 1998).

Antes do século XX, o solo era estudado quase exclusivamente no contexto da agricultura e da produção de alimentos. À medida que o impacto global da humanidade sobre os recursos naturais aumentou nos últimos 150 anos, as conexões entre o solo e os problemas ambientais mais amplos começaram a ser analisadas. Desta forma, o conceito de degradação do solo e sua avaliação foram desenvolvidos como parte de avaliações mais holísticas da degradação induzida pelo homem de agências internacionais como FAO e ONU Meio Ambiente.

Todos os solos (seja ativamente manejado ou não) fornecem serviços ecossistêmicos relevantes em várias escalas, incluindo a produção de alimentos, a regulação da água e do clima, a provisão de energia e a biodiversidade. Diversas publicações enfatizam que o bemestar humano também depende dos recursos do solo (DOMINATI et al., 2014; AMUNDSON et al., 2015; BANWART, 2011). Assim, diversos autores demonstraram a importância do solo e ressaltaram a necessidade de sua integração nas avaliações de serviços ecossistêmicos (DOMINATI et al., 2010; ADHIKARI; HARTEMINK, 2016; BOUMA, 2014; BOUMA et al., 2012; HAYGARTH; RITZ, 2009; HEWITT et al., 2015; ROBINSON et al., 2013).

A conversão do uso da terra, por sua vez, pode reduzir esses serviços oferecidos pelos solos. A degradação do solo reduz ou elimina inerentemente as funções do solo e sua capacidade de prover os serviços ecossistêmicos essenciais para o bem-estar humano. Minimizar ou eliminar a degradação significativa do solo é essencial para manter os serviços oferecidos além de representar maior custo-efetivo do que reabilitar os solos após a degradação ter ocorrido (GOMIERO, 2016).

Barrios (2007), com o objetivo de explorar e discutir os impactos diretos e indiretos da biota do solo em serviços ecossistêmicos e na produtividade da terra em paisagens agrícolas concluiu que os organismos do solo são parte integrante do mesmo e influenciam os processos ecossistêmicos que contribuem para a oferta de uma ampla gama de serviços ecossistêmicos essenciais. Na revisão conduzida pelo autor, alguns serviços são destacados e discutidos sob o contexto de paisagens agrícolas, como por exemplo, o serviço de ciclagem de nutrientes, 
envolvendo o papel de organismos de fixação de nitrogênio, decompositores e transformadores. Além disso, Barrios (2007) discute sobre serviços de regulação, que envolve a modificação da estrutura do solo além de serviços de controle de pestes e doenças. Nesse estudo ficou evidente que o conhecimento da biodiversidade do solo e sua contribuição específica para a função do ecossistema e a provisão de serviços ecossistêmicos são ainda limitados.

Já o estudo de Velasquez, Lavelle, Andrade (2007) fornece subindicadores que refletem a provisão de serviços ecossistêmicos do solo e consideram as seguintes propriedades do solo como indicadores: propriedades que determinam a infiltração e armazenamento de água; fertilidade química; matéria orgânica; sequestro de carbono avaliado pela morfologia do solo; e biodiversidade do solo expressa pela estrutura e abundância de comunidades de macroinvertebrados.

Partindo da premissa de que a estrutura e funcionalidade dos solos na paisagem facilitam os processos necessários para o bem-estar da humanidade e do sistema terrestre, Robinson, Lebron, Vereecken (2009, p.1910) tiveram como objeto de estudo a necessidade de uma definição apropriada de capital natural do solo, delimitando para isso o foco em massa; energia e entropia, chegando à síntese: "estoque de massa biótica e abiótica que contém energia e organização”. Além disso, os autores listam de maneira geral os seguintes serviços ecossistêmicos do solo: (i) suporte: estabilidade física e suporte para plantas, renovação, retenção e entrega de nutrientes para plantas, habitat; (ii) regulação: regulação dos principais ciclos, tampão, filtragem e moderação do ciclo hidrológico, eliminação de resíduos e matéria orgânica morta; (iii) provisão de materiais; (iv) cultural: patrimônio, preservação arqueológica de artefatos, valor espiritual e locais religiosos.

O estudo de Dominati, Patterson, Mackay (2010) representa um dos estudos mais relevantes obtidos na revisão bibliográfica sobre os serviços ecossistêmicos relacionados ao solo, pois o framework desenvolvido além de introduzir o solo como capital natural, ilustra sua formação, a manutenção e a degradação como também as intervenções que afetam esses processos. Para tanto os autores realizaram uma ampla revisão e, ao comparar os diferentes modelos e frameworks de serviços ecossistêmicos do solo na literatura, sintetizaram as seguintes funções dos solos: 
- Fertilidade: os ciclos de nutrientes do solo asseguram a fertilidade e a entrega de nutrientes para as plantas, contribuindo assim para seu crescimento;

- Filtragem e reservatório: os solos corrigem e armazenam solutos e, portanto, purificam a água. Eles também armazenam água para plantas usarem e participam de mitigação de enchentes;

- Estrutural: os solos fornecem apoio físico às plantas, animais e infraestruturas humanas;

- Regulação do clima: os solos participam da regulação do clima através do sequestro de carbono e regulação das emissões de gases de efeito estufa $\left(\mathrm{N}_{2} \mathrm{O}\right.$ e $\left.\mathrm{CH}_{4}\right)$;

- Conservação da biodiversidade: os solos são um reservatório de biodiversidade, fornecendo habitat para milhares de espécies que regulam, por exemplo, o controle de pragas ou a disposição de resíduos;

- Recursos: os solos podem ser uma fonte de materiais como a argila por exemplo.

Conforme apresentado anteriormente, o modelo em cascata desenvolvido por Potschin e Haines-Young (2010) é um framework comumente aplicado, útil para atribuir valores não monetários e monetários a serviços ecossistêmicos (SPANGENBERG; VON HAAREN; SETTELE, 2014). Para entender a cascata de provisão dos serviços ecossistêmicos fornecidos pelos solos, é importante compreender que as propriedades do solo podem se referir a qualquer componente do solo que possa ser medido e usado para avaliá-los (DOMINATI et al., 2010). Segundo Dominati et al. (2010), as propriedades do solo influenciam a intensidade com que os processos ocorrem e são ao mesmo tempo os produtos desses processos. Esses autores fizeram observações interessantes sobre a existência de duas classes: propriedades do solo inerentes e manejáveis. O primeiro está relacionado a estoques que podem mudar lentamente através de processos pedológicos e inclui profundidade, textura e mineralogia do solo, enquanto propriedades manejáveis do solo incluem conteúdo de nutrientes, matéria orgânica, macroporosidade e umidade do solo, todas podendo ser alteradas pelo manejo e influenciadas por uso da terra. Por sua vez, os processos do solo são uma série de ações no solo que trazem um resultado, podendo ser biológicos, geoquímicos e físicos (VEREECKEN et al. 2016) (Quadro 7). 
Quadro 8: Processos, funções, serviços, benefícios e valor relacionados ao solo identificados na revisão de literatura.

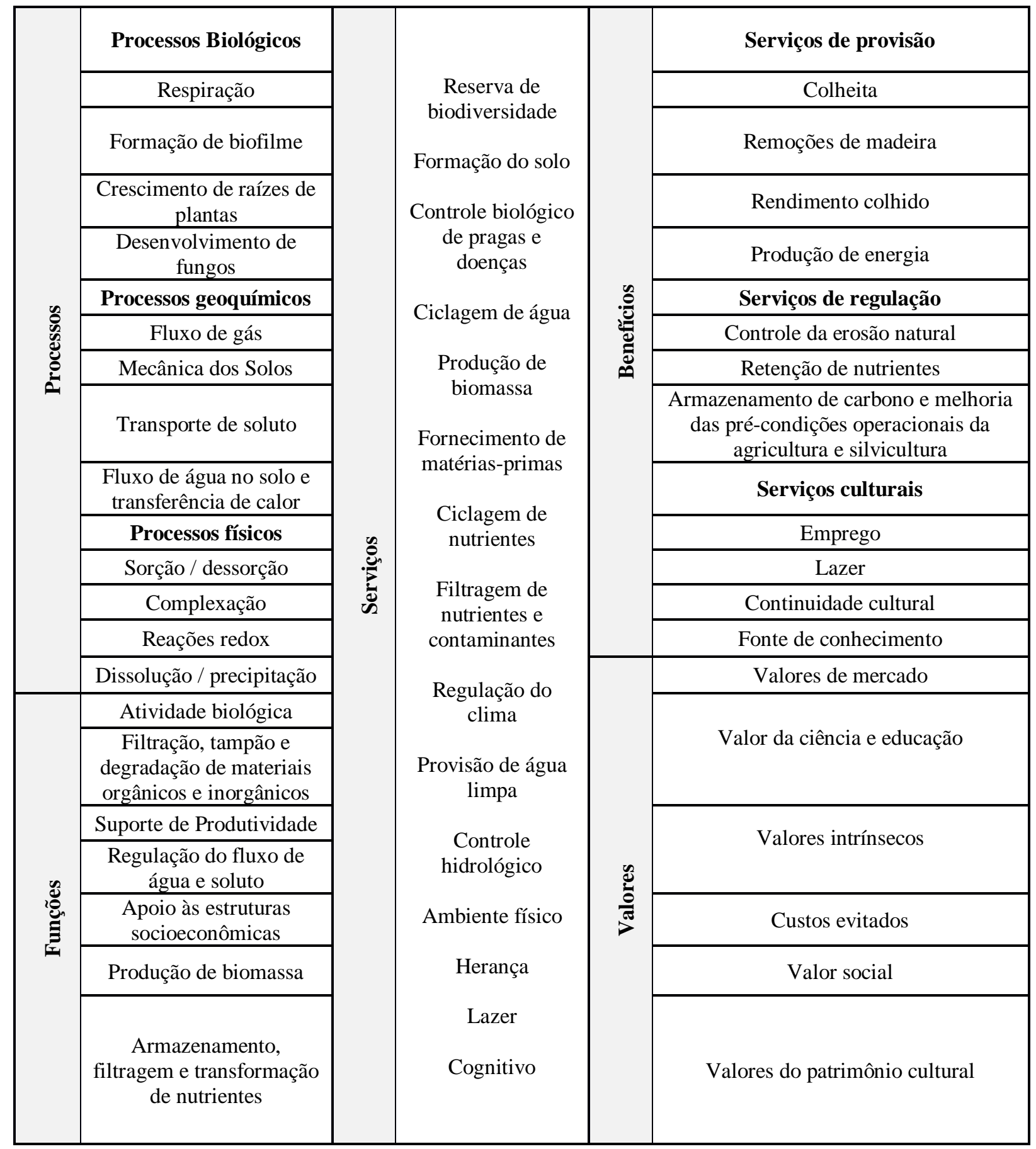

Fonte: elaboração própria. 
Seguindo os passos da cascata, o Quadro 7 também apresenta as principais funções do solo de acordo com Calzolari et al. (2016) e Seybold et al. (1997). Para a terceira esfera da cascata (serviços ecossistêmicos), consideramos o solo como capital natural que gera fluxos de benefícios que satisfazem as necessidades humanas, direta ou indiretamente, através de suas funções (COSTANZA et al., 1997; DOMINATI et al., 2010).

MILNE et al. (2015 p.35) resume os seguintes tipos de serviços fornecidos pelo solo:

- Serviços de suporte: ciclagem de nutrientes, retenção e liberação de água, formação de solo, fornecimento de habitat para biodiversidade, troca de gases com a atmosfera e degradação de plantas e outros materiais complexos.

- Serviços de regulação: regulação do clima através do sequestro de carbono da atmosfera e do controle de emissões de gases de efeito estufa, regulação do fluxo de água, filtração e purificação de água, regulação da qualidade do ar por atenuação de poluentes e contaminação da terra.

- Serviços de provisão: produção de alimentos, combustível e fibra, disponibilidade de água e recursos minerais não renováveis.

- Serviços culturais: preservação de vestígios arqueológicos; atividades recreativas ao ar livre; interesses éticos, espirituais e religiosos.

Já Adhikari; Hartemink (2016) realizaram uma revisão sobre a relação entre solo e serviços ecossistêmicos e desenvolveram um novo diagrama conceitual que liga as principais propriedades do solo aos serviços através das funções do solo para o bem-estar dos seres humanos. Esse estudo também é relevante porque destaca que o solo é um sistema complexo, exigindo uma abordagem holística para entender o processo ecossistêmico e os serviços que oferece à sociedade (ADHIKARI; HARTEMINK, 2016).

No presente trabalho foram reunidas informações fornecidas por estes e outros diferentes trabalhos, em especial em Jónsson; Davídsdóttir (2016) que analisaram 16 frameworks e resumiram os serviços ecossistêmicos relacionados ao solo listados no Quadro 7.

Com vistas a essas definições e exemplos, é possível dizer que os serviços ecossistêmicos relacionados ao solo e seus benefícios parecem se misturar e as diferenças entre eles ainda não estão bem definidas na literatura.

Outro problema, relacionado à classificação CICES, é que as únicas classes explicitamente relacionadas ao solo são: formação e composição do solo, mas sabe-se que os 
recursos do solo são amplamente extraídos e utilizados para uso direto e também desempenham outros papeis importantes em muitos serviços, como manutenção do ciclo de vida, regulação do clima e preservação do patrimônio (ROBINSON et al., 2017). Portanto, após a revisão, foi organizada uma lista de serviços ecossistêmicos relacionados aos solos direta ou indiretamente utilizando os grupos e classes do CICES e empregados no modelo de cascata (Figura 12). 
Figura 12: Elementos e exemplos da estrutura em cascata dos serviços ecossistêmicos relacionados ao solo.

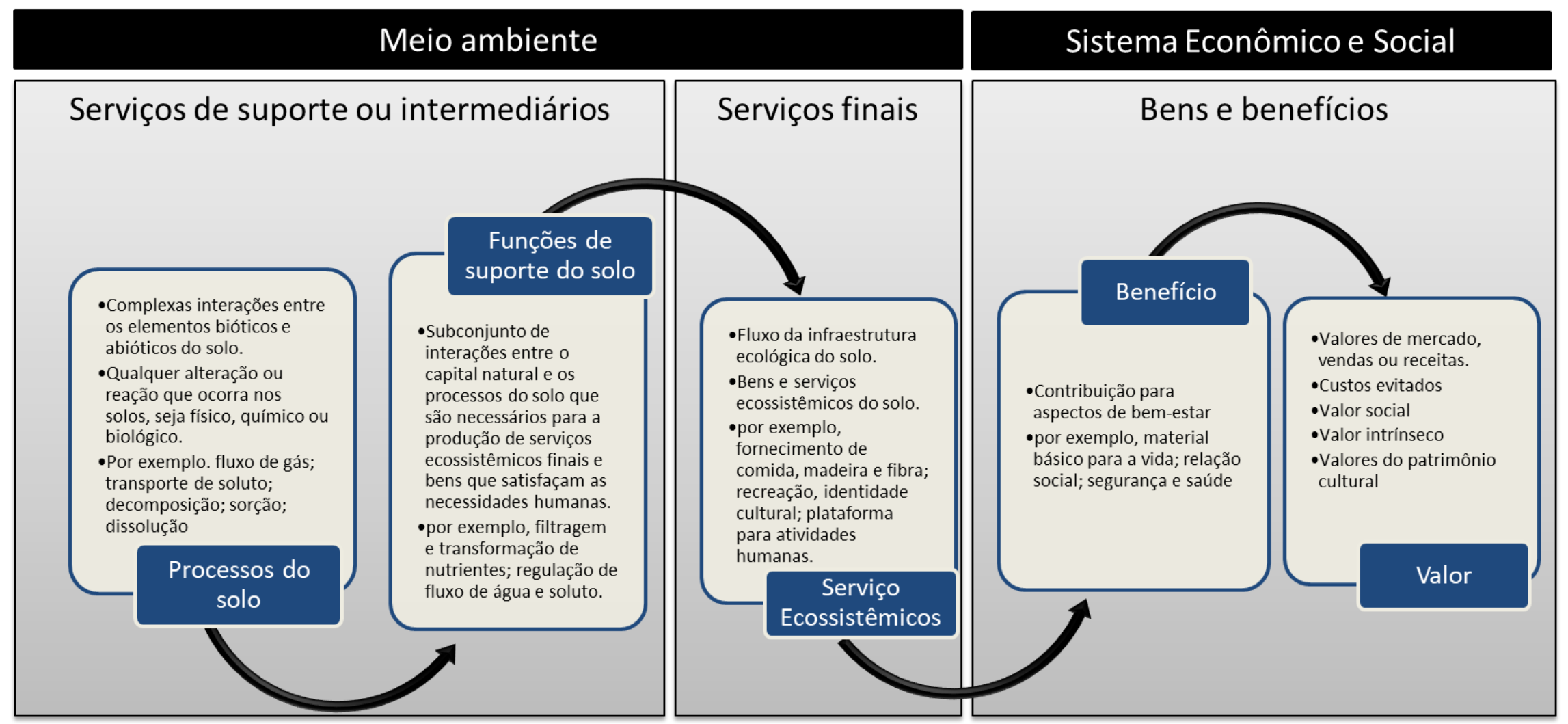

Fonte: Tradução de Pavan; Ometto (2018). 


\subsection{Mecanismo ambiental revisado}

De modo geral, após a revisão bibliográfica, fica claro que uma lista de lacunas teóricas e / ou práticas ainda existe na avaliação completa de serviços ecossistêmicos em estudos de ACV. Também se notou a predominância de estudos que ligam serviços ecossistêmicos somente ao uso da terra e indicadores de qualidade do solo.

Conclui-se também que apesar dos recentes avanços na avaliação de impacto do uso da terra sobre os serviços ecossistêmicos na ACV, ainda há lacunas sobre o tema como, por exemplo, a necessidade de um método de avaliação que: i) inclua todos os serviços ecossistêmicos, considerando as possíveis interações entre eles e sua hierarquia; ii) seja facilmente aplicável e compatível com bancos de dados de ICV; iii) use fatores de caracterização espacialmente diferenciados; e iv) no caso de impactos relacionados ao uso da terra, diferencie os tipos e intensidade de uso, especialmente para diferentes tipos agrícolas (KNOESTER, 2015).

Assim, reuniram-se informações científicas de processos e funções do solo, modelagem em AICV e serviços ecossistêmicos a fim de melhorar e sintetizar uma nova estrutura conceitual para avaliação de serviços ecossistêmicos relacionados ao solo em estudos de ACV e eventualmente tais limitações sejam sobrepujadas. Trata-se de uma contribuição científica teórica e multidisciplinar que se encontra publicada em Pavan; Ometto (2018).

O mecanismo ambiental do uso da terra (ou seja, a cadeia de causa e efeito do impacto) foi objeto de estudo de muitas pesquisas, como em EC (2010); Koellner et al. (2013); Vidal Legaz et al. (2017). Particularmente os modelos de Koellner et al. (2013) e Vidal Legaz et al. (2017) foram adotados como parâmetro de comparação e harmonização com o modelo de cascata. No entanto, a nova estrutura conceitual apresentada aqui difere das duas anteriores, pois não só agrega os cinco níveis do modelo em cascata, mas também mapeia a oferta de serviços ecossistêmicos relacionados ao solo, permitindo que futuras pesquisas possam quantificar impactos positivos ambientais.

A fim de fundir os dois temas de estudo (modelo em cascata de serviços ecossistêmicos e mecanismo ambiental da AICV), primeiro foram identificados e resumidos os processos do solo que são afetados pelas intervenções humanas registradas no ICV, que por sua vez se relacionam às atividades de uso da terra, contaminação biológica, emissões de substâncias, erosão do solo, plantio direto, etc. Foi adotada a classificação de Vereecken et al. (2016) sobre processos biológicos, físicos, geoquímicos, de suporte e de degradação. Todos 
esses processos do solo são fundamentais para o desempenho subsequente das funções do solo, desde o suporte à vegetação até oportunidades para atividades não comerciais (por exemplo, estética, educação e valor científico) (HAYGARTH; RITZ, 2009).

É importante reconhecer dois fatores problemáticos na próxima etapa: primeiro, que há uma relação múltipla entre os serviços ecossistêmicos e segundo que não há consenso para classificar serviços relacionados ao solo. Assim, trata-se de uma questão não totalmente esgotada na literatura e deve ser aplicada com cuidado para evitar dupla contagem.

No presente estudo, após a revisão da literatura sobre propriedades do solo, funções e serviços ecossistêmicos, os atributos do solo foram relacionados às classes do CICES. Portanto, para o novo modelo conceitual apresentado na Figura 13, vários serviços baseados em Dominati et al. (2010) e na classificação de CICES foram ligadas às suas funções relacionadas após a verificação de evidências na literatura especializada. Esta análise de dados levou à geração de uma matriz ligando os atributos do solo aos serviços ecossistêmicos, que por sua vez forneceu a base para a construção do diagrama. O total de 13 serviços ecossistêmicos relacionados ao solo foi listado, o que corresponde ao nível do ponto médio da ACV. Algumas semelhanças podem ser encontradas entre as classes do CICES e os impactos apresentados por Koellner et al. (2013), como as categorias de regulação da erosão, regulação do clima, produção de biomassa e regulação de água doce.

Ressalta-se que durante a fase de AICV, as mudanças ambientais devido a uma intervenção antropogênica são avaliadas. Tradicionalmente, o foco permanece nos impactos negativos causados pelo sistema do produto. No entanto, os elementos que compõem o novo modelo conceitual mostram os serviços ecossistêmicos potencialmente afetados e podem apoiar o desenvolvimento de modelos de caracterização que não apenas avaliem os possíveis danos causados pelas atividades humanas, mas também novas metodologias visando mapear a demanda e oferta de serviços ecossistêmicos em uma perspectiva positiva.

A próxima etapa resume os benefícios gerados por esses serviços, ou seja, mudanças positivas no bem-estar a partir do atendimento de necessidades (TEEB, 2010). De acordo com Boerema (2016), as medidas para os benefícios podem ser divididas em aquelas relacionadas à demanda social (por exemplo, safra de alimentos) e aquelas ligadas ao uso real (por exemplo, alimentos consumidos). Os benefícios dos serviços de provisão são mais comumente mensurados, pois são concretos, mais compreensíveis e geralmente avaliados como a parte usada da produção total. Os benefícios associados ao fornecimento de serviços ecossistêmicos relacionado com o solo são: emprego, rendimento colhido, produção de 
energia e fonte de conhecimento. Muitos dos benefícios de regulação e manutenção são indiretos (por exemplo, erosão evitada e regulação do clima), outros são mais diretos e concretos (por exemplo, qualidade do ar) (MONONEN et al., 2016). No novo modelo conceitual, os benefícios encontrados na literatura e vinculados a esses serviços incluem: erosão evitada, controle de enchentes e estoques e sequestro de carbono. Quanto aos benefícios dos serviços culturais, há um desafio para lidar com questões abstratas e os benefícios relacionados à experiência pessoal na natureza. No quadro atual, os seguintes benefícios foram resumidos aos serviços culturais: fonte de conhecimento, continuidade cultural e recreação.

Logo, a modelagem intermediária deve expressar a variedade desses serviços, variando de indicadores mais próximos às funções do solo, serviços ecossistêmicos intermediários até o fornecimento de serviços ecossistêmicos finais e seus benefícios. Para o primeiro, usando os indicadores já desenvolvidos para o uso da terra poderia ser um ponto de partida, enquanto ferramentas de avaliação de serviços ecossistêmicos como InVEST (KAREIVA et al., 2011) e ARIES (VILLA et al., 2014), poderiam ser usadas afim de desenvolver indicadores espacialmente explícitos capazes de traduzir o impacto aos serviços ecossistêmicos e seus diferentes benefícios.

Paralelamente ao nível de ponto final da modelagem de avaliação de impacto (ou AoP), está a esfera de valor do modelo em cascata. Aqui, são listados seis tipos de valores: econômicos, (como valores de mercado, vendas ou rendas), valores intrínsecos, custos evitados, valores sociais, valores do patrimônio cultural e o valor da ciência e da educação (Figura 13). Assim, recomenda-se que os avanços metodológicos na avaliação do nível final devem abranger demandas e valores de serviços ecossistêmicos, expressos em valores monetários. 
Figura 13: Mecanismo ambiental dos serviços ecossistêmicos relacionados ao solo de acordo com o modelo de cascata.

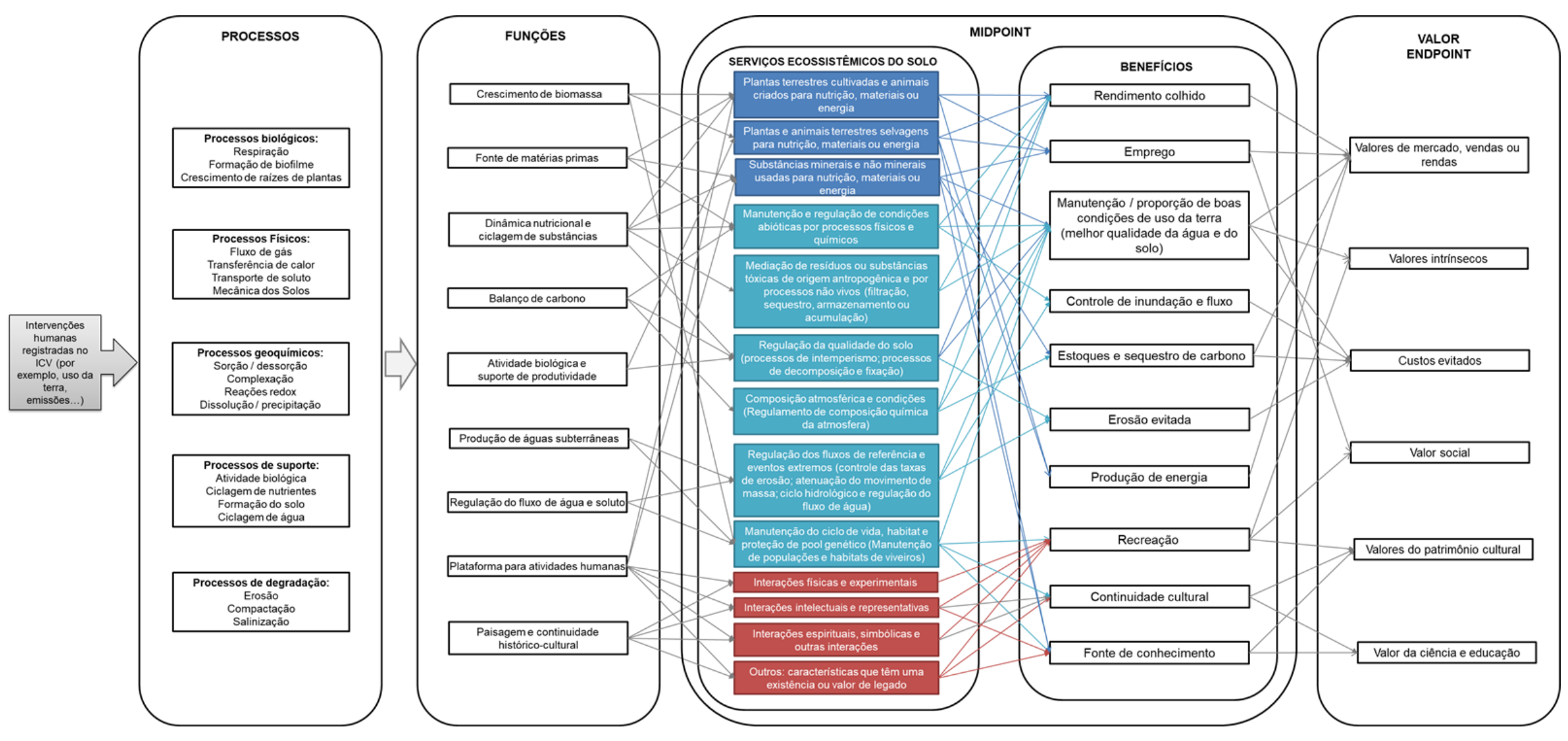

Fonte: Tradução de Pavan; Ometto (2018). 
Um breve exemplo de aplicação é apresentado abaixo (Figura 14). O foco é dado ao serviço da regulação da qualidade do solo e seus possíveis indicadores, bem como técnicas de modelagem e avaliação. É importante ressaltar, entretanto, que o principal objetivo do framework, no momento, é concretizar o conceito de serviços ecossistêmicos relacionado ao solo na ACV, além de fornecer uma base para desenvolvimentos futuros. 
Figura 14: Exemplo detalhado da estrutura conceitual para o serviço de regulação da qualidade do solo.
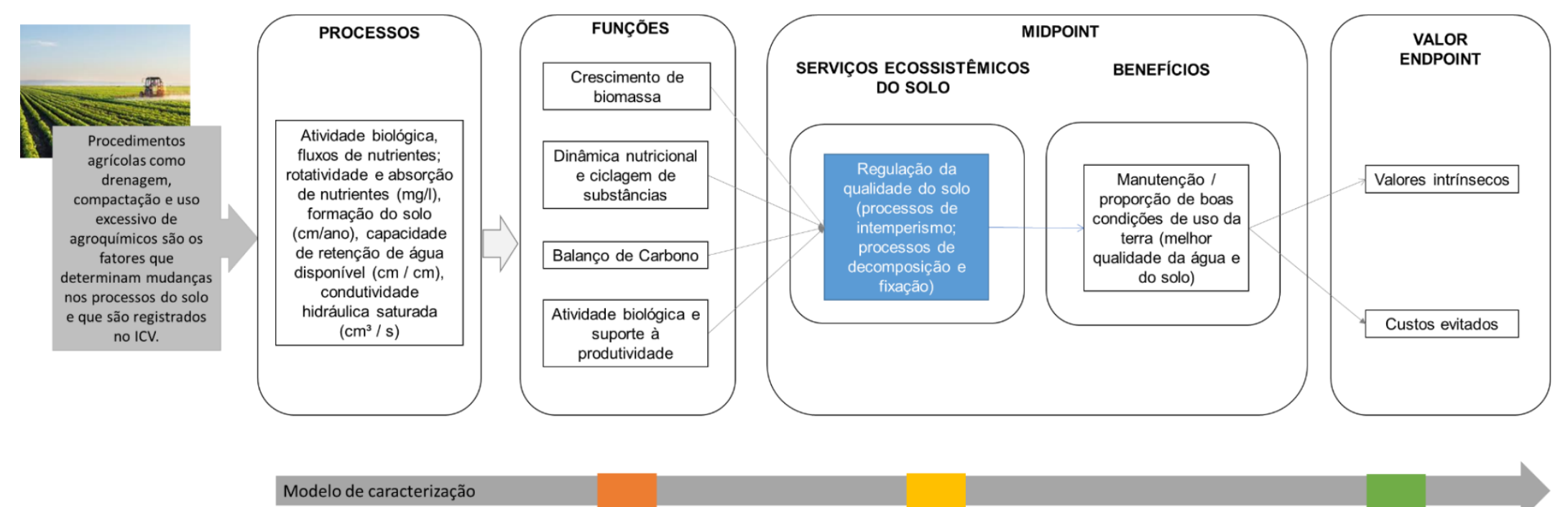

$$
\begin{gathered}
\text { Indicadores biológicos: respiração } \mathrm{CO}_{2} \\
\text { ( } \mathrm{mg} / \mathrm{g}) \text {; Formação / acumulação de } \\
\text { solo (gC / ha / ano); indicadores de } \\
\text { fertilidade do solo: ganho de } \\
\text { nutrientes, turnover de nutrientes: } \mathrm{N} \\
\left(\mathrm{kg} / \mathrm{m}^{2}\right)
\end{gathered}
$$

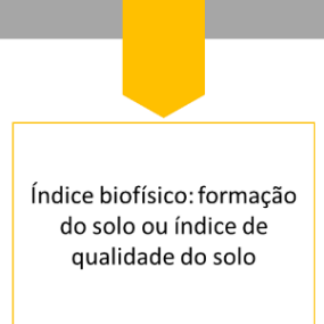

Valor do habitat para a formação do solo

\$/ha/anoliperda da função de ciclagem de

(\$/ha/ano), perda da funça de ciclagem de

ciclagem de nutrientes: preço de mercado dos fertilizantes $(\$ / \mathrm{t})$

Fonte: Tradução de Pavan; Ometto (2018). 
O novo framework desenvolvido não pretende substituir os outros, mas acrescentar novos elementos à discussão da avaliação de impacto em serviços ecossistêmicos na ACV. É importante enfatizar que a lista de processos, funções, serviços, benefícios e valores visa melhorar o mecanismo ambiental relacionado aos impactos do uso da terra, mas permanece aberta para incluir informações adicionais. Além disso, embora nem todo modelo de caracterização da AICV consiga abordar todos os elementos da estrutura em cascata, saber quais componentes e vínculos são estudados é fundamental para a evolução da avaliação dos impactos dos serviços ecossistêmicos relacionados ao solo.

Também é relevante expandir revisões e iniciativas semelhantes para diferentes tipos de mecanismos ambientais, por exemplo, impactos de emissões na regulação da composição química da atmosfera ou serviços de polinização.

Portanto, há várias discussões sobre o formato do modelo em cascata e as definições incorporadas (LA NOTTE et al., 2017; SPANGENBERG et al., 2014). No entanto, o resultado fundamental que emerge dessa revisão é que, independentemente do modo como as etapas da cascata são denominadas, ele provou-se útil para compreender os mecanismos que ligam os sistemas ecológicos / ecossistêmicos ao bem-estar humano. Além disso, seu uso possibilita abordar de forma mais abrangente os benefícios ambientais associados às atividades humanas, reduzindo assim o risco de mudança de carga ambiental e melhorando a identificação de compensações e sinergias. Finalmente, o uso do sistema de classificação CICES não apenas fornece uma hierarquia para a modelagem na AICV, mas também expande o espectro de serviços ecossistêmicos abordados. 


\section{ANÁLISE DE MODELOS DE CARACTERIZAÇÃO RELACIONADOS AO USO DA TERRA E SERVIÇOS ECOSSISTÊMICOS}

Além da revisão descrita anteriormente, em estudo prévio, dezesseis modelos de caracterização foram classificados de acordo com diferentes critérios, como: abordagem intermediária (em inglês midpoint) e de danos (em inglês endpoint), área de cobertura, área de coleta dos dados, diferenciação biogeográfica, tempo de recuperação, situação de referência, robustez científica e relevância ambiental (PAVAN; OMETTO, 2016). Nessa análise, quatro modelos de caracterização operacionais de abrangência de aplicação global, apresentaram robustez científica e relevância ambiental satisfatória para a avaliação dos impactos nos serviços ecossistêmicos: Brandão; Milà i Canals (2013); Müller-Wenk; Brandão (2010); Nunez et al. (2010); e Saad, Koellner, Margni (2013). Assim, estes modelos foram selecionados para a análise frente aos critérios descritos no item 5.2.

Desta forma, os resultados da análise relacionada à documentação e transparência e disponibilidade de dados são apresentados nos Quadros 9. 
Quadro 9: Resultado da análise de viabilidade de regionalização.

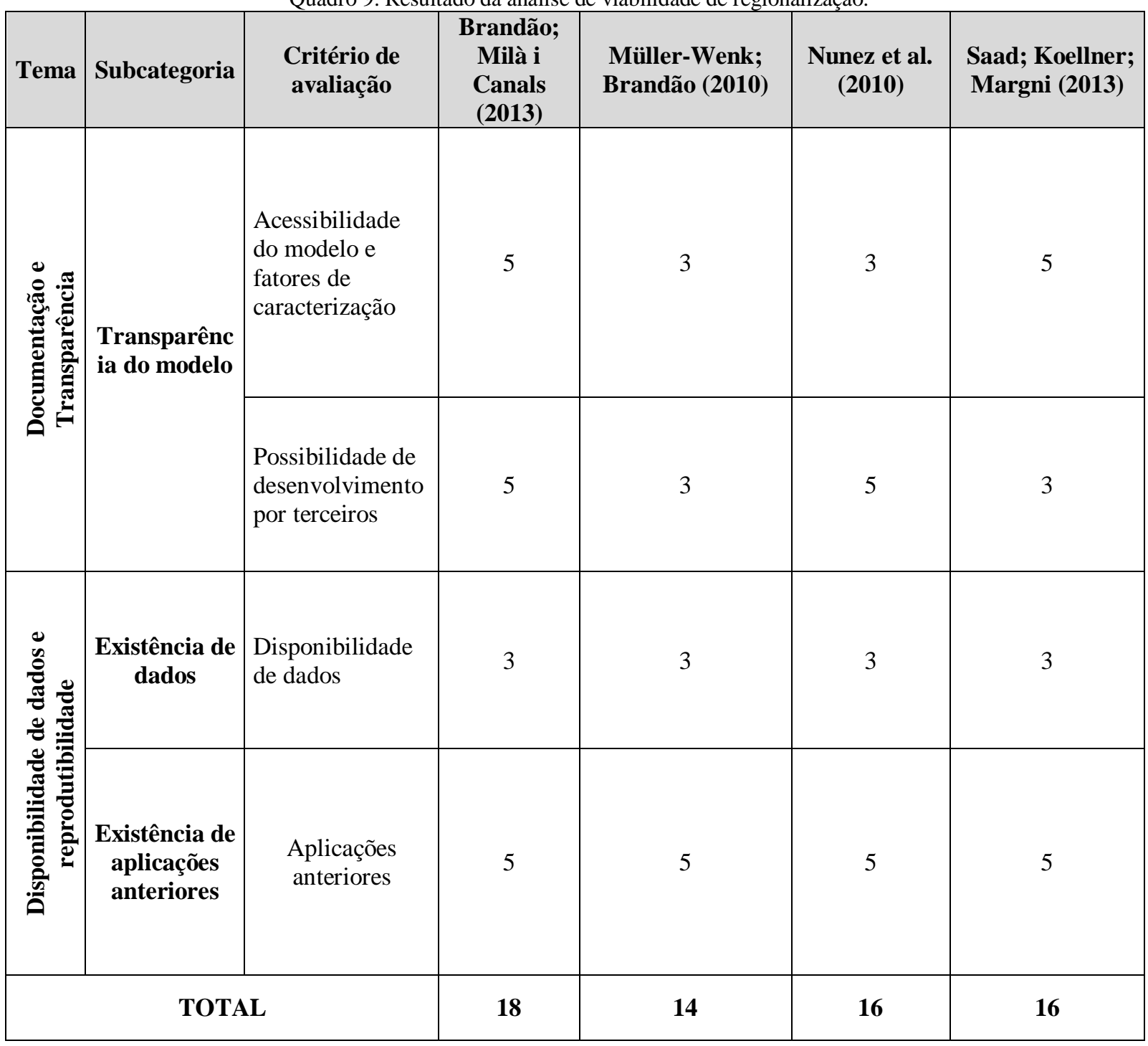

Fonte: elaboração própria. 
O modelo desenvolvido por Brandão; Milà i Canals (2013) foi selecionado para a adaptação para o contexto brasileiro por ter apresentado maior pontuação na análise. O estudo aborda o mecanismo de impacto ligando a ocupação e transformação da terra aos efeitos sobre a fertilidade (física, química e biológica) do solo, expressa pelo carbono orgânico do solo (COS). O Potencial de Produção Biótica (PPB) abordado pelos autores está associado aos serviços de provisão (produção primária) e se refere à mudança na capacidade produtiva ou a capacidade do ecossistema de sustentar a futura produção de biomassa. Trata-se de impactos dependentes principalmente de aspectos como o clima (temperatura e precipitação), tipo de solo, cobertura vegetal, a história do uso da terra e práticas de manejo. Apesar do grande número de propriedades que determinam o PPB, a adoção do COS como um indicador é uma simplificação razoável, apoiada por evidências de que estes estão intimamente relacionados (CHRISTENSEN; JOHNSTON, 1997; FAO, 2017). 


\section{DESENVOLVIMENTO DOS FATORES DE CARACTERIZAÇÃO ESPACIALMENTE DIFERENCIADOS PARA O BRASIL}

A seguir são apresentados os parâmetros do modelo de caracterização adaptado para ser aplicado no Brasil de maneira espacialmente diferenciada.

\subsection{Definição do mecanismo ambiental}

Como visto, os solos são um recurso fundamental, central para a criação de uma série de bens e serviços ecossistêmicos e ao bem-estar humano. A manutenção ou o aprimoramento dos recursos do solo é essencial para o atendimento da necessidade global de segurança alimentar, hídrica e energética seja atendida (FAO, 2015). Por sua vez, os serviços ecossistêmicos fornecidos pelos solos são principalmente determinados pelas suas três propriedades básicas: textura, mineralogia e matéria orgânica, que juntos formam o capital natural dos solos (PALM et al., 2007).

O termo matéria orgânica do solo (MOS) é usado para descrever os constituintes orgânicos no solo em vários estágios de decomposição, como tecidos de plantas, animais mortos e organismos do solo. A MOS é fundamental para a estabilização da estrutura do solo, retenção e liberação de nutrientes vegetais e manutenção da capacidade de retenção de água, tornando-se um indicador-chave não apenas para a produtividade agrícola, mas também para a resiliência ambiental (FAO, 2017).

O carbono orgânico do solo (COS) é o principal componente da MOS e é um contribuinte crucial para a produção de alimentos, mitigação e adaptação às mudanças climáticas, afetando a maioria dos processos relevantes para as funções do solo. Assim, o COS é um indicador da qualidade do solo associado ao ciclo de nutrientes e sua estabilidade e estrutura agregadas com implicações diretas na infiltração de água, vulnerabilidade à erosão e, por fim, na produtividade da vegetação e nos contextos agrícolas (SMITH et al., 2008). Além disso, o $\operatorname{COS}$ e a biodiversidade do solo estão comumente ligadas a três dimensões da segurança alimentar: aumento da disponibilidade de alimentos, restauração da produtividade em solos degradados e resiliência dos sistemas de produção de alimentos (FAO 2015; 2018).

Isto se explica, pois um alto teor de COS e, portanto de MOS, fornece às plantas os nutrientes que necessitam, aumentando a fertilidade do solo e a disponibilidade de água, o que, por sua vez, melhora a produtividade dos alimentos. Os estoques de COS refletem o equilíbrio entre ganhos de matéria orgânica, dependentes da produtividade e práticas de 
manejo, e perdas decorrentes da decomposição pela ação de organismos do solo, lixiviação e erosão. Ademais, o COS é fundamental na manutenção das funções do solo quando usados para a agricultura, principalmente em solos tropicais (TORNIQUIST, 2007).

Assim, o COS tem sido usado há muito tempo como um indicador da qualidade do solo, devido à sua capacidade de melhorar a estabilidade estrutural do solo, que afeta a capacidade de porosidade, aeração e filtração de água para fornecer água limpa. Recentemente, teores de COS acima e abaixo do solo também passaram a ser adotados no âmbito dos Objetivos do Desenvolvimento Sustentável (ODS), como subindicadores da meta relacionada ao combate à desertificação e restauração de terras e solos degradados ${ }^{10}(\mathrm{FAO}$, ITPS, 2018). Outro exemplo de aplicação encontra-se no âmbito da Convenção das Nações Unidas de Combate à Desertificação (UNCCD), em que o COS foi adotado como indicador da qualidade global do solo associado ao ciclo de nutrientes, estabilidade e estrutura agregadas com implicações diretas na infiltração de água, biodiversidade do solo, vulnerabilidade à erosão e, por fim, na produtividade da vegetação e nos contextos agrícolas (UNCCD, 2018).

A fertilidade do solo refere-se à capacidade do solo para apoiar e sustentar o crescimento das plantas, e é influenciada não somente pelo armazenamento de nutrientes na MOS, mas também pela reciclagem de nutrientes de formas minerais orgânicas para plantas e por processos físicos e químicos que controlam a disponibilidade de nutrientes para a atmosfera e água. No geral, a fertilidade e o funcionamento dos solos dependem das interações entre a matriz mineral do solo, plantas e microrganismos.

Os serviços de provisão referem-se à entrega de produtos ecossistêmicos como alimentos, fibras, combustíveis e água doce, por exemplo. Portanto, muitos autores recorrem a indicadores relacionados à biomassa para quantificar os impactos nestes serviços. Brandão; Milà i Canals (2013) sugeriram que os impactos da ocupação e transformação da terra devem ser estimados em sua capacidade de longo prazo de produzir biomassa, referida como Potencial de Produção Biótica (PPB). Esses autores recomendaram o COS como um indicador para o PPB, fornecendo referências para a ligação entre COS e produtividade.

Tal modelo parte da premissa de que a produtividade da terra ou ecossistema pode ser medida em biomassa produzida por unidade de área, por unidade de tempo. Destaca-se que a produção biótica é um fluxo e não um estoque, portanto, esta categoria de impacto não se

\footnotetext{
${ }^{10}$ Objetivo 15: Proteger, restaurar e promover o uso sustentável de ecossistemas terrestres, manejar florestas de forma sustentável, combater a desertificação e deter e reverter a degradação da terra e deter a perda de biodiversidade
} 
refere às perdas de produção de biomassa, como resultado de uma utilização específica da terra (o que seria refletido por alterações na produção primária líquida), mas à alteração na capacidade de produção ou a capacidade do ecossistema para sustentar futura produção de biomassa (BRANDÃO; MILÀ I CANALS, 2013).

Em suma, o impacto do uso da terra no PPB é dado em função de três parâmetros: alteração no teor de matéria orgânica, área e tempo. Segundo Brandão; Milà i Canals (2013) o impacto pode ser medido como um déficit de carbono (ou crédito, neste caso expresso por valores negativos) com a unidade [kg.C.ano], referindo-se a quantidade de carbono adicional temporariamente presente ou ausente do solo devido à ocupação, em relação a um sistema de referência.

O indicador da categoria de impacto COS já é utilizado na ACV e em estudos de avaliação de impacto em geral, visto que está intimamente relacionado com outros indicadores de qualidade do solo, tais como a capacidade de troca cationnica, biota e estrutura do solo. Devido às limitações envolvidas na avaliação de impactos da transformação da terra, sobretudo relacionadas à definição do tempo de recuperação, apenas as intervenções de ocupação são abordadas neste estudo.

Quanto ao cálculo dos impactos, Brandão; Milà i Canals (2013) modificaram o método desenvolvido por Milà i Canals; Romanya; Cowell (2007) seguindo as considerações discutidas por Milà i Canals et al. (2007a) e Koellner et al. (2013b) sendo a fórmula geral utilizada para calcular os fatores de caracterização para a ocupação da terra apresentada na Equação 3. Concluindo, o Quadro 10 a seguir sintetiza os componentes da AICV definidos para condução deste trabalho.

$$
F C_{o c}[t C / h a]=C O S_{p o t}-\operatorname{COS}_{U T 2}
$$

Onde:

$\operatorname{COS}_{\text {pot }}=$ Nível potencial de carbono orgânico do solo (situação de referência)

COSuT2 = Carbono orgânico durante o uso da terra 
Quadro 10: Síntese dos termos e parâmetros adotados na adaptação do modelo de caracterização.

\begin{tabular}{|c|c|}
\hline Tipo de Serviço Ecossistêmico & Serviço de provisão \\
\hline Categoria de Impacto & Potencial de Produção Biótica \\
\hline Modelo de caracterização & Brandão; Milà i Canals (2013) \\
\hline Intervenções & Ocupação da terra \\
\hline Indicador de categoria & Déficit de carbono orgânico no solo \\
\hline Fator de caracterização & Variação da capacidade de produção de biomassa do solo \\
(tC/ha). \\
\hline Resultado do indicador de categoria & tC.ano por unidade funcional \\
\hline Pontos finais & Danos potenciais aos serviços ecossistêmicos \\
\hline Área de proteção & Recursos naturais e Serviços Ecossistêmicos \\
\hline
\end{tabular}

\subsection{Definição da situação de referência}

A escolha de um cenário-base (baseline) é comumente utilizada em outros campos de estudo, podendo-se comparar os termos referência ecológica e ecossistema de referência à chamada situação de referência empregada na ACV.

$\mathrm{Na}$ área de restauração ecológica, por exemplo, uma referência ecológica indica as características pretendidas de um ecossistema depois de ter sido submetido ao processo de restauração. A referência pode consistir em um ou mais ecossistemas intactos ou "locais de referência" ou suas descrições ecológicas. Estas referências, suas descrições ecológicas e / ou evidências indiretas contribuem para a elaboração de um modelo de referência, que informa o desenvolvimento de planos de projetos de restauração (CLEWELL; ARONSON, 2013). Quando se trata da restauração de florestas, a comparação com os ecossistemas de referência foi destacada por Fengler et al. (2017) como um aspecto crucial, uma vez que pode fornecer critérios para avaliar os resultados das ações realizadas e identificar limitações técnicas existentes que podem não permitir uma restauração completa. De maneira semelhante, Aronson; Milton; Blignaut (2007), definem como local de referência (reference site em inglês) um ecossistema natural utilizado como base para o monitoramento e avaliação de locais visando à restauração ou reabilitação.

Já na modelagem da AICV, os fatores de caracterização são calculados em relação a uma referência sendo que quanto mais próximo do estado desejado, menor será o impacto (CAO et al., 2016). A seleção da situação de referência na caracterização do impacto do uso da terra é um parâmetro fundamental da modelagem e deve ser consistente com o objetivo e escopo da ACV (MILÀ I CANALS et al., 2007). Tal escolha afeta a comparação de diferentes sistemas e a relevância desta escolha recebeu pouca atenção até recentemente sendo que 
poucos autores de modelos discutiram suas implicações. Não obstante, Nordborg et al. (2016), salientam que a parte mais desafiadora do desenvolvimento de fatores de caracterização regionalizados foi encontrar áreas de terra adequadas a partir das quais derivar dados representativos para parametrizar as situações de referência.

No contexto de estudos sobre estoques de COS, na condição de vegetação nativa não perturbada se considera geralmente um equilíbrio dinâmico com outros reservatórios de carbono terrestre, sendo também relacionados ao clima, terreno, mineralogia do solo, tamanho das partículas e suas interações (WATSON et al., 2000; CANADELL et al., 2007).

A seguir são descritos os diferentes tipos de escolhas para este parâmetro. Ademais, a fim de compreender como estudos voltados à avaliação da qualidade do solo através de índices de teor de carbono orgânico definem o estado inicial, foi feito um levantamento bibliográfico utilizando as seguintes palavras-chave e combinações: "Soil Organic Carbon" AND "Baseline" OR "reference model" OR "Potential Natural Vegetation" OR "default reference".

Como apresentado anteriormente, o conceito de vegetação natural potencial (VNP) está relacionado a um estado de vegetação hipotética natural que mostra o potencial biótico da natureza na ausência de influência e perturbação humana. Ao comparar o VNP com a vegetação real, as influências antropogênicas podem ser avaliadas e quantificadas. Segundo Moravec (1998) mapas podem ser construídos com base na vegetação real, onde a vegetação existente serve como ponto de referência para distribuição potencial aos locais de habitats semelhantes, mas onde essa vegetação está ausente. Assim, o desenvolvimento e o uso de mapas de VNP tornaram-se úteis para determinar os efeitos do impacto humano nos padrões de vegetação (RICOTTA et al., 2002; CARRANZA et al., 2003; CAPELO et al., 2007).

Segundo Westhoff; Van der Maarel (1973), VNP é a vegetação que se desenvolveria em determinado habitat se toda a influência humana no local e nos arredores cessasse. Carranza et al (2003), reconhecendo que a definição de VNP é hipotética e sua caracterização é geralmente difícil e controversa, propuseram o uso da distribuição da VNP como um framework de referência para uma análise quantitativa de mudança de paisagem em SIG. Os autores concluíram que apesar do caráter hipotético da maioria dos mapas, estes podem ser utilizados para sumarizar mudanças de paisagem de forma quantitativa como um primeiro passo para um modelo geral para a avaliação dos efeitos de perturbação nos padrões de vegetação e na biodiversidade. Embora sejam necessários refinamentos, o uso de mapas de VNP como base para a análise quantitativa parece útil para investigar diferentes paisagens em 
diferentes níveis hierárquicos de descrição da vegetação, com ênfase especial na dinâmica da vegetação.

Ao se analisar a combinação das seguintes palavras-chave: "Potential Natural Vegetation" e "Soil organic Carbon", apenas cinco estudos são identificados sendo três deles no campo da ACV. Nordborg et al. (2016) avaliaram a viabilidade e os desafios da aplicação de um conjunto de métodos indicados para avaliação dos impactos relacionados ao uso da terra na ACV. Neste contexto os autores utilizaram a definição de VNP para a escolha da situação de referência, definindo como um ponto na história, antes do início do uso da terra ser avaliado. Assim, determinaram o VNP como sendo florestas de folhas decíduas com base em registros da vegetação histórica na Suécia, país em que o estudo foi conduzido. Os autores também discutiram as implicações desta escolha, concluindo ser uma opção problemática. Isto se deve ao fato do uso do VNP implicar a adoção de uma teoria sobre estados finais estáveis do ecossistema natural sendo que ecossistemas naturais na realidade são dinâmicos e sujeitos a mudanças de fatores biofísicos e eventos como tempestades e incêndios, por exemplo (NORDBORG et al. 2016).

Outro resultado encontrado na literatura, a publicação de Morais et al. (2016) teve objetivo semelhante ao presente estudo tendo em vista que operacionalizaram um modelo de caracterização regionalizado para a Europa obtendo fatores de caracterização para avaliação do PPB. Os autores adotaram o VNP como situação de referência na modelagem.

Já Wang; Ni; Prentice (2011) realizaram um estudo de sensibilidade para investigar as respostas da distribuição da VNP na China aos efeitos separados e combinados de temperatura, precipitação e produtividade e armazenamento de carbono.

Bondeau et al. (2007) desenvolveram um modelo da superfície terrestre planetária que simula processos biofísicos e biogeoquímicos, bem como produtividade e rendimento de importantes culturas, utilizando um conceito de tipos funcionais de culturas. Apesar de discutir o conceito de VNP, os autores não adotaram este conceito para compreender a diferença de carbono da vegetação, o carbono do solo e a produtividade primária líquida devido à atividade de agricultura.

Por fim, destaca-se o estudo de Cerri et al. (2007) cujo objetivo foi prever os estoques de carbono do solo (e suas mudanças) na Amazônia brasileira entre o período de 2000 e 2030 utilizando o sistema de modelagem de carbono do solo GEFSOC. Para tanto usaram um mapa de vegetação nativa da Amazônia brasileira como entrada para as simulações regionais. $\mathrm{O}$ conjunto de dados original consistiu em uma versão digital do mapa de vegetação do Brasil, representando a VNP. 
Tendo feita essa revisão sobre o tema, a VNP foi adotada como situação de referência, visto que é um conceito já incluído na AICV, mantendo-se assim a compatibilidade com os demais modelos de caracterização para impactos do uso da terra. Como resultado, foram encontradas quatro fontes de dados de COS em vegetação nativa para o Brasil: IPCC (2006), Bernoux et al. (2001), Bernoux et al. (2002) e Batjes (2010), sendo necessária uma análise detalhada dos materiais e os métodos empregados.

\section{- IPCC (2006)}

O documento contendo os guias para inventários nacionais de gases de efeito estufa produzido pelo Painel Intergovernamental sobre Mudanças Climática (IPCC) no ano de 2006, de ampla abrangência na comunidade científica, tem em seu Volume 4 as orientações para a preparação de inventários no setor de agricultura, florestas e outros uso da terra (AFOLU). Este volume integra a orientação previamente separada nas Diretrizes Revisadas do IPCC de 1996 para inventários nacionais de gases de efeito estufa para agricultura (Capítulo 4) e uso e transformação da terra e silvicultura (Capítulo 5). Assim, além da orientação e métodos para estimar as emissões e remoções de gases de efeito estufa para o setor, também inclui guia para quantificação de emissões e remoções de $\mathrm{CO}_{2}$ resultantes de mudanças nos estoques de carbono na biomassa, matéria orgânica morta e solos minerais.

O nível de complexidade metodológico para elaboração desses inventários é diferenciado através de três Tier (níveis ou camadas), sendo o Tier 1 o método mais básico e mais utilizado. Já o Tier 2 é um método intermediário e o Tier 3 o mais complexo, demandando mais dados e informações detalhadas. O Tier 1 é recomendado em casos de limitações de dados disponíveis (indisponibilidade de fatores de emissão específicos para o país, ou dados do uso da terra). Nestes casos, os guias do IPCC disponibilizam dados defaults, os quais permitem a realização das estimativas, dentre eles os valores de referência de COS em vegetação nativa para solos minerais (IPCC, 2006), os quais são foco deste trabalho.

Os dados são derivados de bancos de dados de solo descritos por Jobbagy e Jackson (2000) e Bernoux et al. (2002). Por sua vez, a análise de Jobbagy e Jackson (2000) faz uso das seguintes bases globais de dados do solo: National Soil Characterization Database (NSCD) produzida pelo Departamento de Agricultura dos EUA (USDA, 1994), World Inventory of Soil Emission Potential Database (WISE) compilado pelo International Soil Reference and Information Centre (BATJES; BRIDGES 1994, BATJES 1995). 
Apesar de referenciar a origem, a documentação do IPCC não fornece o detalhamento de como estes dados foram empregados para gerar os valores de $\operatorname{COS}_{\text {ref }}$ para combinações de regiões climáticas e tipos de solo. Considera-se essa uma grande limitação referente à falta de transparência na metodologia, visto que os dados disponíveis em Jobbagy e Jackson (2000) e Bernoux et al. (2002) foram obtidos em escopos diferentes, até mesmo quanto à suas especificações de profundidade do solo nos experimentos.

- $\quad$ Batjes (2010)

Esta publicação faz parte do Projeto de Benefícios do Carbono (The Carbon Benefits Project -CBP) do ISRIC - World Soil Information. A principal contribuição do ISRIC ao projeto, na sua qualidade de centro de dados mundiais para solos, foi de coletar e analisar dados históricos do solo para desenvolver uma estrutura global de estoques de carbono orgânico do solo sob vegetação nativa em toda a gama de climas e tipos de solo. Essa estrutura é compatível com os inventários de gases de efeito estufa do Tier 1 do IPCC e foi desenvolvida especificamente para regiões com dados escassos (BATJES, 2010).

Os dados de solo necessários e informações auxiliares sobre uso da terra e vegetação nativa foram derivados do banco de dados do perfil do solo ISRIC-WISE, contendo cerca de 10250 perfis, complementados com cerca de 1900 perfis das regiões do clima-solo do IPCC. Este estudo considera apenas os perfis em vegetação natural para os quais dados medidos de COS estão disponíveis (cerca de 5560 perfis). Os estoques médios de COS, para a profundidade de referência do IPCC de $30 \mathrm{~cm}$, variam muito dentro de cada grupo funcional, com coeficientes de variação (CV) variando de $22 \%$ a $106 \%$.

Os resultados atuais indicam que o erro relativo estimado, padrão, de $\pm 90 \%$ assumido independentemente da região climática e do tipo de solo mineral nas Diretrizes do IPCC de 2006 é muito conservador. Segundo os autores são necessários critérios mais precisos para a definição de zonas climáticas e tipos de solo para reduzir a incerteza.

Esse estudo baseia-se majoritariamente em dados de perfil do solo derivados de pesquisas anteriores e dados de perfis de solos mantidos no banco de dados ISRIC-WISE, não envolvendo nova amostragem de solo. A distribuição global dos perfis georreferenciados indica uma boa representatividade de dados coletados do território brasileiro.

Os resultados estatísticos são organizados em combinações de tipos de solo e zonas climáticas (definidos pelo IPCC). Além disso, o estudo ainda traz os dados de estoques de carbono do solo em vegetação nativa, agrupados por zona climática do IPCC, tipo de solo 
mineral e ampla classe de vegetação e também agrupados por zona climática do IPCC, tipo de solo mineral e classe de textura do solo.

- Bernoux et al. $(2001 ; 2002)$

Reconhecendo a limitação de estudos envolvendo estimativas de carbono nos solos brasileiros em um nível nacional, os autores apresentam resultados confiáveis e espacialmente distribuídos dos valores de carbono em camadas de 0-30 cm em solos em vegetação não perturbada. Assim, esses valores são úteis como valores de referência (baseline) em avaliações de impactos de mudança no uso da terra bem como para futuras melhorias nas estimativas do teor de carbono no solo do Brasil.

O procedimento metodológico de Bernoux et al. (2002) envolveu a elaboração de um mapa das unidades de análise, denominadas pelos autores como Associação Solo-Vegetação (ASV), além da organização dos dados de concentração de carbono, tipo de solo, densidade e tipos de vegetação.

Os dados de vegetação representam a vegetação potencial, ou seja, a VNP. Segundo os autores, a classificação do IBGE (1988) foi utilizada com algumas adaptações. Por exemplo, o grupo original de Florestas ombrófilas abertas e Florestas ombrófilas densas foram transformados em três categorias - duas na região amazônica e uma categoria para Floresta Atlântica. As demais adaptações são encontradas todas detalhadas na publicação de Bernoux et al (2002). Ao final, os autores analisaram a representatividade das informações contidas no banco de dados do perfil do solo e os resultados estatísticos são disponibilizados em uma tabela com valores expressos em $\mathrm{kgC} / \mathrm{m}^{2}$.

O procedimento metodológico de Bernoux et al. (2002) também envolveu a reclassificação das 69 classes categorizadas nas 18 ordens de solo do Sistema Brasileiro de Classificação de Solo conforme recomendações do IPCC (1997), que leva em consideração a textura do solo, a saturação por bases e a umidade. Assim, seis grandes grupos de solos são listados pelos autores: solos com argila de atividade alta; latossolos com argila de atividade baixa; não latossolos com argila de atividade baixa; solos arenosos; solos hidromórficos e outros solos.

Além disso, os autores usaram o mapa de vegetação do IBGE (1988) para agrupamento das classes de vegetação em 15 categorias (BERNOUX et al., 2002). Para esta classificação, as categorias foram distribuídas da seguinte forma: Floresta Amazônica Aberta; Floresta Amazônica Densa; Floresta Atlântica; Floresta Estacional Decidual; Floresta 
Estacional Semidecidual; Floresta Ombrófila Mista; Savana Sul; Savana Amazônica; Cerrado; Estepe do Sul; Estepe Nordeste (Caatinga); Estepe Oeste (Pantanal); Refúgios Ecológicos de Montanhas e Terras Altas; Áreas de Formação Pioneira e Áreas Arenosas e Vegetação Lenhosa Oligotrófica de Áreas Pantanosas.

Sobre as incertezas dos dados os autores listam os fatores que mais influenciam os resultados. Em primeiro lugar, as informações da base de dados do solo provêm de diferentes fontes. Mesmo que a maioria das equipes seguisse classificações semelhantes do solo e vegetação, discrepâncias ainda podem surgir porque cada levantamento de solo realizado utilizou diferentes métodos de definição de tipos de vegetação e solo. Por exemplo, um tipo de vegetação pode ser classificado por um autor como "savana estépica" (ou Caatinga), e por outro como "savana" (ou Cerrado). A influência desse tipo de incerteza é muito difícil de quantificar. Além disso, a falta de dados de densidade do solo, e, portanto, o uso de equação de regressão multilinear para estimar os mesmos, representa outra fonte de incerteza. Mas, a fonte mais importante de incertezas segundo Bernoux et al. (2002) está na metodologia empregada na determinação das concentrações de carbono, baseadas na oxidação por dicromato.

Segundo os autores, apesar dessas limitações e também da falta de precisão total dos dados históricos do solo, o estudo permite quantificar limites razoáveis no total de carbono orgânico armazenado em solos brasileiros, sendo que foi utilizado inclusive na Terceira Comunicação Nacional do Brasil à Convenção-Quadro das Nações Unidas sobre Mudança do Clima (BRASIL, 2016).

Já no estudo com o objetivo de fornecer uma primeira aproximação dos fluxos de $\mathrm{CO}_{2}$ dos solos no Brasil para os períodos 1970-1990 e 1975-1995, Bernoux et al. (2001) também utilizaram esses dados de COS na vegetação nativa, apresentando-os agregados em estados.

Frente às alternativas apresentadas e após a análise das três opções citadas, adotou-se o estudo de Bernoux et al. (2002) na definição da situação de referência e, portanto, os valores de $\operatorname{COS}_{\text {pot }}$ do presente modelo são equivalentes à mediana para cada categoria de ASV (Figura 15). No entanto, uma vez que a distinção do tipo de clima é também importante para a aplicação do modelo, os valores de $\operatorname{COS}_{\text {pot }}$ foram recalculados a fim de ponderar os valores de acordo com a distribuição dos climas em cada ASV, com base na área relativa. O resultado destes cálculos se encontra na Tabela 9, apresentada no Apêndice. 
Figura 15: Estoque de carbono nos solos do Brasil (tC/ha).

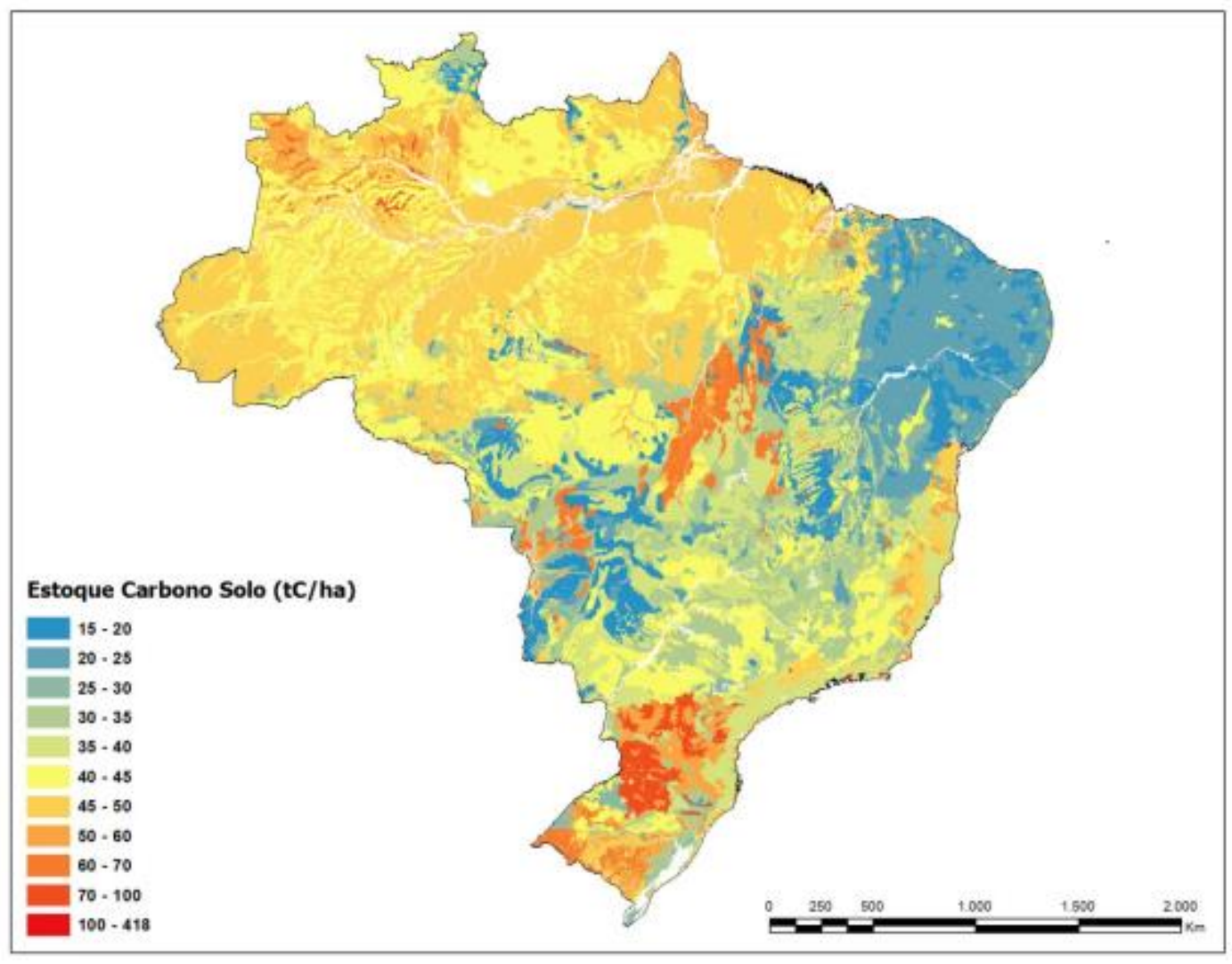

Fonte: Bernoux et al. (2002).

Ressalta-se aqui que apesar de também ter sido identificado um mapa de COS para o país, elaborado e divulgado pela Embrapa ${ }^{11}$, não foi possível sua aplicação no presente estudo por falta de detalhamento do procedimento metodológico, premissas sob as quais o mapa foi desenvolvido bem como pela indisponibilidade dos dados espaciais.

\subsection{Estoques de carbono por tipos de uso da terra}

O IBGE adota um sistema multinível de classificação para uso e cobertura da terra, amplo e dividido em três níveis. O nível I (classes) contém cinco itens: áreas antrópicas não agrícolas, áreas antrópicas agrícolas, áreas de vegetação natural, água e outras áreas. O nível II (subclasses) abrange 12 itens, traduzindo o uso da terra em uma escala mais regional, enquanto o nível III (unidades) explicita o uso da terra propriamente dito (IBGE, 2013).

Em função da disponibilidade de dados sobre uso da terra foi necessário trabalhar em um nível mais simplificado e a obtenção dos valores dos estoques de COS baseou-se no

\footnotetext{
${ }^{11}$ http://geoinfo.cnps.embrapa.br/documents/1115 Acesso em 31 jan. 2019.
} 
procedimento proposto pelo Painel Intergovernamental de Mudanças Climáticas (IPCC), o qual é um método indireto de quantificação do carbono do solo. Assim, as classes de uso da terra inclusas são: culturas anuais, culturas perenes, pastagem e áreas de pousio, correspondentes ao nível II da classificação brasileira.

O passo inicial envolve a seleção dos valores do estoque de referência, com base no clima e no tipo de solo, para cada área. Para tanto foram utilizados os dados de COS sob vegetação natural (na profundidade de $30 \mathrm{~cm}$ ), publicados Bernoux et al. (2002) já descritos anteriormente.

Ainda segundo o IPCC, a mudança de estoque é influenciada pelo uso da terra (contínuo com culturas, pastagens, arroz inundado, etc.), a perturbação do solo (preparo convencional, plantio direto, etc.) e a quantidade de resíduos e matéria orgânica depositada (i.e. quantidade de palha e raízes que retornam ao solo após cada ciclo). Assim, as alterações nos estoques do COS em solos minerais é o produto de três fatores:

1. Fator de mudança de estoque para os sistemas de uso da terra $\left(\mathrm{F}_{\mathrm{LU}}\right)$;

2. Fator de mudança de estoque para as práticas de manejo $\left(\mathrm{F}_{\mathrm{MG}}\right)$;

3. Fator de mudança de estoque para entrada de matéria orgânica $\left(\mathrm{F}_{\mathrm{I}}\right)$.

As Tabelas 1 e 2 a seguir apresentam os fatores $F_{L U}, F_{M G}$ e $F_{I}$ disponibilizados pelo IPCC e utilizados neste trabalho. 
Tabela 1: Fatores relativos de mudança de estoque para diferentes atividades e manejo em terras agrícolas.

\begin{tabular}{|c|c|c|c|}
\hline Fator & Zona climática & IPCC default & Erro \\
\hline \multirow{5}{*}{$\mathrm{F}_{\mathrm{LU}} \mathrm{Culturas}$ anuais } & Clima temperado seco & 0.8 & $\pm 9 \%$ \\
\hline & Clima temperado úmido & 0.69 & $\pm 12 \%$ \\
\hline & Clima tropical seco & 0.58 & $\pm 61 \%$ \\
\hline & Clima tropical úmido & 0.48 & $\pm 46 \%$ \\
\hline & Clima tropical montanhoso & 0.64 & $\pm 50 \%$ \\
\hline $\mathrm{F}_{\mathrm{LU}}$ Culturas Perenes & Todos climas & 1.00 & $\pm 50 \%$ \\
\hline \multirow{3}{*}{$\mathrm{F}_{\mathrm{LU}}$ Pousio } & Clima temperado e tropical, seco & 0.93 & $\pm 11 \%$ \\
\hline & Clima temperado e tropical, úmido & 0.82 & $\pm 17 \%$ \\
\hline & Clima tropical montanhoso & 0.88 & $\pm 50 \%$ \\
\hline F $_{M G}$ Preparo convencional & Todos climas & 1.00 & $\pm \mathrm{ND}$ \\
\hline \multirow{5}{*}{$\mathrm{F}_{\mathrm{MG}}$ Preparo reduzido } & Clima temperado seco & 1.02 & $\pm 6 \%$ \\
\hline & Clima temparado úmido & 1.08 & $\pm 5 \%$ \\
\hline & Clima tropical seco & 1.09 & $\pm 9 \%$ \\
\hline & Clima tropical úmido & 1.15 & $\pm 8 \%$ \\
\hline & Clima tropical montanhoso & 1.09 & $\pm 50 \%$ \\
\hline \multirow{5}{*}{$\mathrm{F}_{\mathrm{MG}}$ Plantio direto } & Clima temperado seco & 1.10 & $\pm 5 \%$ \\
\hline & Clima temparado úmido & 1.15 & $\pm 4 \%$ \\
\hline & Clima tropical seco & 1.17 & $\pm 8 \%$ \\
\hline & Clima tropical úmido & 1.22 & $\pm 7 \%$ \\
\hline & Clima tropical montanhoso & 1.16 & $\pm 50 \%$ \\
\hline \multirow{5}{*}{ F I Baixa } & Clima temperado seco & 0.95 & $\pm 13 \%$ \\
\hline & Clima temparado úmido & 0.92 & $\pm 14 \%$ \\
\hline & Clima tropical seco & 0.95 & $\pm 13 \%$ \\
\hline & Clima tropical úmido & 0.92 & $\pm 14 \%$ \\
\hline & Clima tropical montanhoso & 0.94 & $\pm 50 \%$ \\
\hline FI Média & Todos climas & 1.00 & ND \\
\hline \multirow{3}{*}{$\begin{array}{l}\text { FI Alta sem aporte de matéria } \\
\text { orgânica }\end{array}$} & Clima temperado e tropical, seco & 1.04 & $\pm 13 \%$ \\
\hline & Clima temperado e tropical, úmido & 1.11 & $\pm 10 \%$ \\
\hline & Clima tropical montanhoso & 1.08 & $\pm 50 \%$ \\
\hline \multirow{3}{*}{$\begin{array}{l}\mathrm{F}_{\mathrm{I}} \text { Alta com aporte de matéria } \\
\text { orgânica }\end{array}$} & Clima temperado e tropical, seco & 1.37 & $\pm 12 \%$ \\
\hline & Clima temperado e tropical, úmido & 1.44 & $\pm 13 \%$ \\
\hline & Clima tropical montanhoso & 1.41 & $\pm 50 \%$ \\
\hline
\end{tabular}

Fonte: IPCC (2006). 
Tabela 2: Fatores relativos de mudança de estoque para diferentes atividades e manejo em pastagens.

\begin{tabular}{|c|c|c|c|}
\hline Fator & Zona climática & IPCC default & Erro \\
\hline $\mathrm{F}_{\mathrm{LU}}$ Pastagem & Todos climas & 1.00 & ND \\
\hline F $_{M G}$ Não degradada & Todos climas & 1.00 & ND \\
\hline \multirow{3}{*}{$\mathrm{F}_{\mathrm{MG}}$ Moderadamente degradada } & Clima temperado & 0.95 & $\pm 13 \%$ \\
\hline & Clima tropical & 0.97 & $\pm 11 \%$ \\
\hline & Clima tropical montanhoso & 0.96 & $\pm 40 \%$ \\
\hline F $_{\text {MG }}$ Severamente degradada & Todos climas & 0.7 & $\pm 40 \%$ \\
\hline \multirow{3}{*}{$\mathrm{F}_{\mathrm{MG}}$ Melhorada } & Clima temperado & 1.14 & $\pm 11 \%$ \\
\hline & Clima tropical & 1.17 & $\pm 9 \%$ \\
\hline & Clima tropical montanhoso & 1.16 & $\pm 40 \%$ \\
\hline FI Média entrada de insumo* & Todos climas & 1.0 & ND \\
\hline $\mathrm{F}_{\mathrm{I}}$ Entrada alta de insumo $*$ & Todos climas & 1.11 & $\pm 7 \%$ \\
\hline
\end{tabular}

*Aplicáveis apenas para a categoria melhorada Fonte: IPCC (2006).

Logo, utilizando os fatores publicados pelo IPCC e os valores de Bernoux et al. (2002), foram obtidos valores de COS para pastagens segundo três diferentes práticas de manejo (melhorada, moderadamente degradada, severamente degradada) e dois níveis de entrada de matéria orgânica (média e alta).

Quanto aos fatores de uso da terra para pastagens permanentes, todas as áreas independentemente da localização recebem valor um. Quanto às práticas de manejo, o fator para pastagens moderadamente degradadas representa áreas superpastejadas ou moderadamente degradadas, com produtividade um pouco reduzida (em relação às pastagens nativas ou não degradadas) e que não recebem insumos. Já os fatores para pastagens severamente degradadas implicam perda importante de produtividade e cobertura vegetal em longo prazo devido a danos mecânicos severos à vegetação e / ou severa erosão do solo. Fatores para pastagens melhoradas são direcionados a áreas manejadas de forma sustentável com moderada pressão e que recebem pelo menos uma melhoria (por exemplo, fertilização, melhoria de espécies, irrigação) (IPCC, 2006).

Os fatores de mudança de estoque para entrada de matéria orgânica para pastagens são dois: médio, o qual se aplica a áreas melhoradas, onde nenhum insumo adicional de manejo é usado; e, alto, o qual se aplica a áreas melhoradas onde um ou mais insumos / melhorias adicionais de manejo são usadas.

Já para agricultura, foram obtidos valores para duas classes de uso da terra (culturas anuais e perenes) segundo três práticas de manejo (preparo convencional, preparo reduzido e 
plantio direto) e quatro níveis de entrada de matéria orgânica (baixa, média, alta sem aporte de matéria orgânica e alta com aporte de matéria orgânica).

O fator de uso da terra representa a perda de carbono que ocorre após 20 anos de cultivo contínuo (IPCC, 2006). A classe de culturas anuais (ou culturas temporárias) representa área que tem sido continuamente gerenciada por mais de 20 anos, sendo culturas que seu ciclo de vida (plantio e colheita) está compreendido no espaço de até um ano como a soja e feijão, por exemplo. Dentre estas culturas destacam-se as de grãos e cereais, cana-deaçúcar, bulbos, raízes, tubérculos e hortaliças. A classe de culturas perenes (ou culturas permanentes) representa culturas de árvores perenes de longo prazo (culturas que vivem mais de três anos). Nesta categoria estão espécies frutíferas, como laranjeiras, cajueiros, coqueiros, macieiras e bananeiras; espécies produtoras de fibras, como coco-da-baía, espécies oleaginosas; além de espécies como cafeeiros, seringueiras e cacaueiros (IBGE, 2013).

Além desses, com os dados do IPCC foram também calculados valores do COS para áreas de pousio, que representa a prática de interrupção temporária de atividades ou usos agrícolas para possibilitar a recuperação da capacidade de uso ou da estrutura física do solo (BRASIL, 2012)

Fatores de mudança de estoque para as práticas de manejo incluem o preparo convencional, em que há substancial perturbação do solo sendo que no momento do plantio, pouco da superfície é coberta por resíduos (por exemplo, <30\%). Já no preparo reduzido, há redução da perturbação do solo (geralmente superficial e sem inversão total do solo). Normalmente deixando a superfície com $>30 \%$ de cobertura por resíduos no plantio. Por fim, no plantio direto, prática que consiste em semear diretamente no solo sem remover resíduos do cultivo anterior, há apenas um mínimo de perturbação do solo na zona de semeadura e na metodologia do IPCC considera-se o uso de herbicidas para controle de ervas daninhas (IPCC, 2006).

Fatores de mudança de estoque para entrada de matéria orgânica incluem quatro níveis para agricultura. O nível baixo ocorre quando há a remoção de resíduos por meio de coleta ou queima, produção de culturas que geram baixos resíduos (por exemplo: tabaco, algodão), sem fertilização mineral ou culturas fixadoras de nitrogênio. $O$ fator médio é direcionado a cultivos onde todos os resíduos de culturas são devolvidos ao campo. Considerando-se que se os resíduos forem removidos, é adicionada matéria orgânica suplementar (por exemplo, esterco), ou casos em que há fertilização mineral ou cultura de fixação de nitrogênio em rotação (IPCC, 2006). O terceiro nível, alto sem aporte de matéria orgânica, representa culturas com maiores insumos de resíduos em relação aos outros sistemas de cultivo devido a 
práticas adicionais, como a produção de culturas com alto resíduo, uso de adubos verdes, culturas de cobertura, uso frequente de gramíneas perenes em rotações anuais de culturas, mas sem aplicação de adubo. O último fator, alto com aporte de matéria orgânica, representa um aumento significativo na entrada de carbono em relação aos outros sistemas de cultivo devido a uma prática adicional de adição regular de esterco animal (IPCC, 2006). Os resultados dos valores encontrados para cada tipo de uso da terra encontram-se na Tabela 10, 11 e 12 no Apêndice.

Salienta-se aqui que a descrição do procedimento metodológico da obtenção destes fatores é insatisfatória. De acordo com o IPCC, dados experimentais foram analisados em modelos lineares de efeitos mistos, representando tanto efeitos fixos quanto aleatórios. Efeitos fixos incluem profundidade, número de anos desde a mudança de manejo, e o tipo de mudança de manejo (por exemplo, preparo reduzido vs. plantio direto). Admite-se a limitação em utilizar esses fatores, visto a falta de transparência em sua obtenção, mas também pelos valores apresentados no intervalo de erros, os quais não incluem o erro sistemático potencial devido a amostras pequenas que podem não ser representativas do verdadeiro impacto para todas as regiões do mundo.

\subsection{Definição da resolução espacial}

A magnitude dos teores de COS é espacial e temporalmente variável, sendo influenciado por diferentes fatores abióticos e bióticos (WEISSERT et al., 2016). Dentre eles, a temperatura e a precipitação são fatores significativos que controlam a dinâmica de COS (DEB et al., 2015) (Figura 16).

Figura 16: Fatores que afetam o Carbono Orgânico do Solo.

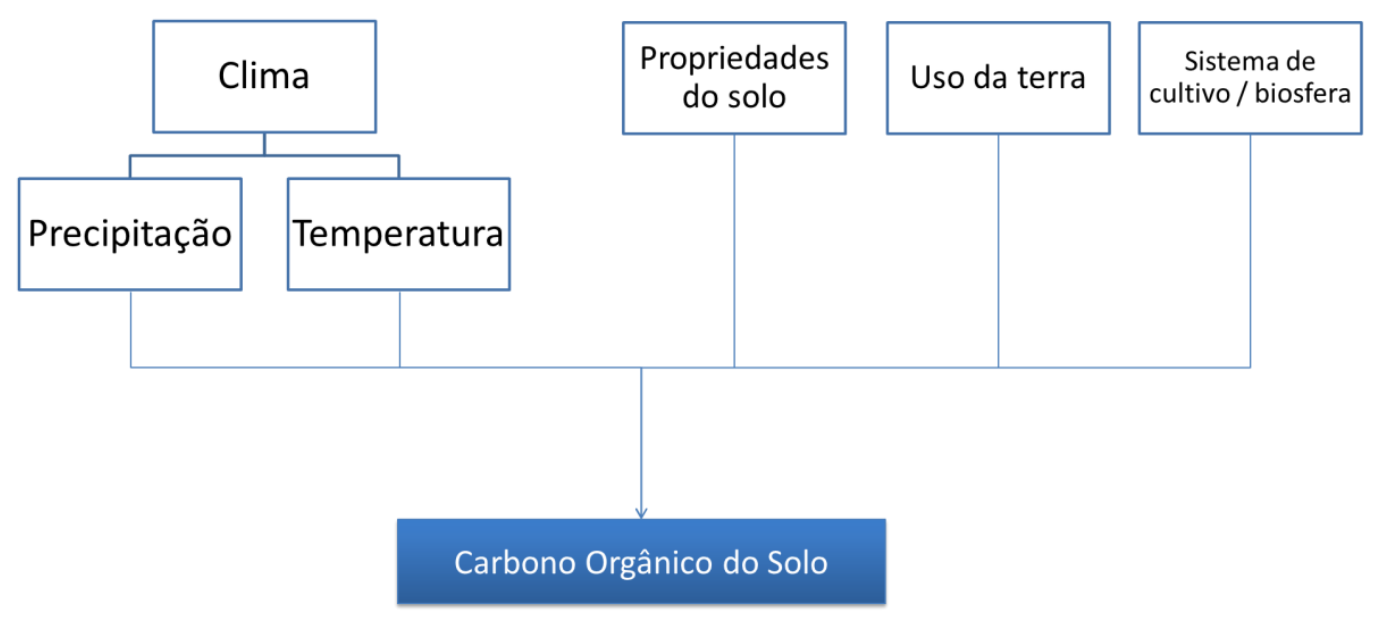

Fonte: Deb et al. (2015). 
Levando em consideração esses fatores e o uso dos dados de Bernoux et al. (2002), foram adotadas como diferenciação espacial as unidades de análise denominadas Associação Solo-Vegetação (ASV). O Quadro 11 a seguir sintetiza os seis tipos de solo com base na classificação proposta pelo IPCC (2003), a qual leva em consideração a textura do solo, a saturação por bases e a umidade além das quinze classes de vegetação organizadas por Bernoux et al. (2002) de acordo com a fisionomia da vegetação e/ou a localização geográfica (Figura 17).

Quadro 11: Classes de solo e vegetação a serem combinadas para constituir as unidades biogeográficas.

\begin{tabular}{|c|c|}
\hline Tipos de Solo & Classes de vegetação \\
\hline S1- solos com argila de atividade alta & V1 - floresta amazônica aberta; \\
\hline S2 - latossolos com argila de atividade baixa & V2 - floresta amazônica densa; \\
\hline S3 - não latossolos com argila de atividade baixa & V3 - floresta atlântica \\
\hline S4 - solos arenosos & V4 - floresta estacional decidual; \\
\hline S5 - solos hidromórficos & V5 - floresta estacional semidecidual; \\
\hline \multirow[t]{10}{*}{ S6 - outros Solos } & V6 - floresta ombrófila mista \\
\hline & V7 - savana sul \\
\hline & V8 - savana amazônica \\
\hline & V9 - cerrado \\
\hline & V10 - estepe do Sul \\
\hline & V11 - estepe nordeste (caatinga) \\
\hline & V12 - estepe oeste (pantanal) \\
\hline & V13 - refúgios ecológicos de montanhas e terras altas \\
\hline & V14 - áreas de formação pioneira \\
\hline & $\begin{array}{l}\text { V15 - áreas arenosas e vegetação lenhosa oligotrófica de } \\
\text { áreas pantanosas. }\end{array}$ \\
\hline
\end{tabular}

Fonte: Baseado em Bernoux et al. (2002).

Das 90 combinações possíveis, 16 são inviáveis e excluídas por falta de dados. Assim, os resultados apresentados no item 8.5 a seguir são distribuídos em 28 classes de uso da terra por 74 unidades ASV (Figura 19). No Quadro 12, disponível no Apêndice, são listadas as unidades ASV presentes em cada estado brasileiro. 
Figura 17: Distribuição das classes de solo.

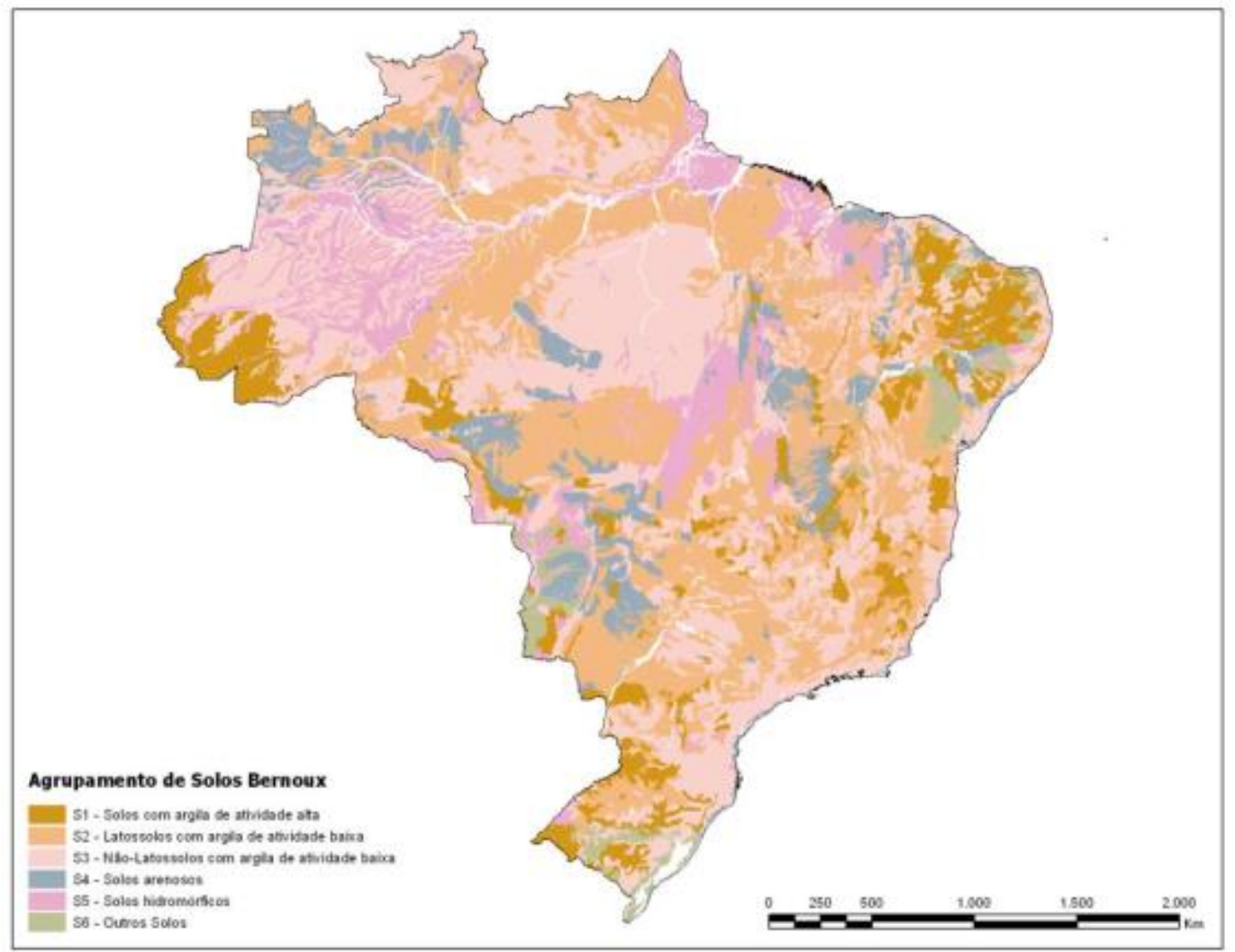

Fonte: Brasil (2016).

Figura 18: Classes de vegetação do Brasil.

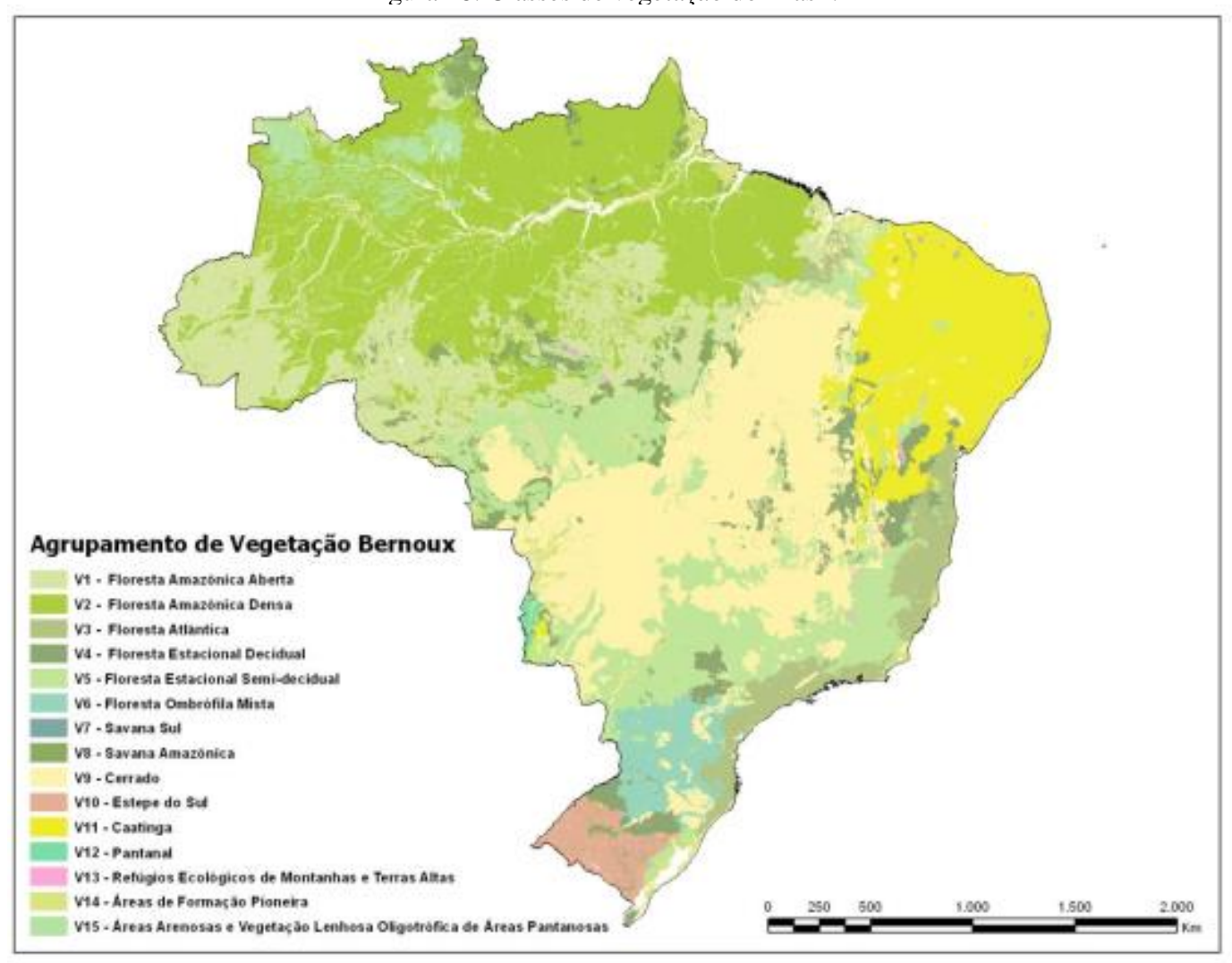

Fonte: Brasil (2016). 
Figura 19: Associações Solo-Vegetação no Brasil

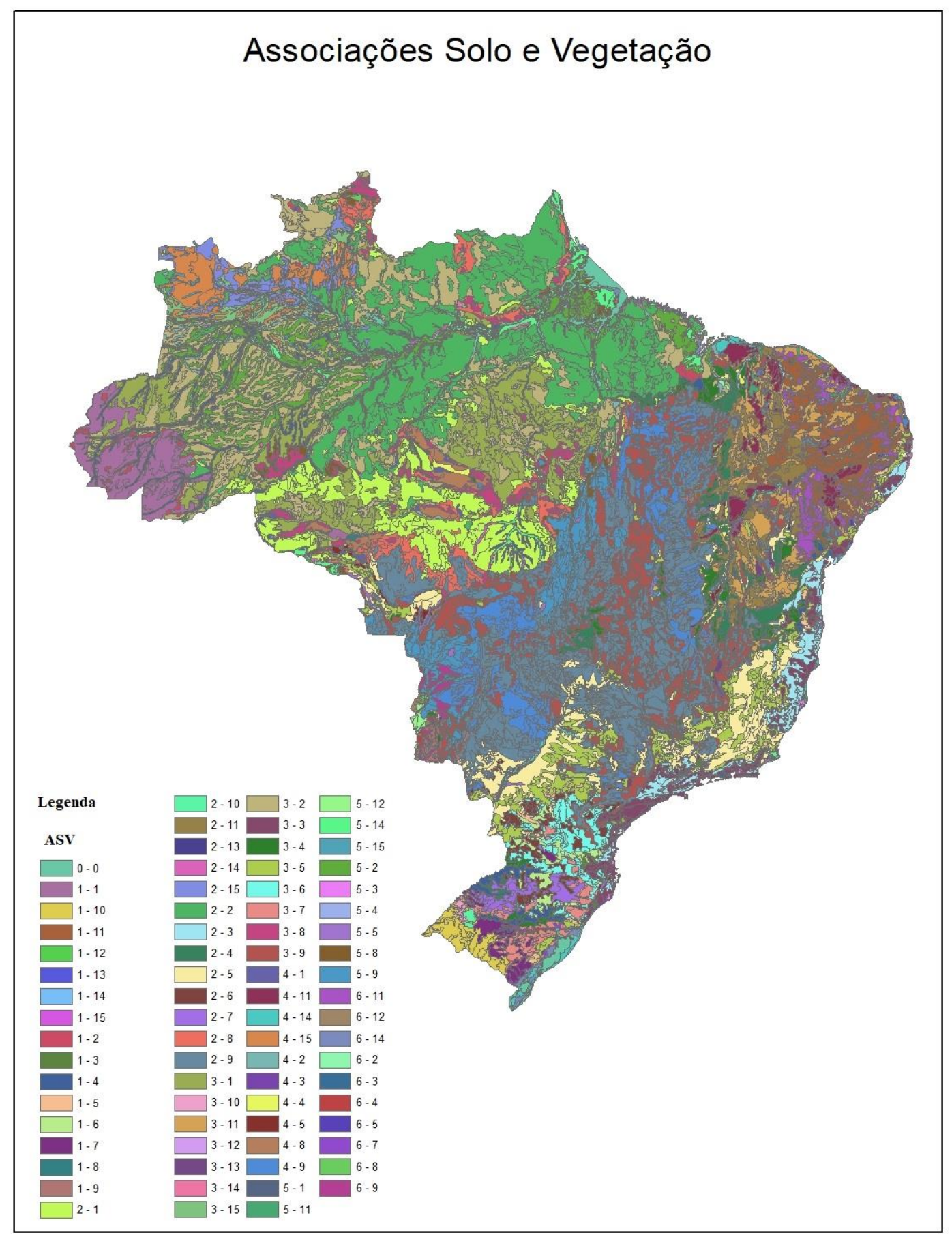

Fonte: elaboração própria a partir dos dados de Bernoux et al. (2002). 


\subsection{Cálculo dos fatores de caracterização}

A seguir são apresentados os resultados dos cálculos dos fatores de caracterização para os impactos de ocupação de diferentes usos da terra explicados anteriormente. Os resultados são apresentados segundo a divisão biogeográfica descrita no item 8.2, de acordo com a distribuição dos tipos de solo e vegetação. Quanto maiores os valores, maior o impacto causado à região. Ressalta-se que valores de fatores de caracterização negativos representam acúmulo de COS, ou seja, o teor de COS no sistema produtivo é maior que no sistema de referência.

A conversão de ecossistemas naturais para a agricultura é conhecida por causar grandes perdas de COS, mas que também dependem das práticas de cultivo e manejo (OGLE et al., 2005; BAYER et al., 2006). A quantidade de carbono armazenada, emitida ou removida de áreas agrícolas depende do tipo de cultura, práticas de manejo e variáveis do solo e do clima. Por exemplo, culturas anuais (cereais, vegetais) são colhidas a cada ano, portanto não há armazenamento em longo prazo de carbono na biomassa. No entanto, a vegetação lenhosa perene em pomares, vinhas e sistemas agroflorestais pode armazenar carbono significativo em biomassa de vida longa, dependendo do tipo de espécie, densidade, taxas de crescimento e práticas de colheita e poda. Os estoques de carbono nos solos podem ser significativos e mudanças nos estoques podem ocorrer em conjunto com as propriedades e práticas de manejo do solo, incluindo tipo e rotação de culturas, preparo do solo, drenagem e manejo de resíduos (IPCC, 2006).

A primeira classe, de culturas anuais (Tabela 3), representa áreas que tenham sido continuamente gerenciadas por mais de 20 anos, com culturas que o ciclo de vida - plantio e colheita - está compreendido no espaço de até um ano (como a soja e feijão). Neste caso os fatores de entrada e manejo também são aplicados para estimar as mudanças no estoque de carbono. 
Tabela 3: Fatores de caracterização para impactos de ocupação causados por culturas anuais (tC/ha) (Continua)

\begin{tabular}{|c|c|c|c|c|c|c|c|c|c|c|c|c|}
\hline \multirow{3}{*}{ ASV } & \multicolumn{12}{|c|}{ Culturas anuais } \\
\hline & \multicolumn{4}{|c|}{ Preparo convencional } & \multicolumn{4}{|c|}{ Preparo reduzido } & \multicolumn{4}{|c|}{ Plantio direto } \\
\hline & B & $\mathbf{M}$ & AS & $\mathbf{A C}$ & B & $\mathbf{M}$ & AS & $\mathbf{A C}$ & B & $\mathbf{M}$ & AS & $\mathrm{AC}$ \\
\hline S1V1 & 28,42 & 26,47 & 23,78 & 15,72 & 25,05 & 22,80 & 19,71 & 10,44 & 23,48 & 21,09 & 17,81 & 7,98 \\
\hline S1V2 & 17,84 & 16,60 & 14,90 & 9,75 & 15,71 & 14,29 & 12,34 & 6,43 & 14,71 & 13,20 & 11,13 & 4,86 \\
\hline S1V3 & 27,51 & 25,00 & 21,71 & 10,72 & 29,61 & 21,34 & 17,68 & 5,48 & 21,92 & 18,95 & 15,06 & $-33,22$ \\
\hline S1V4 & 22,16 & 20,08 & 17,27 & 8,49 & 19,41 & 17,09 & 13,96 & 4,19 & 17,67 & 15,21 & 11,89 & 1,50 \\
\hline S1V5 & 19,74 & 18,11 & 16,05 & 8,53 & 17,35 & 15,54 & 13,23 & 4,87 & 15,82 & 13,89 & 11,43 & 2,52 \\
\hline S1V6 & 43,26 & 38,43 & 31,79 & 11,87 & 37,67 & 32,35 & 25,04 & 3,12 & 33,78 & 28,13 & 20,35 & $-2,97$ \\
\hline S1V7 & 30,65 & 27,73 & 23,72 & 11,69 & 26,81 & 23,56 & 19,09 & 5,68 & 24,47 & 21,01 & 16,26 & 2,01 \\
\hline S1V8 & 19,89 & 26,80 & 22,43 & 14,82 & 23,62 & 21,50 & 18,59 & 9,85 & 22,14 & 19,89 & 16,80 & 7,52 \\
\hline S1V9 & 12,68 & 11,73 & 10,48 & 6,29 & 11,16 & 10,09 & 8,66 & 3,94 & 10,32 & 9,18 & 7,67 & 2,65 \\
\hline S1V10 & 31,15 & 28,12 & 23,95 & 11,45 & 27,23 & 23,86 & 19,23 & 5,32 & 24,79 & 21,21 & 16,28 & 1,50 \\
\hline S1V11 & 11,20 & 10,49 & 9,83 & 5,30 & 9,97 & 9,16 & 8,43 & 3,46 & 8,95 & 8,08 & 7,29 & 1,98 \\
\hline S1V12 & 18,90 & 17,58 & 15,79 & 10,44 & 16,64 & 15,14 & 13,09 & 6,93 & 15,59 & 14,01 & 11,83 & 5,30 \\
\hline S1V13 & 16,90 & 15,63 & 13,85 & 7,75 & 14,85 & 13,37 & 11,35 & 4,51 & 13,65 & 12,07 & 9,93 & 2,66 \\
\hline S1V14 & 31,50 & 31,53 & 27,92 & 22,96 & 8,08 & 27,43 & 23,47 & 18,02 & 1,67 & 24,53 & 20,31 & 14,52 \\
\hline S1V15 & 28,40 & 26,47 & 23,78 & 15,72 & 25,05 & 22,80 & 19,71 & 10,44 & 23,48 & 21,09 & 17,81 & 7,98 \\
\hline $\mathrm{S} 2 \mathrm{~V} 1$ & 26,50 & 24,70 & 22,19 & 14,67 & 23,38 & 21,28 & 18,40 & 9,74 & 21,91 & 19,68 & 16,62 & 7,44 \\
\hline $\mathrm{S} 2 \mathrm{~V} 2$ & 29,00 & 26,99 & 24,25 & 16,02 & 25,54 & 23,25 & 20,10 & 10,64 & 23,94 & 21,51 & 18,16 & 8,13 \\
\hline $\mathrm{S} 2 \mathrm{~V} 3$ & 25,46 & 23,40 & 20,76 & 11,23 & 22,38 & 20,08 & 17,12 & 6,49 & 20,44 & 17,99 & 14,85 & 3,52 \\
\hline S2V4 & 14,22 & 1 & 11 & 6,06 & 12 & 1 & 9,91 & 3,48 & 1 & 10,01 & 8,52 & 1,66 \\
\hline S2V5 & 20,69 & 18,96 & 16,66 & 8,29 & 18,09 & 16,16 & 13,59 & 4,31 & 16,42 & 14,37 & 11,64 & 1,76 \\
\hline S2V6 & 46,35 & 41,47 & 34,76 & 14,62 & 40,43 & 35,04 & 27,62 & 5,36 & 36,50 & 30,77 & 22,88 & $-0,79$ \\
\hline S2V7 & 40,57 & 36,19 & 30,17 & 12,12 & 35,36 & 30,53 & 23,89 & 3,97 & 31,84 & 26,70 & 19,64 & $-1,55$ \\
\hline $\mathrm{S} 2 \mathrm{~V} 8$ & 11,05 & 10,29 & 9,25 & 6,11 & 9,74 & 8,87 & 7,67 & 4,06 & 9,13 & 8,20 & 6,93 & 3,10 \\
\hline S2V9 & 22,76 & 21,12 & 18,92 & 11,67 & 20,03 & 18,16 & 15,66 & 7,43 & 18,59 & 16,61 & 13,95 & 5,21 \\
\hline S2V10 & 26,02 & 24,23 & 21,77 & 14,39 & 22,93 & 20,88 & 18,05 & 9,56 & 21,49 & 19,31 & 16,31 & 7,30 \\
\hline S2V11 & 11,84 & 11,05 & 10,32 & 5,45 & 10,50 & 9,63 & 8,83 & 3,49 & 9,41 & 8,48 & 7,62 & 1,90 \\
\hline S2V12 & - & - & - & - & - & - & - & - & - & - & - & - \\
\hline S2V13 & 23,00 & 21,20 & 19,04 & 9,41 & 20,19 & 18,20 & 15,81 & 5,19 & 18,18 & 16,06 & 13,52 & 2,18 \\
\hline S2V14 & 23,06 & 21,47 & 19,29 & 12,75 & 20,32 & 18,50 & 15,99 & 8,47 & 19,04 & 17,11 & 14,45 & 6,47 \\
\hline S2V15 & 26,13 & 24,34 & 21,86 & 14,45 & 23,03 & 20,97 & 18,12 & 9,60 & 21,59 & 19,39 & 16,38 & 7,34 \\
\hline
\end{tabular}

B: Baixa, M: Médio; AS: Alto sem aporte de matéria orgânica (adubo); AC: Alto com aporte de matéria orgânica (adubo).

Fonte: autoria própria. 
Tabela 3: Fatores de caracterização para impactos de ocupação causados por culturas anuais (tC/ha) (Continuação)

\begin{tabular}{|c|c|c|c|c|c|c|c|c|c|c|c|c|}
\hline \multirow{3}{*}{ ASV } & \multicolumn{12}{|c|}{ Culturas anuais } \\
\hline & \multicolumn{4}{|c|}{ Preparo convencional } & \multicolumn{4}{|c|}{ Preparo reduzido } & \multicolumn{4}{|c|}{ Plantio direto } \\
\hline & $\mathrm{B}$ & M & AS & $\mathrm{AC}$ & B & M & AS & $\mathrm{AC}$ & $\mathrm{B}$ & M & AS & $\mathrm{AC}$ \\
\hline $\mathrm{S} 3 \mathrm{~V} 1$ & 27,25 & 25,37 & 22,78 & 15,02 & 24,02 & 21,86 & 18,88 & 9,96 & 22,50 & 20,21 & 17,05 & 7,58 \\
\hline $\mathrm{S} 3 \mathrm{~V} 2$ & 25,95 & 24,15 & 21,67 & 14,16 & 22,86 & 20,79 & 17,95 & 9,33 & 21,39 & 19,20 & 16,18 & 7,04 \\
\hline S3V3 & 27,46 & 19,50 & 17,14 & 9,42 & 18,68 & 16,69 & 14,04 & 5,39 & 17,14 & 15,03 & 12,21 & 3,02 \\
\hline S3V4 & 19,62 & 18,15 & 16,38 & 9,17 & 17,30 & 15,66 & 13,67 & 5,64 & 15,80 & 14,04 & 11,93 & 3,36 \\
\hline S3V5 & 18,55 & 17,08 & 15,12 & 8,41 & 16,28 & 14,62 & 12,41 & 4,90 & 14,94 & 13,19 & 10,84 & 2,85 \\
\hline S3V6 & 24,70 & 21,91 & 18,07 & 6,56 & 21,50 & 18,43 & 14,21 & $-55,25$ & 19,25 & 15,99 & 11,50 & $-1,97$ \\
\hline S3V7 & 23,49 & 21,04 & 17,68 & 7,59 & 20,49 & 17,79 & 14,07 & 2,91 & 18,53 & 15,65 & 11,69 & $-0,17$ \\
\hline S3V8 & 20,63 & 19,19 & 17,23 & 10,99 & 18,17 & 16,52 & 14,28 & 7,15 & 16,94 & 15,18 & 12,81 & 5,24 \\
\hline S3V9 & 18,62 & 17,26 & 15,44 & 9,26 & 16,37 & 14,83 & 12,77 & 5,78 & 15,14 & 13,50 & 11,31 & 3,88 \\
\hline S3V10 & 33,99 & 31,63 & 28,38 & 18,62 & 29,95 & 27,24 & 23,50 & 12,29 & 28,05 & 25,17 & 21,20 & 9,31 \\
\hline S3V11 & 12,30 & 11,48 & 10,66 & 5,80 & 10,90 & 9,99 & 9,07 & 3,72 & 9,83 & 8,85 & 7,87 & 2,15 \\
\hline S3V12 & 19,66 & 18,30 & 16,45 & 10,87 & 17,32 & 15,77 & 13,63 & 7,22 & 16,24 & 14,59 & 12,32 & 5,52 \\
\hline S3V13 & 12,74 & 11,26 & 9,42 & 1,52 & 10,59 & 8,96 & 6,93 & $-1,73$ & 8,96 & 7,23 & 5,06 & $-4,17$ \\
\hline S3V14 & 18,30 & 17,00 & 15,30 & 10,00 & 16,10 & 14,70 & 12,60 & 6,60 & 15,10 & 13,50 & 11,40 & 4,90 \\
\hline S3V15 & 26,90 & 25,00 & 22,50 & 14,90 & 23,70 & 21,50 & 18,60 & 9,90 & 22,20 & 19,90 & 16,80 & 7,50 \\
\hline S4V1 & 23,00 & 21,40 & 19,20 & 12,70 & 20,20 & 18,40 & 15,90 & 8,40 & 19,00 & 17,00 & 14,40 & 6,40 \\
\hline $\mathrm{S} 4 \mathrm{~V} 2$ & 28,20 & 26,26 & 23,59 & 15,56 & 24,86 & 22,62 & 19,55 & 10,32 & 23,29 & 20,92 & 17,66 & 7,87 \\
\hline S4V3 & 34,60 & 32,16 & 28,85 & 18,57 & 30,49 & 27,69 & 23,91 & 12,16 & 28,46 & 25,50 & 21,48 & 9,00 \\
\hline S4V4 & 13,15 & 12,26 & 11,25 & 6,75 & 11,63 & 10,64 & 9,49 & 4,46 & 10,67 & 9,61 & 8,39 & 3,02 \\
\hline S4V5 & 14,57 & 13,57 & 12,29 & 7,86 & 12,86 & 11,72 & 10,25 & 5,21 & 11,96 & 10,75 & 9,19 & 3,83 \\
\hline S4V6 & - & - & - & - & - & - & - & - & - & - & - & - \\
\hline S4V7 & - & - & - & - & - & - & - & - & - & - & - & - \\
\hline S4V8 & 24,40 & 22,72 & 20,42 & 13,50 & 21,51 & 19,58 & 16,92 & 8,96 & 20,16 & 18,11 & 15,29 & 6,85 \\
\hline S4V9 & 10,44 & 9,73 & 8,79 & 5,66 & 9,21 & 8,40 & 7,32 & 3,75 & 8,59 & 7,72 & 6,57 & 2,78 \\
\hline S4V10 & - & - & - & - & - & - & - & - & - & - & - & - \\
\hline S4V11 & 7,34 & 6,85 & 6,35 & 3,63 & 6,51 & 5,96 & 5,40 & 2,39 & 5,91 & 5,33 & 4,73 & 1,50 \\
\hline S4V12 & - & - & - & - & - & - & - & - & - & - & - & - \\
\hline S4V13 & - & - & - & - & - & - & - & - & - & - & - & - \\
\hline S4V14 & 26,85 & 24,83 & 22,05 & 13,68 & 23,63 & 21,32 & 18,17 & 8,64 & 21,99 & 19,55 & 16,19 & 6,08 \\
\hline S4V15 & 34,30 & 31,93 & 28,68 & 18,85 & 30,23 & 27,50 & 23,76 & 12,48 & 28,31 & 25,42 & 21,45 & 9,48 \\
\hline
\end{tabular}

B: Baixa, M: Médio; AS: Alto sem aporte de matéria orgânica (adubo); AC: Alto com aporte de matéria orgânica (adubo).

Fonte: autoria própria. 
Tabela 3: Fatores de caracterização para impactos de ocupação causados por culturas anuais (tC/ha) (Continuação)

\begin{tabular}{|c|c|c|c|c|c|c|c|c|c|c|c|c|}
\hline \multirow{3}{*}{ ASV } & \multicolumn{12}{|c|}{ Culturas anuais } \\
\hline & \multicolumn{4}{|c|}{ Preparo convencional } & \multicolumn{4}{|c|}{ Preparo reduzido } & \multicolumn{4}{|c|}{ Plantio direto } \\
\hline & B & M & AS & $\mathrm{AC}$ & B & M & AS & $\mathrm{AC}$ & B & M & AS & $\mathrm{AC}$ \\
\hline S5V1 & 24,35 & 22,67 & 20,37 & 13,46 & 21,46 & 19,53 & 16,89 & 8,94 & 20,11 & 18,07 & 15,26 & 43,60 \\
\hline $\mathrm{S} 5 \mathrm{~V} 2$ & 29,43 & 27,40 & 24,62 & 16,27 & 25,94 & 23,61 & 20,41 & 10,81 & 24,31 & 21,84 & 18,44 & 8,26 \\
\hline S5V3 & 19,86 & 18,48 & 16,59 & 10,88 & 17,49 & 15,92 & 13,75 & 7,18 & 16,38 & 14,70 & 13,08 & 5,44 \\
\hline S5V4 & 17,23 & 16,07 & 14,62 & 9,13 & 15,22 & 13,90 & 12,24 & 6,04 & 14,09 & 12,68 & 26,07 & 4,31 \\
\hline S5V5 & 29,38 & 27,37 & 24,69 & 16,03 & 25,91 & 23,61 & 20,53 & 10,64 & 24,19 & 21,75 & 50,06 & 7,97 \\
\hline S5V6 & - & - & - & - & - & - & - & - & - & - & - & - \\
\hline S5V7 & - & - & - & - & - & - & - & - & - & - & - & - \\
\hline S5V8 & 19,28 & 17,96 & 16,14 & 34,32 & 17,00 & 15,47 & 13,38 & 7,07 & 15,92 & 14,31 & 12,09 & 5,39 \\
\hline S5V9 & 37,13 & 34,58 & 31,07 & 20,54 & 32,73 & 29,79 & 25,75 & 13,64 & 30,67 & 27,56 & 23,27 & 10,42 \\
\hline S5V10 & - & - & - & - & - & - & - & - & - & - & - & - \\
\hline S5V11 & 12,81 & 11,95 & 10,95 & 6,61 & 11,33 & 10,36 & 9,23 & 4,36 & 10,41 & 9,37 & 8,17 & 2,98 \\
\hline S5V12 & - & - & - & - & - & - & - & - & - & - & - & - \\
\hline S5V13 & - & - & - & - & - & - & - & - & - & - & - & - \\
\hline S5V14 & 33,06 & 30,78 & 27,66 & 18,28 & 29,14 & 26,52 & 22,93 & 12,14 & 27,31 & 24,53 & 20,72 & 9,28 \\
\hline S5V15 & 50,54 & 47,06 & 42,28 & 27,95 & 44,54 & 40,54 & 35,05 & 18,56 & 41,74 & 37,50 & 31,67 & 14,18 \\
\hline S6V1 & - & - & - & - & - & - & - & - & - & - & - & - \\
\hline S6V2 & 26,86 & 25,01 & 22,47 & 14,85 & 23,67 & 21,55 & 18,63 & 9,87 & 22,19 & 19,93 & 16,83 & 7,54 \\
\hline S6V3 & 233,30 & 217,26 & 195,20 & 129,02 & 205,62 & 187,17 & 161,81 & 85,70 & 192,71 & 173,14 & 146,22 & 65,48 \\
\hline S6V4 & 17,27 & 16,09 & 14,54 & 9,36 & 15,24 & 13,89 & 12,12 & 6,21 & 14,20 & 12,77 & 28,67 & 4,60 \\
\hline S6V5 & 16,07 & 15,00 & 13,75 & 8,27 & 14,22 & 13,01 & 11,60 & 5,46 & 13,05 & 11,76 & 14,34 & 3,71 \\
\hline S6V6 & - & - & - & - & - & - & - & - & - & - & - & - \\
\hline S6V7 & 17,34 & 15,99 & 14,14 & 8,60 & 15,24 & 13,72 & 11,62 & 5,32 & 14,16 & 12,54 & 10,31 & 3,62 \\
\hline S6V8 & 14,29 & 13,28 & 12,08 & 6,89 & 12,60 & 11,47 & 10,13 & 4,34 & 11,51 & 10,31 & 8,88 & 2,71 \\
\hline S6V9 & 18,20 & 16,95 & 15,26 & 10,00 & 16,05 & 14,62 & 12,67 & 6,64 & 15,01 & 13,49 & 11,43 & 5,02 \\
\hline S6V10 & - & - & - & - & - & - & - & - & - & - & - & - \\
\hline S6V11 & 9,68 & 9,05 & 8,48 & 4,57 & 8,60 & 7,90 & 7,28 & 2,99 & 7,71 & 6,97 & 6,30 & 1,70 \\
\hline S6V12 & 12,12 & 11,28 & 10,14 & 6,70 & 10,68 & 9,72 & 8,40 & 4,45 & 10,01 & 8,99 & 7,59 & 3,40 \\
\hline S6V13 & - & - & - & - & - & - & - & - & - & - & - & - \\
\hline S6V14 & 19,52 & 17,99 & 15,89 & 9,55 & 17,16 & 15,42 & 13,04 & 5,86 & 15,92 & 14,08 & 11,55 & 3,92 \\
\hline S6V15 & - & - & - & - & - & - & - & - & - & - & - & - \\
\hline
\end{tabular}

B: Baixa, M: Médio; AS: Alto sem aporte de matéria orgânica (adubo); AC: Alto com aporte de matéria orgânica (adubo).

Fonte: autoria própria 
Cabe destacar que os resultados obtidos aqui, baseados no modelo de caracterização voltado à categoria de Potencial de Produção Biótica, não indicam que categorias de impacto relacionadas à mudança climática e qualidade do solo estejam totalmente alinhadas entre si. Sendo assim, especial atenção deve ser dada pelo usuário que utilizar os fatores de caracterização conjuntamente. Vale ressaltar também que as discussões apresentadas em seguida se referem a apenas impactos potenciais no carbono orgânico do solo, sendo apenas um dos aspectos que influenciam a qualidade do solo dentro de vários indicadores possíveis para avaliações de impacto ambiental e sustentabilidade de sistemas produtivos.

De acordo com os resultados obtidos (Tabela 3), para todas as classes de uso da terra a unidade que apresenta maior fator de caracterização, e por consequência, maior impacto potencial, foi a S6V3 (Outros solos, Mata Atlântica). Em contrapartida, sabe-se que solos arenosos apresentam grande potencial de armazenamento temporário de carbono (MARQUES et al., 2013), o que pode explicar o fato da unidade S4V11 (Solos arenosos, Caatinga) apresentar menor valor, e, portanto, menor impacto potencial, na maioria das classes de uso da terra.

As exceções são encontradas nas classes de preparo convencional de alta entrada de matéria orgânica com aporte de adubo onde o menor impacto é encontrado na unidade S3V13 (Não latossolos com argila de atividade baixa, Refúgios Ecológicos de Montanhas e Terras Altas) e nos casos de preparo reduzido e plantio direto de alta entrada de matéria orgânica com aporte de adubo, em que o menor impacto se dá na unidade S3V6 (Não latossolos com argila de atividade baixa, Floresta Ombrófila Mista) e S1V3 (solos com argila de atividade alta, Mata Atlântica) respectivamente, representando um incremento no teor de carbono no solo. Já na classe de plantio direto de baixa entrada de matéria orgânica o menor valor encontrado e, portanto, a unidade de menor impacto potencial, foi S1V14 (solos com argila de atividade alta, Áreas de Formação Pioneira).

Dentro de uma mesma classe de uso da terra, observa-se uma grande variação nos valores dos fatores de caracterização, como por exemplo, no caso da classe de plantio direto de alta entrada sem aporte de adubo em que o maior valor encontrado é 30 vezes maior que o menor fator de caracterização encontrado na mesma classe.

A Figura 20 a seguir apresenta a dispersão dos valores dos fatores de caracterização para culturas anuais, evidenciando de modo geral a perda de carbono na maioria das ASV representando impactos na qualidade do solo e alguns casos em que há melhoria no teor de COS (e.g. plantio direto de alta entrada de matéria orgânica). 
Figura 20: Distribuição dos resultados dos fatores de caracterização para culturas anuais.

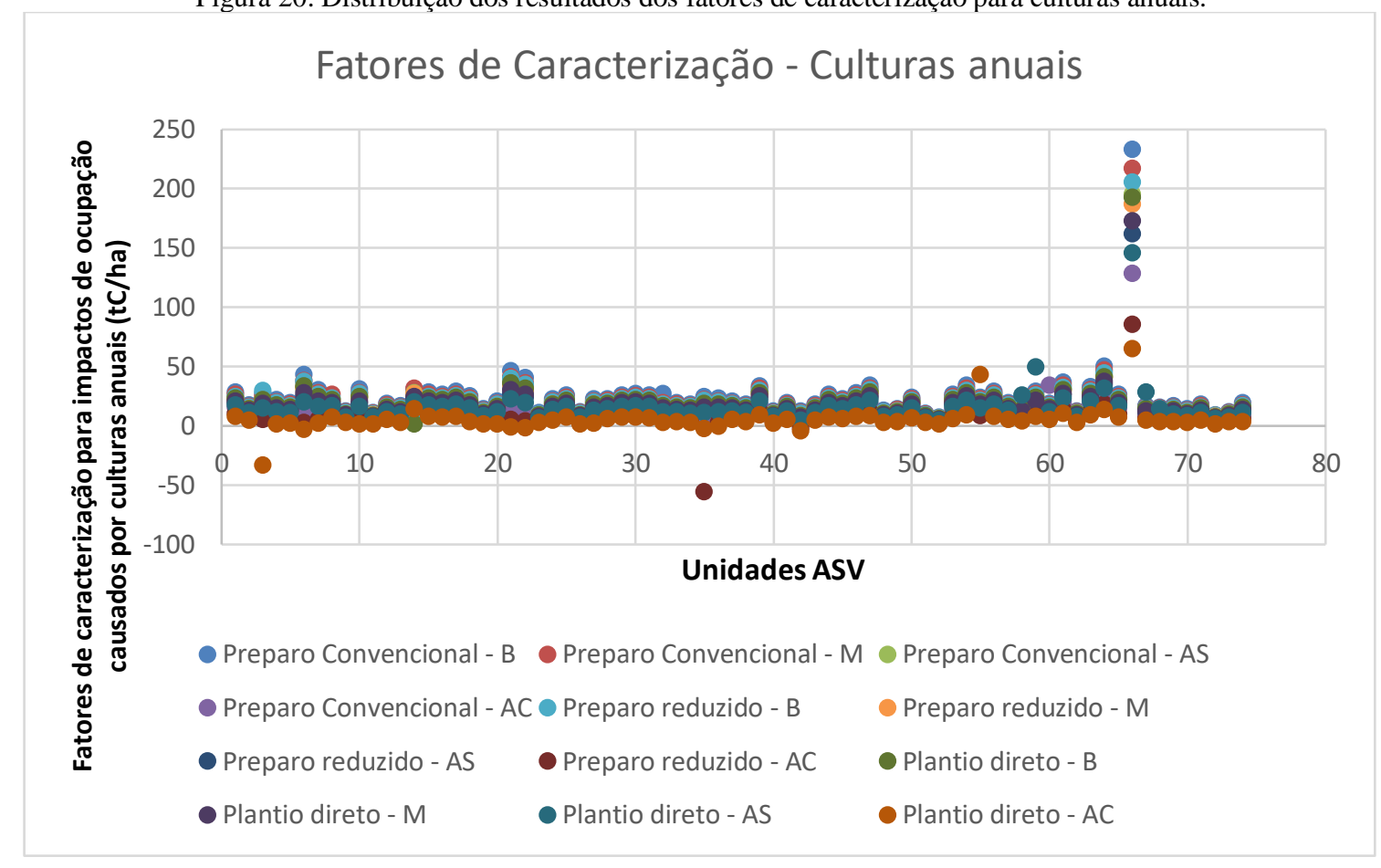

Fonte: elaboração própria.

Já os resultados dos fatores de caracterização para culturas perenes (Tabela 4) mostraram-se mais diversificados, havendo uma predominância de resultados com valores negativos. Nesse sentido, os menores valores encontrados na maioria das classes foram referentes à unidade S6V3 (Outros solos, Mata Atlântica) sendo apenas nas classes de preparo convencional de baixa entrada de matéria orgânica e de alta sem aporte de adubo que a unidade S3V8 (Não latossolos com argila de atividade baixa, Savana Amazônica) obteve os menores resultados.

Analisando os maiores valores encontrados nos fatores de caracterização para culturas perenes, não foi possível encontrar um padrão, sendo a unidade S4V11 (Solos arenosos, Caatinga) que apresenta maiores impactos nas classes de preparo reduzido de média entrada de matéria orgânica e alta com aporte de adubo, e nas classes de plantio direto de média entrada de matéria orgânica e alta (sem e com aporte de adubo). Salienta-se que nestes cinco casos os valores encontrados ainda sim representam uma melhoria nos teores de COS. Nas classes de preparo convencional, os maiores valores foram encontrados nas unidades S6V3 (Outros solos, Mata Atlântica) (para baixa entrada de matéria orgânica) e S2V6 (Latossolos com argila de atividade baixa, Floresta Ombrófila Mista) (para alta entrada de matéria 
orgânica) enquanto nas classes de preparo reduzido (baixa e alta sem aporte de adubo) e plantio direto (baixa entrada de matéria orgânica) os maiores valores encontrados foram na S2V3 (Latossolos com argila de atividade baixa, Mata Atlântica).

Tabela 4: Fatores de caracterização para impactos de ocupação causados por culturas perenes (tC/ha) (Continua)

\begin{tabular}{|c|c|c|c|c|c|c|c|c|c|c|c|c|}
\hline \multirow{3}{*}{ ASV } & \multicolumn{11}{|c|}{ Culturas perenes } & \multirow{3}{*}{ Pousic } \\
\hline & \multicolumn{3}{|c|}{ Preparo convencional } & \multicolumn{4}{|c|}{ Preparo reduzido } & \multicolumn{4}{|c|}{ Plantio direto } & \\
\hline & B & AS & $\mathrm{AC}$ & B & M & AS & $\mathrm{AC}$ & B & M & $\mathrm{AS}$ & $\mathrm{AC}$ & \\
\hline S1V1 & 2,55 & $-5,60$ & $-22,40$ & 0,33 & $-7,64$ & $-14,07$ & $-33,39$ & $-6,23$ & $-11,20$ & $-18,03$ & $-38,52$ & 9,16 \\
\hline S1V2 & 2,56 & $-3,52$ & $-14,15$ & $-1,06$ & $-3,95$ & $-8,82$ & $-21,02$ & $-3,91$ & $-7,03$ & $-11,32$ & $-24,27$ & 5,75 \\
\hline S1V3 & 4,39 & $-5,77$ & $-25,01$ & $-1,83$ & $-6,73$ & $-13,19$ & $-34,65$ & $-5,69$ & $-10,90$ & $-17,77$ & $-40,60$ & 9,49 \\
\hline S1V4 & 3,65 & $-4,93$ & $-20,34$ & $-1,44$ & $-5,53$ & $-11,05$ & $-28,29$ & $-4,49$ & $-8,83$ & $-14,70$ & $-33,02$ & 8,09 \\
\hline S1V5 & 2,94 & $-3,74$ & $-17,24$ & $-1,51$ & $-4,80$ & $-9,00$ & $-24,08$ & $-4,27$ & $-7,77$ & $-12,23$ & $-28,29$ & 6,15 \\
\hline S1V6 & 7,90 & $-10,87$ & $-43,47$ & $-1,76$ & $-10,50$ & $-22,53$ & $-58,60$ & $-8,12$ & $-17,42$ & $-30,21$ & $-68,56$ & 17,78 \\
\hline S1V7 & 5,14 & $-7,06$ & 10,49 & $-1,99$ & $-7,75$ & $-15,66$ & $-39,40$ & $-6,13$ & $-12,24$ & $-20,65$ & $-45,87$ & 11,56 \\
\hline S1V8 & 3,84 & $-5,28$ & $-21,12$ & $-2,78$ & $-7,20$ & $-13,27$ & $-31,49$ & $-5,88$ & $-10,56$ & $-17,00$ & $-36,33$ & 8,64 \\
\hline S1V9 & 1,84 & $-2,45$ & $-10,50$ & $-1,16$ & $-3,25$ & $-6,04$ & $-15,16$ & $-2,77$ & $-4,99$ & $-7,95$ & $-17,65$ & 4,01 \\
\hline S1V10 & 5,28 & $-7,26$ & 13,48 & $-1,93$ & $-7,83$ & $-15,95$ & $-40,32$ & $-6,18$ & $-12,45$ & $-21,08$ & $-46,97$ & 11,88 \\
\hline S1V11 & 1,31 & $-1,21$ & $-9,20$ & $-0,93$ & $-2,38$ & $-3,73$ & $-12,50$ & $-2,73$ & $-4,28$ & $-5,72$ & $-15,12$ & 2,08 \\
\hline S1V12 & 2,70 & $-3,72$ & $-14,87$ & $-1,96$ & $-5,07$ & $-9,35$ & $-22,17$ & $-4,14$ & $-7,44$ & $-11,97$ & $-25,58$ & 6,08 \\
\hline S1V13 & 2,48 & $-3,37$ & $-14,62$ & $-1,53$ & $-4,33$ & $-8,15$ & $-20,83$ & $-3,75$ & $-6,72$ & $-10,77$ & $-24,24$ & 5,38 \\
\hline S1V14 & 5,84 & $-8,03$ & $-32,12$ & $-1,16$ & $-7,60$ & $-12,86$ & $-39,45$ & $-5,86$ & $-12,71$ & $-18,29$ & $-46,58$ & 13,14 \\
\hline S1V15 & 4,07 & $-5,60$ & $-22,40$ & $-2,95$ & $-7,64$ & $-14,07$ & $-33,39$ & $-6,23$ & $-11,20$ & $-18,03$ & $-38,52$ & 9,16 \\
\hline $\mathrm{S} 2 \mathrm{~V} 1$ & 3,80 & $-5,23$ & $-20,90$ & $-2,76$ & $-7,12$ & $-13,13$ & $-31,16$ & $-5,81$ & $-10,45$ & $-16,82$ & $-35,95$ & 8,55 \\
\hline $\mathrm{S} 2 \mathrm{~V} 2$ & 4,15 & $-5,71$ & $-22,84$ & $-3,01$ & $-7,78$ & $-14,35$ & $-34,04$ & $-6,35$ & $-11,42$ & $-18,38$ & $-39,28$ & 9,34 \\
\hline $\mathrm{S} 2 \mathrm{~V} 3$ & 3,76 & $-4,84$ & $-22,10$ & 6,99 & $-6,26$ & $-1,67$ & $-17,90$ & 4,17 & $-10,03$ & $-5,02$ & $-22,26$ & 16,32 \\
\hline $\mathrm{S} 2 \mathrm{~V} 4$ & 1,90 & $-2,25$ & $-12,41$ & $-1,17$ & $-3,28$ & $-5,78$ & $-17,03$ & $-3,30$ & $-5,55$ & $-8,22$ & $-20,22$ & 3,62 \\
\hline $\mathrm{S} 2 \mathrm{~V} 5$ & 3,08 & $-4,10$ & $-18,72$ & $-1,65$ & $-5,09$ & $-9,68$ & $-25,98$ & $-4,56$ & $-8,21$ & $-13,09$ & $-30,42$ & 6,51 \\
\hline S2V6 & 8,19 & 54,10 & 39,48 & $-2,32$ & $-11,43$ & $-23,95$ & $-61,55$ & $-8,92$ & $-18,60$ & $-31,92$ & $-71,88$ & 18,43 \\
\hline S2V7 & 7,27 & $-10,00$ & $-40,00$ & $-1,87$ & $-9,94$ & $-21,03$ & $-54,31$ & $-7,73$ & $-16,31$ & $-28,10$ & $-63,48$ & 16,36 \\
\hline S2V8 & 1,58 & $-2,17$ & $-8,71$ & $-1,15$ & $-2,97$ & $-5,47$ & $-12,98$ & $-2,42$ & $-4,35$ & $-7,01$ & $-14,98$ & 3,56 \\
\hline S2V9 & 3,25 & $-4,38$ & $-18,60$ & $-2,21$ & $-5,92$ & $-10,92$ & $-27,10$ & $-5,03$ & $-8,97$ & $-14,27$ & $-31,53$ & 7,12 \\
\hline S2V10 & 3,73 & $-5,13$ & $-20,50$ & $-2,70$ & $-6,99$ & $-12,88$ & $-30,57$ & $-5,70$ & $-10,25$ & $-16,51$ & $-35,27$ & 8,39 \\
\hline S2V11 & 1,40 & $-1,30$ & $-9,82$ & $-0,97$ & $-2,50$ & $-3,94$ & $-13,28$ & $-2,88$ & $-4,52$ & $-6,06$ & $-16,07$ & 2,21 \\
\hline S2V12 & - & - & - & - & - & - & - & - & - & - & - & - \\
\hline S2V13 & 3,14 & $-3,78$ & $-20,42$ & $-1,83$ & $-5,31$ & $-9,52$ & $-27,91$ & $-5,30$ & $-8,22$ & $-13,49$ & $-33,09$ & 6,06 \\
\hline S2V14 & 3,30 & $-4,54$ & $-18,17$ & $-2,39$ & $-6,19$ & $-11,41$ & $-27,08$ & $-5,05$ & $-9,08$ & $-14,62$ & $-31,25$ & 7,43 \\
\hline S2V15 & 3,74 & $-5,15$ & $-20,59$ & $-2,71$ & $-7,02$ & $-12,94$ & $-30,70$ & $-5,73$ & $-10,30$ & $-16,58$ & $-35,42$ & 8,42 \\
\hline
\end{tabular}

B: Baixa, M: Médio; AS: Alto sem aporte de matéria orgânica (adubo); AC: Alto com aporte de matéria orgânica (adubo).

Fonte: elaboração própria. 
Tabela 4: Fatores de caracterização para impactos de ocupação causados por culturas perenes (tC/ha) (Continuação)

\begin{tabular}{|c|c|c|c|c|c|c|c|c|c|c|c|c|}
\hline \multirow{3}{*}{ ASV } & \multicolumn{11}{|c|}{ Culturas perenes } & \multirow{3}{*}{ Pousio } \\
\hline & \multicolumn{3}{|c|}{ Preparo convencional } & \multicolumn{4}{|c|}{ Preparo reduzido } & \multicolumn{4}{|c|}{ Plantio direto } & \\
\hline & B & AS & $\mathrm{AC}$ & B & M & AS & $\mathrm{AC}$ & B & M & AS & $\mathrm{AC}$ & \\
\hline S3V1 & 3,91 & $-5,38$ & $-21,52$ & $-2,82$ & $-7,32$ & $-32,05$ & $-32,05$ & $-5,97$ & $-10,74$ & $-36,98$ & $-36,98$ & 8,80 \\
\hline $\mathrm{S} 3 \mathrm{~V} 2$ & 3,72 & $-5,11$ & $-20,59$ & 0,25 & $-6,94$ & $-9,29$ & $-26,01$ & $-2,77$ & $-10,23$ & $-12,93$ & $-30,74$ & 8,35 \\
\hline $\mathrm{S} 3 \mathrm{~V} 3$ & 3,26 & $-4,35$ & $-18,50$ & $-1,69$ & $-5,37$ & $-10,28$ & $-26,21$ & $-4,51$ & $-8,42$ & $-13,63$ & $-30,57$ & 7,12 \\
\hline $\mathrm{S} 3 \mathrm{~V} 4$ & 2,73 & $-3,32$ & $-16,50$ & $-1,65$ & $-4,71$ & $-8,45$ & $-23,21$ & $-4,40$ & $-7,66$ & $-11,64$ & $-27,37$ & 5,48 \\
\hline S3V5 & 2,74 & $-3,67$ & $-16,00$ & $-1,60$ & $-4,69$ & $-8,84$ & $-22,74$ & $-4,05$ & $-7,34$ & $-11,75$ & $-26,51$ & 5,93 \\
\hline S3V6 & 4,54 & $-6,25$ & $-25,00$ & $-0,96$ & $-5,98$ & $-12,88$ & $-33,60$ & $-4,61$ & $-9,95$ & $-17,30$ & $-39,32$ & 10,22 \\
\hline S3V7 & 4,13 & $-5,68$ & $-22,70$ & $-1,22$ & $-5,81$ & $-12,12$ & $-31,07$ & $-4,54$ & $-9,42$ & $-16,13$ & $-36,27$ & 9,29 \\
\hline S3V8 & $-51,83$ & $-58,36$ & $-16,60$ & $-2,08$ & $-5,44$ & $-10,01$ & $-24,38$ & $-4,55$ & $-8,13$ & $-12,98$ & $-28,23$ & 6,50 \\
\hline S3V9 & 2,66 & $-3,55$ & $-15,40$ & $-1,77$ & $-4,79$ & $-8,84$ & $-22,30$ & $-4,13$ & $-7,34$ & $-11,63$ & $-25,94$ & 5,75 \\
\hline S3V10 & 4,90 & $-6,73$ & $-26,90$ & $-3,49$ & $-9,11$ & $-16,85$ & $-40,05$ & $-7,43$ & $-13,40$ & $-21,60$ & $-46,22$ & 11,02 \\
\hline S3V11 & 1,50 & $-1,51$ & $-10,20$ & $-1,04$ & $-2,70$ & $-4,38$ & $-13,92$ & $-2,95$ & $-4,72$ & $-6,52$ & $-16,72$ & 2,54 \\
\hline S3V12 & 2,82 & $-3,87$ & $-15,50$ & $-2,04$ & $-5,28$ & $-9,73$ & $-23,09$ & $-4,31$ & $-7,74$ & $-12,47$ & $-26,64$ & 6,34 \\
\hline S3V13 & 2,60 & $-3,35$ & $-16,50$ & $-1,31$ & $-4,19$ & $-7,91$ & $-22,46$ & $-3,98$ & $-7,05$ & $-11,00$ & $-26,49$ & 5,28 \\
\hline S3V14 & 2,65 & $-3,64$ & $-14,60$ & $-1,87$ & $-4,91$ & $-9,09$ & $-21,63$ & $-3,85$ & $-7,22$ & $-11,66$ & $-24,97$ & 5,96 \\
\hline S3V15 & 3,85 & $-5,29$ & $-21,20$ & $-2,79$ & $-7,22$ & $-13,30$ & $-31,55$ & $-5,89$ & $-10,58$ & $-17,04$ & $-36,40$ & 8,66 \\
\hline S4V1 & 3,29 & $-4,52$ & $-18,10$ & $-2,38$ & $-6,16$ & $-11,36$ & $-26,96$ & $-5,03$ & $-9,04$ & $-14,56$ & $-31,10$ & 7,40 \\
\hline S4V2 & 4,04 & $-5,56$ & $-22,30$ & $-2,92$ & $-7,57$ & $-13,96$ & $-33,16$ & $-6,18$ & $-11,11$ & $-17,89$ & $-38,26$ & 9,09 \\
\hline S4V3 & 4,98 & $-6,76$ & $-27,60$ & $-3,46$ & $-9,32$ & $-16,91$ & $-40,83$ & $-7,16$ & $-13,78$ & $-21,85$ & $-47,23$ & 11,07 \\
\hline S4V4 & 1,71 & $-2,01$ & $-10,60$ & $-1,23$ & $-18,81$ & $-5,44$ & $-15,03$ & $-3,04$ & $-21,76$ & $-7,52$ & $-17,75$ & $-8,62$ \\
\hline S4V5 & 2,02 & $-2,64$ & $-11,60$ & $-1,46$ & $-3,77$ & $-6,80$ & $-16,95$ & $-3,25$ & $-5,71$ & $-8,92$ & $-19,72$ & 4,35 \\
\hline S4V6 & - & - & - & - & - & - & - & - & - & - & - & - \\
\hline S4V7 & - & - & - & - & - & - & - & - & - & - & - & - \\
\hline S4V8 & 3,50 & $-4,81$ & $-19,20$ & $-2,53$ & $-6,56$ & $-12,08$ & $-28,67$ & $-5,35$ & $-9,61$ & $-15,48$ & $-33,07$ & 7,87 \\
\hline S4V9 & 1,46 & $-1,94$ & $-8,20$ & $-1,06$ & $-21,59$ & $-4,96$ & $-12,19$ & $-2,32$ & $-24,14$ & $-6,46$ & $-14,15$ & $-11,05$ \\
\hline S4V10 & - & - & - & - & - & - & - & - & - & - & - & - \\
\hline S4V11 & 0,91 & $-0,96$ & $-5,90$ & $-0,65$ & $-1,67$ & $-2,75$ & $-8,72$ & $-1,74$ & $-2,82$ & $-3,98$ & $-10,36$ & 1,62 \\
\hline S4V12 & - & - & - & - & - & - & - & - & - & - & - & - \\
\hline S4V13 & - & - & - & - & - & - & - & - & - & - & - & - \\
\hline S4V14 & 4,05 & $-5,44$ & $-22,00$ & $-2,47$ & $-7,03$ & $-13,30$ & $-32,18$ & $-5,70$ & $-10,55$ & $-17,19$ & $-37,24$ & 9,03 \\
\hline S4V15 & $-13,05$ & $-24,59$ & $-27,10$ & $-3,55$ & $-9,20$ & $-19,76$ & $-40,36$ & $-7,52$ & $-13,52$ & $-24,72$ & $-46,58$ & 11,05 \\
\hline
\end{tabular}

B: Baixa, M: Médio; AS: Alto sem aporte de matéria orgânica (adubo); AC: Alto com aporte de matéria orgânica (adubo).

Fonte: elaboração própria. 
Tabela 4: Fatores de caracterização para impactos de ocupação causados por culturas perenes (tC/ha) (Continuação)

\begin{tabular}{|c|c|c|c|c|c|c|c|c|c|c|c|c|}
\hline \multirow{3}{*}{ ASV } & \multicolumn{11}{|c|}{ Culturas perenes } & \multirow{3}{*}{ Pousio } \\
\hline & \multicolumn{3}{|c|}{ Preparo convencional } & \multicolumn{4}{|c|}{ Preparo reduzido } & \multicolumn{4}{|c|}{ Plantio direto } & \\
\hline & $\mathrm{B}$ & AS & $\mathrm{AC}$ & $\mathrm{B}$ & $\mathrm{M}$ & AS & $\mathrm{AC}$ & $\mathrm{B}$ & $\mathrm{M}$ & $\mathrm{AS}$ & $\mathrm{AC}$ & \\
\hline S4V15 & $-13,05$ & $-24,59$ & $-27,10$ & $-3,55$ & $-9,20$ & $-19,76$ & $-40,36$ & $-7,52$ & $-13,52$ & $-24,72$ & $-46,58$ & 11,05 \\
\hline S5V1 & 3,49 & $-4,80$ & $-19,20$ & $-2,53$ & $-6,54$ & $-12,06$ & $-28,60$ & $-5,34$ & $-9,59$ & $-15,44$ & $-33,00$ & 7,85 \\
\hline S5V2 & 4,22 & $-5,80$ & $-23,20$ & $-3,06$ & $-7,91$ & $-14,57$ & $-34,57$ & $-6,45$ & $-11,59$ & $-18,67$ & $-39,88$ & 9,49 \\
\hline S5V3 & 2,85 & $-3,91$ & $-15,70$ & $-2,05$ & $-5,32$ & $-9,81$ & $-23,38$ & $-4,35$ & $-7,83$ & $-12,59$ & $-26,99$ & 6,39 \\
\hline S5V4 & 2,33 & $-2,94$ & $-13,70$ & $-1,69$ & $-4,34$ & $-7,70$ & $-19,92$ & $-3,90$ & $-6,72$ & $-10,29$ & $-23,30$ & 4,85 \\
\hline S5V5 & 4,14 & $-5,54$ & $-23,20$ & $-3,00$ & $-7,74$ & $-14,10$ & $-34,35$ & $-6,51$ & $-11,54$ & $-18,30$ & $-39,79$ & 9,10 \\
\hline S5V6 & - & - & - & - & - & - & - & - & - & - & - & - \\
\hline S5V7 & - & - & - & - & - & - & - & - & - & - & - & - \\
\hline S5V8 & 2,76 & $-3,78$ & $-15,20$ & $-2,00$ & $-5,17$ & $-9,52$ & $-22,64$ & $-4,23$ & $-7,59$ & $-12,21$ & $-26,13$ & 6,19 \\
\hline S5V9 & 5,32 & $-7,32$ & $-29,30$ & $-3,86$ & $-9,98$ & $-18,39$ & $-43,62$ & $-8,14$ & $-14,63$ & $-23,55$ & $-50,33$ & 11,97 \\
\hline S5V10 & - & - & - & - & - & - & - & - & - & - & - & - \\
\hline S5V11 & 5,33 & 3,17 & $-3,70$ & $-1,21$ & $-3,10$ & $-5,36$ & $-14,67$ & $-2,95$ & $-4,97$ & $-7,37$ & $-17,30$ & 3,30 \\
\hline S5V12 & - & - & - & - & - & - & - & - & - & - & - & - \\
\hline S5V13 & - & - & - & - & - & - & - & - & - & - & - & - \\
\hline S5V14 & 4,74 & $-6,51$ & $-26,00$ & $-3,43$ & $-8,88$ & $-16,37$ & $-38,84$ & $-7,25$ & $-13,02$ & $-20,97$ & $-44,80$ & 10,66 \\
\hline S5V15 & 7,24 & $-9,96$ & $-39,80$ & $-5,25$ & $-13,58$ & $-25,02$ & $-59,37$ & $-11,08$ & $-19,91$ & $-32,06$ & $-68,49$ & 16,29 \\
\hline S6V1 & - & - & - & - & - & - & - & - & - & - & - & - \\
\hline S6V2 & 3,85 & $-5,29$ & $-21,20$ & $-2,79$ & $-7,22$ & $-13,30$ & $-31,55$ & $-5,89$ & $-10,58$ & $-17,04$ & $-36,40$ & 8,66 \\
\hline S6V3 & 33,42 & $-45,96$ & $-183,83$ & $-24,23$ & $-62,67$ & $-115,52$ & $-274,08$ & $-51,14$ & $-91,92$ & $-147,98$ & $-316,19$ & 75,20 \\
\hline S6V4 & 2,41 & $-3,19$ & $-13,70$ & $-1,74$ & $-4,50$ & $-8,16$ & $-20,14$ & $-3,84$ & $-6,77$ & $-10,65$ & $-23,38$ & 5,24 \\
\hline S6V5 & 2,10 & $-2,47$ & $-12,90$ & $-1,51$ & $-3,88$ & $-6,69$ & $-18,39$ & $-3,71$ & $-6,23$ & $-9,22$ & $-21,70$ & 4,11 \\
\hline S6V6 & - & - & - & - & - & - & - & - & - & - & - & - \\
\hline S6V7 & 2,62 & $-3,61$ & $-14,40$ & $-1,58$ & $-4,57$ & $-8,68$ & $-21,01$ & $-3,69$ & $-6,86$ & $-11,22$ & $-24,31$ & 5,90 \\
\hline S6V8 & 1,99 & $-2,41$ & $-12,00$ & $-1,43$ & $-3,68$ & $-6,42$ & $-17,21$ & $-3,43$ & $-5,82$ & $-8,74$ & $-20,23$ & 3,99 \\
\hline S6V9 & 2,59 & $-3,51$ & $-14,40$ & $-1,87$ & $-4,84$ & $-8,88$ & $-21,33$ & $-4,01$ & $-7,16$ & $-11,44$ & $-24,66$ & 5,75 \\
\hline S6V10 & - & - & - & - & - & - & - & - & - & - & - & - \\
\hline S6V11 & 1,13 & $-1,03$ & $-7,90$ & $-0,80$ & $-2,04$ & $-3,18$ & $-10,75$ & $-2,36$ & $-3,69$ & $-4,90$ & $-13,02$ & 1,76 \\
\hline S6V12 & 1,74 & $-2,39$ & $-9,50$ & $-1,26$ & $-3,26$ & $-6,00$ & $-14,24$ & $-2,66$ & $-4,77$ & $-7,69$ & $-16,42$ & 3,91 \\
\hline S6V13 & - & - & - & - & - & - & - & - & - & - & - & - \\
\hline S6V14 & 2,97 & $-4,07$ & $-16,35$ & $-1,75$ & $-5,12$ & $-9,76$ & $-23,72$ & $-4,14$ & $-7,73$ & $-12,65$ & $-27,48$ & 6,67 \\
\hline S6V15 & - & - & - & - & - & - & - & - & - & - & - & - \\
\hline
\end{tabular}

B: Baixa, M: Médio; AS: Alto sem aporte de matéria orgânica (adubo); AC: Alto com aporte de matéria orgânica (adubo).

Fonte: elaboração própria. 
Segundo Ghimire et al. (2018), culturas forrageiras perenes aumentam a qualidade, disponibilidade e diversidade do substrato microbiano do solo melhorando assim o armazenamento do COS, o que está de acordo com os resultados encontrados. Ademais, culturas perenes, particularmente leguminosas, têm grande potencial para melhorar a qualidade do solo e aumentar a sustentabilidade em sistemas esgotados e intensamente cultivados (LADONI et al., 2016). A adição de resíduos orgânicos também pode colaborar no ciclo de nutrientes e teores de COS, assim, influenciar positivamente os processos do solo de forma a levar ao desenvolvimento de sistemas sustentáveis. A Figura 21 a seguir apresenta a variação nos resultados dos fatores de caracterização para os diferentes níveis de manejo em culturas perenes, incluindo casos em que existe significativa potencial melhoria na qualidade do solo (e.g. plantio direto com alta entrada de matéria orgânica e adubagem).

Figura 21: Distribuição dos resultados dos fatores de caracterização para culturas perenes.

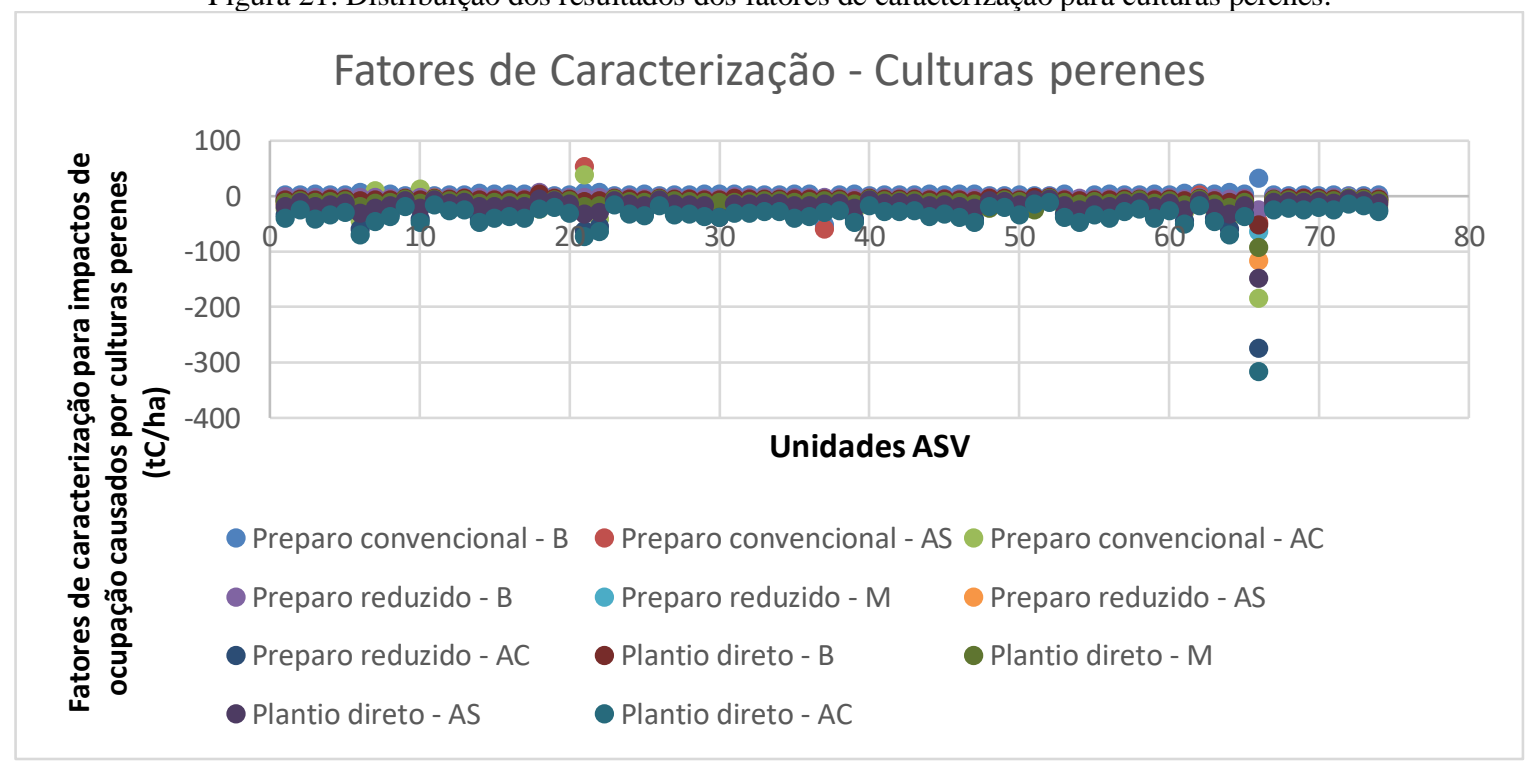

Fonte: elaboração própria.

No que se refere às áreas de pousio, observa-se que a unidade S6V3 (Outros solos, Mata Atlântica) apresenta o maior valor de fator de caracterização e a S4V9 (Solos arenosos, Cerrado) o menor valor, representando uma melhoria na qualidade do solo.

Além destes, também foram obtidos fatores de caracterização para as seguintes classes de pastagem:

- Não degradada: representando pastagens não degradadas e manejadas de forma sustentável, mas sem melhorias significativas no manejo. 
- Moderadamente degradada: representando pastagens superexploradas (onde é comum o solo ficar descoberto) ou moderadamente degradadas com produtividade um pouco reduzida (em relação às pastagens nativas) e não recebendo insumos de manejo.

- Severamente degradada: implica perda importante de produtividade e cobertura vegetal devido a danos mecânicos severos à vegetação e / ou severa erosão do solo.

- Pastagens melhoradas: representando pastagens que são manejadas moderada pressão e que recebem pelo menos uma melhoria (por exemplo, fertilização, melhoria de espécies, irrigação).

A classe de pastagens melhoradas é subdivida em duas classes de acordo com a entrada de matéria orgânica: (i) Média entrada de insumo e (ii) Alta entrada de insumo, onde um ou mais insumos (ou melhorias adicionais de manejo) são usados.

O manejo das pastagens (roçada, intensidade de pastejo, adubação nitrogenada) é conhecido por afetar o equilíbrio do COS (CONANT et al., 2001; SOUSSANA et al., 2004, 2007), o que é evidenciado na variação dos resultados apresentados na Tabela 5. 
Tabela 5: Fatores de caracterização para impactos de ocupação causados por atividades de pastagem (tC/ha) (Continua)

\begin{tabular}{|c|c|c|c|c|}
\hline \multirow{3}{*}{ ASV } & \multicolumn{4}{|c|}{ Pastagem } \\
\hline & \multicolumn{2}{|c|}{ Melhorada } & \multirow{2}{*}{$\begin{array}{c}\text { Moderadamente } \\
\text { degradada }\end{array}$} & \multirow{2}{*}{$\begin{array}{l}\text { Severamente } \\
\text { degradada }\end{array}$} \\
\hline & $\begin{array}{l}\text { Média entrada de } \\
\text { insumo }\end{array}$ & $\begin{array}{c}\text { Alta entrada de } \\
\text { insumo }\end{array}$ & & \\
\hline S1V1 & $-8,65$ & $-8,65$ & 1,53 & 15,30 \\
\hline S1V2 & $-5,46$ & $-9,61$ & 0,98 & 9,70 \\
\hline S1V3 & $-9,28$ & $-16,72$ & 2,17 & 17,50 \\
\hline S1V4 & $-7,38$ & $-13,33$ & 1,77 & 14,00 \\
\hline S1V5 & $-6,68$ & $-11,92$ & 1,41 & 12,30 \\
\hline S1V6 & $-14,95$ & $-27,46$ & 4,20 & 29,60 \\
\hline S1V7 & $-10,11$ & $-18,28$ & 2,46 & 19,30 \\
\hline S1V8 & $-8,16$ & $-14,34$ & 1,44 & 14,40 \\
\hline S1V9 & $-4,07$ & $-6,96$ & 1,00 & 7,30 \\
\hline S1V10 & $-10,33$ & $-18,73$ & 2,57 & 19,80 \\
\hline S1V11 & $-4,11$ & $-7,23$ & 0,73 & 7,30 \\
\hline S1V12 & $-5,75$ & $-10,10$ & 1,01 & 10,14 \\
\hline S1V13 & $-5,79$ & $-9,59$ & 1,16 & 10,20 \\
\hline S1V14 & $-10,98$ & $-20,21$ & 3,15 & 21,90 \\
\hline S1V15 & $-8,65$ & $-15,20$ & 1,53 & 15,30 \\
\hline S2V1 & $-8,08$ & $-14,19$ & 1,43 & 14,20 \\
\hline $\mathrm{S} 2 \mathrm{~V} 2$ & $-8,82$ & $-15,50$ & 1,56 & 15,60 \\
\hline S2V3 & $-8,57$ & $-15,26$ & 1,80 & 15,70 \\
\hline S2V4 & $-5,13$ & $-9,08$ & 1,03 & 9,20 \\
\hline S2V5 & $-7,24$ & $-12,91$ & 1,59 & 13,30 \\
\hline S2V6 & $-15,74$ & $-28,75$ & 4,20 & 30,70 \\
\hline S2V7 & $-13,87$ & $-25,40$ & 3,78 & 27,30 \\
\hline S2V8 & $-3,31$ & $-5,91$ & 0,59 & 5,90 \\
\hline S2V9 & $-7,25$ & $-20,58$ & 1,36 & 12,90 \\
\hline S2V10 & $-7,92$ & $-13,92$ & 1,40 & 14,00 \\
\hline S2V11 & $-4,37$ & $-7,69$ & 0,79 & 7,70 \\
\hline S2V12 & - & - & - & - \\
\hline S2V13 & $-8,34$ & $-14,80$ & 1,73 & 15,10 \\
\hline S2V14 & $-7,02$ & $-12,34$ & 1,24 & 12,40 \\
\hline S2V15 & $-7,96$ & $-13,98$ & 1,40 & 14,00 \\
\hline
\end{tabular}

Fonte: elaboração própria. 
Tabela 5: Fatores de caracterização para impactos de ocupação causados por atividades de pastagem (tC/ha) (Continuação)

\begin{tabular}{|c|c|c|c|c|}
\hline \multirow{3}{*}{ ASV } & \multicolumn{4}{|c|}{ Pastagem } \\
\hline & \multicolumn{2}{|c|}{ Melhorada } & \multirow{2}{*}{$\begin{array}{c}\text { Moderadamente } \\
\text { degradada }\end{array}$} & \multirow{2}{*}{$\begin{array}{c}\text { Severamente } \\
\text { degradada }\end{array}$} \\
\hline & $\begin{array}{l}\text { Média entrada de } \\
\text { insumo }\end{array}$ & $\begin{array}{l}\text { Entrada alta de } \\
\text { insumo }\end{array}$ & & \\
\hline S3V1 & $-8,31$ & $-14,60$ & 1,47 & 14,70 \\
\hline S3V2 & $-7,96$ & $-13,99$ & 1,42 & 14,10 \\
\hline S3V3 & $-6,98$ & $-12,47$ & 1,50 & 12,90 \\
\hline S3V4 & $-6,65$ & $-11,78$ & 5,43 & 12,00 \\
\hline S3V5 & $-6,17$ & $-10,96$ & 1,28 & 11,20 \\
\hline S3V6 & $-8,57$ & $-15,76$ & 36,89 & 17,00 \\
\hline S3V7 & $-7,94$ & $-14,49$ & 2,10 & 15,50 \\
\hline S3V8 & $-6,45$ & $-11,35$ & 1,17 & 11,40 \\
\hline S3V9 & $-6,04$ & $-10,66$ & 1,16 & 10,80 \\
\hline S3V10 & $-10,38$ & $-18,25$ & 1,85 & 18,40 \\
\hline S3V11 & $-4,44$ & $-7,81$ & 0,80 & 7,90 \\
\hline S3V12 & $-5,98$ & $-10,51$ & 1,06 & 10,60 \\
\hline S3V13 & $-6,49$ & $-11,60$ & 1,46 & 12,00 \\
\hline S3V14 & $-5,60$ & $-9,86$ & 1,01 & 9,90 \\
\hline S3V15 & $-8,18$ & $-14,37$ & 1,44 & 14,40 \\
\hline S4V1 & $-6,99$ & $-12,28$ & 1,23 & 12,30 \\
\hline S4V2 & $-8,60$ & $-15,11$ & 1,52 & 15,20 \\
\hline S4V3 & $-10,69$ & $-18,83$ & 1,94 & 19,00 \\
\hline S4V4 & $-4,40$ & $-7,74$ & 0,78 & 7,80 \\
\hline S4V5 & $-4,59$ & $-8,06$ & 0,81 & 8,10 \\
\hline S4V6 & - & - & - & - \\
\hline S4V7 & - & - & - & - \\
\hline S4V8 & $-7,43$ & $-13,05$ & 1,31 & 13,10 \\
\hline S4V9 & $-3,26$ & $-5,73$ & 0,58 & 5,80 \\
\hline S4V10 & - & - & - & - \\
\hline S4V11 & $-2,57$ & $-4,51$ & 0,45 & 4,50 \\
\hline S4V12 & - & - & - & - \\
\hline S4V13 & - & - & - & - \\
\hline S4V14 & $-8,30$ & 7,24 & 1,67 & 15,10 \\
\hline S4V15 & $-10,48$ & $-18,42$ & 1,86 & 18,50 \\
\hline
\end{tabular}

Fonte: elaboração própria. 
Tabela 5: Fatores de caracterização para impactos de ocupação causados por atividades de pastagem (tC/ha) (Continuação)

\begin{tabular}{|c|c|c|c|c|}
\hline \multirow{3}{*}{ ASV } & \multicolumn{4}{|c|}{ Pastagem } \\
\hline & \multicolumn{2}{|c|}{ Melhorada } & \multirow{2}{*}{$\begin{array}{c}\text { Moderadamente } \\
\text { degradada }\end{array}$} & \multirow{2}{*}{$\begin{array}{c}\text { Severamente } \\
\text { degradada }\end{array}$} \\
\hline & $\begin{array}{l}\text { Média entrada de } \\
\text { insumo }\end{array}$ & $\begin{array}{l}\text { Entrada alta de } \\
\text { insumo }\end{array}$ & & \\
\hline S5V1 & $-7,41$ & $-13,02$ & 1,31 & 13,10 \\
\hline S5V2 & $-8,96$ & $-15,74$ & 1,58 & 15,80 \\
\hline S5V3 & $-6,08$ & $-10,68$ & 1,08 & 10,70 \\
\hline S5V4 & $-5,56$ & $-9,77$ & 0,98 & 14,60 \\
\hline S5V5 & $-9,11$ & $-16,01$ & 1,61 & 16,10 \\
\hline S5V6 & - & - & - & - \\
\hline S5V7 & - & - & - & - \\
\hline S5V8 & $-5,88$ & $-10,34$ & 1,04 & 10,40 \\
\hline S5V9 & $-11,31$ & $-19,86$ & 2,00 & 19,90 \\
\hline S5V10 & - & - & - & - \\
\hline S5V11 & $-4,27$ & $-7,50$ & 0,75 & 10,50 \\
\hline S5V12 & - & - & - & - \\
\hline S5V13 & - & - & - & - \\
\hline S5V14 & $-10,06$ & $-17,68$ & 1,78 & 17,80 \\
\hline S5V15 & $-15,39$ & $-27,03$ & 2,72 & 27,10 \\
\hline S6V1 & - & - & - & - \\
\hline S6V2 & $-8,18$ & $-14,37$ & 1,44 & 14,40 \\
\hline S6V3 & $-71,03$ & $-124,80$ & 12,53 & 125,30 \\
\hline S6V4 & $-5,41$ & $-9,50$ & 0,95 & 9,50 \\
\hline S6V5 & $-5,37$ & $-9,44$ & 0,95 & 9,50 \\
\hline S6V6 & - & - & - & - \\
\hline S6V7 & $-5,42$ & $-9,63$ & 1,09 & 9,80 \\
\hline S6V8 & $-4,93$ & $-8,66$ & 0,87 & 8,70 \\
\hline S6V9 & $-5,59$ & $-9,83$ & 0,99 & 9,90 \\
\hline S6V10 & - & - & - & - \\
\hline S6V11 & $-3,55$ & $-6,24$ & 0,63 & 6,30 \\
\hline S6V12 & $-3,69$ & $-6,48$ & 0,65 & 6,50 \\
\hline S6V13 & - & - & - & - \\
\hline S6V14 & $-6,13$ & $-10,90$ & 1,24 & 11,20 \\
\hline S6V15 & - & - & - & - \\
\hline
\end{tabular}

Fonte: elaboração própria. 
Figura 22: Distribuição dos resultados dos fatores de caracterização para pastagens.

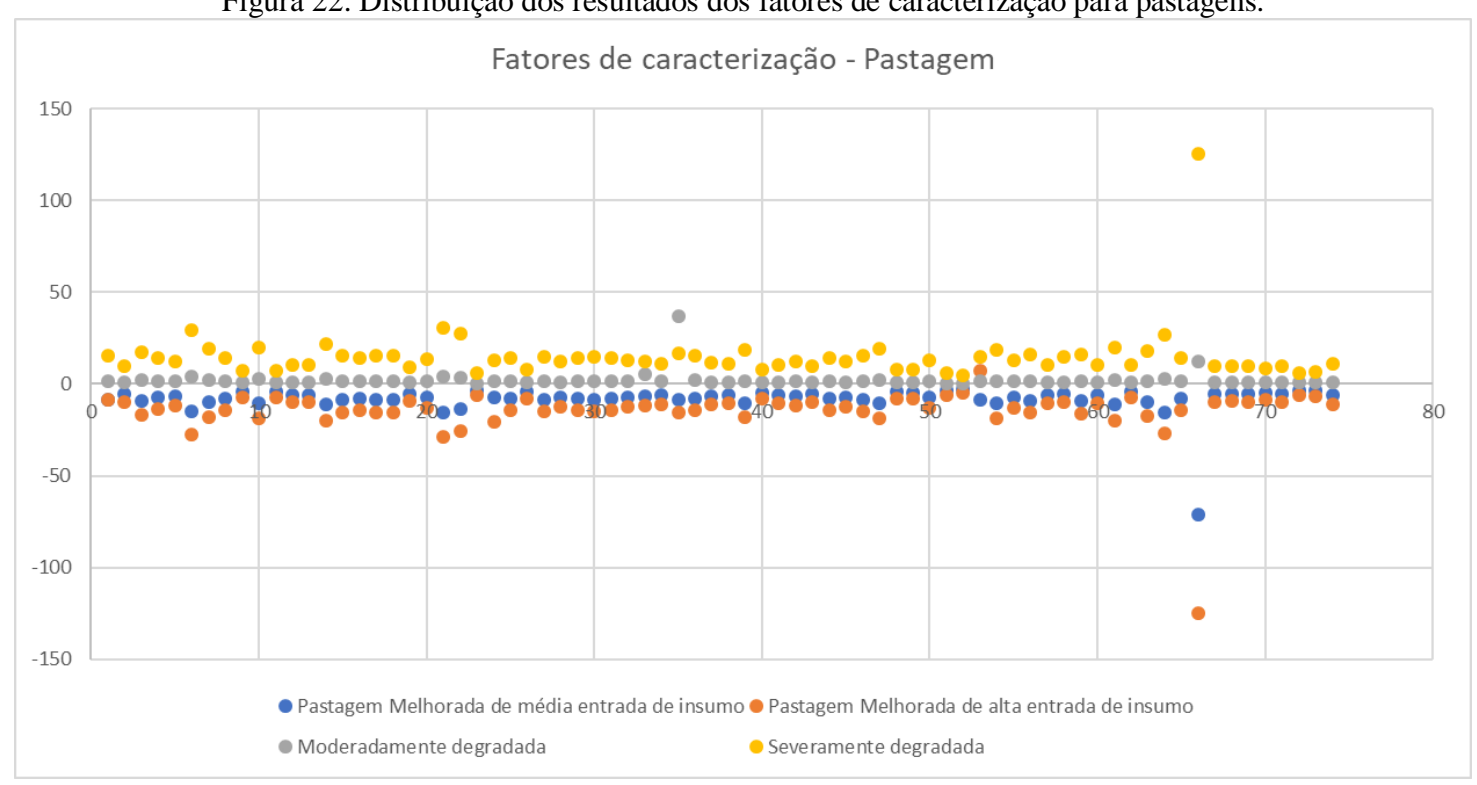

Fonte: elaboração própria

Os valores máximos encontrados nos fatores de caracterização de pastagens (Figura 22) foram na unidade S4V11 (Solos arenosos, Caatinga) para pastagens melhoradas de entrada média de insumos, S4V14 (Solos arenosos, Áreas de Formação Pioneira) em pastagens melhoradas de entrada alta de insumos, S3V6 (Não latossolos com argila de atividade baixa, Floresta Ombrófila Mista) em pastagens moderadamente degradadas e S6V3 (Outros solos, Mata Atlântica) em pastagens severamente degradadas.

A conversão de vegetação nativa para a área de cultivo pode causar perdas de carbono do solo, mas a conversão para pastagens pode até aumentar o potencial dos solos para funcionarem como sumidouros de carbono (FERREIRA et al., 2016). Isso foi evidenciado nos resultados do presente estudo sendo que os valores mínimos encontrados foram da unidade S6V3 (Outros solos, Mata Atlântica) para pastagens melhoradas de entrada média e alta de insumos e S4V11 (Solos arenosos, Caatinga) para pastagens moderadamente e severamente degradadas.

De modo geral, é importante destacar que não necessariamente resultados finais de incremento de carbono no solo representam melhoria na qualidade do ecossistema. $\mathrm{Na}$ realidade, a interpretação destes valores deve considerar que quanto menos influência humana no ecossistema melhor. Nesse sentido, idealmente valores mais próximos à situação de referência (fatores de caracterização próximos à zero) representariam resultados mais adequados em termos de conservação ambiental. 
Reconhecendo a necessidade de fatores de caracterização de fácil aplicação e de forma compatível com os dados compilados no ICV, considerou-se importante também a disponibilização de fatores de caracterização para as 27 unidades federativas do Brasil. Assim, o mesmo procedimento metodológico (aplicação dos fatores de mudança do IPCC) foi

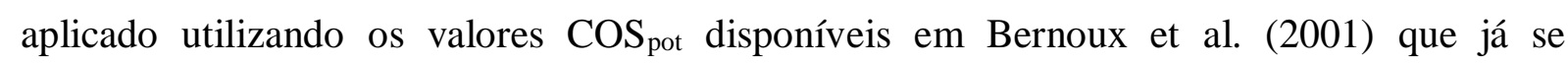
encontram sintetizados de acordo com os estados brasileiros sendo os resultados apresentados nas Tabelas 6, 7 e 8 a seguir.

Vale ressaltar que os fatores de caracterização para este tipo de diferenciação biogeográfica devem ser utilizados com ressalvas e transparência, visto que existe uma grande diversidade de solos e vegetação nos estados, podendo levar a resultados menos precisos em termos de regionalização. 
Tabela 6: Fatores de caracterização para culturas anuais agregados por estados brasileiros $(\mathrm{tC} / \mathrm{ha})$.

\begin{tabular}{|c|c|c|c|c|c|c|c|c|c|c|c|c|}
\hline \multirow{3}{*}{$\begin{array}{c}\text { Estado / Região } \\
\text { Região norte }\end{array}$} & \multicolumn{12}{|c|}{ Culturas anuais } \\
\hline & \multicolumn{4}{|c|}{ Preparo convencional } & \multicolumn{4}{|c|}{ Preparo reduzido } & \multicolumn{4}{|c|}{ Plantio direto } \\
\hline & B & M & AS & $\mathrm{AC}$ & B & M & AS & $\mathrm{AC}$ & B & M & AS & $\mathrm{AC}$ \\
\hline Acre & 27,25 & 25,38 & 22,80 & 15,07 & 24,02 & 21,86 & 18,90 & 10,01 & 22,51 & 20,22 & 17,08 & 7,65 \\
\hline Amapá & 27,31 & 25,43 & 22,85 & 15,10 & 24,07 & 21,91 & 18,94 & 10,03 & 22,56 & 20,26 & 17,11 & 7,66 \\
\hline Amazonas & 26,69 & 24,86 & 22,33 & 14,76 & 23,53 & 21,41 & 18,51 & 9,80 & 22,05 & 19,81 & 16,73 & 7,49 \\
\hline Pará & 25,74 & 23,97 & 21,54 & 14,24 & 22,69 & 20,65 & 17,85 & 9,46 & 21,26 & 19,10 & 16,13 & 7,23 \\
\hline Rondônia & 25,30 & 23,56 & 21,16 & 13,99 & 22,29 & 20,29 & 17,54 & 9,29 & 20,89 & 18,77 & 15,85 & 7,10 \\
\hline Roraima & 25,69 & 23,92 & 21,49 & 14,20 & 22,64 & 20,61 & 17,81 & 9,44 & 21,22 & 19,06 & 16,10 & 7,21 \\
\hline Tocantins & 22,62 & 21,06 & 18,92 & 12,51 & 19,93 & 18,14 & 15,68 & 8,31 & 18,68 & 16,78 & 14,17 & 6,35 \\
\hline \multicolumn{13}{|l|}{ Região nordeste } \\
\hline Alagoas & 16,07 & 15,04 & 14,21 & 7,35 & 14,30 & 13,17 & 12,26 & 4,79 & 12,72 & 11,51 & 10,53 & 2,52 \\
\hline Bahia & 14,73 & 13,78 & 13,02 & 6,74 & 13,10 & 12,06 & 11,23 & 4,39 & 11,65 & 10,54 & 9,65 & 2,31 \\
\hline Ceará & 11,09 & 10,37 & 9,80 & 5,07 & 9,87 & 9,08 & 8,46 & 3,31 & 8,78 & 7,94 & 7,27 & 1,74 \\
\hline Maranhão & 21,83 & 20,33 & 18,27 & 12,07 & 19,24 & 17,52 & 15,14 & 8,02 & 18,03 & 16,20 & 13,68 & 6,13 \\
\hline Paraíba & 11,40 & 10,67 & 10,08 & 5,22 & 10,15 & 9,34 & 8,70 & 3,40 & 9,03 & 8,16 & 7,47 & 1,79 \\
\hline Pernambuco & 11,94 & 11,17 & 10,55 & 5,46 & 10,62 & 9,78 & 9,11 & 3,56 & 9,45 & 8,55 & 7,83 & 1,87 \\
\hline Piauí & 12,80 & 11,97 & 11,31 & 5,85 & 11,38 & 10,48 & 9,76 & 3,82 & 10,13 & 9,16 & 8,39 & 2,00 \\
\hline $\begin{array}{c}\text { Rio Grande do } \\
\text { Norte }\end{array}$ & 10,96 & 10,25 & 9,68 & 5,01 & 9,75 & 8,97 & 8,36 & 3,27 & 8,67 & 7,84 & 7,18 & 1,72 \\
\hline Sergipe & 13,16 & 12,31 & 11,63 & 6,02 & 11,70 & 10,78 & 10,04 & 3,92 & 10,41 & 9,42 & 8,62 & 2,06 \\
\hline \multicolumn{13}{|c|}{ Região Centro-Oeste } \\
\hline Distrito Federal & 23,06 & 21,48 & 19,30 & 12,75 & 20,33 & 18,50 & 15,99 & 8,47 & 19,05 & 17,11 & 14,45 & 6,47 \\
\hline Goiás & 22,95 & 21,37 & 19,20 & 12,69 & 20,23 & 18,41 & 15,92 & 8,43 & 18,96 & 17,03 & 14,38 & 6,44 \\
\hline Mato Grosso & 23,90 & 22,26 & 20,00 & 13,22 & 21,06 & 19,17 & 16,58 & 8,78 & 19,74 & 17,74 & 14,98 & 6,71 \\
\hline $\begin{array}{l}\text { Mato Grosso do } \\
\text { Sul }\end{array}$ & 20,05 & 18,67 & 16,77 & 11,09 & 17,67 & 16,08 & 13,90 & 7,36 & 16,56 & 14,88 & 12,56 & 5,63 \\
\hline \multicolumn{13}{|l|}{ Região sudeste } \\
\hline Espirito Santo & 26,47 & 24,65 & 22,15 & 14,64 & 23,33 & 21,24 & 18,36 & 9,72 & 21,86 & 19,64 & 16,59 & 7,43 \\
\hline Minas Gerais & 17,47 & 16,34 & 15,44 & 7,99 & 15,54 & 14,31 & 13,32 & 5,21 & 13,82 & 12,50 & 11,45 & 2,74 \\
\hline Rio de Janeiro & 24,02 & 22,47 & 21,23 & 10,99 & 21,37 & 19,68 & 18,32 & 7,16 & 19,01 & 17,19 & 15,74 & 3,76 \\
\hline São Paulo & 22,50 & 20,96 & 18,83 & 12,44 & 19,83 & 18,05 & 15,61 & 8,27 & 18,59 & 16,70 & 14,10 & 6,32 \\
\hline \multicolumn{13}{|l|}{ Região sul } \\
\hline Paraná & 32,55 & 30,32 & 27,24 & 18,00 & 28,69 & 26,12 & 22,58 & 11,96 & 26,89 & 24,16 & 20,40 & 9,14 \\
\hline $\begin{array}{c}\text { Rio Grande do } \\
\text { Sul }\end{array}$ & 34,06 & 31,72 & 28,50 & 18,84 & 30,02 & 27,33 & 23,62 & 12,51 & 28,14 & 25,28 & 21,35 & 9,56 \\
\hline Santa Catarina & 35,68 & 33,23 & 29,85 & 19,73 & 31,45 & 28,63 & 24,75 & 13,11 & 29,47 & 26,48 & 22,36 & 10,02 \\
\hline
\end{tabular}

Fonte: elaboração própria. 
Tabela 7: Fatores de caracterização para usos da terra com culturas perenes e áreas de pousio, agregados em estados brasileiros (tC/ha).

\begin{tabular}{|c|c|c|c|c|c|c|c|c|c|c|c|c|}
\hline \multirow{3}{*}{$\begin{array}{c}\begin{array}{c}\text { Estado / } \\
\text { Região }\end{array} \\
\text { Região } \\
\text { norte }\end{array}$} & \multicolumn{11}{|c|}{ Culturas perenes } & \multirow{3}{*}{ Pousio } \\
\hline & \multicolumn{3}{|c|}{ Preparo convencional } & \multicolumn{4}{|c|}{ Preparo reduzido } & \multicolumn{4}{|c|}{ Plantio direto } & \\
\hline & B & AS & $\mathrm{AC}$ & B & M & AS & $\mathrm{AC}$ & B & M & AS & $\mathrm{AC}$ & \\
\hline Acre & 3,90 & $-5,37$ & $-21,47$ & $-2,83$ & $-7,32$ & $-13,49$ & $-32,01$ & $-5,97$ & $-10,74$ & $-17,28$ & $-36,93$ & 3,42 \\
\hline Amapá & 3,91 & $-5,38$ & $-21,52$ & $-2,84$ & $-7,33$ & $-13,52$ & $-32,08$ & $-5,99$ & $-10,76$ & $-17,32$ & $-37,01$ & 8,80 \\
\hline Amazonas & 3,82 & $-5,26$ & $-21,03$ & $-2,77$ & $-7,17$ & $-13,22$ & $-31,36$ & $-5,85$ & $-10,52$ & $-16,93$ & $-36,18$ & 3,35 \\
\hline Pará & 3,69 & $-5,07$ & $-20,28$ & $-2,67$ & $-6,92$ & $-12,75$ & $-30,24$ & $-5,64$ & $-10,14$ & $-16,33$ & $-34,89$ & 3,23 \\
\hline Rondônia & 3,62 & $-4,98$ & $-19,93$ & $-2,63$ & $-6,79$ & $-12,53$ & $-29,72$ & $-5,54$ & $-9,97$ & $-16,05$ & $-34,28$ & 3,17 \\
\hline Roraima & 3,68 & $-5,06$ & $-20,24$ & $-2,67$ & $-6,90$ & $-12,72$ & $-30,18$ & $-5,63$ & $-10,12$ & $-16,29$ & $-34,81$ & 3,22 \\
\hline Tocantins & 3,24 & $-4,46$ & $-17,82$ & $-2,35$ & $-6,08$ & $-11,20$ & $-26,57$ & $-4,96$ & $-8,91$ & $-14,35$ & $-30,65$ & 2,84 \\
\hline \multicolumn{13}{|c|}{ Região nordeste } \\
\hline Alagoas & 1,79 & $-1,43$ & $-15,75$ & $-1,27$ & $-3,22$ & $-4,78$ & $-17,66$ & $-3,99$ & $-6,09$ & $-7,76$ & $-21,58$ & 2,51 \\
\hline Bahia & 1,64 & $-1,31$ & $-14,43$ & $-1,16$ & $-2,95$ & $-4,38$ & $-16,18$ & $-3,66$ & $-5,58$ & $-7,11$ & $-19,78$ & 2,30 \\
\hline Ceará & 1,24 & $-0,99$ & $-10,87$ & $-0,88$ & $-2,22$ & $-3,30$ & $-12,18$ & $-2,75$ & $-4,20$ & $-5,35$ & $-14,89$ & 1,73 \\
\hline Maranhão & 3,13 & $-4,30$ & $-17,20$ & $-2,27$ & $-5,86$ & $-10,81$ & $-25,65$ & $-4,79$ & $-8,60$ & $-13,85$ & $-29,59$ & 2,74 \\
\hline Paraíba & 1,27 & $-1,02$ & $-11,18$ & $-0,90$ & $-2,29$ & $-3,39$ & $-12,53$ & $-2,83$ & $-4,32$ & $-5,51$ & $-15,31$ & 1,78 \\
\hline Pernambuco & 1,33 & $-1,06$ & $-11,70$ & $-0,94$ & $-2,39$ & $-3,55$ & $-13,12$ & $-2,97$ & $-4,52$ & $-5,77$ & $-16,04$ & 1,86 \\
\hline Piauí & 1,43 & $-1,14$ & $-12,54$ & $-1,01$ & $-2,57$ & $-3,81$ & $-14,06$ & $-3,18$ & $-4,85$ & $-6,18$ & $-17,18$ & 2,00 \\
\hline $\begin{array}{c}\text { Rio Grande } \\
\text { do Norte }\end{array}$ & 1,22 & $-0,98$ & $-10,74$ & $-0,87$ & $-2,20$ & $-3,26$ & $-12,04$ & $-2,72$ & $-4,15$ & $-5,29$ & $-14,71$ & 1,71 \\
\hline Sergipe & 1,47 & $-1,17$ & $-12,89$ & $-1,04$ & $-2,64$ & $-3,91$ & $-14,45$ & $-3,27$ & $-4,98$ & $-6,35$ & $-17,66$ & 2,05 \\
\hline \multicolumn{13}{|c|}{ Região Centro-Oeste } \\
\hline $\begin{array}{l}\text { Distrito } \\
\text { Federal } \\
\end{array}$ & 3,30 & $-4,54$ & $-18,17$ & $-2,40$ & $-6,19$ & $-11,42$ & $-27,09$ & $-5,06$ & $-9,09$ & $-14,63$ & $-31,26$ & 2,89 \\
\hline Goiás & 3,29 & $-4,52$ & $-18,08$ & $-2,38$ & $-6,17$ & $-11,36$ & $-26,96$ & $-5,03$ & $-9,04$ & $-14,56$ & $-31,10$ & 2,88 \\
\hline $\begin{array}{c}\text { Mato } \\
\text { Grosso }\end{array}$ & 3,42 & $-4,71$ & $-18,83$ & $-2,48$ & $-6,42$ & $-11,83$ & $-28,08$ & $-5,24$ & $-9,42$ & $-15,16$ & $-32,39$ & 3,00 \\
\hline $\begin{array}{c}\text { Mato } \\
\text { Grosso do } \\
\text { Sul }\end{array}$ & 2,87 & $-3,95$ & $-15,80$ & $-2,08$ & $-5,39$ & $-9,93$ & $-23,55$ & $-4,39$ & $-7,90$ & $-12,72$ & $-27,17$ & 2,51 \\
\hline \multicolumn{13}{|c|}{ Região sudeste } \\
\hline $\begin{array}{c}\text { Espirito } \\
\text { Santo }\end{array}$ & 3,79 & $-5,21$ & $-20,86$ & $-2,75$ & $-7,11$ & $-13,11$ & $-31,09$ & $-5,80$ & $-10,43$ & $-16,79$ & $-35,87$ & 3,32 \\
\hline $\begin{array}{l}\text { Minas } \\
\text { Gerais }\end{array}$ & 1,95 & $-1,56$ & $-17,12$ & $-1,38$ & $-3,50$ & $-5,20$ & $-19,19$ & $-4,34$ & $-6,61$ & $-8,43$ & $-23,45$ & 2,72 \\
\hline $\begin{array}{l}\text { Rio de } \\
\text { Janeiro }\end{array}$ & 2,68 & $-2,14$ & $-23,54$ & $-1,90$ & $-4,82$ & $-7,15$ & $-26,39$ & $-5,97$ & $-9,10$ & $-11,60$ & $-32,26$ & 3,75 \\
\hline São Paulo & 3,22 & $-4,43$ & $-17,73$ & $-2,34$ & $-6,04$ & $-11,14$ & $-26,44$ & $-4,93$ & $-8,87$ & $-14,27$ & $-30,50$ & 2,82 \\
\hline \multicolumn{13}{|l|}{ Região sul } \\
\hline Paraná & 4,66 & $-6,41$ & $-25,65$ & $-3,38$ & $-8,74$ & $-16,12$ & $-38,24$ & $-7,14$ & $-12,83$ & $-20,65$ & $-44,12$ & 4,08 \\
\hline $\begin{array}{c}\text { Rio Grande } \\
\text { do Sul }\end{array}$ & 4,88 & $-6,71$ & $-26,84$ & $-3,54$ & $-9,15$ & $-16,87$ & $-40,02$ & $-7,47$ & $-13,42$ & $-21,61$ & $-46,16$ & 4,27 \\
\hline $\begin{array}{c}\text { Santa } \\
\text { Catarina }\end{array}$ & 5,11 & $-7,03$ & $-28,12$ & $-3,71$ & $-9,59$ & $-17,67$ & $-41,92$ & $-7,82$ & $-14,06$ & $-22,63$ & $-48,36$ & 4,47 \\
\hline
\end{tabular}

Fonte: elaboração própria. 
Tabela 8: Fatores de caracterização para atividades de pastagem, agregados por estados brasileiros (tC/ha).

\begin{tabular}{|c|c|c|c|c|}
\hline \multirow{3}{*}{$\begin{array}{c}\text { Estado / Região } \\
\text { Região norte }\end{array}$} & \multicolumn{4}{|c|}{ Pastagem } \\
\hline & \multicolumn{2}{|c|}{ Melhorada } & \multirow{2}{*}{$\begin{array}{c}\text { Moderadamente } \\
\text { degradada }\end{array}$} & \multirow{2}{*}{$\begin{array}{c}\text { Severamente } \\
\text { degradada }\end{array}$} \\
\hline & $\begin{array}{l}\text { Média entrada de } \\
\text { insumo }\end{array}$ & $\begin{array}{l}\text { Entrada alta de } \\
\quad \text { insumo }\end{array}$ & & \\
\hline Acre & $-8,30$ & $-14,58$ & 1,46 & 14,64 \\
\hline Amapá & $-8,31$ & $-14,61$ & 1,47 & 14,67 \\
\hline Amazonas & $-8,13$ & $-14,28$ & 1,43 & 14,34 \\
\hline Pará & $-7,84$ & $-13,77$ & 1,38 & 13,83 \\
\hline Rondônia & $-7,70$ & $-13,53$ & 1,36 & 13,59 \\
\hline Roraima & $-7,82$ & $-13,74$ & 1,38 & 13,80 \\
\hline Tocantins & $-6,89$ & $-12,10$ & 1,22 & 12,15 \\
\hline \multicolumn{5}{|l|}{ Região nordeste } \\
\hline Alagoas & $-6,09$ & $-10,69$ & 1,07 & 10,74 \\
\hline Bahia & $-5,58$ & $-9,80$ & 0,98 & 9,84 \\
\hline Ceará & $-4,20$ & $-7,38$ & 0,74 & 7,41 \\
\hline Maranhão & $-6,65$ & $-11,68$ & 1,17 & 11,73 \\
\hline Paraíba & $-4,32$ & $-7,59$ & 0,76 & 7,62 \\
\hline Pernambuco & $-4,52$ & $-7,95$ & 0,80 & 7,98 \\
\hline Piauí & $-4,85$ & $-8,51$ & 0,86 & 8,55 \\
\hline Rio Grande do Norte & $-4,15$ & $-7,29$ & 0,73 & 7,32 \\
\hline Sergipe & $-4,98$ & $-8,75$ & 0,88 & 8,79 \\
\hline \multicolumn{5}{|l|}{ Região Centro-Oeste } \\
\hline Distrito Federal & $-7,02$ & $-12,34$ & 1,24 & 12,39 \\
\hline Goiás & $-6,99$ & $-12,28$ & 1,23 & 12,33 \\
\hline Mato Grosso & $-7,28$ & $-12,78$ & 1,28 & 12,84 \\
\hline Mato Grosso do Sul & $-6,10$ & $-10,72$ & 1,08 & 10,77 \\
\hline \multicolumn{5}{|l|}{ Região sudeste } \\
\hline Espirito Santo & $-8,06$ & $-14,16$ & 1,42 & 14,22 \\
\hline Minas Gerais & $-6,61$ & $-11,62$ & 1,17 & 11,67 \\
\hline Rio de Janeiro & $-9,10$ & $-15,98$ & 1,61 & 16,05 \\
\hline São Paulo & $-6,85$ & $-12,04$ & 1,21 & 12,09 \\
\hline \multicolumn{5}{|l|}{ Região sul } \\
\hline Paraná & $-9,91$ & $-17,41$ & 1,75 & 17,49 \\
\hline Rio Grande do Sul & $-10,37$ & $-18,22$ & 1,83 & 18,30 \\
\hline Santa Catarina & $-10,86$ & $-19,09$ & 1,92 & 19,17 \\
\hline
\end{tabular}

Fonte: elaboração própria. 
Nas Figuras 23, 24 e 25 a seguir são apresentados os resultados dos fatores de caracterização para as diferentes classes de uso da terra, de acordo com os estados brasileiros.

Figura 23: Distribuição dos fatores de caracterização para culturas anuais de acordo com os estados brasileiros.

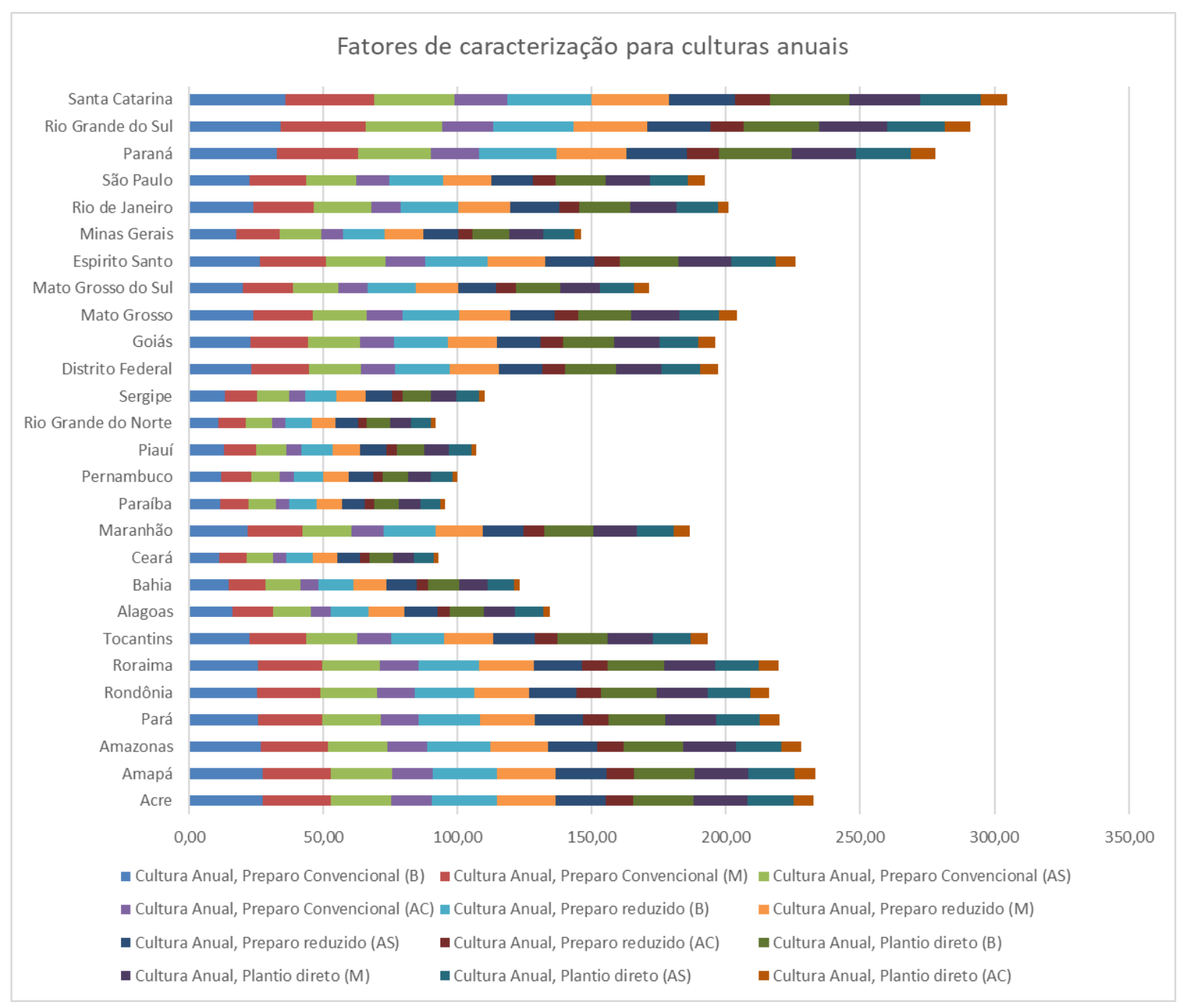

Fonte: elaboração própria. 
Figura 24: Distribuição dos fatores de caracterização para culturas perenes de acordo com os estados brasileiros.

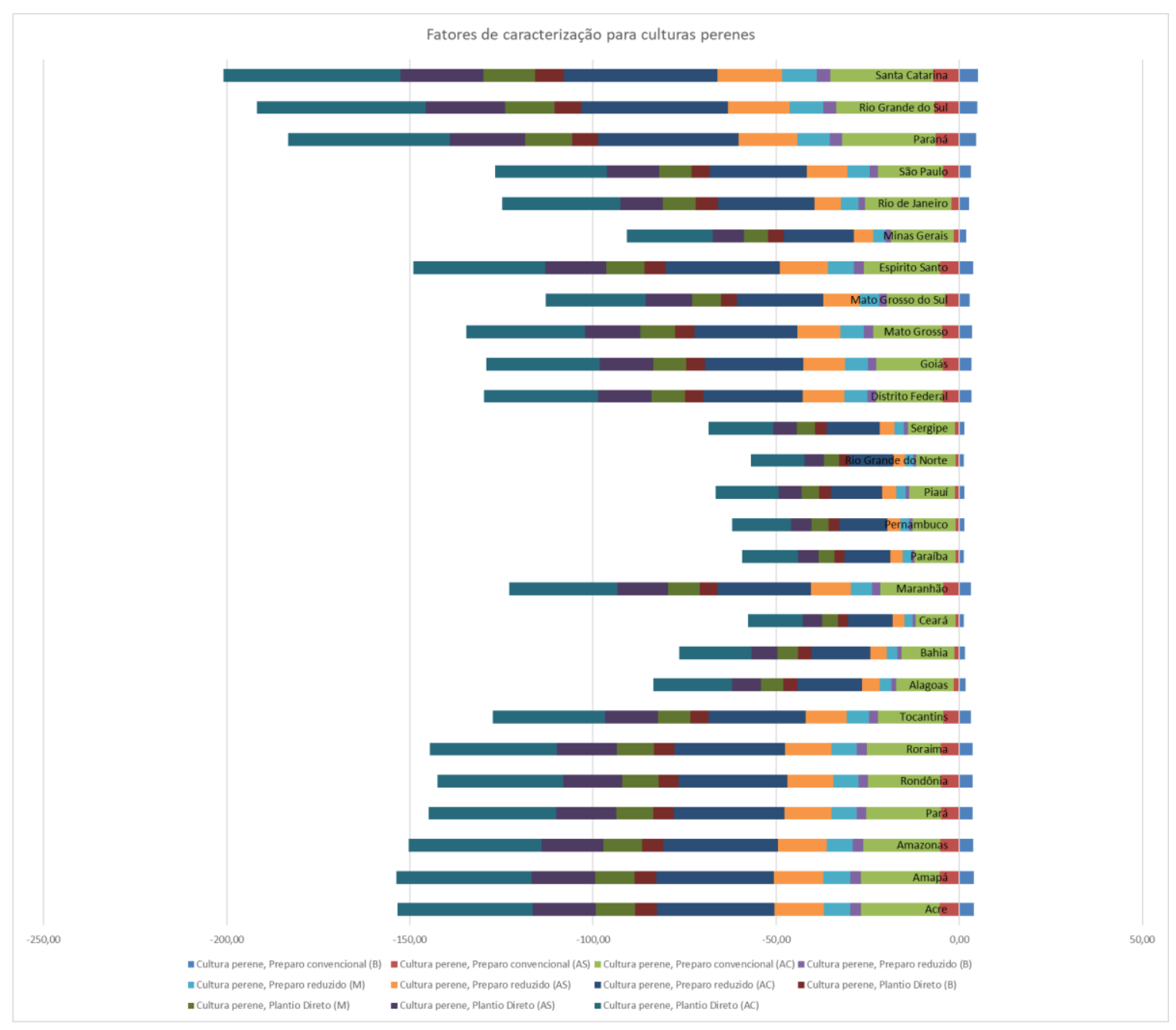

Fonte: elaboração própria. 
Figura 25: Distribuição dos fatores de caracterização para pastagens de acordo com os estados brasileiros.

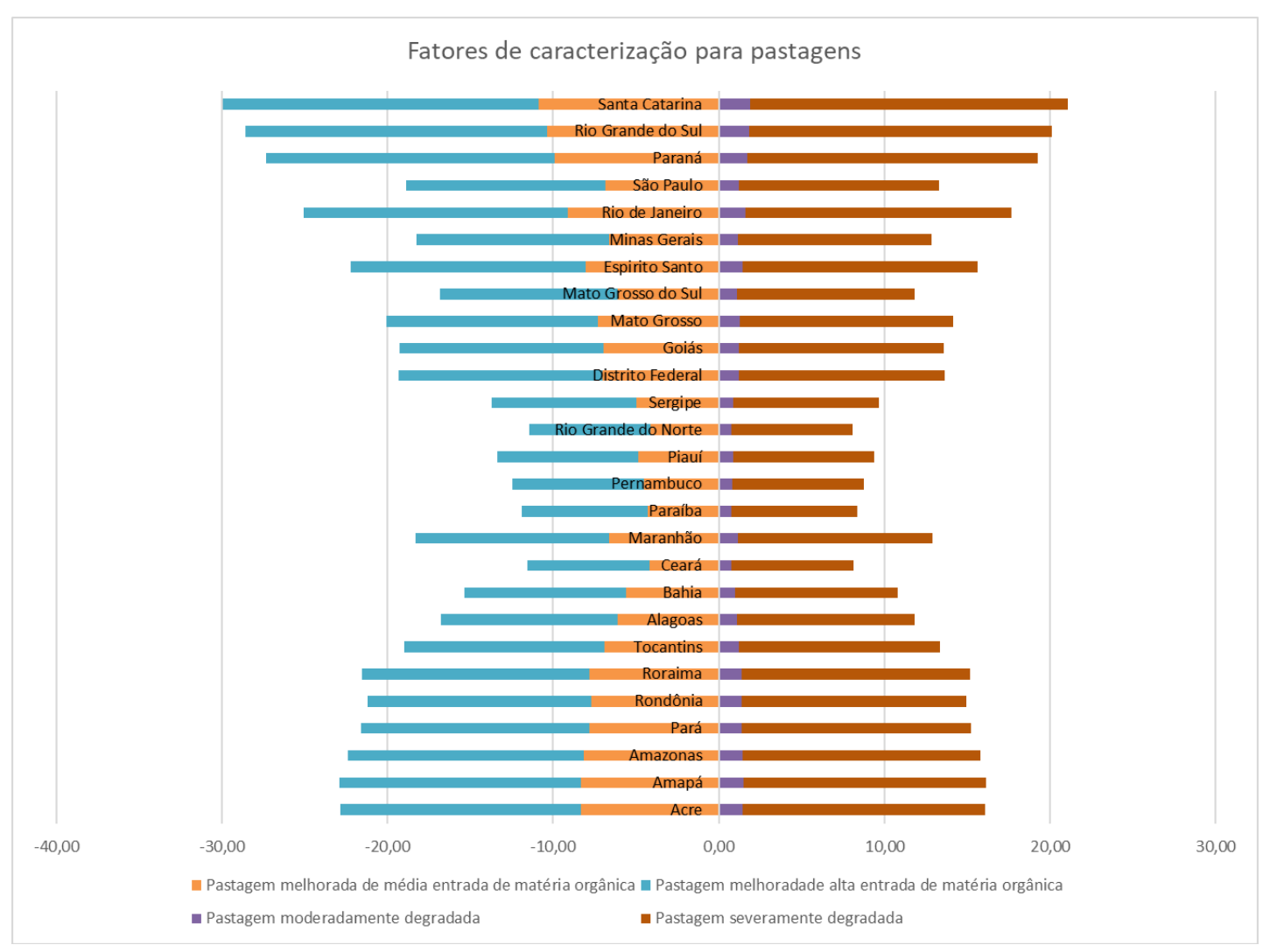

Fonte: elaboração própria.

Já nas Figuras 26, 27 e 28 a seguir são apresentados mapas exemplificando os resultados espacializados de um tipo de cada classe de uso da terra. 
Figura 26: Variação dos fatores de caracterização para culturas anuais de preparo convencional e média entrada de matéria orgânica.

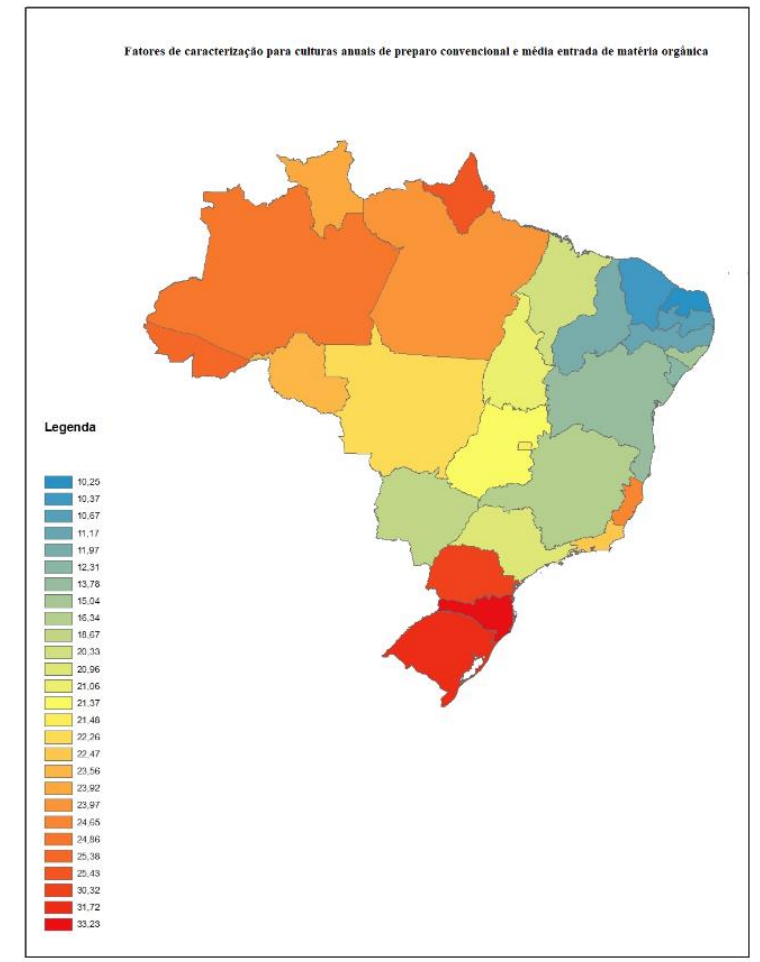

Fonte: elaboração própria.

Figura 27: Variação dos fatores de caracterização para culturas perenes de preparo convencional e baixa entrada de matéria orgânica.

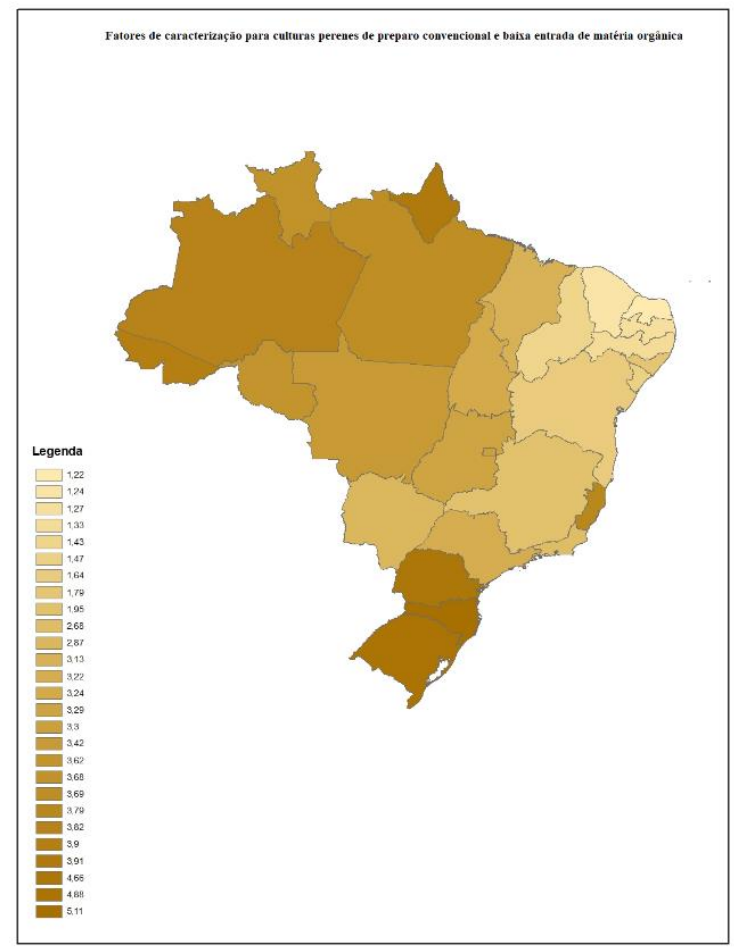

Fonte: elaboração própria 
Figura 28: Variação dos fatores de caracterização para pastagens moderadamente degradadas.

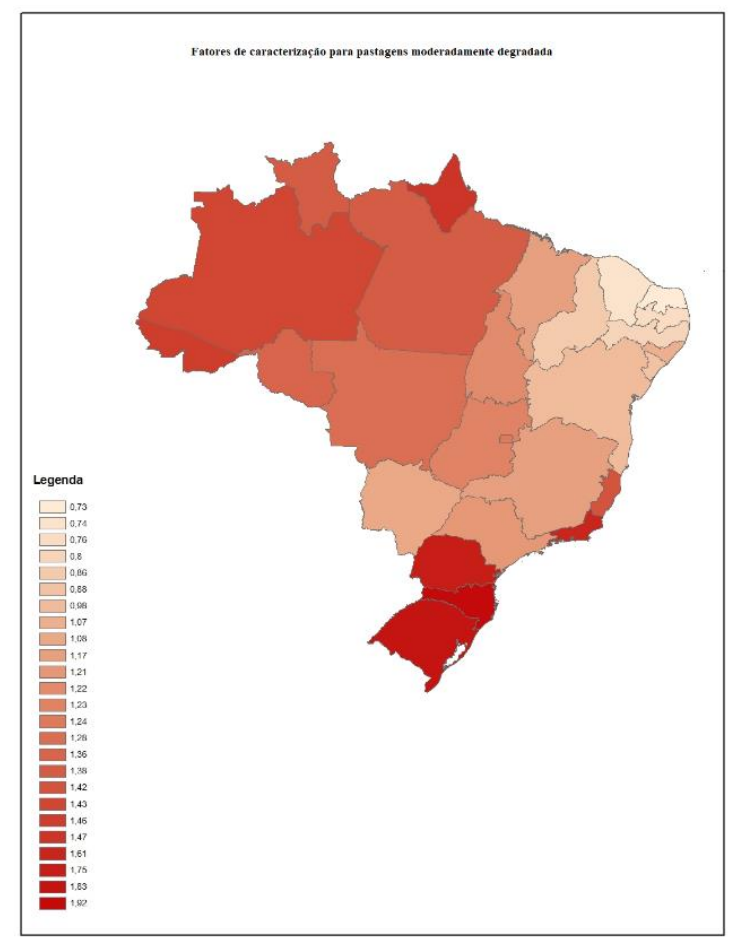

Considerando os resultados de maneira geral, nota-se que na região norte os menores impactos para agricultura de maneira geral encontram-se no estado do Amapá, enquanto que para atividades de pecuária os menores impactos potenciais seriam no estado do Tocantins. Já na região nordeste, os menores impactos potenciais para pastagem e culturas perenes são encontrados no estado do Maranhão enquanto que para culturas anuais os menores valores são encontrados para o estado do Rio Grande do Norte. Ao analisar os menores fatores de caracterização encontrados na Região Centro-Oeste e, portanto, que representa menor impacto ambiental, é possível observar que para culturas anuais o valor mínimo encontrado é no estado do Mato Grosso do Sul e para as culturas perenes e pastagens, os valores mínimos encontrados são no estado do Mato Grosso. Na região sudeste o estado de Minas Gerais apresentou os menores valores dos fatores de caracterização para culturas anuais enquanto o Rio de Janeiro e o Espírito Santo para a pastagem e culturas perenes, respectivamente. Por fim, na região sul, o Paraná apresenta os menores valores de fatores de caracterização para culturas anuais e Santa Catarina tanto para pastagem quanto para culturas perenes.

Ao verificar os maiores valores encontrados, ou seja, os maiores impactos potenciais, no caso das culturas anuais os estados de maior contribuição, por região, são: Amapá, Maranhão, Mato Grosso, Espírito Santo e Santa Catarina. Para culturas perenes, os maiores potenciais de impacto são encontrados nos estados de Tocantins, Rio Grande do Norte, Mato 
Grosso do Sul, Minas Gerais e Paraná. Por fim, para os potenciais impactos de pastagens, os maiores valores encontrados dentre as cinco regiões brasileiras foram nos estados do Amapá, Maranhão, Mato Grosso, Rio de Janeiro e Santa Catarina.

\subsection{Discussão}

O COS é o carbono que permanece no solo após a decomposição parcial de qualquer material produzido por organismos vivos. Constitui um elemento-chave do ciclo global do carbono e é o principal componente da matéria orgânica do solo (MOS) (FAO, 2018). O material orgânico morto (principalmente na forma de resíduos vegetais) é incorporado pela fauna do solo, levando à entrada de carbono no solo através da transformação de material orgânico por microrganismos heterotróficos. Quando a MOS é decomposta, os gases de efeito estufa com base de carbono são emitidos para a atmosfera. Além disso, o carbono também é parcialmente exportado dos solos para os rios e oceanos como carbono orgânico dissolvido (COD) ou em processos de erosão (FAO, 2017).

A quantidade de COS nos solos é espacial e temporalmente variável, dependendo do balanço de entradas e saídas de carbono. Em princípio, os fatores que controlam a decomposição da matéria orgânica no solo incluem a temperatura do solo e o teor de água (determinado principalmente pelas condições climáticas) influenciando assim o armazenamento de COS através do seu efeito na atividade microbiana. Além disso, o carbono também pode ser perdido ou ganho através da erosão ou deposição do solo, levando à redistribuição do carbono no solo nas escalas local e regional.

A importância do COS para a saúde do solo, fertilidade e produção de alimentos é relacionada ao papel desempenhado na estabilização da estrutura do solo, retenção e liberação de nutrientes das plantas e infiltração e armazenamento de água no solo. Portanto, a perda de COS indica certo grau de degradação do solo. A conservação e a melhoria dos estoques de COS são importantes em todos os solos utilizados para a produção de alimentos para manter as funções do solo que garantem e melhoram a segurança alimentar (FAO, 2017).

A perda de COS afeta negativamente não só a saúde do solo e produção de alimentos, mas também agrava a mudança climática. Isso significa que mudanças na MOS (e, portanto, no COS) não só alteram a prestação de serviços ecossistêmicos necessários para a produção agrícola, mas também a capacidade dos solos de regularem alterações climáticas. Desta forma, impactos antropogênicos no solo podem transformá-lo em um sumidouro ou uma fonte 
de GEEs. Na escala global, o solo é o principal reservatório terrestre de carbono e, portanto, têm grande influência na concentração de dióxido de carbono $\left(\mathrm{CO}_{2}\right)$ na atmosfera. Do ponto de vista da mitigação das mudanças climáticas, a prevenção de perdas de COS de solos ricos em carbono é, portanto, uma prioridade devido à grande quantidade de GEEs que podem potencialmente liberar para a atmosfera.

Por outro lado, muitos solos têm o potencial de aumentar o estoque de COS, mitigando assim as alterações climáticas, reduzindo a concentração atmosférica de $\mathrm{CO}_{2}$. É, portanto, crucial ter um bom conhecimento do atual estoque de COS e sua distribuição espacial para informar as várias partes interessadas a fim de ter um melhor uso da terra e fornecer melhores oportunidades para mitigar e adaptar-se às mudanças climáticas, além de assegurar a produção agrícola.

No entanto, ainda existem grandes incertezas nas estimativas de estoques de COS em escalas globais, continentais, regionais e locais. O efeito do preparo do solo na qualidade do solo é alvo de muitas discussões e estudos (e.g. JAGADAMMA et al., 2007; LI et al., 2009; VERHULST et al. 2010) e de forma semelhante, os resultados da presente pesquisa variaram consideravelmente. De forma geral, considera-se que os estoques de COS diminuem quando os resíduos da colheita são colhidos e não retornados ao solo. Em contrapartida, o preparo do solo leva os resíduos de culturas para mais perto dos microrganismos, aumentando assim a decomposição da matéria orgânica (LAL, 2004). Logo, maiores estoques de carbono em solos agrícolas podem ser alcançados através do retorno de resíduos vegetais ao solo até certos limites de incorporação (HOBBS et al. 2008). Tais limites máximos dependem dos requisitos de nitrogênio das culturas, eficiência de uso da terra e ainda é difícil estabelecer um valor único que possa ser universal ou regionalmente aceito (MUSINGUZI et al., 2013). Vários estudos têm mostrado que o plantio direto resulta em um maior sequestro de carbono, devido à melhor agregação do solo que o protege da mineralização em comparação com o preparo convencional (YEBOAH et al, 2016). Ademais, o maior estoque de COS em tratamentos adubados (esterco) pode ser explicado pela entrada direta de carbono pelo adubo e entrada indireta de carbono através do aumento da produção primária líquida (incluindo raízes e resíduos de culturas) (MAILLARD; ANGERS, 2014).

Apesar desses padrões gerais, observa-se uma heterogeneidade nos resultados do presente estudo, o que reafirma a importância da adoção de procedimentos metodológicos que considerem as especificidades regionais e, portanto, possibilitem a aplicação de modelos e fatores de caracterização espacialmente regionalizados. De modo geral, observa-se que culturas anuais apresentam maiores impactos potenciais em comparação às culturas perenes, 
sendo que os maiores impactos são encontrados nas Regiões Norte e Sul. Além disso, verifica-se que a Região Nordeste apresenta os menores valores e tende a ter um ganho maior de carbono no solo. Ao analisar os resultados para pastagens de uma formal geral (incluindo todos os níveis de manejo), é possível observar que os menores impactos são encontrados na Região Nordeste e Sudeste enquanto as Regiões Norte e Sul apresentam os maiores impactos potenciais. Analisando-se as culturas perenes, os padrões são diferentes, sendo que os menores impactos se encontram nas Regiões Sul e Norte enquanto os maiores impactos potenciais são encontrados nas Regiões Sudeste e Nordeste, porém todos representando valores negativos, representando ganhos em termos de carbono no solo.

Sabe-se que as mudanças nas formas de ocupação do território brasileiro não ocorrem de forma linear ao longo do tempo e são heterogêneas nas cinco regiões do país uma vez que são relacionadas a fatores econômicos, ambientais, históricos e culturais (IBGE, 2018). Os resultados do presente estudo, representando os potenciais impactos na qualidade do solo podem subsidiar discussões sobre o novo Atlas Nacional Digital do Brasil publicado pelo IBGE em 2018, que inclui os resultados dos dados preliminares do Censo Agropecuário 2017. Estes dados mostram o retrato atual do uso da terra no país sendo que a análise estatística do IBGE entre os anos 2006 e 2017 computou o aumento da área ocupada com lavouras temporárias em todas as grandes regiões, com exceção do Nordeste. Quando se analisa a área ocupada por estas culturas (que incluem algodão herbáceo, arroz, aveia, cana-de-açúcar, mandioca e milho por exemplo), nota-se que as regiões mais expressivas são a Região CentroOeste e em seguida a Região Sul, sendo pelos resultados do presente estudo esta última é a região de maiores valores de impacto potencial.

Em contrapartida, as lavouras permanentes (que incluem banana; cacau, café, castanha-de-caju, laranja e uva por exemplo) tiveram decréscimo em todas as grandes regiões. Quanto às pastagens houve crescimento de $9,15 \%$ das pastagens plantadas em comparação com o ano de 2006 (Figura 29). Ao se analisar os dados de áreas de pastagens plantadas, chama atenção a contribuição da Região Centro-Oeste em seguida a Região Norte. De acordo com os resultados aqui obtidos, o impacto potencial na Região Norte tem a segunda maior média dos valores dos fatores de caracterização, seguida pela Região Centro-Oeste, representando opções menos indicadas para este tipo de uso da terra. 
Figura 29: Evolução das culturas temporárias, permanentes e pastagens no território brasileiro.
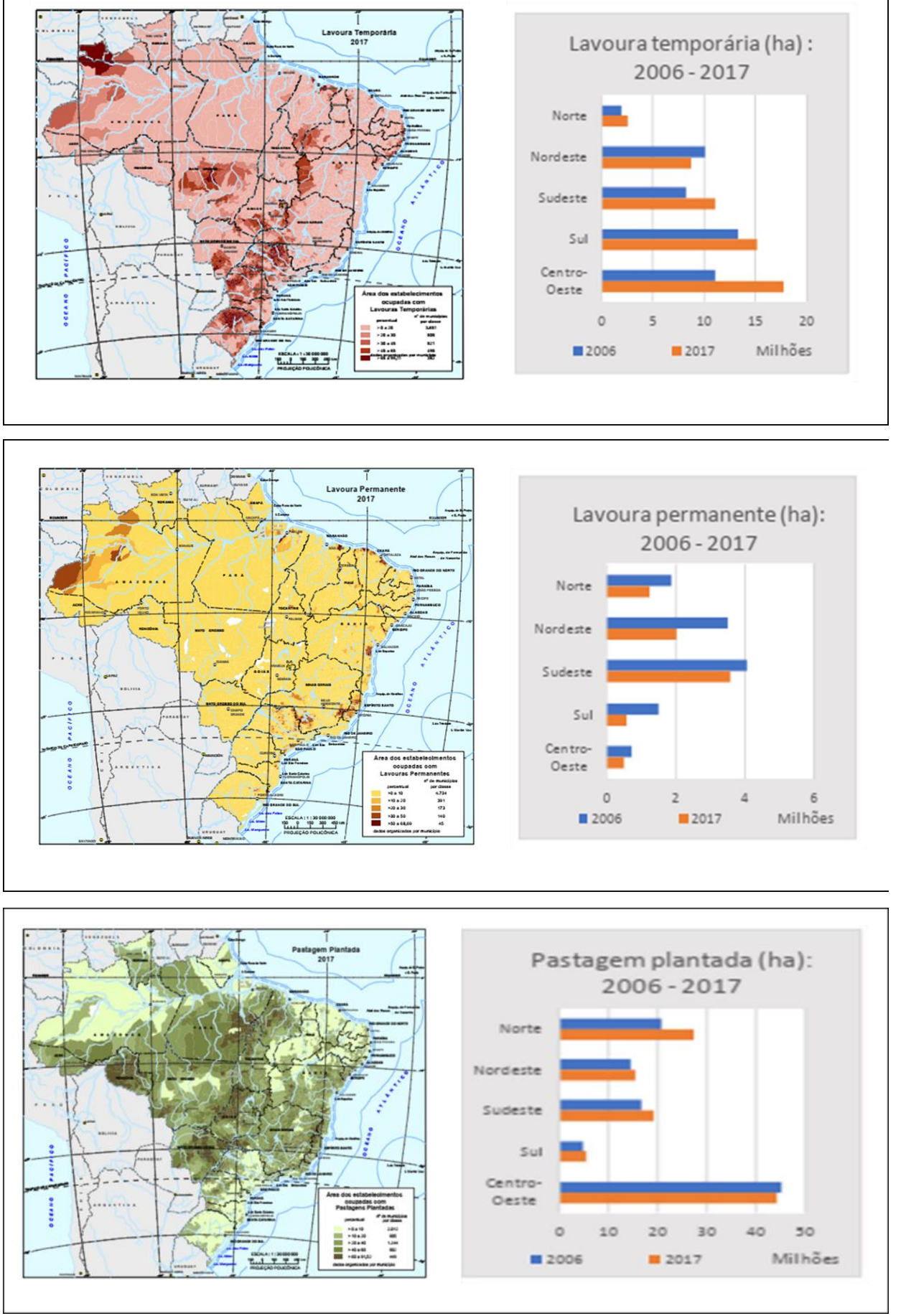

Fonte: IBGE $(2018)^{12}$.

Considera-se pertinente também a comparação dos resultados deste estudo e o modelo originalmente adotado para adaptação. Levando em consideração que os fatores de caracterização são disponibilizados em diferentes sistemas de diferenciação espacial, os

${ }^{12}$ Disponível em: https://www.ibge.gov.br/apps/atlas_nacional/ 
fatores de caracterização fornecidos por Brandão; Milà i Canals (2013) para regiões de clima tropical úmido foram utilizados a fins de comparação.

Ao analisar os fatores de caracterização para culturas anuais de preparo convencional, nota-se uma diferença significativa visto que enquanto a modelagem regionalizada para as 74 ASV brasileiras tem resultados que variam de 1,52 a 233,30 tC/ha, os resultados de Brandão; Milà i Canals (2013) variam de 17 a 30 tC/ha. No entanto, quando esses resultados são comparados com os valores encontrados para ASVs em que o tipo de clima é exclusivamente tropical úmido (e.g. S1V8, S1V12 e S2V10), a variação é de 10,43 a 26,02 tC/ha, notando-se uma maior correspondência entre os dois.

Quando se trata de culturas anuais de preparo reduzido, os resultados encontrados pelos autores variam de 11 a $27 \mathrm{tC} / \mathrm{ha}$, valores muito diferentes dos encontrados no presente estudo, que variam de $-55,25$ a 205,62 tC/ha. Considerando as ASVs de clima tropical úmido a variação muda para 6,93 a 23,62 tC/ha.

Ao analisar os resultados para culturas anuais de plantio direto os valores variam de 8 a 25 tC/ha no estudo global de Brandão; Milà i Canals (2013) enquanto os aqui apresentados variam entre -33,22 e 192,71 tC/ha nos resultados por ASV e 5,29 e 22,13 tC/ha considerando classes de clima tropical (S1V8, S1V12 e S2V10).

De maneira semelhante os resultados para pastagens diferiram significativamente, variando de 6 a $16 \mathrm{tC} /$ ha no estudo global ao passo que os resultados regionalizados variam de $-124,80$ a 125,30 tC/ha. Neste caso, a comparação com as classes de clima tropical também resulta em divergências visto que os valores variam de -14,33 a 14,4 tC/ha. Para culturas perenes, os fatores de caracterização apresentados por Brandão; Milà i Canals (2013) têm valor zero o que significaria não haver qualquer tipo de impacto e no caso das áreas de pousio existe apenas um fator de caracterização aplicável em áreas de clima tropical úmido, de valor 10 tC/ha. Ressalta-se que neste estudo são apresentados fatores de caracterização regionais para 74 ASV tanto para culturas perenes em diferentes níveis de manejo quanto para áreas de pousio, que por sua vez variam de $-11,05$ a 75,20 tC/ha, evidenciando a importância da aplicação de modelos e fatores de caracterização regionalizados.

No entanto, reconhecendo a disponibilidade limitada de conjuntos de dados sobre o estoque de COS nos níveis nacional e regional, é importante salientar as limitações enfrentadas no estudo. Primeiro, os resultados são dependentes dos valores de $\operatorname{COS}_{\text {pot }}$ obtidos em Bernoux et al. (2002), que por sua vez apresentam incertezas, como já descrito no item 8.2. Sabe-se que na provisão destes dados, as incertezas são cumulativas desde o processo de amostragem do solo, análise e transformação de dados até o desenvolvimento dos mapas. 
Logo, a redução de incertezas é necessária em todos esses estágios (FAO, 2017). No entanto, considerando os modelos e fatores de caracterização atualmente disponíveis, a aplicação desses dados representa uma opção mais apropriada de situação de referência para avaliar impactos no estoque de COS, significando grande avanço para o desenvolvimento de estudos de ACV no Brasil.

Ademais, a falta de dados espaciais organizados sobre o estoque de COS em diferentes tipos de uso da terra gerou a necessidade da utilização dos fatores relativos de mudança de estoque fornecidos pelo IPCC. Ressalta-se que a metodologia empregada no desenvolvimento desses fatores não é transparente, sendo derivados de uma pequena base de dados, e como consequência, sua aplicação insere grande incerteza nos resultados (vide Tabela 1). Nesse sentido é possível antever uma melhoria dos resultados do presente estudo em um curto prazo visto que há previsão de que as diretrizes metodológicas do IPCC serão atualizadas e divulgadas em 2019. O refinamento abordará vários aspectos, dentre eles os fatores de mudança nos teores de COS e levará em conta os avanços científicos feitos na medição de COS (através de sensoriamento remoto, SIG, etc.). Prevê-se também que a nova orientação focará na representação da terra, especialmente na identificação e rastreamento de sistemas de uso e gestão da terra e mudanças associadas ao longo do tempo (IPCC, 2015).

Outra restrição apontada nesta etapa de aplicação do modelo de caracterização e cálculo dos fatores de caracterização está no fato dos resultados não serem capazes de integrar as esferas de 'benefício' e 'valor' discutidas anteriormente na proposição do modelo conceitual (Capítulo 6). Para tanto seria necessário adicionar procedimentos metodológicos ao modelo a fim de converter os indicadores biofísicos em indicadores monetários, por exemplo, através da estimativa da perda de produtividade.

Apesar de existirem problemas e limitações a serem resolvidos, acredita-se que a aplicação do modelo colabore não somente para a avaliação de impactos relacionados aos serviços ecossistêmicos, como também para o avanço de uma metodologia de AICV regionalizada. Nesse sentido, destaca-se que são disponibilizados aqui mais de dois mil fatores de caracterização aos usuários de ACV aplicáveis em 28 classes diferentes de uso da terra para 74 unidades biogeográficas (ASV). Além desses, são apresentados fatores de caracterização também para as 27 unidades federativas do país. Os resultados deste estudo são, portanto, úteis não só para incrementar a disponibilidade de dados sobre os efeitos de manejo nos teores de COS no país, mas também para facilitar a inclusão da categoria de impacto relacionada ao uso da terra em estudos brasileiros. 
A aplicação dos resultados aqui apresentados deve ser utilizada com cautela, considerando as limitações e as premissas que embasam a modelagem dos impactos do uso da terra na AICV. Por exemplo, a premissa de que a qualidade se mantem a mesma durante a fase de ocupação é questionável visto que em uma sequência de anos com atividades de agricultura altamente mecanizada, alta aplicação de agrotóxicos resultará em um declínio da qualidade do ambiente ao longo do tempo. Além disso, como a área é um fator multiplicador, impactos em ecossistemas frágeis, mas que ocupam uma pequena área podem ser menores comparados ao impacto de uma área maior. Levando em consideração essas ressalvas, os resultados podem auxiliar tomadas de decisão baseadas na ACV visando priorizar sistemas de manejo de solo que menos alterem o ambiente (valores próximos a zero). Tais propósitos estão de acordo com os princípios e objetivos da Economia Circular, ao fornecer informações úteis para uma transição a uma economia direcionada à eco-efetividade e à reformulação de produtos com pegada positiva no ecossistema, indo além da lógica de minimizar impactos negativos. A avaliação dos impactos relacionados aos serviços ecossistêmicos do solo não só revela as externalidades negativas como também pode auxiliar na priorização da eficiência dos recursos no centro da tomada de decisões. Assim, a possibilidade da quantificação de impactos positivos é extremamente relevante para uma Economia Circular que visa aumentar o capital natural estimulando fluxos de nutrientes no sistema e criando as condições necessárias para regeneração ${ }^{13}$.

${ }^{13}$ https://www.ellenmacarthurfoundation.org/pt/economia-circular-1/principios-1 


\section{SEÇÃO V. CONSIDERAÇÕES FINAIS}

Apresentam-se no próximo capítulo as conclusões quanto aos objetivos e resultados alcançados no presente estudo, além de sugestões para pesquisas futuras.

\section{CONCLUSÕES}

Foi realizada a proposta de discussão sobre a inserção do conceito de serviços ecossistêmicos na Avaliação do Ciclo de Vida (ACV). Ressalta-se, portanto o caráter multidisciplinar do estudo, uma vez que foram empregados conceitos de Avaliação de Impacto do Ciclo de Vida, uso da terra e serviços ecossistêmicos. A evolução da temática dos serviços ecossistêmicos na ACV e os métodos disponíveis para quantificá-los foram mapeados na revisão de literatura. Nota-se que a maioria desses métodos se concentra nos impactos causados pelo uso da terra. A revisão também apontou que os indicadores escolhidos na AICV geralmente não abrangem os benefícios e valores fornecidos à sociedade pelos serviços ecossistêmicos.

A inclusão dos serviços ecossistêmicos na ACV é uma tarefa complexa, pois atravessa diferentes domínios do conhecimento e desafia as divisões estabelecidas na ACV. Através da revisão bibliográfica foi realizada uma comparação do modelo em cascata e do mecanismo ambiental do uso da terra na ACV. Além disso, o detalhamento da estrutura do modelo em cascata facilitou a identificação de aspectos relacionados ao solo em cada nível, provando ser uma maneira útil de mapear a cadeia de causa-e-efeito. A definição dos elementos através de processos e funções do solo até os benefícios obtidos e o respectivo valor também provou ser relevante para a compreensão da hierarquia entre serviços ecossistêmicos. A contribuição teórica do presente trabalho reside na atualização da abordagem dos impactos relacionados ao solo na AICV através da perspectiva do modelo em cascata de serviços ecossistêmicos. Assim, o modelo conceitual proposto como primeiro resultado deste trabalho é uma estrutura geral que pode apoiar refinamentos adicionais na AICV também de maneira regionalizada, incluindo novos tipos de serviços ecossistêmicos, bem como os benefícios fornecidos à sociedade. Ademais, ele amplia o processo de modelagem de impacto para uma perspectiva mais sistêmica, que pode melhorar não apenas os resultados de ACV, mas também as soluções e estratégias que diferentes partes interessadas derivam deles.

Já a avaliação dos modelos de caracterização com melhor potencial de uso e/ou adaptação para o Brasil pela robustez científica e disponibilidade de dados teve como resultado a adoção do modelo proposto por Brandão; Milà i Canals (2013) para a fase 
aplicada deste trabalho. Desta forma, foram calculados fatores de caracterização de impactos nos serviços ecossistêmicos relacionados à fertilidade do solo para o Brasil, através de um modelo de caracterização de AICV espacialmente diferenciado. No mecanismo ambiental foi definido como indicador informações do teor de Carbono Orgânico do Solo (COS), já comumente empregado em estudos da qualidade do solo, pois reflete o equilíbrio entre os ganhos de matéria orgânica, dependentes da produtividade e das práticas de manejo das culturas e perdas devido à decomposição pela ação de organismos do solo ou processos de lixiviação e erosão.

Considerando a necessidade de aperfeiçoamento nas metodologias de avaliação de impactos do uso da terra nos serviços ecossistêmicos e desenvolvimento da AICV regionalizada no Brasil, os dados coletados para adaptação e aplicação do modelo representa um avanço ao considerar as variações nos impactos entre diferentes regiões a partir de características como tipos de clima, vegetação e solo.

Diante das questões abordadas, destaca-se como contribuições inéditas o cálculo e disponibilização de mais de dois mil fatores de caracterização aos usuários de ACV, aplicáveis em 28 classes diferentes de uso da terra para 74 unidades biogeográficas (ASV). Além desses, são apresentados fatores de caracterização também para as 27 unidades federativas do país, que apesar de estarem agregados em divisões políticas, levam em consideração dados regionais de COS.

A principal limitação encontrada na condução do estudo é relacionada à baixa disponibilidade de conjuntos de dados organizados sobre o solo e estoques de COS nos níveis nacional e regional. Por consequência, o uso da metodologia Tier 1 do IPCC, utilizando valores de fatores padrão (default), introduzem elevadas incertezas. Assim, sugere-se como trabalhos futuros, a atualização dos resultados utilizando dados mais precisos quanto ao parâmetro de estoques de COS sob os diferentes usos da terra. Nesse sentindo mais dados de campo são necessários sobre o efeito das mudanças de uso da terra, induzidas pelo homem, na dinâmica do COS e sua relação com o tipo de solo e condição climática. Além disso, trabalhos envolvendo a mensuração e análise de tendências na variação de COS é uma tarefa desafiadora que precisa ser abordada por meio de metodologias e técnicas padronizadas de amostragem e modelagem que devem buscar o uso de soluções inovadoras para coleta e compartilhamento de dados.

Quanto às discussões sobre a integração entre ACV e serviços ecossistêmicos, neste trabalho foi proposta uma reformulação do mecanismo ambiental ligado ao uso da terra, fundamentado no modelo em cascata. Como recomendações futuras seria relevante 
complementar a avaliação de impacto com informações sobre as externalidades associadas à oferta e demanda de serviços ecossistêmicos, e eventualmente determinar indicadores a nível endpoint de custo-benefício.

Observou-se também que os serviços ecossistêmicos lidam com os benefícios obtidos do ambiente, enquanto a ACV avalia principalmente os impactos negativos, com categorias de impacto representando classes de problemas ambientais. Isso revela uma diferença significativa entre essas duas áreas. Trabalhos futuros visando a união destes campos podem levar a um melhor entendimento do sistema de produtos, não apenas focando em danos ambientais, mas também em impactos positivos e agregação de valor.

Finalmente, países como o Brasil, de grande importância no contexto de produção agrícola, devem priorizar o uso e manejo sustentável da terra evitando processos de perda de nutrientes, contaminação, erosão e compactação do solo bem como investir no desenvolvimento de bases de dado para o monitoramento da qualidade dos solos. Neste contexto, a avaliação dos impactos relacionados aos serviços ecossistêmicos do solo não só possibilita revelar as externalidades negativas como também pode auxiliar na priorização da eficiência dos recursos e manutenção da qualidade do ecossistema em processos de tomada de decisões. 


\section{REFERÊNCIAS}

ADHIKARI, K.; HARTEMINK, A. E. Linking soils to ecosystem services - A global review. Geoderma, v. 262, p. 101-111, 2016.

ALI, M.; KENNEDY, C. M.; KIESECKER, J.; GENG, Y. Integrating biodiversity offsets within Circular Economy policy in China. Journal of Cleaner Production, v. 185, p.32-43, 2018.

AMUNDSON, R.; BERHE, A. A.; HOPMANS, J. W.; OLSON, C.; SZTEIN, A. E.; SPARKS, D. L. Soil science. Soil and human security in the 21 st century. Science (New York, N.Y.), v. 348, n. 6235, p. 1261071, 2015.

APITZ, S. E. Ecosystem services and environmental decision making: Seeking order in complexity. Integrated Environmental Assessment and Management, v. 9, n. 2, p. 214-230, 2013.

ARBAULT, D. RIVIÈRE, M.; RUGANI, B.; BENETTO, E.; TIRUTA-BARNA, L. Integrated earth system dynamic modeling for life cycle impact assessment of ecosystem services. Science of the Total Environment, v. 472, p. 262-272, 2014.

ARONSON, J.; MILTON, S. J.; BLIGNAUT, J. Restoring Natural Capital: Science, Business, and Practice. Island Press, USA, 2007. 400p. ISBN-13: 978-1-59726-076-3.

ASSOCIAÇÃO BRASILEIRA DE NORMAS TÉCNICAS - ABNT. NBR ISO 14040: Gestão Ambiental - Avaliação do Ciclo de Vida - Princípios e Estrutura: ABNT, 2009a.

. NBR ISO 14044: Gestão Ambiental - Avaliação do Ciclo de Vida - Requisitos e Orientações. Brasil: ABNT, 2009b.

BANWART, S. Save our soils. Nature, v. 474, n. 7350, p. 151-152, 2011.

BARE, J. Life cycle impact assessment research developments and needs. Clean Technologies and Environmental Policy, v. 12, p. 341-351, 2010.

BARE, J. Recommendation for land use impact assessment: First steps into framework, theory, and implementation. Clean Technologies and Environmental Policy, v. 13, n. 1, p. 7-18, 2011.

BARRIOS, E. Soil biota, ecosystem services and land productivity. Ecological Economics, v. 64, n. 2, p. 269-285, 2007.

BASTA, N.; BUSALACCHI, D.; HUNDAL, L.; KUMAR, K.; DICK, R.; LANNO, R.; CARLSON, J.; COX, A. E.; GRANATO, T. C. Restoring ecosystem function in degraded urban soil using biosolids, biosolids blend, and compost. Journal of Environmental Quality, v. 45, 74-83, 2016.

BATJES, N. H. A global framework of soil organic carbon stocks under native vegetation for use with the simple assessment option of the Carbon Benefits Project system. Report 2010/10, Carbon Benefits Project (CBP) and ISRIC - World Soil Information, Wageningen, 2010.

BATJES, N. H. A homogenized soil data file for global environmental research: a subset of FAO, ISRIC and NRCS profiles (Version 1.0). Working Paper and Preprint 95/10, ISRIC, Wageningen, The Netherlands, 1995.

BATJES, N. H.; BRIDGES, E. M. Potential emissions of radioactively active gases from soil to atmosphere with special reference to methane: development of a global database (WISE). Journal of Geophysical Research, v. 99, p. 479-16 489, 1994. 
BAYER, C.; MARTIN-NETO, L.; MIELNICZUK, J.; PAVINATO, A.; DIECKOW, J. Carbon sequestration in two Brazilian Cerrado soils under no-till Soil Till. Res., v. 86, p. 237-245, 2006.

BERGHÖFER, A.; SCHNEIDER, A.; Indicators for Managing Ecosystem Services - Options \& Examples. ValuES Project Report. Helmholtz Zentrum für Umweltforschung (UFZ) GmbH, Leipzig, and Deutsche Gesellschaft für Internationale Zusammenarbeit (GIZ) GmbH, Eschborn. Germany. 49p., 2015.

BERNOUX, M.; CARVALHO, C. M. S.; VOLKOFF, B. $\mathrm{CO}_{2}$ emission from mineral soils following land-cover change Brazil. Global Change Biology, v. 7, p. 779-787, 2001.

BERNOUX, M.; DA CONCEIÇÃO, M. S. C.; VOLKOFF, B.; CERRI, C. C. Brazil's Soil Carbon Stocks. Soil Science Society of America Journal, v. 66, n. 3, p. 888-896, 2002.

BIE, C. A. J. M. de; LEEUWEN, J. A. van; ZUIDEMA, P. A. The land use database: a knowledge based software program for structured storage and retrieval of user defined land use data sets: user's reference manual. Version 1.04 for MS-DOS. [Enschede, The Netherlands]: International Institute for Geo-Information Science and Earth Observation: Food and Agriculture Organization: United Nations Environment Programme: Wageningen University, 41 p., 1996.

BJØRN, A.; OWSIANIAK, M.; LAURENT, A.; MOLIN, C.; WESTH, T. B.; HAUSCHILD, M. Z. Mapping and characterization of LCA networks. International Journal of Life Cycle Assessment, v. 18, n. 4, p. 812-827, 2013.

BOEREMA, A. Ecosystem services : study of human influences on nature and the effects for society. Universiteit Antwerpen, 2016.

BOEREMA, A.; REBELO, A.J.; BODI, M.B.; ESLER, K.J.; MEIRE, P. Are ecosystem services adequately quantified? Journal of Applied Ecology, v. 54, n. 2, p. 358-370, 2017.

BONDEAU, A. SMITH, P. C.; ZAEHLE, S.; SCHAPHOFF, S.; LUCHT, W.; CRAMER, W.; GERTEN, D.; LOTZE-CAMPEN, H.; MÜLLER, C.; REICHSTEIN, M.; SMITH, B. Modelling the role of agriculture for the 20th century global terrestrial carbon balance. Global Change Biology, v. 13, n. 3, p. 679-706, 2007.

BOUMA, J. BROLL, G.; CRANE, T. A.; DEWITTE, O.; GARDI, C.; SCHULTE, R. P.O.; TOWERS, W. Soil information in support of policy making and awareness raising. Current Opinion in Environmental Sustainability, v. 4, p. 552-558, 2012.

BOUMA, J. Soil science contributions towards Sustainable Development Goals and their implementation: Linking soil functions with ecosystem services. Journal of Plant Nutrition and Soil Science, v. 177, n. 2, p. 111-120, 2014.

BOYD, J.; BANZHAF, S. What are ecosystem services? The need for standardized environmental accounting units. Ecological Economics, v. 63, p. 616-626, 2007.

BRANDÃO, M.; I CANALS, L. M.; CANALS, L. M. Global characterisation factors to assess land use impacts on biotic production. International Journal of Life Cycle Assessment, v. 18, n. 6, p. 1243-1252, 2013.

BRASIL. Lei n. 12.651, de 25 de maio de 2012. Dispõe sobre a proteção da vegetação nativa; altera as Leis nos 6.938, de 31 de agosto de 1981, 9.393, de 19 de dezembro de 1996, e 11.428, de 22 de dezembro de 2006; revoga as Leis nos 4.771, de 15 de setembro de 1965, e 7.754, de 14 de abril de 1989, e a Medida Provisória no 2.166-67, de 24 de agosto de 2001; e dá outras providências. 2012. 
Diário Oficial da União, Brasília, DF, Ano CXLIX, n. 102, 28 maio 2012. Seção 1, p.1. Disponível em <http://www.planalto.gov.br/ccivil_03/_Ato2011-2014/2012/Lei/L12651.htm>. Acesso em 10 março de 2018.

BRASIL. Ministério da Ciência, Tecnologia e Inovação. Secretaria de Políticas e Programas de Pesquisa e Desenvolvimento. Coordenação-Geral de Mudanças Globais de Clima. Terceira Comunicação Nacional do Brasil à Convenção-Quadro das Nações Unidas sobre Mudança do Clima Volume III/ Ministério da Ciência, Tecnologia e Inovação. Brasília: Ministério da Ciência, Tecnologia e Inovação, 2016. 336 p.: il. ISBN: 978-85-88063-19-8

BRASIL. Resolução $\mathbf{n}^{0}$ 04/2010. Dispõe sobre a Aprovação do Programa Brasileiro de Avaliação do Ciclo de Vida e dá outras providências. Conselho Nacional de metrologia, Normalização, e Qualidade Industrial - CONMETRO, Ministério do Desenvolvimento, Indústria e Comércio Exterior - MDIC.

BROUWER, R.; BRANDER, L.; KUIK, O.; PAPYRAKIS, E.; BATEMAN, I. A synthesis of approaches to assess and value ecosystem services in the EU in the context of TEEB. University of Amsterdam, 2013.

BRUEL, A.; TROUSSIER, N.; GUILLAUME, B.; SIRINA, N. Considering Ecosystem Services in Life Cycle Assessment to Evaluate Environmental Externalities. Procedia CIRP, v. 48, n. May, p. 382-387, 2016.

BURKHARD, B.; KROLL, F.; NEDKOV, S.; MÜLLER, F. Mapping ecosystem service supply, demand and budgets. Ecol. Indic. 21, 17-29, 2012.

CALZOLARI, C.; UNGARO, F.; FILIPPI, N.; GUERMANDI, M.; MALUCELLI, F.; MARCHI, N.; STAFFILANI, F.; TAROCCO, P. A methodological framework to assess the multiple contributions of soils to ecosystem services delivery at regional scale. Geoderma, v. 261, p. 190-203, 2016.

CANADELL, J.G.; KIRSCHBAUM, M.U.F.; KURZ, W.A.; SANZ, M.-J.; SCHLAMADINGER, B.; YAMAGATA, Y. Factoring out natural and indirect human effects on terrestrial carbon sources and sinks. Environmental Science \& Policy v. 10, p. 370-384, 2007.

CAO, V.; MARGNI, M.; FAVIS, B.D.; DESCHÊNES, L. Aggregated indicator to assess land use impacts in LCA based on the economic value of ecosystem services. Journal of Cleaner Production, p. 1-11, 2015.

CAPELO, J.; MASQUITA, S.; COSTA, J. C.; RIBEIRO, S.; ARSÉNIO, P.; NETO, C.; MONTEIROHENRIQUES, T.; AGUIAR, C.; HONRADO, J.; ESPÍRITO-SANTO, D.; LOUSÃ, M. A methodological approach to potential vegetation modeling using GIS techniques and phytosociological expert-knowledge: Application to mainland Portugal. Phytocoenologia, v. 37, n. 3-4, p. 399-415, 2007.

CARRANZA, M. L.; RICOTTA, C.; FORTINI, P.; BLASI, C. Quantifying landscape change with actual vs. potential natural vegetation maps. Phytocoenologia, v. 33, p. 591-601 2003.

CERRI, C. E. P.; EASTER, M.; PAUSTIAN, K.; KILLIAN, K.; COLEMAN, K.; BERNOUX, M.; FALLOON, P.; POWLSON, D.; BATJES, N. H.; MILNE, E.; CERRI, C. C. Predicted soil organic carbon stocks and changes in the Brazilian Amazon between 2000 and 2030. Agriculture, Ecosystems and Environment, v. 122, n. 1, p. 58-72, 2007.

CHEN, H.; YANG, Y.; YANG, Y.; JIANG, W.; ZHOU, J. A bibliometric investigation of life cycle assessment research in the web of science databases. The International Journal of Life Cycle Assessment, p. 1674-1685, 2014. 
CHERUBINI, E. (Org.) Diálogos Setoriais Brasil e União Europeia: desafios e soluções para o fortalecimento da ACV no Brasil. Instituto Brasileiro de Informação em Ciência e Tecnologia Ibict, Brasília: 2015.

CHOUDHURY, K.; JANSEN, L. J. M. Terminology for Integrated Resources Planning and Management. Rome: Food and Agriculture Organization of the United States; Land and Water Development Division, 1999.

CHRISTENSEN, B. T.; JOHNSTON, A. E. Soil organic matter and soil quality - Lessons learned from long-term experiments at Askov and Rothamsted. In: GREGORICH, E.G.; CARTER, M.R. (Eds.) Soil quality for crop production and ecosystem health. Developments in soil science, v.25. Elsevier Science, p. 399-430, 1997.

CLEWELL, A. F.; ARONSON, J. Overview. In: Ecological Restoration. The Science and Practice of Ecological Restoration. Island Press, Washington, DC, 2013.

COELHO, M. R.; SANTOS, H. G.; SILVA, E. F.; AGLIO, M. D. O recurso natural solo. In: MANZATTO, C.V.; FREITAS JUNIOR, E \& PERES, J.R.R. (Org.). Uso Agrícola dos Solos Brasileiros. Rio de Janeiro: EMBRAPA SOLOS, p. 1-11, 2002.

CONANT, R. T.; PAUSTIAN, K.; ELLIOTT, E. T. Grassland management and conversion into grassland: effects on soil carbon. Ecological Applications, v. 11, p. 343-355, 2001.

COOK, D.; DAVÍĐSDÓTTIR, B.; KRISTÓFERSSON, D. M. An ecosystem services perspective for classifying and valuing the environmental impacts of geothermal power projects. Energy for Sustainable Development, v. 40, p. 126-138, 2017.

CORINE. Land cover technical guide: addendum 2000. Copennhagen: European Environment Agency, 2000. 2 parts (Technical Report, n40). Disponível em: http://www.eea.europa.eu/publications/tech40add. Acesso em: 27 ago. 2015.

COSTANZA, R.; DALY, H.; FOLKE, C.; HAWKEN, P.; HOLLING, C. S.; MCMICHAEL, A.J.; PIMENTEL, D.; RAPPORT, D. Managing our Environmental Portfolio, BioScience, v. 50, Issue 2, 1 February 2000, p.149-155, 2000.

COSTANZA, R.; D'ARGE, R.; DE GROOT, R.; FARBER, S.; GRASSO, M.; HANNON, B.; LIMBURG, K.; NAEEM, S.; O'NEILL, R. V.; PARUELO, J.; RASKIN, R. G.; SUTTON, P.; VAN DEN BELT, M. The value of the world's ecosystem services and natural capital. Nature, v. 387, n. 6630, p. 253-260, 1997.

COSTANZA, R., DE GROOT, R., BRAAT, L., KUBISZEWSKI, I., FIORAMONTI, L., SUTTON, P., GRASSO, M. Twenty years of ecosystem services: how far have we come and how far do we still need to go? Ecosystem Services, v. 28, p. 1-16, 2017.

CRENNA, E.; SALA, S.; POLCE, C.; COLLINA, E. Pollinators in life cycle assessment: towards a framework for impact assessment. Journal of Cleaner Production, v. 140, p. 525-536, 2017.

DAILY, G. C. Introduction: What are ecosystem services? In GC Daily, Ed. Nature's Services: Societal Dependence on Natural Ecosystems, Island Press, Washington, DC., 1997.

DAILY, GC, T SÖDERQVIST, S ANIYAR, K ARROW, P DASGUPTA, P EHRLICH, C FOLKE, A-M JANSSON, B-O JANSSON, N KAUTSKY, S LEVIN, J LUBCHENCO, K-G MÄLER, D SIMPSON, D STARRETT, D TILMAN, B WALKER. The value of nature and the nature of value. Science, v. 289, p. 395-396, 2000. 
DALY, H.E.; FARLEY, J. Ecological Economics: principles and applications. Island Press, Washington, DC, 2004.

DE BAAN, L.; ALKEMADE, R.; KOELLNER, T. Land use impacts on biodiversity in LCA: A global approach. International Journal of Life Cycle Assessment, v. 18, n. 6, p. 1216-1230, 2013.

DE GROOT, R. S. Functions of Nature: Evaluation of Nature in Environmental Planning, Management and Decision Making. Journal of Chemical Information and Modeling, v. 53, n. 9, p. 1689-1699, 1992.

DE GROOT, R. S.; ALKEMADE, R.; BRAAT, L.; HEIN, L.; WILLEMEN, L. Challenges in integrating the concept of ecosystem services and values in landscape planning, management and decision making. Ecosystem Services - Bridging Ecology, Economy and Social Sciences, v. 7, p. 260-272, 2010a.

DE GROOT, R.; FISHER, B.; CHRISTIE, M.; ARONSON, J.; BRAAT, L.; GOWDY, J.; HAINESYOUNG, R.; MALTBY, E.; NEUVILlE, A.; POLASKY, S.; PORTELA, R.; RING, I. (2010) Integrating the ecological and economic dimensions in biodiversity and ecosystem service valuation. In: Kumar P (ed.) The Economics of Ecosystems and Biodiversity: Ecological and Economic Foundations, London: Earthscan, 9-40, 2010b.

DE GROOT, R.S.; VAN DER PERK, J.; CHIESURA, A.; MARGULIEW, S. Ecological functions and socio-economic values of critical natural capital as a measure for ecological integrity and environmental health. In: Crabbe, P., Holland, A., Ryszkowski, L., Westra, L. (Eds.), Implementing Ecological Integrity: Restoring Regional and Global Environmental and Human Health. NATOScience Series, IV. Earth and Environmental Sciences, vol. 1. Kluwer Academic Publishers, Dordrecht/Boston/London, p. 191-214, 2000.

DE SOUZA, D. M.; LOPES, G. R.; HANSSON, J.; HANSEN, K. Ecosystem services in life cycle assessment: A synthesis of knowledge and recommendations for biofuels. Ecosystem Services, v. 30, p. 200-210, 2018.

DEB, S.; BHADORIA, P. B. S.; MANDAL, B.; RAKSHIT, A.; SINGH, H. B. Soil organic carbon: Towards better soil health, productivity and climate change mitigation. Climate change and Environmental Sustainability, v. 3, p. 26-34, 2015.

DEXTER, A.R.; YOUNGS, I.M. Soil physic toward 2000. Soil and Tillage Research, v. 24, p. 101106, 1992.

DOMINATI, E.; MACKAY, A.; GREEN, S.; PATTERSON, M. A soil change-based methodology for the quantification and valuation of ecosystem services from agro-ecosystems: A case study of pastoral agriculture in New Zealand. Ecological Economics, v. 100, p. 119-129, 2014.

DOMINATI, E.; PATTERSON, M.; MACKAY, A. A framework for classifying and quantifying the natural capital and ecosystem services of soils. Ecological Economics, v. 69, n. 9, p. 1858-1868, 2010.

ECOLOGIC INSTITUTE; SERI (2010) Establishing Environmental Sustainability Thresholds and Indicators. Final report to the European Commission's DG Environment, 2010.

EHRLICH, P. R.; MOONEY, H. A. Extinction, substitution, and ecosystem services. BioScience, v. 33 , n. 4, p. 248-254, 1983.

ELLEN MACARTHUR FOUNDATION. Uma economia circular no Brasil: uma exploratória inicial. 2017.

Disponível

em: 
$<$ https://www.ellenmacarthurfoundation.org/assets/downloads/languages/UmaEconomia-Circular-noBrasil_Uma-Exploracao-Inicial.pdf>. Acesso em: 23 fev. 2018.

EMPRESA BRASILEIRA DE PESQUISA AGROPECUÁRIA (EMBRAPA). Centro Nacional de Pesquisa em Solos. Sistema brasileiro de classificação de solos. Brasília, DF: Embrapa Produção de Informação, 412 p., 1999.

EUROPEAN PLATFORM ON LIFE CYCLE ASSESSMENT (EPLCA). List of tools: Internet site developed by the European Commission. Direction Generale. Joint Research Centre. Institue for Environment and Sustainability, 2010.

FARBER, S.; COSTANZA, R.; CHILDERS, D. L.; ERICKSON, J.; GROSS, K.; GROVE, M.; HOPKINSON, C. S.; KAHN, J.; PINCETL, S.; TROY, A.; WARREN, P. WILSON, M. Linking Ecology and Economics for Ecosystem Management. BioScience, v. 56, n. 2, p. 121, 2006.

FARLEY, J. Ecosystem services: The economics debate. Ecosystem Services, v. 1, p. 40-49, 2012.

FENGLER, F. H.; BRESSANE, A.; CARVALHO, M. M.; LONGO, R.M.; DE MEDEIROS, G. A.; DE MELO, W. J.; JAKOVAC, C. C.; RIBEIRO, A I. Forest restoration assessment in Brazilian Amazonia: A new clustering-based methodology considering the reference ecosystem. Ecological Engineering, v. 108, p. 93-99, 2017.

FERREIRA, A. C. C.; LEITE, L. F. C.; DE ARAÚJO, A. S. F.; EISENHAUER, N. Land-Use Type Effects on Soil Organic Carbon and Microbial Properties in a Semi-arid Region of Northeast Brazil. Land Degradation and Development, v. 27, p. 171-178, 2016.

FINNVEDEN, G.; HAUSCHILD, M. Z.; EKVALL, T.; GUINÉE, J.; HEIJUNGS, R.; HELLWEG, S.; KOEHLER, A.; PENNINGTON, D.; SUH, S. Recent developments in Life Cycle Assessment. Journal of Environmental Management, v. 91, n. 1, p. 1-21, 2009.

FISHER, B.; KERRY TURNER, R. Ecosystem services: Classification for valuation. Biological Conservation, v. 141, p. 1167-1169, 2008.

FISHER, B.; TURNER, R. K.; MORLING, P. Defining and classifying ecosystem services for decision making. Ecological Economics, v. 68, p. 643-653 2009.

FOLEY, J. A.; DEFRIES, R.; ASNER, G. P.; BARFORD, C.; BONAN, G.; CARPENTER, S. R.; CHAPIN, F. S.; COE, M. T.; DAILY, G. C.; GIBBS, H. K.; HELKOWSKI, J. H.; HOLLOWAY, T.; HOWARD, E. A.; KUCHARIK, C. J.; MONFREDA, C.; PATZ, J. A.; PRENTICE, I. C.; RAMANKUTTY, N.; SNYDER, P. K. Global consequences of land use. Science, v. 309, n. 5734, p. 570-574, 2005.

FOOD AND AGRICULTURE ORGANIZATION OF THE UNITED NATIONS (FAO). Soil Organic Carbon: the hidden potential. Food and Agriculture Organization of the United Nations Rome, Italy, 2017.

. Status of the World's Soil Resources (SWSR) - Main Report. Rome, Italy, Food and Agriculture Organization of the United Nations and Intergovernmental Technical Panel on Soils, 648 p, 2015.

A framework for land evaluation. Soils bulletin 32. Soil resources development and conservation service land and water development division, Rome, 1976.

.Global Soil Organic Carbon Map (GSOCmap) Technical Report. Rome. 162 p. 2018. 
Unlocking the Potential of Soil Organic Carbon: Outcome Document of the Global Symposium on Soil Organic Carbon, 21-23, FAO Headquarters, Rome, Italy, 2017.

. World Reference Base for Soil Resources, ISSS-ISRIC-FAO. World Soil Resources Report No. 84. Rome, 1998.

GAVA, O., BARTOLINI, F., VENTURI, F., BRUNORI, G., ZINNAI, A., \& PARDOSSI, A. A Reflection of the Use of the Life Cycle Assessment Tool for Agri-Food Sustainability. Sustainability, v. 11, n. 1, p. 71, 2019.

GHALEY, B. B.; PORTER, J. R.; SANDHU, H. S. Soil-based ecosystem services: a synthesis of nutrient cycling and carbon sequestration assessment methods. International Journal of Biodiversity Science, Ecosystem Services \& Management, v. 10 (3), p. 177-186, 2014.

GHIMIRE, R.; NORTON, J. B.; NORTON, U. Soil organic matter dynamics under irrigated perennial forage-annual crop rotations. Grass and Forage Science, v. 73, p. 907-917, 2018.

GIANNETTI, B. F.; ALMEIDA, C. M. V. B. Ecologia Industrial. São Paulo: Edgard Blücher, 2006.

GÓMEZ-BAGGETHUN, E. DE GROOT, R.; LOMAS, P.L.; MONTES, C. The history of ecosystem services in economic theory and practice: From early notions to markets and payment schemes. Ecological Economics, v. 69, n. 6, p. 1209-1218, 2010.

GOMIERO, T. Soil degradation, land scarcity and food security: Reviewing a complex challenge. Sustainability, v. 8, 281, 2016.

GOUVELLO, C. Estudo de baixo carbono para o Brasil. Brasília: Banco Mundial, p. 38, 2010.

GREGORICH, E. G.; CARTER, M. R. Soil Quality for Crop Production and Ecosystem Health. Developments in Soil Science 25, Elsevier, Amsterdam, p. 115-141, 1997.

GROOT, R. S. DE; WILSON, M. A.; BOUMANS, R. M. J. A typology for the classification, description and valuation of ecosystem functions, goods and services. Ecological Economics, v. 41, p. 393-408, 2002.

HAINES, Y. R.; POTSCHIN, M. Common International Classification of Ecosystem Services (CICES): 2011 Update. European Environment Agency, p. 1-14, 2011.

Common International Classification of Ecosystem Services (CICES) V5.1 and Guidance on the Application of the Revised Structure, 53p., 2018

. Common International Classification of Ecosystem Services (CICES): Consultation on Version 4, August-December 2012. EEA Framework Contract No EEA/IEA/09/003, 2013.

. The links between biodiversity, ecosystem services and human well-being. Ecosystem Ecology: A new Synthesis, p. 110-139, 2010.

HAUSCHILD, M., GOEDKOOP, M., GUINÉE, J., HEIJUNGS, R., HUIJBREGTS, M., JOLLIET, O., MARGNI, M., SCHRYVER, A., HUMBERT, S., LAURENT, A., SALA, S., PANT, R. Identifying best existing practice for characterization modelling in life cycle impact assessment. International Journal of Life Cycle Assessment, v. 18, p. 683-697, 2013. 
HAUSCHILD, M.; JESWIET, J.; ALTING, L. From life cycle assessment to sustainable production: Status and perspectives. CIRP Annals - Manufacturing Technology, Paris, v. 54, n. 2, p. 535-555, 2005.

HAYGARTH, P. M.; RITZ, K. The future of soils and land use in the UK: Soil systems for the provision of land-based ecosystem services. Land Use Policy, v. 26, p. S187-S197, 2009.

HÄYHÄ, T.; FRANZESE, P. P. Ecosystem services assessment: A review under an ecologicaleconomic and systems perspective. Ecological Modelling, v. 289, p.124-132, 2014.

HELLWEG, S.; MILÀ I CANALS, L. Emerging approaches, challenges and opportunities in life cycle assessment. Science, v. 344, n. 6188, p. 1109-13, 2014.

HERNANI, L. C.; FREITAS, P. L.; PRUSKI, F. F.; DE MARIA, I.C.; CASTRO FILHO, C. A erosão e seu impacto. In: MANZATTO, C. V.; FREITAS JÚNIOR, E.; PERES, J. R. R. (Org.). Uso agrícola dos solos brasileiros. Rio de Janeiro: EMBRAPA, p. 47-60, 2002.

HEWITT, A.; DOMINATI, E.; WEBB, T.; CUTHILL, T. Soil natural capital quantification by the stock adequacy method. Geoderma, v. 241-242, p. 107-114, 2015.

HOBBS, P.R.; SAYRE, K.D.; GUPTA, R.K. The role of conservation agriculture in sustainable agriculture. Philosophical Transactions of the Royal Society, 363: 543-555, 2008.

HUNT, R.G.; FRANKLIN, W.E. LCA - How it came about. Int J Life Cycle Assess, v.1, p. 4-7, 1996.

INSTITUTO BRASILEIRO DE GEOGRAFIA E ESTATÍSTICA (IBGE). Indicadores de desenvolvimento sustentável: Brasil: 2015. Coordenação de Recursos Naturais e Estudos Ambientais e Coordenação de Geografia. Rio de Janeiro: IBGE, 352p. 2015.

. Manual Técnico de Uso da Terra. 171p., Instituto Brasileiro de Geografia e Estatística (IBGE), Manuais Técnicos em Geociências, Rio de Janeiro, RJ, Brasil, 2013. ISBN: 978-85-2404307-9.

<http://www.ibge.gov.br/home/download/geociencias.shtm>. Acesso em: 28 out. 15

Mapa da cobertura e uso da terra. Esc. 1:5.000.000. 1. ed. 2010. Disponível em: . Mapa de vegetação do Brasil, escala 1:5,000,000. Fundação Instituto Brasileiro de Geografia e Estatística, Rio de Janeiro, 1988.

Monitoramento da cobertura e uso da terra do Brasil: 2014 - 2016. 29p. Instituto Brasileiro de Geografia e Estatística (IBGE), Rio de Janeiro, RJ, Brasil, 2018.

INSTITUTO BRASILEIRO DO MEIO AMBIENTE E DOS RECURSOS NATURAIS RENOVÁVEIS (IBAMA). Relatório de Qualidade do Meio Ambiente - RQMA. Brasília: Ibama, 2013.

IPCC - Intergovernmental Panel On Climate Change. IPCC Guidelines for National Greenhouse Gas Inventories. Prepared by the National Greenhouse Gas Inventories Programme. Kanagawa: Institute for Global Environmental Strategies, 2006.

Good Practice Guidance for Land Use, Land-Use Change and Forestry. Kanagawa: Institute for Global Environmental Strategies, 2003. 
Technical Assessment of IPCC Inventory Guidelines - Results of Questionnaire Survey AFOLU. Bonn: s.n.. 2015.

IPCC/UNEP/OECD/IEA. Revised 1996 IPCC Guidelines for national greenhouse gas inventories: Reporting Instructions (Vol 1); Workbook (Vol. 2); Reference Manual (Vol. 3). Intergovernamental Panel on Climate Change, United Nations Environment Programe, Organization for Economic Co-Operation and Development, International Energy Agency, Paris, 1997.

JAGADAMMA, S.; LAL, R.; HOEFT, R. G.; NAFZIGER, E. D.; ADEE, E. A. Nitrogen fertilization and cropping systems effects on soil organic carbon and total nitrogen pools under chisel-plow tillage in Illinois. Soil and Tillage Research, v. 95, p. 348-356, 2007.

JAX, K. Function and "functioning" in ecology: What does it mean? Oikos, v. 111, p. 641-648, 2005.

JOBBÁGY, E.G.; JACKSON, R.B. The vertical distribution of soil organic carbon and its relation to climate and vegetation. Ecological Applications, v.10, p.423-436, 2000.

JOINT RESEARCH CENTRE OF THE EUROPEAN COMMISSION (EC-JRC). Framework and Requirements for Life Cycle Impact Assessment Models and Indicators. ILCD Handbook International Reference Life Cycle Data System, European Union. 2010a.

General guide for Life Cycle Assessment - Detailed guidance. ILCD Handbook International Reference Life Cycle Data System, European Union. 2010b.

JOLLIET, O., MÜLLER-WENK, R., BARE, J., BRENT, A., GOEDKOOP, M., HEIJUNGS, R., ITSUBO, N., PEÑA, C., PENNINGTON, D., POTTING, J., REBITZER, G., STEWART, M., DE HAES, H., WEIDEMA, B. The LCIA midpoint-damage framework of the UNEP/SETAC life cycle initiative, The International Journal of Life Cycle Assessment, Volume 9, Issue 6, pp 394- 404, Novembro, 2004.

JÓNSSON, J. Ö. G.; DAVÍDSDÓTTIR, B. Classification and valuation of soil ecosystem services. Agricultural Systems, v. 145, p. 24-38, 2016.

KANDZIORA, M.; BURKHARD, B.; MÜLLER, F. Interactions of ecosystem properties, ecosystem integrity and ecosystem service indicators: A theoretical matrix exercise. Ecological Indicators, v. 28, p. 54-78, 2013.

KAREIVA, P.; TALlIS, H.; RICKETTS, T.H.; DAILY, G.C.; POLASKY, S. Natural Capital: Theory and Practice of Mapping Ecosystem Services. Oxford University Press, 2011.

KeESSTRA, S. D., BOUMA, J., WALlingA, J., TITTONELl, P., SMITH, P., CERDÀ, A., MONTANARELLA, L., QUINTON, J. N., PACHEPSKY, Y., VAN DER PUTTEN, W. H., BARDGETT, R. D., MOOLENAAR, S., MOL, G., JANSEN, B.; FRESCO, L. O.: The significance of soils and soil science towards realization of the United Nations Sustainable Development Goals, SOIL, v. 2, p. 111-128, 2016.

KOBIYAMA, M.; USHIWATA,C.T.; BARCIK, C. Recuperação de Áreas Degradas: conceito, um exemplo e uma sugestão. Rio de Janeiro: Saneamento e Progresso, p. 95-102,1993.

KOELLNER, T.; DE BAAN, L.; BECK, T.; BRANDÃO, M.; CIVIT, B.; GOEDKOOP, M.; MARGNI, M.; MILÀ I CANALS, L.; MÜLLER-WENK, R.; WEIDEMA, B.; WITTSTOCK, B. Principles for life cycle inventories of land use on a global scale. International Journal of Life Cycle Assessment, v. 18, n. 6, p. 1203-1215, 2013 a. 
. UNEP-SETAC guideline on global land use impact assessment on biodiversity and ecosystem

services in LCA. International Journal of Life Cycle Assessment, v. 18, n. 6, p. 1188-1202, 2013b.

KOELLNER, T.; GEYER, R. Global land use impact assessment on biodiversity and ecosystem services in LCA. International Journal of Life Cycle Assessment, v. 18, n. 6, p. 1185-1187, 2013.

KOELLNER, T.; SCHOLZ, R. Assessment of land use impacts on the natural environment. Part 2: Generic characterization factors for local species diversity in Central Europe. International Journal of Life Cycle Assessment, v. 13, n. 1, p. 32-48, 2008.

KREMEN, C., OSTFELD, R.S. A call to ecologists: measuring, analyzing, and managing ecosystem services. Frontiers in Ecology and the Environment, v. 3, p. 540-548, 2005.

LA NOTTE, A.; D'AMATO, D.; MÄKINEN, H.; PARACCHINI, M. L.; LIQUETE, C.; EGOH, B.; GENELETTI, D.; CROSSMAN, N. D. Ecosystem services classification: A systems ecology perspective of the cascade framework. Ecological Indicators, v. 74, p. 392-402, 2017.

LADONI, M.; BASIR, A.; ROBERTSON, P. G.; KRAVCHENKO, A. N. Scaling-up: Cover crops differentially influence soil carbon in agricultural fields with diverse topography. Agriculture, Ecosystems and Environment, v. 225, p. 93-103, 2016.

LAL R. Soil carbon sequestration impacts on global climate change and food security. Science, v. 304, p. 1623-1627, 2004.

LANGE, M. V. A mudança do estoque de carbono por transformação da terra e seu uso no Inventário de Ciclo de Vida de produtos de origem renovável: estudo de caso da possível expansão da palma de óleo na Amazônia legal brasileira. 2012. 90 f. Dissertação (Mestrado em Engenharia Mecânica e de Materiais), Universidade Tecnológica Federal do Paraná, Curitiba, 2012.

LI, X. G.; ZHANG, P. L.; YIN, P.; LI, Y. K.; MA, Q. F.; LONG, R. J. Soil organic carbon and nitrogen fractions and water-stable aggregation as affected by cropping and grassland reclamation in an arid sub-alpine soil. Land Degradation and Development, v. 20, p. 176-186, 2009.

LYONS, K. G.; BRIGHAM, C. A.; TRAUT, B.H.; SCHWARTZ, M. W. Rare Species and Ecosystem Functioning. Conservation Biology, v. 19, n. 4, p. 1019-1024, 2005.

MAES, J.; EGOH, B.; WILLEMEN, L.; LIQUETE, C.; VIHERVAARA, P.; SCHÄGNER, J.P.; GRIZZETTI, B.; DRAKOU, E.G.; LA NOTTE, A.; ZULIAN, G.; BOURAOUI, F.; LUISA PARACCHINI, M.; BRAAT, L.; BIDOGLIO, G. Mapping ecosystem services for policy support and decision making in the European Union. Ecosystem Services, v. 1, n. 1, p. 31-39, 2012.

MAES, J.; LIQUETE, C.; TELLER, A.; ERHARD, M.; PARACCHINI, MARIA L.; BARREDO, J. I.; GRIZZETTI, B.; CARDOSO, A.; SOMMA, F.; PETERSEN, J. E.; MEINER, A.; GELABERT, E. R.; ZAL, N.; KRISTENSEN, P.; BASTRUP-BIRK, A.; BIALA, K.; PIRODDI, C.; EGOH, B.; DEGEORGES, P.; FIORINA, C.; SANTOS-MARTIN, F.; NARUŠEVIČIUS, V.; VERBOVEN, J.; PEREIRA, H. M.; BENGTSSON, J.; GOCHEVA, K.; MARTA-PEDROSO, C.; SNÄLL, T.; ESTREGUIL, C.; SAN-MIGUEL-AYANZ, J.; PÉREZ-SOBA, M.; GRÊT-REGAMEY, A.; LILLEBØ, A. I. MALAK, D. A.; CONDÉ, S.; MOEN, J.; CZÚCZ, B.; DRAKOU, E. G.; ZULIAN, G.; LAVALLE, C. An indicator framework for assessing ecosystem services in support of the EU Biodiversity Strategy to 2020. Ecosystem Services, v. 17, p. 14-23, 2016. 
MAES, J.; PARACCHINI, M.L.; ZULIAN, G. A European assessment of the provision of ecosystem services - Towards an atlas of ecosystem services. JRC Scientific and Technical Reports (EUR collection) JRC63505. Publications Office of the European Union, 2011.

MAES J, TELLER A, ERHARD $M$, LIQUETE C, BRAAT L, BERRY P, EGOH B, PUYDARRIEUX P, FIORINA C, SANTOS F, PARACCHINI ML et al. Mapping and Assessment of Ecosystems and their Services. An analytical framework for ecosystem assessments under action 5 of the EU biodiversity strategy to 2020 Publications office of the European Union, Luxembourg, 2013. ISBN 978-92-79-29369-6

MAIA DE SOUZA, D.; BRAGA, T.; BRITO DE FIGUEIRÊDO, M. C.; FOLEGATTI MATSUURA, M. I. S.; TEIXEIRA DIAS, F. R.; UGAYA, C. M. L. Life cycle thinking in Brazil: challenges and advances towards a more comprehensive practice. The International Journal of Life Cycle Assessment, v. 22, p. 462-465, 2016.

MAILLARD, É.; ANGERS, D. A. Animal manure application and soil organic carbon stocks: A metaanalysis. Global Change Biology, v. 20, p. 666-679, 2014.

MARQUES, J. D. O.; LUIZÃO, F.J.; TEIXEIRA, W.G.; ARAÚJO, E.M. Carbono Orgânico em solos sob floresta na Amazônia Central. In: VIII Congresso Norte Nordeste de Pesquisa e Inovação CONNEPI, Salvador-BA, 2013, ISBN 978-85-67562-01-8.

MARROQUÍN, M. C. Adequação às condições brasileiras de modelo de caracterização para a categoria de impacto do uso do solo. Dissertação (Mestrado em Engenharia Química). Escola Politécnica da Universidade de São Paulo, São Paulo, 2013.

MARTIN-LOPEZ, B.; MONTES, C.; BENAYAS, J. Economic valuation of biodiversity conservation: the meaning of numbers. Conserv. Biol. v. 22, p. 624-635, 2008.

MCGARIGAL, K.; MARKS, B.J. Fragstats - Spatial Pattern Analysis Program for Quantifying Landscape Structure. Forest Science Department, Oregon State University, Corvallis, 1994.

MEA. Millennium ecosystem assessment. Ecosystems and human well-being: current state and trends. Island Press, Washington, 2005.

MILÀ I CANALS, L. Contributions to LCA methodology for agricultural systems: Site dependency and soil degradation impact assessment. 250p. Tese (Doutorado em Ciências Ambientais) Universidad Autònoma de Barcelona, Barcelona, 2003.

MILÀ I CANALS, L.; BAUER, C.; DEPESTELE, J.; DUBREUIL, A.; KNUCHEL, R.F.; GAILLARD, G.; MICHELSEN, O.; MÜLLER-WENK, R.; RYDGREN, B. Key elements in a framework for land use impact assessment within LCA. International Journal of Life Cycle Assessment, v. 12, n. 1, p. 5-15, 2007a.

MILÀ I CANALS L.; ROMANYA, J.; COWELL, S. J. Method for assessing impacts on life support functions (LSF) related to the use of 'fertile land' in Life Cycle Assessment (LCA). J Clean Prod, v.15, p.1426-1440, 2007b.

MILNE, E.; BANWART, S. A.; NOELLEMEYER, E.; ABSON, D. J.; BALLABIO, C.; BAMPA, F.; BATIONO, A.; BATJES, N. H.; BERNOUX, M.; BHATTACHARYYA, T.; BLACK, H.; BUSCHIAZZO, D. E.; CAI, Z.; CERRI, C. E.; CHENG, K.; COMPAGNONE, C.; CONANT, R.; COUTINHO, H. L C.; DE BROGNIEZ, D.; BALIEIRO, F. DE C.; DUFFY, C.; FELlER, C.; FIDALGO, E. C C.; DA SILVA, C. F.; FUNK, R.; GAUDIG, G.; GICHERU, P. T.; GOLDHABER, M.; GOTTSCHALK, P.; GOULET, F.; GOVERSE, T.; GRATHWOHL, P.; JOOSTEN, H.; KAMONI, P. T.; KIHARA, J.; KRAWCZYNSKI, R.; LA SCALA, N.; LEMANCEAU, P.; LI, L.; LI, 
Z.; LUGATO, E.; MARON, P. A.; MARTIUS, C.; MELILLO, J.; MONTANARELLA, L.; NIKOLAIDIS, N.; NZIGUHEBA, G.; PAN, G.; PASCUAL, U.; PAUSTIAN, K.; PI??EIRO, GE.; POWLSON, D.; QUIROGA, A.; RICHTER, D.; SIGWALT, A.; SIX, J.; SMITH, J.; SMITH, P.; STOCKING, M.; TANNEBERGER, F.; TERMANSEN, M.; VAN NOORDWIJK, M.; VAN WESEMAEL, B.; VARGAS, R.; VICTORIA, R. L.; WASWA, B.; WERNER, D.; WICHMANN, S.; WICHTMANN, W.; ZHANG, X.; ZHAO, Y.; ZHENG, J.; ZHENG, J. Soil carbon, multiple benefits. Environmental Development, v. 13, p. 33-38, 2015.

MONONEN, L.; AUVINEN, A. P.; AHOKUMPU, A. L.; RÖNKÄ, M.; AARRAS, N.; TOLVANEN, H.; KAMPPINEN, M.; VIIRRET, E.; KUMPULA, T.; VIHERVAARA, P. National ecosystem service indicators: Measures of social-ecological sustainability. Ecological Indicators, v. 61, p. 27-37, 2016.

MORAIS, T. G.; DOMINGOS, T.; TEIXEIRA, R. F. M. A spatially explicit life cycle assessment midpoint indicator for soil quality in the European Union using soil organic carbon. The International Journal of Life Cycle Assessment, v. 21, p. 1-16, 2016.

MORAVEC, J. Reconstructed Natural versus Potential Natural Vegetation in Vegetation Mapping: A Discussion of Concepts. Applied Vegetation Science, v. 1, p. 173-176, 1998.

MORIOKA, S. N. O desafio da integração da sustentabilidade no sistema de mensuração de desempenho corporativo: Contribuições de um estudo bibliométrico e estudos de casos. 188p. Dissertação (Mestrado em Engenharia de Produção). Escola Politécnica da Universidade de São Paulo, São Paulo, 2014.

MÜLLER-WENK, R.; BRANDÃO, M. Climatic impact of land use in LCA-carbon transfers between vegetation soil and air. Int J Life Cycle Assess v. 15, p. 172-182, 2010.

MURRAY, A.; SKENE, K.; HAYNES, K. The circular economy: an interdisciplinary exploration of the concept and application in a global context. Journal of Business Ethics, v. 140, p. 369-380, 2017.

MUTEL, C.; LIAO, X.; PATOUILLARD, L.; BARE, J.; FANTKE, P.; FRISCHKNECHT, R.; HAUSCHILD, M. Z.; JOLLIET, O.; MAIA DE SOUZA, D.; LAURENT, A.; PFISTER, S.; VERONES, F. Overview and recommendations for regionalized life cycle impact assessment. International Journal of Life Cycle Assessment, 2018. DOI: 10.1007/s11367-018-1539-4

MUSINGUZI, P., MUSINGUZI, P., TENYWA, J. S., EBANYAT, P., TENYWA, M. M., MUBIRU, D. N., BASAMBA, T. A., LEIP, A. Soil organic carbon thresholds and nitrogen management in tropical agroecosystems: concepts and prospects. Journal of Sustainable Development; Vol. 6, No. $12 ; 2013$.

NAHLIK, A.M.; KENTULA, M.E.; FENNESSY, M.S.; LANDERS, D.H. Where is the consensus? A proposed foundation for moving ecosystem service concepts into practice. Ecological Economics, v. 77, p. 27-35, 2012.

NORDBORG, M.; SASU-BOAKYE, Y.; CEDERBERG, C.; BERNDES, G. Challenges in developing regionalized characterization factors in land use impact assessment: impacts on ecosystem services in case studies of animal protein production in Sweden. The International Journal of Life Cycle Assessment, v.22, p. 328-345, 2016.

NOTARNICOLA, B. et al. The role of life cycle assessment in supporting sustainable agri-food systems: A review of the challenges. Journal of Cleaner Production, v. 140, p. 399-409, 2017. 
NUNEZ, M. Civit, B.; Muñoz, P.; Arena, A.; Rieradevall, J.; Antón, A. Assessing potential desertification environmental impact in life cycle assessment. International Journal of Life Cycle Assessment, v. 15, n. 1, p. 67-78, 2010.

OGLE, S.M.; BREIDT, F.J.; PAUSTIAN, K. Agricultural management impacts on soil organic carbon storage under moist and dry climatic conditions of temperate and tropical regions. Biogeochemistry, v. 72, p. 87-121, 2005.

OLSON, D. M., DINERSTEIN, E., WIKRAMANAYAKE, E. D., BURGESS, N. D., POWELL, G. V. N., UNDERWOOD, E. C., D'AMICO, J. A., ITOUA, I., STRAND, H. E., MORRISON, J. C., LOUCKS, C. J., ALLNUTT, T. F., RICKETTS, T. H., KURA, Y., LAMOREUX, J. F., WETTENGEL, W. W., HEDAO, P., KASSEM, K. R. Terrestrial ecoregions of the world: a new map of life on Earth. Bioscience 51(11):933-938, 2001.

OMETTO, A. R. Avaliação do ciclo de vida do álcool etílico hidratado combustível pelos métodos EDIP, exergia e emergia. 2005. Tese (Doutorado em Hidráulica e Saneamento) - Escola de Engenharia de São Carlos, Universidade de São Paulo, São Carlos, 2005.

OMETTO, A. R.; ROMA, WNL, ORTEGA, E. Emergy life cycle assessment of fuel ethanol in Brazil. In Ortega, E. \& Ulgiati, S. (editors): Proceedings of IV Biennial International Workshop "Advances in Energy Studies”. Unicamp, Campinas, SP, Brazil. June 16-19, p. 389-399, 2004.

OTHONIEL, B.; RUGANI, B.; HEIJUNGS, R.; BENETTO, E.; WITHAGEN, C. Assessment of Life Cycle Impacts on Ecosystem Services: Promise, Problems, and Prospects. Environmental Science and Technology, v. 50, n. 3, p. 1077-1092, 2016.

PALM, C., SANCHEZ, P., AHAMED, S.; AWITI, A. Soils: a contemporary perspective. Annu. Rev. Environ. Resour., v. 32, p. 99-129, 2007.

PAVAN, A. L. R.; OMETTO, A. R. Ecosystem Services in Life Cycle Assessment: A novel conceptual framework for soil. Science of the Total Environment, v. 643, p. 1337-1347, 2018.

PAVAN, A. L. R.; OMETTO, A. R. Regionalization of land use impact models for life cycle assessment: Recommendations for their use on the global scale and their applicability to Brazil. Environmental Impact Assessment Review, v. 60, p. 148-155, 2016.

POTSCHIN, M., HAINES-YOUNG, R. Linking people and nature: Socio-ecological systems. In: Burkhard, B., Maes, J. (Eds.), Ecosystem Services Mapping. Pensoft Publishers, Bulgaria, pp. 41-43, 2017.

2013.

Conceptual Frameworks and the Cascade Model. OpenNESS Synthesis Paper no 3, p. 1-6,

Ecosystem Services: Exploring a geographical perspective. Progress in Physical Geography, v. 35, p. 575-594, 2011.

POTSCHIN-YOUNG, M.; HAINES-YOUNG, R.; GÖRG, C.; HEINK, U.; JAX, K.; SCHLEYER, C. Understanding the role of conceptual frameworks: Reading the ecosystem service cascade. Ecosystem Services, v. 29, p. 428-440, 2017.

POTTING, J.; HAUSCHILD, M.Z. Spatial differentiation in life cycle impact assessment e a decade of method development to increase the environmental realism of LCIA. Int. J. Life Cycle Assess. v. 11, p.11-13, 2006.

RICKETTS, T. H.; DAILY, G. C.; EHRLICH, P. R.; MICHENER, C. Economic value of tropical forest to coffee production. PNAS (Proc Natl Acad Sci), v. 101, p. 12579-12582, 2004. 
RICOTTA, C.; CARRANZA, M. L.; AVENA, G.; BLASI, C. Are potential natural vegetation maps a meaningful alternative to neutral landscape models? Applied Vegetation Science, v. 5, p. 271-275, 2002.

RING, I.; HANSJÜRGENS, B.; ELMQVIST, T.; WITTMER, H.; SUKHDEV, P. Challenges in framing the economics of ecosystems and biodiversity: The TEEB initiative. Current Opinion in Environmental Sustainability, v. 2, p. 15-26, 2010.

ROBINSON, D. A.; HOCKLEY, N.; COOPER, D. M.; EMMETT, B. A.; KEITH, A. M.; LEBRON, I.; REYNOLDS, B.; TIPPING, E.; TYE, A. M.; WATTS, C. W.; WHALLEY, W. R.; BLACK, H. I. J; WARREN, G. P.; ROBINSON, J. S. Natural capital and ecosystem services, developing an appropriate soils framework as a basis for valuation. Soil Biology and Biochemistry, v. 57, p. 10231033, 2013.

ROBINSON, D. A.; LEBRON, I.; VEREECKEN, H. On the Definition of the Natural Capital of Soils: A Framework for Description, Evaluation, and Monitoring. Soil Science Society of America Journal, v. 73, n. 6, p. 1904, 2009.

ROBINSON, D. A.; SEATON, F.; SHARPS, K.; THOMAS, A.; PARRY ROBERTS, F.; VAN DER PLOEG, M.; JONES, L.; STOLTE, J.; PUIG DE LA BELLACASA, M.; HARRISON, P.; EMMETT, B. Soil Resources, the Delivery of Ecosystem Services and Value, 2017

ROSENBAUM, R. K.; BACHMANN, T. M.; GOLD, L. S.; HUIJBREGTS, M. A. J.; JOLLIET, O.; JURASKE, R.; KOEHLER, A.; LARSEN, H. F.; MACLEOD, M.; MARGNI, M.; MCKONE, T. E.; PAYET, J.; SCHUHMACHER, M.; VAN DE MEENT, D.; HAUSCHILD, M. Z. USEtox - The UNEP-SETAC toxicity model: Recommended characterisation factors for human toxicity and freshwater ecotoxicity in life cycle impact assessment. International Journal of Life Cycle Assessment, v. 13, n. 7, p. 532-546, 2008.

RUGANI, B.; BENETTO, E.; ARBAULT, D.; TIRUTA-BARNA, L. Emergy-based mid-point valuation of ecosystem goods and services for life cycle impact assessment. Revue de Métallurgie, v. 110, n. 4, p. 249-264, 2013.

SAAD, R.; MARGNI, M.; KOELLNER, T.; WITTSTOCK, B.; DESCHÊNES, L. Assessment of land use impacts on soil ecological functions: development of spatially differentiated characterization factors within a Canadian context. International Journal of Life Cycle Assessment, 16(3), 198-211, 2011.

SALLES, J. M. Valuing biodiversity and ecosystem services: Why put economic values on nature? Comptes Rendus Biologies, v.334, p. 469-482, 2011.

SCHATSKY, D. Life Cycle Assessment. A Guide for Sustainability and Strategy Executives, ISSP Conference, 2011.

SCHRÖTER, M., VAN DER ZANDEN, E. H., VAN OUDENHOVEN, A. P., REMME, R. P., SERNA-CHAVEZ, H. M., DE GROOT, R. S., \& OPDAM, P. Ecosystem services as a contested concept: a synthesis of critique and counter-arguments. Conservation Letters, v. 7, n. 6, p. 514-523, 2014.

SEYBOLD, C. A.; MAUSBAUCH, M. J.; KARLEN, D. L.; ROGERS, H. H. Quantification of soil quality. Soil Processes and the Carbon Cycle, 1997.

SINGH, S.; BAKSHI, B.R. Eco-LCA: A Tool for Quantifying the Role of Ecological Resources in LCA. IEEE International Symposium on Sustainable Systems and Technology, 2009. 
SMITH, P.; FANG, C.; DAWSON, J. J.; MONCRIEFF, J. B. Impact of global warming on soil organic carbon. Advances in agronomy, v. 97, p. 1-43, 2008.

SOIL SURVEY STAFF. Soil Taxonomy. Soil Taxonomy A Basic System of Soil Classification for Making and Interpreting Soil Surveys, 1999.

SOJKA, R.E., UPCHURCH, D.R., Reservations regarding the soil quality concept. Soil Sci. Soc. Am. J. 63, 1039-1054. 1999.

SOUSSANA, J. F.; LOISEAU, P.; VUICHARD, N.; CESCHIA, E.; BALESDENT, J.; CHEVALLIER, T.; ARROUAYS, D. Carbon cycling and sequestration opportunities in temperate grasslands. Soil Use and Management, v. 20, p. 219-230, 2004.

SOUZA, D. M. Proposta de um modelo de caracterização de impactos do uso da terra, segundo indicadores de biodiversidade, em AICV: cálculo de fatores de caracterização, para ecorregiões brasileiras. Tese (Doutorado em Engenharia Ambiental), Universidade Federal de Santa Catarina. Florianópolis, 2010.

SOUZA, D. M.; TEIXEIRA, R. F. M.; OSTERMANN, O. P. Assessing biodiversity loss due to land use with Life Cycle Assessment: Are we there yet? Global Change Biology, v. 21, n. 0, p. 32-47, 2015.

SPANGENBERG, J. H.; VON HAAREN, C.; SETTELE, J. The ecosystem service cascade: Further developing the metaphor. Integrating societal processes to accommodate social processes and planning, and the case of bioenergy. Ecological Economics, v. 104, p. 22-32, 2014.

TANSLEY, A.G. The use and abuse of vegetational concepts and terms. Ecology, v. 3, p. 284-307, 1935.

TEEB. A Economia dos Ecossistemas e da Biodiversidade. Relatório para o Setor de Negócios. Sumário Executivo,2010.

TOFFOLETTO, L.; BULLE, C.; GODIN, J.; REID, C.; DESCHÊNES, L. LUCAS - A New LCIA Method Used for a Canadian Specific Context. International Journal of Life Cycle Assessment, v. 12, n. 2, p. 93, 2007.

TORNQUIST, C.G. Simulação da dinâmica do carbono orgânico do solo em escala regional: aplicação do modelo Century e sistemas de informações geográficas. 2007. 156p. Tese (Doutorado) Universidade Federal do Rio Grande do Sul, Porto Alegre.

TSONKOVA, P.; QUINKENSTEIN, A.; BÖHM, C.; FREESE, D.; SCHALLER, E. Ecosystem services assessment tool for agroforestry (ESAT-A): An approach to assess selected ecosystem services provided by alley cropping systems. Ecological Indicators, v. 45, p.285-99, 2014.

TURNER, R. K.; DAILY, G. C. The ecosystem services framework and natural capital conservation. Environmental and Resource Economics, v. 39, n. 1, p. 25-35, 2008.

UDO DE HAES, H.; JOLLIET, O.; FINNVEDEN, G.; GOEDKOOP, M.; HAUSCHILD, M.; HERTWICH, E. Life-cycle impact assessment: striving towards best practice. SETAC, Pensacola, FL, USA, 2002.

UNCCD. Default data: methods and interpretation. A guidance document for 2018 UNCCD reporting. United Nations Convention to Combat Desertification (UNCCD), Bonn, Germany, 2018. 
UNITED NATIONS ENVIRONMENT PROGRAMME (UNEP). Life cycle initiative homepage, 2002. Disponível em: http://www.uneptie.org/pc/sustain/Icinitiative/home.htm. Accesso em 09 setembro de 2015.

UNITED NATIONS ENVIRONMENT PROGRAMME (UNEP); SOCIETY FOR ENVIRONMENTAL TOXICOLOGY AND CHEMISTRY (SETAC). Global Guidance Principles for Life Cycle Assessment Databases - A Basis for Greener Processes and Products, United Nations Environment Programme (UNEP) e da Society for Environmental Toxicology and Chemistry (SETAC), ISBN: 978-92-807-3174-3, $2011 \mathrm{~b}$.

. Life Cycle management: How business uses it to decrease footprint, create opportunities and make value chains more sustainable, United Nations Environment Programme (UNEP) e da Society for Environmental Toxicology and Chemistry (SETAC), Paris, 2009.

Towards a Life Cycle Sustainability Assessment - making informed choices on products, United Nations Environment Programme (UNEP) e da Society for Environmental Toxicology and Chemistry (SETAC), ISBN: 978-92-807-3175-0, 2011a.

UNITED STATES GEOLOGICAL SURVEY (USGS). Land Change Science Program, 2013. Disponível em: http://www.usgs.gov/climate_landuse/lcs/pdfs/LCSinfosheetMarch2013.pdf. Acesso em: 27 Ago de 2015.

USDA. National Soil Characterization Data. Soil Survey Laboratory, National Soil Survey Center, Soil Conservation Service, Lincoln, Nebraska, USA, 1994.

USEPA. National Ecosystem Services Classification System (NESCS): Framework design and policy application - Final Report, EPA-800-R-15-002. United States Environmental Protection Agency: Washington, DC, 2015.

VAN OUDENHOVEN, A.P.E.; PETZ, K.; ALKEMADE, R.; HEIN, L.; DE GROOT, R.S. Framework for systematic indicator selection to assess effects of land management on ecosystem services. Ecological Indicators, v.21, p.110-22, 2012.

VELASQUEZ, E.; LAVELLE, P.; ANDRADE, M. GISQ, a multifunctional indicator of soil quality. Soil Biology and Biochemistry, v. 39, n. 12, p. 3066-3080, 2007.

VEREECKEN, H.; SCHNEPF, A.; HOPMANS, J.W.; JAVAUX, M.; OR, D.; ROOSE, T.; VANDERBORGHT, J.; YOUNG, M.H.; AMELUNG, W.; AITKENHEAD, M.; ALLISON, S.D.; ASSOULINE, S.; BAVEYE, P.; BERLI, M.; BRÜGGEMANN, N.; FINKE, P.; FLURY, M.; GAISER, T.; GOVERS, G.; GHEZZEHEI, T.; HALLETT, P.; HENDRICKS FRANSSEN, H.J.; HEPPELL, J.; HORN, R.; HUISMAN, J.A.; JACQUES, D.; JONARD, F.; KOLLET, S.; LAFOLIE, F.; LAMORSKI, K.; LEITNER, D.; MCBRATNEY, A.; MINASNY, B.; MONTZKA, C.; NOWAK, W.; PACHEPSKY, Y.; PADARIAN, J.; ROMANO, N.; ROTH, K.; ROTHFUSS, Y.; ROWE, E.C.; SCHWEN, A.; ŠIMŮNEK, J.; TIKTAK, A.; VAN DAM, J.; VAN DER ZEE, S.E.A.T.M.; VOGEL, H.J.; VRUGT, J.A.; WÖHLING, T.; YOUNG, I.M.; HENDRICKS FRANSSEN, H.J.; HEPPELL, J.; HORN, R.; HUISMAN, J.A.; JACQUES, D.; JONARD, F.; KOLLET, S.; LAFOLIE, F.; LAMORSKI, K.; LEITNER, D.; MCBRATNEY, A.; MINASNY, B.; MONTZKA, C.; NOWAK, W.; PACHEPSKY, Y.; PADARIAN, J.; ROMANO, N.; ROTH, K.; ROTHFUSS, Y.; ROWE, E.C.; SCHWEN, A.; ŠIMU゚NEK, J.; TIKTAK, A.; VAN DAM, J.; VAN DER ZEE, S.E.A.T.M.; VOGEL, H.J.; VRUGT, J.A.; WÖHLING, T.; YOUNG, I.M. Modeling Soil Processes: Review, Key Challenges, and New Perspectives. Vadose Zone Journal, v. 15, p.1-57, 2016.

VERHULST, N.; GOVAERTS, B.; VERACHTERT, E.; CASTELLANOS-NAVARRETE, A.; MEZZALAMA, M.; WALL, P.; DECKERS, J.; SAYRE, K.D. Conservation agriculture, improving 
soil quality for sustainable production systems? In: Lal R., Stewart B.A. (eds.): Advances in Soil Science: Food Security and Soil Quality. Boca Raton, CRC Press, 137-208, 2010.

VERONES, F.; BARE, J.; BULLE, C.; FRISCHKNECHT, R.; HAUSCHILD, M.; HELLWEG, S.; HENDERSON, A.; JOLLIET, O.; LAURENT, A.; LIAO, X.; LINDNER, J. P.; MAIA DE SOUZA, D.; MICHELSEN, O.; PATOUILlARD, L.; PFISTER, S.; POSTHUMA, L.; PRADO, V.; RIDOUTT, B.; ROSENBAUM, R. K.; SALA, S.; UGAYA, C. M.; FANTKE, P. LCIA framework and cross-cutting issues guidance within the UNEP-SETAC Life Cycle Initiative. Journal of Cleaner Production, v. 161, p. 957-967, 2017.

VIDAL LEGAZ, B., D. MAIA DE SOUZA, R. F. M. TEIXEIRA, A. ANTÓN, B. P.; S. SALA. Soil quality, properties, and functions in life cycle assessment: an evaluation of models. Journal of Cleaner Production, v. 140, Part 2, p. 502-515, 2017.

VILlA, F.; BAGSTAD, K.J.; VOIGT, B.; JOHNSON, G. W.; PORTELA, R.; HONZÁK, M.; BATKER, D. A methodology for adaptable and robust ecosystem services assessment. PLoS ONE, v. 9, n. 3, 2014.

VOGTLANDER, J.G.; LINDEIJER, E.; WITTE, J.P.M.; HENDRIKS, C. Characterizing the change of land-use based on flora: application for EIA and LCA. Journal of Cleaner Production, v. 12, p.47-57, 2004.

WALLACE, K.J. Classification of ecosystem services: Problems and solutions. Biological Conservation, v. 139, p.235-46, 2007.

WANDER, M.M.; DRINKWATER, L.E. Fostering soil stewardship through soil quality assessment. Appl. Soil Ecol., 15:61-73, 2000.

WANG, H.; NI, J.; PRENTICE, I. C. Sensitivity of potential natural vegetation in China to projected changes in temperature, precipitation and atmospheric $\mathrm{CO}_{2}$. Regional Environmental Change, v. 11, n. 3, p. 715-727, 2011.

WATSON, R. T.; NOBLE, I. R.; BOLIN, B.; RAVINDRANATH, N. H.; VERARDO, D. J.; DOKKEN, D. J. Land use, land-use change, and forestry. Cambridge University Press Cambridge, 2000.

WEISSERT, L. F.; SALMOND, J. A.; SCHWENDENMANN, L. Variability of soil organic carbon stocks and soil CO2efflux across urban land use and soil cover types. Geoderma, v. 271, p. 80-90, 2016.

WESTHOFF, V.; E. VAN DER MAAREL. The Braun-Blanquet approach, In: Handbook of vegetation science V. Ordination and classification of communities (Ed. R.H. Whittaker), 617- 726, 1973.

WOJTACH, A. Ecosystem Services in the Circular Economy. Ekonomia i Środowisko, v. 4, 99-108, 2016.

YEBOAH, S.; ZHANG, R.; CAI, L.; LI, L.; XIE, J. LUO, Z.; LIU, J.; WU, J. Tillage effect on soil organic carbon, microbial biomass carbon and crop yield in spring wheat-field pea rotation. Plant Soil Environ, v. 62, p. 279-285, 2016.

ZAMAN, A. U.; LEHMANN, S. The zero waste index: A performance measurement tool for waste management systems in a "zero waste city". Journal of Cleaner Production, v.50, p. 123-132, 2013. 
ZEDLER, J. B. Wetlands at Your Service: Reducing Impacts of Agriculture at the Watershed Scale. Frontiers in Ecology and the Environment, v. 1, p. 65-72, 2003.

ZHANG, Y.I., SINGH, S., BAKSHI, B.R. Accounting for ecosystem services in life cycle assessment part I: a critical review. Environ. Sci. Technol. 44 (7), 2232-2242, 2010 a.

ZHANG, Y.I., ANIL, B., BAKSHI, B.R. Accounting for ecosystem services in life cycle assessment part II: toward an ecologically based LCA. Environ. Sci. Technol. 44 (7), 2624-2631, 2010 b. 


\section{APÊNDICE}

Tabela 9: Valores de COSpot utilizados na aplicação do modelo de caracterização de acordo com tipo de clima, solo e vegetacão (tC/ha) (Continua).

\begin{tabular}{|c|c|c|c|c|c|}
\hline ASV & Zona Climática & Área & Porcentagem & $\mathrm{COS}_{\text {pot }}$ & $\begin{array}{c}\text { COS }_{\text {pot }} \\
\text { Ponderado }\end{array}$ \\
\hline S1V1 & Tropical úmida & 413829,3 & $100,00 \%$ & 5,09 & 5,090 \\
\hline \multirow{3}{*}{ S1V2 } & Tropical úmida & 32734,62 & $97,27 \%$ & \multirow{3}{*}{3,22} & 3,132 \\
\hline & Tropical montanhoso & 789,09 & $2,34 \%$ & & 0,076 \\
\hline & Temperado úmida & 128,61 & $0,38 \%$ & & 0,012 \\
\hline \multirow{3}{*}{ S1V3 } & Tropical seca & 1942,48 & $15,69 \%$ & \multirow{3}{*}{5,83} & 0,914 \\
\hline & Tropical úmida & 5992,55 & $48,39 \%$ & & 2,821 \\
\hline & Temperado úmida & 4448,84 & $35,92 \%$ & & 2,094 \\
\hline \multirow{3}{*}{ S1V4 } & Tropical seca & 9059,78 & $6,21 \%$ & \multirow{3}{*}{4,67} & 0,290 \\
\hline & Tropical úmida & 78625,39 & $53,92 \%$ & & 2,518 \\
\hline & Temperado úmida & 58121,46 & $39,86 \%$ & & 1,862 \\
\hline \multirow{4}{*}{ S1V5 } & Tropical seca & 8301,46 & $24,86 \%$ & \multirow{4}{*}{4,09} & 1,017 \\
\hline & Tropical úmida & 16462,33 & $49,29 \%$ & & 2,016 \\
\hline & Tropical montanhoso & 1296,11 & $3,88 \%$ & & 0,159 \\
\hline & Temperado úmida & 7336,36 & $21,97 \%$ & & 0,898 \\
\hline \multirow{2}{*}{ S1V6 } & Tropical úmida & 44237,84 & $37,61 \%$ & \multirow{2}{*}{9,88} & 3,716 \\
\hline & Temperado úmida & 73391,91 & $62,39 \%$ & & 6,164 \\
\hline \multirow{2}{*}{ S1V7 } & Tropical úmida & 34240,59 & $58,10 \%$ & \multirow{2}{*}{6,42} & 3,730 \\
\hline & Temperado úmida & 24697,90 & $41,90 \%$ & & 2,690 \\
\hline S1V8 & Tropical úmida & 2676,69 & $100 \%$ & 4,80 & 4,800 \\
\hline \multirow{4}{*}{ S1V9 } & Tropical seca & 4278,40 & $12,43 \%$ & \multirow{4}{*}{2,44} & 0,303 \\
\hline & Tropical úmida & 25431,62 & $73,92 \%$ & & 1,804 \\
\hline & Tropical montanhoso & 1238,98 & $3,60 \%$ & & 0,088 \\
\hline & Temperado úmida & 3457,16 & $10,05 \%$ & & 0,245 \\
\hline \multirow{2}{*}{ S1V10 } & Tropical úmida & 43040,06 & $55,26 \%$ & \multirow{2}{*}{6,60} & 3,647 \\
\hline & Temperado úmida & 34852,00 & $44,74 \%$ & & 2,953 \\
\hline \multirow{3}{*}{ S1V11 } & Tropical seca & 315760,18 & $85,28 \%$ & \multirow{3}{*}{2,42} & 2,064 \\
\hline & Tropical úmida & 52020,86 & $14,05 \%$ & & 0,340 \\
\hline & Tropical montanhoso & 2488,02 & $0,67 \%$ & & 0,016 \\
\hline S1V12 & Tropical úmida & 1133,32 & $100,00 \%$ & 3,38 & 3,380 \\
\hline \multirow{3}{*}{ S1V13 } & Tropical úmida & 807,46 & $61,87 \%$ & \multirow{3}{*}{3,41} & 2,110 \\
\hline & Tropical montanhoso & 484,03 & $37,09 \%$ & & 1,265 \\
\hline & Temperado úmida & 13,55 & $1,04 \%$ & & 0,035 \\
\hline \multirow{2}{*}{ S1V14 } & Tropical úmida & 110,53 & $34,51 \%$ & \multirow{2}{*}{7,30} & 2,519 \\
\hline & Temperado úmida & 209,76 & $65,49 \%$ & & 4,781 \\
\hline S1V15 & Tropical úmida & 75,01 & $100 \%$ & 5,09 & 5,090 \\
\hline
\end{tabular}

Fonte: Bernoux et al 2002. 
Tabela 9: Valores de $\operatorname{COS}_{\text {pot }}$ utilizados na aplicação do modelo de caracterização de acordo com tipo de clima, solo e vegetação (tC/ha) (Continuação).

\begin{tabular}{|c|c|c|c|c|c|}
\hline ASV & Zona Climática & Área & Porcentagem & $\mathrm{COS}_{\text {pot }}$ & $\begin{array}{c}\text { COS }_{\text {pot }} \\
\text { Ponderado }\end{array}$ \\
\hline $\mathrm{S} 2 \mathrm{~V} 1$ & Tropical úmida & 346897,36 & $100,00 \%$ & 4,75 & 4,750 \\
\hline \multirow{2}{*}{$\mathrm{S} 2 \mathrm{~V} 2$} & Tropical úmida & 2000472,43 & $99,97 \%$ & \multirow{2}{*}{5,19} & 5,189 \\
\hline & Tropical montanhoso & 563,26 & $0,03 \%$ & & 0,001 \\
\hline \multirow{4}{*}{ S2V3 } & Tropical seca & 60116,58 & $20,86 \%$ & \multirow{4}{*}{5,23} & 1,091 \\
\hline & Tropical úmida & 150639,92 & $52,28 \%$ & & 2,734 \\
\hline & Tropical montanhoso & 27291,19 & $9,47 \%$ & & 0,495 \\
\hline & Temperado úmida & 50094,17 & $17,39 \%$ & & 0,909 \\
\hline \multirow{4}{*}{ S2V4 } & Tropical seca & 86749,69 & $38,24 \%$ & \multirow{4}{*}{3,08} & 1,178 \\
\hline & Tropical úmida & 62315,54 & $27,47 \%$ & & 0,846 \\
\hline & Tropical montanhoso & 77590,51 & $34,20 \%$ & & 1,053 \\
\hline & Temperado úmida & 221,90 & $0,10 \%$ & & 0,003 \\
\hline \multirow{4}{*}{ S2V5 } & Tropical seca & 60363,11 & $6,15 \%$ & \multirow{4}{*}{4,43} & 0,272 \\
\hline & Tropical úmida & 418181,48 & $42,60 \%$ & & 1,887 \\
\hline & Tropical montanhoso & 428262,47 & $43,63 \%$ & & 1,933 \\
\hline & Temperado úmida & 74874,73 & $7,63 \%$ & & 0,338 \\
\hline \multirow{3}{*}{ S2V6 } & Tropical úmida & 49663,94 & $44,97 \%$ & \multirow{3}{*}{10,25} & 4,610 \\
\hline & Tropical montanhoso & 326,72 & $0,30 \%$ & & 0,030 \\
\hline & Temperado úmida & 60436,71 & $54,73 \%$ & & 5,610 \\
\hline \multirow{2}{*}{$\mathrm{S} 2 \mathrm{~V} 7$} & Tropical úmida & 25078,00 & $41,96 \%$ & \multirow{2}{*}{9,09} & 3,814 \\
\hline & Temperado úmida & 34686,00 & $58,04 \%$ & & 5,276 \\
\hline \multirow{2}{*}{ S2V8 } & Tropical seca & 528,02 & $0,24 \%$ & \multirow{2}{*}{1,98} & 0,005 \\
\hline & Tropical úmida & 219421,85 & $99,76 \%$ & & 1,975 \\
\hline \multirow{4}{*}{ S2V9 } & Tropical seca & 98015,10 & $6,56 \%$ & \multirow{4}{*}{4,31} & 0,283 \\
\hline & Tropical úmida & 1184867,35 & $79,26 \%$ & & 3,416 \\
\hline & Tropical montanhoso & 190262,00 & $12,73 \%$ & & 0,549 \\
\hline & Temperado úmida & 21750,69 & $1,45 \%$ & & 0,063 \\
\hline S2V10 & Tropical úmida & 3553,62 & $100 \%$ & 4,66 & 4,660 \\
\hline \multirow{3}{*}{ S2V11 } & Tropical seca & 223315,27 & $82,57 \%$ & \multirow{3}{*}{2,58} & 2,130 \\
\hline & Tropical úmida & 31572,26 & $11,67 \%$ & & 0,301 \\
\hline & Tropical montanhoso & 15578,76 & $5,76 \%$ & & 0,149 \\
\hline $\mathrm{S} 2 \mathrm{~V} 12$ & - & - & - & - & - \\
\hline \multirow{4}{*}{$\mathrm{S} 2 \mathrm{~V} 13$} & Tropical seca & 726,36 & $33,61 \%$ & \multirow{4}{*}{5,04} & 1,694 \\
\hline & Tropical úmida & 562,47 & $26,03 \%$ & & 1,312 \\
\hline & Tropical montanhoso & 821,72 & $38,03 \%$ & & 1,917 \\
\hline & Temperado úmida & 50,35 & $2,33 \%$ & & 0,117 \\
\hline \multirow{2}{*}{$\mathrm{S} 2 \mathrm{~V} 14$} & Tropical seca & 30,21 & $0,12 \%$ & \multirow{2}{*}{4,13} & 0,005 \\
\hline & Tropical úmida & 24920,34 & $99,88 \%$ & & 4,125 \\
\hline S2V15 & Tropical úmida & 96929,69 & $100,00 \%$ & 4,68 & 4,680 \\
\hline
\end{tabular}

Fonte: Bernoux et al 2002. 
Tabela 9: Valores de $\operatorname{COS}_{\text {pot }}$ utilizados na aplicação do modelo de caracterização de acordo com tipo de clima, solo e vegetação (tC/ha) (Continuação).

\begin{tabular}{|c|c|c|c|c|c|}
\hline ASV & Zona Climática & Área & Porcentagem & $\operatorname{COS}_{\mathrm{pot}}$ & $\begin{array}{c}\mathrm{COS}_{\text {pot }} \\
\text { Ponderado }\end{array}$ \\
\hline \multirow{2}{*}{ S3V1 } & Tropical úmida & 742029,84 & $99,46 \%$ & \multirow{2}{*}{4,89} & 4,863 \\
\hline & Temperado úmida & 4051,69 & $0,54 \%$ & & 0,027 \\
\hline \multirow{2}{*}{ S3V2 } & Tropical úmida & 1066278,19 & $96,77 \%$ & \multirow{2}{*}{4,69} & 4,538 \\
\hline & Tropical montanhoso & 35611,54 & $3,23 \%$ & & 0,152 \\
\hline \multirow{4}{*}{ S3V3 } & Tropical seca & 32883,75 & $10,13 \%$ & \multirow{4}{*}{4,29} & 0,435 \\
\hline & Tropical úmida & 202521,55 & $62,41 \%$ & & 2,677 \\
\hline & Tropical montanhoso & 15424,18 & $4,75 \%$ & & 0,204 \\
\hline & Temperado úmida & 73694,07 & $22,71 \%$ & & 0,974 \\
\hline \multirow{5}{*}{ S3V4 } & Tropical seca & 59455,15 & $36,80 \%$ & \multirow{5}{*}{4} & 1,472 \\
\hline & Tropical úmida & 78024,40 & $48,29 \%$ & & 1,932 \\
\hline & Tropical montanhoso & 6354,05 & $3,93 \%$ & & 0,157 \\
\hline & Temperado seca & 173,92 & $0,11 \%$ & & 0,004 \\
\hline & Temperado úmida & 17565,50 & $10,87 \%$ & & 0,435 \\
\hline \multirow{4}{*}{ S3V5 } & Tropical seca & 30626,41 & $7,03 \%$ & \multirow{4}{*}{3,74} & 0,263 \\
\hline & Tropical úmida & 264758,90 & $60,76 \%$ & & 2,272 \\
\hline & Tropical montanhoso & 99434,63 & $22,82 \%$ & & 0,853 \\
\hline & Temperado úmida & 40953,80 & $9,40 \%$ & & 0,351 \\
\hline \multirow{3}{*}{ S3V6 } & Tropical úmida & 70886,82 & $36,06 \%$ & \multirow{3}{*}{5,68} & 2,048 \\
\hline & Tropical montanhoso & 143,69 & $0,07 \%$ & & 0,004 \\
\hline & Temperado úmida & 125569,83 & $63,87 \%$ & & 3,628 \\
\hline \multirow{2}{*}{ S3V7 } & Tropical úmida & 39480,92 & $46,55 \%$ & \multirow{2}{*}{5,16} & 2,402 \\
\hline & Temperado úmida & 45325,74 & $53,45 \%$ & & 2,758 \\
\hline \multirow{3}{*}{ S3V8 } & Tropical seca & 9028,44 & $4,36 \%$ & \multirow{3}{*}{3,81} & 0,166 \\
\hline & Tropical úmida & 182343,98 & $88,10 \%$ & & 3,356 \\
\hline & Tropical montanhoso & 15611,95 & $7,54 \%$ & & 0,287 \\
\hline \multirow{4}{*}{ S3V9 } & Tropical seca & 66400,38 & $7,94 \%$ & \multirow{4}{*}{3,6} & 0,286 \\
\hline & Tropical úmida & 601922,19 & $71,95 \%$ & & 2,590 \\
\hline & Tropical montanhoso & 159154,10 & $19,02 \%$ & & 0,685 \\
\hline & Temperado úmida & 9148,91 & $1,09 \%$ & & 0,039 \\
\hline \multirow{2}{*}{ S3V10 } & Tropical úmida & 4174,35 & $98,47 \%$ & \multirow{2}{*}{6,12} & 6,027 \\
\hline & Temperado úmida & 64,66 & $1,53 \%$ & & 0,093 \\
\hline \multirow{3}{*}{ S3V11 } & Tropical seca & 235435,15 & $72,30 \%$ & \multirow{3}{*}{2,62} & 1,894 \\
\hline & Tropical úmida & 70442,96 & $21,63 \%$ & & 0,567 \\
\hline & Tropical montanhoso & 19778,75 & $6,07 \%$ & & 0,159 \\
\hline S3V12 & Tropical úmida & 350,01 & $100 \%$ & 3,52 & 3,520 \\
\hline \multirow{4}{*}{ S3V13 } & Tropical seca & 4492,68 & $15,01 \%$ & \multirow{4}{*}{3,99} & 0,599 \\
\hline & Tropical úmida & 7860,89 & $26,27 \%$ & & 1,048 \\
\hline & Tropical montanhoso & 15505,68 & $51,82 \%$ & & 2,068 \\
\hline & Temperado seca & 2063,28 & $6,90 \%$ & & 0,275 \\
\hline \multirow{2}{*}{ S3V14 } & Tropical úmida & 11594,573 & $97,54 \%$ & & 3,228 \\
\hline & Temperado úmida & 292,7949 & $2,46 \%$ & 3,31 & 0,082 \\
\hline S3V15 & Tropical úmida & 43947,25 & $100,00 \%$ & 4,81 & 4,810 \\
\hline
\end{tabular}

Fonte: Bernoux et al 2002. 
Tabela 9: Valores de $\operatorname{COS}_{\text {pot }}$ utilizados na aplicação do modelo de caracterização de acordo com tipo de clima, solo e vegetação (tC/ha) (Continuação).

\begin{tabular}{|c|c|c|c|c|c|}
\hline ASV & Zona Climática & Área & Porcentagem & $\mathrm{COS}_{\text {pot }}$ & $\begin{array}{c}\text { COS }_{\text {pot }} \\
\text { Ponderado }\end{array}$ \\
\hline S4V1 & Tropical úmida & 15656,671 & $100,00 \%$ & 4,11 & 4,110 \\
\hline \multirow{2}{*}{ S4V2 } & Tropical úmida & 26864,555 & $99,37 \%$ & \multirow{2}{*}{5,06} & 5,028 \\
\hline & Tropical montanhoso & 169,19855 & $0,63 \%$ & & 0,032 \\
\hline \multirow{3}{*}{ S4V3 } & Tropical seca & 344,81381 & $4,61 \%$ & \multirow{3}{*}{6,33} & 0,292 \\
\hline & Tropical úmida & 6879,1891 & $91,87 \%$ & & \#REF! \\
\hline & Temperado úmida & 263,59314 & $3,52 \%$ & & 0,223 \\
\hline \multirow{2}{*}{ S4V4 } & Tropical seca & 7576,4089 & $46,46 \%$ & \multirow{2}{*}{2,59} & 1,203 \\
\hline & Tropical úmida & 8731,1776 & $53,54 \%$ & & 1,387 \\
\hline \multirow{2}{*}{ S4V5 } & Tropical seca & 3898,0093 & $17,28 \%$ & \multirow{2}{*}{2,7} & 0,467 \\
\hline & Tropical úmida & 18660,261 & $82,72 \%$ & & 2,233 \\
\hline S4V6 & - & - & - & - & - \\
\hline S4V7 & - & - & - & - & - \\
\hline S4V8 & Tropical úmida & 83434,562 & $100,00 \%$ & 4,37 & 4,370 \\
\hline \multirow{3}{*}{ S4V9 } & Tropical seca & 53740,974 & $12,53 \%$ & \multirow{3}{*}{1,92} & 0,241 \\
\hline & Tropical úmida & 373160,11 & $87,02 \%$ & & 1,671 \\
\hline & Tropical montanhoso & 1921,1304 & $0,45 \%$ & & 0,009 \\
\hline S4V10 & - & - & - & - & - \\
\hline \multirow{2}{*}{ S4V11 } & Tropical seca & 92810,567 & $66,05 \%$ & \multirow{2}{*}{1,51} & 0,997 \\
\hline & Tropical úmida & 47715,497 & $33,95 \%$ & & 0,513 \\
\hline S4V12 & - & - & - & - & - \\
\hline S4V13 & - & - & - & - & - \\
\hline \multirow{3}{*}{ S4V14 } & Tropical seca & 338,23299 & $0,82 \%$ & \multirow{3}{*}{5,02} & 0,041 \\
\hline & Tropical úmida & 35948,311 & $87,14 \%$ & & 4,375 \\
\hline & Temperado úmida & 4965,7633 & $3,04 \%$ & & 0,153 \\
\hline \multirow{2}{*}{ S4V15 } & Tropical úmida & 156059,33 & $98,47 \%$ & \multirow{2}{*}{6,17} & 6,076 \\
\hline & Tropical montanhoso & 2421,0826 & $1,53 \%$ & & 0,094 \\
\hline
\end{tabular}

Fonte: Bernoux et al 2002. 
Tabela 9: Valores de $\operatorname{COS}_{\text {pot }}$ utilizados na aplicação do modelo de caracterização de acordo com tipo de clima, solo e vegetação (tC/ha) (Continuação).

\begin{tabular}{|c|c|c|c|c|c|}
\hline ASV & Zona Climática & Área & Porcentagem & $\operatorname{COS}_{\mathrm{pot}}$ & $\begin{array}{c}\text { COS }_{\text {pot }} \\
\text { Ponderado }\end{array}$ \\
\hline S5V1 & Tropical úmida & 147206,33 & $100,00 \%$ & 4,36 & 4,360 \\
\hline S5V2 & Tropical úmida & 358028,11 & $100,00 \%$ & 5,27 & 5,270 \\
\hline \multirow{2}{*}{ S5V3 } & Tropical úmida & 3929,9647 & $97,64 \%$ & \multirow{2}{*}{3,58} & 3,495 \\
\hline & Tropical montanhoso & 95,089102 & $2,36 \%$ & & 0,085 \\
\hline \multirow{2}{*}{ S5V4 } & Tropical seca & 2343,7919 & $28,71 \%$ & \multirow{2}{*}{3,27} & 0,939 \\
\hline & Tropical úmida & 5818,5707 & $71,29 \%$ & & 2,331 \\
\hline \multirow{2}{*}{ S5V5 } & Tropical seca & 1822,6828 & $9,36 \%$ & \multirow{2}{*}{5,36} & 0,501 \\
\hline & Tropical úmida & 17658,808 & $90,64 \%$ & & 4,859 \\
\hline S5V6 & - & - & - & - & - \\
\hline S5V7 & - & - & - & - & - \\
\hline \multirow{2}{*}{ S5V8 } & Tropical seca & 506,32864 & $1,02 \%$ & \multirow{2}{*}{3,46} & 0,035 \\
\hline & Tropical úmida & 49374,96 & $98,98 \%$ & & 3,425 \\
\hline S5V9 & Tropical úmida & 261105,25 & $100,00 \%$ & 6,65 & 6,650 \\
\hline S5V10 & - & - & - & - & - \\
\hline \multirow{2}{*}{ S5V11 } & Tropical seca & 6486,5093 & $44,00 \%$ & \multirow{2}{*}{2,51} & 1,104 \\
\hline & Tropical úmida & 8254,4977 & $56,00 \%$ & & 1,406 \\
\hline S5V12 & - & - & - & - & - \\
\hline S5V13 & - & - & - & - & - \\
\hline S5V14 & Tropical úmida & 82912,375 & $100,00 \%$ & 5,92 & 5,920 \\
\hline S5V15 & Tropical úmida & 36639,019 & $100,00 \%$ & 9,05 & 9,050 \\
\hline S6V1 & - & - & - & - & - \\
\hline S6V2 & Tropical úmida & 5623,5138 & $100,00 \%$ & 4,81 & 4,810 \\
\hline S6V3 & Tropical úmida & 3125,7002 & $100,00 \%$ & 41,78 & 41,780 \\
\hline \multirow{2}{*}{ S6V4 } & Tropical seca & 777,23514 & $13,95 \%$ & \multirow{2}{*}{3,18} & 0,443 \\
\hline & Tropical úmida & 4795,7391 & $86,05 \%$ & & 2,737 \\
\hline \multirow{2}{*}{ S6V5 } & Tropical seca & 2202,7314 & $45,45 \%$ & \multirow{2}{*}{3,16} & 1,436 \\
\hline & Tropical úmida & 2644,0026 & $54,55 \%$ & & 1,724 \\
\hline S6V6 & - & - & - & - & \\
\hline \multirow{2}{*}{ S6V7 } & Tropical úmida & 3827,7427 & $84,55 \%$ & \multirow{2}{*}{3,28} & 2,773 \\
\hline & Temperado úmida & 699,68327 & $15,45 \%$ & & 0,507 \\
\hline \multirow{2}{*}{ S6V8 } & Tropical seca & 1637,5148 & $38,49 \%$ & \multirow{2}{*}{2,90} & 1,116 \\
\hline & Tropical úmida & 2617,404 & $61,51 \%$ & & 1,784 \\
\hline \multirow{2}{*}{ S6V9 } & Tropical seca & 1069,523 & $4,66 \%$ & \multirow{2}{*}{3,29} & 0,153 \\
\hline & Tropical úmida & 21886,29 & $95,34 \%$ & & 3,137 \\
\hline S6V10 & - & - & - & - & \\
\hline \multirow{2}{*}{ S6V11 } & Tropical seca & 103181,87 & $87,05 \%$ & \multirow{2}{*}{2,09} & 1,819 \\
\hline & Tropical úmida & 15343,746 & $12,95 \%$ & & 0,271 \\
\hline S6V12 & Tropical úmida & 4889,8221 & $100 \%$ & 2,17 & 2,170 \\
\hline S6V13 & - & - & - & - & \\
\hline \multirow{3}{*}{ S6V14 } & Tropical seca & 180,00374 & $0,69 \%$ & \multirow{3}{*}{3,72} & 0,026 \\
\hline & Tropical úmida & 21415,549 & $82,33 \%$ & & 3,063 \\
\hline & Temperado úmida & 4416,2702 & $16,98 \%$ & & 0,632 \\
\hline S6V15 & - & - & - & - & \\
\hline
\end{tabular}


Quadro 12: Estados brasileiros e unidades biogeográficas presentes.

\begin{tabular}{|c|c|}
\hline Estado & Unidades \\
\hline Acre $(\mathrm{AC})$ & S1V1, S1V2, S2V1, S2V2, S3V1, S3V2, S5V1, S5V2 \\
\hline Alagoas (AL) & $\begin{array}{l}\text { S1V5, S1V9, S1V11, S2V3, S2V5, S2V11, S2V14, S3V3, S3V5, S3V9, S3V11, S3V14, S4V5, } \\
\text { S4V11, S4V14, S5V14, S6V3, S6V5, S6V11 }\end{array}$ \\
\hline Amapá (AP) & S2V2, S2V8, S2V14, S3V1, S3V2, S3V8, S3V14, S5V1, S5V2, S5V8, S5V14, S6V2, S6V14 \\
\hline Amazonas (AM) & $\begin{array}{l}\text { S1V1, S1V2, S1V15, S2V1, S2V2, S2V8, S2V14, S2V15, S3V1, S3V2, S3V8, S3V14, S3V15, } \\
\text { S4V1, S4V2, S4V8, S4V15, S5V1, S5V2, S5V8, S5V14, S5V15 }\end{array}$ \\
\hline Bahia (BA) & $\begin{array}{l}\text { S1V3, S1V4, S1V5, S1V9, S1V11, S2V3, S2V4, S2V5, S2V9, S2V11, S2V13, S2V14, S3V3, } \\
\text { S3V4, S3V5, S3V9, S3V11, S3V13, S3V14, S4V3, S4V4, S4V5, S4V9, S4V11, S4V14, S5V3, } \\
\text { S5V4, S5V5, S5V9, S5V11, S5V14, S6V2, S6V4, S6V5, S6V9, S6V11, S6V14 }\end{array}$ \\
\hline Ceará $(\mathrm{CE})$ & $\begin{array}{l}\text { S1V3, S1V5, S1V9, S1V11, S2V3, S2V9, S2V11, S3V3, S3V5, S3V9, S3V11, S3V14, S4V3, } \\
\text { S4V5, S4V9, S4V11, S4V14, S5V11, S5V14, S6V2, S6V5, S6V9, S6V11, S6V14 }\end{array}$ \\
\hline Distrito Fede & S2V3, S2V9, S3V9 \\
\hline Espírito Santo (ES) & $\begin{array}{l}\text { S1V3, S1V5, S1V13, S2V3, S2V5, S2V13, S2V14, S3V3, S3V5, S3V14, S4V3, S4V14, S5V3, } \\
\text { S5V5, S5V14, S6V2 }\end{array}$ \\
\hline Goiás (GO) & S2V4, S2V5, S2V9, S3V4, S3V5, S3V9, S4V4, S4V5, S4V9, S5V4, S5V5, S5V9 \\
\hline Maranhão (MA) & $\begin{array}{l}\text { S1V2, S1V4, S1V9, S1V14, S2V1, S2V2, S2V4, S2V9, S2V11, S2V14, S3V2, S3V4, S3V9, } \\
\text { S3V11, S3V14, S4V1, S4V2 S4V4, S4V9, S4V11, S4V14, S5V1, S5V2, S5V4, S5V9, S5V11, } \\
\text { S5V14, S6V2, S6V4, S6V9, S6V11, S6V14 }\end{array}$ \\
\hline Mato Grosso (MT) & $\begin{array}{l}\text { S1V1, S1V8, S2V1, S2V2, S2V4, S2V5, S2V8, S2V9, S2V14, S3V1, S3V2, S3V4, S3V5, } \\
\text { S3V8, S3V9, S4V1, S4V2, S4V5, S4V8, S4V9, S5V1, S5V5, S5V8, S5V9, S5V14 }\end{array}$ \\
\hline $\begin{array}{l}\text { Mato Grosso } \\
(\mathrm{MS})\end{array}$ & $\begin{array}{l}\text { S1V4, S1V5, S1V9, S1V12, S2V5, S2V9, S2V14, S3V4, S3V5, S3V9, S3V12, S3V14, S4V5, } \\
\text { S4V9, S4V14, S5V4, S5V5, S5V9, S5V12, S5V14, S6V4, S6V5, S6V9, S6V12 }\end{array}$ \\
\hline Minas Gerais (MG) & $\begin{array}{l}\text { S1V3, S1V4, S1V5, S1V9, S1V13, S2V3, S2V4, S2V5, S2V6, S2V9, S2V11, S2V13, S3V3, } \\
\text { S3V4, S3V5, S3V6, S3V9, S3V11, S3V13, S4V4, S4V5, S4V9, S4V11, S5V4, S5V5, S5V9, } \\
\text { S5V11 }\end{array}$ \\
\hline Pará (PA) & $\begin{array}{l}\text { S2V1, S2V2, S2V4, S2V8, S2V9, S2V14, S3V1, S3V2, S3V4, S3V8, S3V9, S3V14, S4V1, } \\
\text { S4V2, S4V4, S4V8, S4V9, S5V1, S5V2, S5V8, S5V9, S5V14, S6V2, S6V8, S6V14 }\end{array}$ \\
\hline Paraíba (PB) & $\begin{array}{l}\text { S1V3, S1V5, S1V11, S2V11, S3V3, S3V5, S3V11, S3V14, S4V3, S4V5, S4V9, S4V11, S6V9, } \\
\text { S6V11 }\end{array}$ \\
\hline Paraná (PR) & $\begin{array}{l}\text { S1V5, S1V6, S1V7, S1V9, S2V3, S2V5, S2V6, S2V7, S2V9, S3V1, S3V3, S3V5, S3V6, } \\
\text { S3V7, S3V9, S4V3, S5V3, S5V5, S6V2, }\end{array}$ \\
\hline Pernambuco (PE) & $\begin{array}{l}\text { S1V3, S1V5, S1V9, S1V11, S2V3, S2V5, S2V9, S2V11, S2V14, S3V3, S3V5, S3V11, S3V14, } \\
\text { S4V11, S4V14, S6V5, S6V11, S6V14 }\end{array}$ \\
\hline Piauí (PI) & $\begin{array}{l}\text { S1V4, S1V5, S1V9, S1V11, S2V4, S2V5, S2V9, S2V11, S2V14, S3V4, S3V5, S3V9, S3V11, } \\
\text { S4V4, S4V5, S4V9, S4V11, S4V14, S5V4, S5V9, S5V11, S5V14, S6V4, S6V11, S6V14 }\end{array}$ \\
\hline Rio de Janeiro (RJ) & $\begin{array}{l}\text { S1V3, S1V5, S2V3, S2V5, S2V6, S2V9, S2V14, S3V3, S3V5, S3V9, S3V14, S4V3, S4V14, } \\
\text { S5V3, S5V5, S5V14, S6V2, S6V5, S6V14 }\end{array}$ \\
\hline $\begin{array}{l}\text { Rio Grande do Norte } \\
(\mathrm{RN})\end{array}$ & $\begin{array}{l}\text { S1V11, S2V5, S2V9, S2V11, S2V14, S3V11, S4V5, S4V9, S4V11, S4V14, S5V11, S6V5, } \\
\text { S6V9, S6V11, S6V14 }\end{array}$ \\
\hline $\begin{array}{l}\text { Rio Grande do Sul } \\
\text { (RS) }\end{array}$ & $\begin{array}{l}\text { S1V3, S1V4, S1V5, S1V6, S1V7, S1V10, S1V14, S2V4, S2V7, S2V10 S3V3, S3V4, S3V5, } \\
\text { S3V6, S3V7, S3V10, S3V14, S4V3, S4V14, S6V4, S6V5, S6V7, S6V14 }\end{array}$ \\
\hline Rondônia (RO) & $\begin{array}{l}\text { S1V1, S1V8, S2V1, S2V2, S2V5, S2V8, S2V9, S2V14, S2V15, S3V1, S3V2, S3V5, S3V8, } \\
\text { S3V13, S3V14, S3V15, S4V1, S4V2, S4V5, S4V8, S4V14, S5V1, S5V2, S5V5, S5V8, S5V14, } \\
\text { S6V8 }\end{array}$ \\
\hline Roraima (RR) & $\begin{array}{l}\text { S1V2, S1V13, S2V1, S2V2, S2V5, S2V8, S3V2, S3V5, S3V8, S4V1, S4V2, S4V8, S4V15, } \\
\text { S5V1, S5V2, S5V8, S5V15 }\end{array}$ \\
\hline Santa Catarina (SC) & $\begin{array}{l}\text { S1V3, S1V4, S1V6, S1V7, S2V2, S2V3, S2V4, S2V6, S2V7, S2V14, S3V3, S3V4, S3V6, } \\
\text { S3V7, S3V14, S4V3, S4V14, S5V3, S5V14 }\end{array}$ \\
\hline São Paulo (SP) & $\begin{array}{l}\text { S1V3, S1V5, S1V6, S1V9, S2V3, S2V5, S2V6, S2V9, S2V14, S3V1, S3V3, S3V5, S3V6, } \\
\text { S3V9, S4V3, S4V5, S4V9, S4V14, S5V3, S5V5, S5V9 }\end{array}$ \\
\hline Sergipe (SE) & $\begin{array}{l}\text { S1V5, S1V9, S1V11, S1V14, S2V5, S2V9, S3V5, S3V9, S3V11, S4V5, S4V9, S4V14, S5V9, } \\
\text { S5V14, S6V5, S6V9, S6V11, S6V14 }\end{array}$ \\
\hline Tocantins (TO) & $\begin{array}{l}\text { S2V1, S2V2, S2V4, S2V5, S2V8, S2V9, S3V1, S3V2, S3V4, S3V5, S3V8, S3V9, S4V1 S4V4, } \\
\text { S4V5, S4V8, S4V9, S5V1, S5V2, S5V5, S5V8, S5V9 }\end{array}$ \\
\hline
\end{tabular}

Fonte: elaboração própria. 
Tabela 10: Valores de COS para culturas perenes (Continua).

\begin{tabular}{|c|c|c|c|c|c|c|c|c|c|c|c|c|c|}
\hline \multirow{3}{*}{ SVA } & \multicolumn{12}{|c|}{ Culturas perenes } & \multirow{3}{*}{ Pousio } \\
\hline & \multicolumn{4}{|c|}{ Preparo convencional } & \multicolumn{4}{|c|}{ o reduzido } & \multicolumn{4}{|c|}{ Plantio direto } & \\
\hline & $\mathrm{B}$ & $\mathrm{M}$ & AS & $\mathrm{AC}$ & $\mathrm{B}$ & $\mathrm{M}$ & AS & $\mathrm{AC}$ & $\mathrm{B}$ & $\mathrm{M}$ & AS & $\mathrm{AC}$ & \\
\hline S1V1 & 4,836 & 5,090 & 5,650 & 7,330 & 5,057 & 5,854 & 6,497 & 8,429 & 5,713 & 6,210 & 6,893 & 8,942 & 4,174 \\
\hline S1V2 & 964 & 3,220 & 3,572 & 4,635 & 3,326 & 3,615 & 4,102 & 5,322 & 3,611 & 3,923 & 4,352 & 5,647 & 645 \\
\hline S1V3 & 391 & 5,830 & 6,407 & 8,331 & 6,013 & 6,503 & 7,149 & 9,295 & 6,399 & 6,920 & 7,607 & 9,890 & 881 \\
\hline S1V4 & 305 & 4,670 & 5,163 & 6,704 & 4,814 & 5,223 & 5,775 & 7,499 & 5,119 & 5,553 & 6,140 & 7,972 & 861 \\
\hline S1V5 & 796 & 4,090 & 4,464 & 5,814 & 4,241 & 4,570 & 4,990 & 6,498 & 4,517 & 4,867 & 5,313 & 6,919 & 475 \\
\hline S1V6 & 090 & 9,880 & 10,967 & 14,227 & 10,056 & 10,930 & 12,133 & 15,740 & 10,692 & 11,622 & 12,901 & 16,736 & 3,102 \\
\hline S1V7 & 906 & 6,420 & 7,126 & 5,371 & 6,619 & 7,195 & 7,986 & 10,360 & 7,033 & 7,644 & 8,485 & 11,007 & 264 \\
\hline S1V8 & 416 & 4,800 & 328 & 6,912 & 5,078 & 5,520 & 6,127 & 7,949 & 5,388 & 5,856 & 6,500 & 8,433 & 936 \\
\hline & 56 & 2,440 & 685 & 3,490 & 556 & 2,765 & & 3,956 & 2,111 & 2,939 & 3,235 & 4,205 & \\
\hline S1V10 & 072 & 6,600 & 7,326 & 5,252 & 6,793 & 7,383 & 8,195 & 10,632 & 7,218 & 7,845 & 8,708 & 11,297 & 412 \\
\hline S1V11 & 889 & 2,420 & 2,541 & 3,340 & 2,513 & 2,658 & 2,793 & 3,670 & 2,693 & 2,848 & 2,992 & 3,932 & 212 \\
\hline S1V12 & 10 & 3,380 & 752 & 4,867 & 3,576 & 3,887 & 4,315 & 5,597 & 3,794 & 4,124 & 4,577 & 5,938 &, 772 \\
\hline S1V13 & 162 & 3,410 & 3,747 & 4,872 &, 563 & 3,843 & 25 & 5,493 & 3,78 & 4,082 & 4,487 & 5,834 & 872 \\
\hline & 716 & 7,300 & 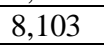 & 10,512 & 7 & 8,060 & & 11,245 & 7,8 & 8,571 & 9,129 & 11,958 & \\
\hline S1V15 & 683 & 5,090 & 5,650 & 7,330 & 5,38 & 5,854 & 6,497 & 8,429 & 5,7 & 6,210 & 6,893 & 8,942 & 174 \\
\hline S2V1 & 770 & 4,75 & & 6,84 & & 5,46 & & 866 & 5 & 5,795 & 6,432 & 8,345 & \\
\hline $\mathrm{S} 2 \mathrm{~V} 2$ & 775 & 5,190 & & 7,474 & & 5,96 & & 8,594 & & 6,332 & 7,028 & 9,118 & 56 \\
\hline S2V3 & 554 & 5,230 & 714 & 7,440 & & 5,856 & 5,397 & 7,020 & 4,8 & 6,233 & 5,732 & 7,456 & 98 \\
\hline S2V4 & 90 & 3,080 & 305 & 4,321 & & 3,408 & 3,658 & 4,783 & 3,4 & 3,635 & 3,902 & 5,102 & 718 \\
\hline S2V5 & 122 & 4,430 & 840 & 6,302 & 4,5 & 4,939 & 5,398 & 7,028 & 4,8 & 5,251 & 5,739 & 7,472 &, 779 \\
\hline S2V6 & 431 & 10,250 & 4,8 & 6,302 & 10,4 & 11,393 & 12,645 & 16,405 & 11,1 & 2,110 & 13,442 & 17,438 & 407 \\
\hline S2V7 & 63 & 9,090 & 10,0 & 13,090 & 9,2 & 10,084 & 11,193 & 14,521 & 9,8 & 10,721 & 11,900 & 15,438 & 54 \\
\hline & 322 & & & 2,8 & & 707 & & 3,278 & 2 & 2,415 & 2,681 & & \\
\hline S2V9 & 85 & 4, & 4,7 & 6 , & 4,5 & 4,90 & 02 & 7,020 & 4,8 & 5,207 & 5,737 & 7,463 & 98 \\
\hline S2V10 & 287 & 4,66 & $=$ & 6,71 & & 5,359 & 5,948 & 7,717 & 5,2 & 5,685 & 6,311 & 8,187 & 3,821 \\
\hline S2V11 & 440 & 2,580 & 2,710 & 3,56 & 2,67 & 2,830 & 2,974 & 3,908 & 2,868 & 3,032 & 3,186 & 4,187 & 2,359 \\
\hline & & & & & & & & & & & & - & \\
\hline $\mathrm{S} 2 \mathrm{~V}$ & 726 & 5,040 & 118 & 7,08 & 223 & 57 & 992 & 83 &, 5 & 5,862 & 6,389 & 8,349 & 434 \\
\hline $\mathrm{S} 2 \mathrm{~V}$ & 800 & 4,1 & & 5,94 & & 47 & & 5,838 & & 5,038 & 5,592 & & \\
\hline S2V1 & 006 & & & 6,7 & & 38 & & 750 & 5,2 & 5,710 & 6,338 & 22 & 38 \\
\hline S3V1 & 199 & 4, & & 7,042 & & 5,622 & 8,0 & 8,095 & $5,4 \xi$ & 5,964 & 8,588 & 588 & 010 \\
\hline S3 & 18 & 4,6 & & 6,74 & & 384 & & 291 & 4,90 & 713 & 5,983 & 7,764 & \\
\hline S3V & 3,964 & 4,2 & & 6,1 & & 4,827 & & 911 & 4,7 & 5,132 & 5,653 & 7,347 & 578 \\
\hline & 27 & & & & & & & & & 4,766 & 5,164 & & \\
\hline S3V5 & 3,466 & 3,7 & & 5,3 & & 209 & 24 & 5,014 & 4, & 1,474 & 4,915 & 6,391 & 3,147 \\
\hline S3V6 & 226 & & & & & & & & & 675 & 7,41 & & \\
\hline S3 & 47 & & & & & 7 & & 326 & 5,6 & 10 & 6,773 & 37 & \\
\hline S3 & 93 & & & 5,4 & & 4 , & & 6,248 & & 4,623 & 5,108 & & 160 \\
\hline & 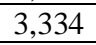 & & & 51. & & & & & & 4,334 & 4,763 & & 3025 \\
\hline S3V10 & 5,630 & 6 , & & 8,8 & & 7 & 7,805 & 10,125 & 6,8 & 7,460 & 8,280 & 10,742 & 5,018 \\
\hline & 470 & & & & & & & & & 3,092 & 3,272 & 4,292 & \\
\hline & 3,238 & & & 5, & & & & & 3,9 & 4,294 & 4,767 & 6,184 & 86 \\
\hline S3V13 & 3,730 & 3,990 & 4,325 & 5,640 & & 4,409 & 4,781 & 6,236 & 4,3 & 4,695 & 5,090 & 39 & 462 \\
\hline$\overline{9}$ & 2304 & 3,3 & & & & & & & & 100 & 4176 & 5007 & \\
\hline S3V15 & 4,425 & 4,8 & & 6,93 & 5, & 5,532 & 6,140 & 7,965 & 5,399 & 5,868 & 6,514 & 8,450 & 944 \\
\hline S4 & 3,781 & 4,1 & & & & & & & & & & & \\
\hline S4 & 4,656 & & & 7,2 & & & & 8,376 & & 6,171 & 6,849 & 8,886 & 51 \\
\hline S4 & 5,832 & 6,3 & & & & & & 10,413 & & 7,708 & 8,515 & & 223 \\
\hline & 2,419 & & & & & & & & & 4,766 & 3,342 & 4,365 & 3452 \\
\hline S4V5 & 2,498 & 2,700 & 2,964 & 3,860 & 2,846 & 3,077 & 3,380 & 4,395 & 3,025 & 3,271 & 3,592 & 4,672 & 2,265 \\
\hline & - & - & - & - & - & 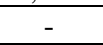 & - & 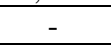 & 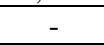 & - & 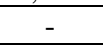 & 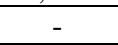 & 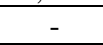 \\
\hline S4V7 & & & & & & & & & - & - & - & 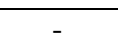 & - \\
\hline S4I & 4,020 & 4,37 & 4,851 & 6,2 & 4,62 & 5,026 & $0,5 / 8$ & 7,237 & 4,90 & 5,331 & 5,918 & 7,677 & 3,583 \\
\hline S4V9 & 1,774 & 1,92 & 2,114 & 2,740 & 2,026 & 4,079 & 2,416 & 3,13 & 2,152 & 4,334 & 2,566 & 3,335 & 3,0 \\
\hline
\end{tabular}


Tabela 10: Valores de COS para culturas perenes (Continuação).

\begin{tabular}{|c|c|c|c|c|c|c|c|c|c|c|c|c|c|}
\hline \multirow{3}{*}{ SVA } & \multicolumn{12}{|c|}{ Culturas perenes } & \multirow{3}{*}{ Pousio } \\
\hline & \multicolumn{4}{|c|}{ Preparo convencional } & \multicolumn{4}{|c|}{ Preparo reduzido } & \multicolumn{4}{|c|}{ Plantio direto } & \\
\hline & $\mathrm{B}$ & $\mathrm{M}$ & AS & $\mathrm{AC}$ & $\mathrm{B}$ & $\mathrm{M}$ & AS & $\mathrm{AC}$ & $\mathrm{B}$ & $\mathrm{M}$ & AS & $\mathrm{AC}$ & \\
\hline S4V10 & - & - & - & - & - & - & - & - & - & - & - & - & - \\
\hline S4V11 & 1,419 & 1,510 & 1,606 & 2,100 & 1,575 & 1,677 & 1,785 & 2,382 & 1,684 & 1,792 & 1,908 & 2,546 & 1,348 \\
\hline S4V12 & - & - & - & - & - & - & - & - & - & - & - & - & - \\
\hline S4V13 & - & - & - & - & - & - & - & - & - & - & - & - & - \\
\hline S4V14 & 615 & 5,020 & 5,564 & 7,220 & 5,267 & 5,723 & 6,350 & 8,238 & 5,590 & 6,075 & 6,739 & 8,744 & 4,117 \\
\hline S4V15 & 7,475 & 6,170 & 8,629 & 8,880 & 6,525 & 7,090 & 8,146 & 10,206 & 6,922 & 7,522 & 8,642 & 10,828 & 5,065 \\
\hline S5V1 & 4,011 & 4,360 & 4,840 & 6,280 & 4,613 & 5,014 & 5,566 & 7,220 & 4,894 & 5,319 & 5,904 & 7,660 & 3,575 \\
\hline S5V2 & 4,848 & 5,270 & 5,850 & 7,590 & 5,576 & 6,061 & 6,727 & 8,727 & 5,915 & 6,429 & 7,137 & 9,258 & 4,321 \\
\hline S5V3 & 3,295 & 3,580 & 3,971 & 5,150 & 3,785 & 4,112 & 4,561 & 5,918 & 4,015 & 4,363 & 4,839 & 6,279 & 2,941 \\
\hline S5V4 & 3,037 & 3,270 & 3,564 & 4,640 & 3,439 & 3,704 & 4,040 & 5,262 & 3,660 & 3,942 & 4,299 & 5,600 & 2,785 \\
\hline S5V5 & 4,946 & 5,360 & 5,914 & 7,680 & 5,660 & 6,134 & 6,770 & 8,795 & 6,011 & 6,514 & 7,190 & 9,339 & 4,450 \\
\hline S5V6 & - & - & - & - & - & - & - & - & - & - & - & - & - \\
\hline S5V7 & - & - & - & - & - & - & - & - & - & - & - & - & - \\
\hline S5V8 & 184 & 3,460 & 3,838 & 4,980 & 3,660 & 3,977 & 4,412 & 5,724 & 3,883 & 4,219 & 4,681 & 6,073 & 2,841 \\
\hline S5V9 & 6,118 & 6,650 & 7,382 & 9,580 & 7,036 & 7,648 & 8,489 & 11,012 & 7,464 & 8,113 & 9,005 & 11,683 & 5,453 \\
\hline S5V10 & - & - & - & - & - & - & - & - & - & - & - & - & - \\
\hline S5V11 & 1,977 & 2,510 & 2,193 & 2,880 & 2,631 & 2,820 & 3,046 & 3,977 & 2,805 & 3,007 & 3,247 & 4,240 & 2,180 \\
\hline S5V12 & - & - & - & - & - & - & - & - & - & - & - & - & - \\
\hline S5V13 & - & - & - & - & - & - & - & - & - & - & - & - & - \\
\hline S5V14 & 5,446 & 5,920 & 6,571 & 8,520 & 6,263 & 6,808 & 7,557 & 9,804 & 6,645 & 7,222 & 8,017 & 10,400 & 4,854 \\
\hline S5V15 & 8,326 & 9,050 & 10,046 & 13,030 & 9,575 & 10,408 & 11,552 & 14,987 & 10,158 & 11,041 & 12,256 & 15,899 & 7,421 \\
\hline S6V1 & - & - & - & - & - & - & - & - & - & - & - & - & - \\
\hline S6V2 & 4,425 & 810 & 228 & 930 & 5,089 & 532 & 140 & 7,965 & 5,399 & 868 & 6,514 & 8,450 & 3,944 \\
\hline S6V3 & 38,438 & 41,780 & 46,376 & 60,163 & 44,203 & 48,047 & 53,332 & 69,188 & 46,894 & 50,972 & 56,578 & 73,399 & 34,260 \\
\hline S6V4 & 2,939 & 3,180 & 3,499 & 4,550 & 3,354 & 3,630 & 3,996 & 5,194 & 3,564 & 3,857 & 4,245 & 5,518 & 2,656 \\
\hline S6V5 & 2,950 & 3,160 & 3,407 & 4,450 & 3,311 & 3,548 & 3,829 & 4,999 & 3,531 & 3,783 & 4,082 & 5,330 & 2,749 \\
\hline S6V6 & - & - & - & - & - & - & - & - & - & - & - & - & - \\
\hline S6V7 & 018 & 3,280 & 3,641 & 4,720 & 3,438 & 3,737 & 4,148 & 5,381 & 3,649 & 3,966 & 4,402 & 5,711 & 2,690 \\
\hline S6V8 & 2,701 & 2,900 & 3,141 & 4,100 & 3,043 & 3,268 & 3,542 & 4,621 & 3,243 & 3,482 & 3,774 & 4,923 & 2,501 \\
\hline S6V9 & 3,031 & 3,290 & 3,641 & 4,730 & 3,477 & 3,774 & 4,178 & 5,423 & 3,691 & 4,006 & 4,434 & 5,756 & 2,715 \\
\hline S6V10 & - & - & - & - & - & - & - & - & - & - & - & - & - \\
\hline S6V11 & 1,977 & 2,090 & 2,193 & 2,880 & 2,170 & 2,294 & 2,408 & 3,165 & 2,326 & 2,459 & 2,580 & 3,392 & 1,914 \\
\hline S6V12 & 1,996 & 2,170 & 2,409 & 3,120 & 2,296 & 2,496 & 2,770 & 3,594 & 2,436 & 2,647 & 2,939 & 3,812 & 1,779 \\
\hline S6V13 & - & - & - & - & - & - & - & - & - & - & - & - & - \\
\hline S6V14 & 3,423 & 3,720 & 4,127 & 5,355 & 3,895 & 4,232 & 4,696 & 6,092 & 4,134 & 4,493 & 4,985 & 6,468 & 3,053 \\
\hline S6V15 & - & - & - & - & - & - & - & - & - & - & - & - & - \\
\hline
\end{tabular}


Tabela 11: Valores de COS para culturas anuais (Continua).

\begin{tabular}{|c|c|c|c|c|c|c|c|c|c|c|c|c|}
\hline \multirow{3}{*}{ SVA } & \multicolumn{12}{|c|}{ Culturas anuais } \\
\hline & \multicolumn{4}{|c|}{ Preparo convencional } & \multicolumn{4}{|c|}{ Preparo reduzido } & \multicolumn{4}{|c|}{ Plantio direto } \\
\hline & B & M & AS & $\mathrm{AC}$ & B & M & AS & $\mathrm{AC}$ & B & M & AS & $\mathrm{AC}$ \\
\hline S1V1 & 2,25 & 2,44 & 2,71 & 3,52 & 2,58 & 2,81 & 3,12 & 4,05 & 2,74 & 2,98 & 3,31 & 4,29 \\
\hline S1V2 & 1,44 & 1,56 & 1,73 & 2,25 & 1,65 & 1,79 & 1,99 & 2,58 & 1,75 & 1,90 & 2,11 & 2,73 \\
\hline S1V3 & 3,08 & 3,33 & 3,66 & 4,76 & 2,87 & 3,70 & 4,06 & 5,28 & 3,64 & 3,93 & 4,32 & 9,15 \\
\hline S1V4 & 2,45 & 2,66 & 2,94 & 3,82 & 2,73 & 2,96 & 3,27 & 4,25 & 2,90 & 3,15 & 3,48 & 4,52 \\
\hline S1V5 & 2,12 & 2,28 & 2,49 & 3,24 & 2,35 & 2,54 & 2,77 & 3,60 & 2,51 & 2,70 & 2,95 & 3,84 \\
\hline S1V6 & 5,55 & 6,04 & 6,70 & 8,69 & 6,11 & 6,64 & 7,38 & 9,57 & 6,50 & 7,07 & 7,84 & 10,18 \\
\hline S1V7 & 3,35 & 3,65 & 4,05 & 5,25 & 3,74 & 4,06 & 4,51 & 5,85 & 3,97 & 4,32 & 4,79 & 6,22 \\
\hline S1V8 & 2,81 & 2,12 & 2,56 & 3,32 & 2,44 & 2,65 & 2,94 & 3,82 & 2,59 & 2,81 & 3,12 & 4,05 \\
\hline S1V9 & 1,17 & 1,27 & 1,39 & 1,81 & 1,32 & 1,43 & 1,57 & 2,05 & 1,41 & 1,52 & 1,67 & 2,18 \\
\hline S1V10 & 3,49 & 3,79 & 4,20 & 5,45 & 3,88 & 4,21 & 4,68 & 6,07 & 4,12 & 4,48 & 4,97 & 6,45 \\
\hline S1V11 & 1,30 & 1,37 & 1,44 & 1,89 & 1,42 & 1,50 & 1,58 & 2,07 & 1,52 & 1,61 & 1,69 & 2,22 \\
\hline S1V12 & 1,49 & 1,62 & 1,80 & 2,34 & 1,72 & 1,87 & 2,07 & 2,69 & 1,82 & 1,98 & 2,20 & 2,85 \\
\hline S1V13 & 1,72 & 1,85 & 2,03 & 2,63 & 1,93 & 2,07 & 2,27 & 2,96 & 2,05 & 2,20 & 2,42 & 3,14 \\
\hline S1V14 & 4,15 & 4,51 & 5,00 & 6,49 & 4,56 & 4,95 & 5,50 & 7,13 & 4,85 & 5,27 & 5,85 & 7,59 \\
\hline S1V15 & 2,25 & 2,44 & 2,71 & 3,52 & 2,58 & 2,81 & 3,12 & 4,05 & 2,74 & 2,98 & 3,31 & 4,29 \\
\hline S2V1 & 2,10 & 2,28 & 2,53 & 3,28 & 2,41 & 2,62 & 2,91 & 3,78 & 2,56 & 2,78 & 3,09 & 4,01 \\
\hline $\mathrm{S} 2 \mathrm{~V} 2$ & 2,29 & 2,49 & 2,77 & 3,59 & 2,64 & 2,87 & 3,18 & 4,13 & 2,80 & 3,04 & 3,37 & 4,38 \\
\hline $\mathrm{S} 2 \mathrm{~V} 3$ & 2,68 & 2,89 & 3,15 & 4,11 & 2,99 & 3,22 & 3,52 & 4,58 & 3,19 & 3,43 & 3,75 & 4,88 \\
\hline S2V4 & 1,66 & 1,77 & 1,89 & 2,47 & 1,83 & 1,95 & 2,09 & 2,73 & 1,95 & 2,08 & 2,23 & 2,91 \\
\hline S2V5 & 2,36 & 2,53 & 2,76 & 3,60 & 2,62 & 2,81 & 3,07 & 4,00 & 2,79 & 2,99 & 3,27 & 4,25 \\
\hline S2V6 & 5,62 & 6,10 & 6,77 & 8,79 & 6,21 & 6,75 & 7,49 & 9,71 & 6,60 & 7,17 & 7,96 & 10,33 \\
\hline S2V7 & 5,03 & 5,47 & 6,07 & 7,88 & 5,55 & 6,04 & 6,70 & 8,69 & 5,91 & 6,42 & 7,13 & 9,24 \\
\hline S2V8 & 0,87 & 0,95 & 1,06 & 1,37 & 1,01 & 1,09 & 1,21 & 1,57 & 1,07 & 1,16 & 1,29 & 1,67 \\
\hline S2V9 & 2,03 & 2,20 & 2,42 & 3,14 & 2,31 & 2,49 & 2,74 & 3,57 & 2,45 & 2,65 & 2,92 & 3,79 \\
\hline $\mathrm{S} 2 \mathrm{~V} 10$ & 2,06 & 2,24 & 2,48 & 3,22 & 2,37 & 2,57 & 2,86 & 3,70 & 2,51 & 2,73 & 3,03 & 3,93 \\
\hline S2V11 & 1,40 & 1,48 & 1,55 & 2,03 & 1,53 & 1,62 & 1,70 & 2,23 & 1,64 & 1,73 & 1,82 & 2,39 \\
\hline $\mathrm{S} 2 \mathrm{~V} 12$ & - & - & - & - & - & - & - & - & - & - & - & - \\
\hline S2V13 & 2,74 & 2,92 & 3,14 & 4,10 & 3,02 & 3,22 & 3,46 & 4,52 & 3,22 & 3,43 & 3,69 & 4,82 \\
\hline S2V14 & 1,82 & 1,98 & 2,20 & 2,86 & 2,10 & 2,28 & 2,53 & 3,28 & 2,23 & 2,42 & 2,68 & 3,48 \\
\hline S2V15 & 2,07 & 2,25 & 2,49 & 3,23 & 2,38 & 2,58 & 2,87 & 3,72 & 2,52 & 2,74 & 3,04 & 3,95 \\
\hline
\end{tabular}


Tabela 11: Valores de COS para culturas anuais (Continuação).

\begin{tabular}{|c|c|c|c|c|c|c|c|c|c|c|c|c|}
\hline \multirow{3}{*}{ SVA } & \multicolumn{12}{|c|}{ Culturas anuais } \\
\hline & \multicolumn{4}{|c|}{ Preparo convencional } & \multicolumn{4}{|c|}{ Preparo reduzido } & \multicolumn{4}{|c|}{ Plantio direto } \\
\hline & B & $\mathrm{M}$ & AS & $\mathrm{AC}$ & B & M & AS & $\mathrm{AC}$ & B & M & AS & $\mathrm{AC}$ \\
\hline $\mathrm{S} 3 \mathrm{~V} 1$ & 2,17 & 2,35 & 2,61 & 3,39 & 2,49 & 2,70 & 3,00 & 3,89 & 2,64 & 2,87 & 3,18 & 4,13 \\
\hline $\mathrm{S} 3 \mathrm{~V} 2$ & 2,10 & 2,28 & 2,52 & 3,27 & 2,40 & 2,61 & 2,89 & 3,76 & 2,55 & 2,77 & 3,07 & 3,99 \\
\hline S3V3 & 1,54 & 2,34 & 2,58 & 3,35 & 2,42 & 2,62 & 2,89 & 3,75 & 2,58 & 2,79 & 3,07 & 3,99 \\
\hline S3V4 & 2,04 & 2,19 & 2,36 & 3,08 & 2,27 & 2,43 & 2,63 & 3,44 & 2,42 & 2,60 & 2,81 & 3,66 \\
\hline S3V5 & 1,89 & 2,03 & 2,23 & 2,90 & 2,11 & 2,28 & 2,50 & 3,25 & 2,25 & 2,42 & 2,66 & 3,46 \\
\hline S3V6 & 3,21 & 3,49 & 3,87 & 5,02 & 3,53 & 3,84 & 4,26 & 5,52 & 3,75 & 4,08 & 4,53 & 5,88 \\
\hline S3V7 & 2,81 & 3,06 & 3,39 & 4,40 & 3,11 & 3,38 & 3,75 & 4,87 & 3,31 & 3,60 & 3,99 & 5,18 \\
\hline S3V8 & 1,75 & 1,89 & 2,09 & 2,71 & 1,99 & 2,16 & 2,38 & 3,09 & 2,12 & 2,29 & 2,53 & 3,29 \\
\hline S3V9 & 1,74 & 1,87 & 2,06 & 2,67 & 1,96 & 2,12 & 2,32 & 3,02 & 2,09 & 2,25 & 2,47 & 3,21 \\
\hline S3V10 & 2,72 & 2,96 & 3,28 & 4,26 & 3,12 & 3,40 & 3,77 & 4,89 & 3,32 & 3,60 & 4,00 & 5,19 \\
\hline S3V11 & 1,39 & 1,47 & 1,55 & 2,04 & 1,53 & 1,62 & 1,71 & 2,25 & 1,64 & 1,74 & 1,83 & 2,41 \\
\hline S3V12 & 1,55 & 1,69 & 1,88 & 2,43 & 1,79 & 1,94 & 2,16 & 2,80 & 1,90 & 2,06 & 2,29 & 2,97 \\
\hline S3V13 & 2,25 & 2,39 & 2,58 & 3,37 & 2,46 & 2,62 & 2,83 & 3,69 & 2,62 & 2,80 & 3,01 & 3,94 \\
\hline S3V14 & 1,48 & 1,61 & 1,78 & 2,31 & 1,70 & 1,84 & 2,05 & 2,65 & 1,80 & 1,96 & 2,17 & 2,82 \\
\hline S3V15 & 2,12 & 2,31 & 2,56 & 3,32 & 2,44 & 2,66 & 2,95 & 3,82 & 2,59 & 2,82 & 3,13 & 4,06 \\
\hline S4V1 & 1,81 & 1,97 & 2,19 & 2,84 & 2,09 & 2,27 & 2,52 & 3,27 & 2,21 & 2,41 & 2,67 & 3,47 \\
\hline S4V2 & 2,24 & 2,43 & 2,70 & 3,50 & 2,57 & 2,80 & 3,10 & 4,03 & 2,73 & 2,97 & 3,29 & 4,27 \\
\hline S4V3 & 2,87 & 3,11 & 3,45 & 4,47 & 3,28 & 3,56 & 3,94 & 5,11 & 3,48 & 3,78 & 4,18 & 5,43 \\
\hline S4V4 & 1,28 & 1,36 & 1,47 & 1,91 & 1,43 & 1,53 & 1,64 & 2,14 & 1,52 & 1,63 & 1,75 & 2,29 \\
\hline S4V5 & 1,24 & 1,34 & 1,47 & 1,91 & 1,41 & 1,53 & 1,68 & 2,18 & 1,50 & 1,63 & 1,78 & 2,32 \\
\hline S4V6 & - & - & - & - & - & - & - & - & - & - & - & - \\
\hline S4V7 & - & - & - & - & - & - & - & - & - & - & - & - \\
\hline S4V8 & 1,93 & 2,10 & 2,33 & 3,02 & 2,22 & 2,41 & 2,68 & 3,47 & 2,35 & 2,56 & 2,84 & 3,69 \\
\hline S4V9 & 0,88 & 0,95 & 1,04 & 1,35 & 1,00 & 1,08 & 1,19 & 1,55 & 1,06 & 1,15 & 1,26 & 1,64 \\
\hline S4V10 & - & & & & & & & & & & & \\
\hline S4V11 & 0,78 & 0,83 & 0,88 & 1,15 & 0,86 & 0,91 & 0,97 & 1,27 & 0,92 & 0,98 & 1,04 & 1,36 \\
\hline S4V12 & - & - & - & - & - & - & - & - & - & - & - & - \\
\hline S4V13 & - & - & - & - & - & - & - & - & - & - & - & - \\
\hline S4V14 & 2,34 & 2,54 & 2,82 & 3,65 & 2,66 & 2,89 & 3,20 & 4,16 & 2,82 & 3,07 & 3,40 & 4,41 \\
\hline S4V15 & 2,74 & 2,98 & 3,30 & 4,28 & 3,15 & 3,42 & 3,79 & 4,92 & 3,34 & 3,63 & 4,03 & 5,22 \\
\hline S5V1 & 1,93 & 2,09 & 2,32 & 3,01 & 2,21 & 2,41 & 2,67 & 3,47 & 2,35 & 2,55 & 2,83 & 0,00 \\
\hline S5V2 & 2,33 & 2,53 & 2,81 & 3,64 & 2,68 & 2,91 & 3,23 & 4,19 & 2,84 & 3,09 & 3,43 & 4,44 \\
\hline S5V3 & 1,59 & 1,73 & 1,92 & 2,49 & 1,83 & 1,99 & 2,21 & 2,86 & 1,94 & 2,11 & 2,27 & 3,04 \\
\hline S5V4 & 1,55 & 1,66 & 1,81 & 2,36 & 1,75 & 1,88 & 2,05 & 2,67 & 1,86 & 2,00 & 0,66 & 2,84 \\
\hline S5V5 & 2,42 & 2,62 & 2,89 & 3,76 & 2,77 & 3,00 & 3,31 & 4,30 & 2,94 & 3,19 & 0,35 & 4,56 \\
\hline S5V6 & - & - & - & - & - & - & - & - & - & - & - & - \\
\hline S5V7 & - & - & - & - & - & - & - & - & - & - & - & - \\
\hline
\end{tabular}


Tabela 11: Valores de COS para culturas anuais (Continuação)

\begin{tabular}{|c|c|c|c|c|c|c|c|c|c|c|c|c|}
\hline \multirow{3}{*}{ SVA } & \multicolumn{12}{|c|}{ Culturas anuais } \\
\hline & \multicolumn{4}{|c|}{ Preparo convencional } & \multicolumn{4}{|c|}{ Preparo reduzido } & \multicolumn{4}{|c|}{ Plantio direto } \\
\hline & B & M & AS & $\mathrm{AC}$ & $\mathrm{B}$ & M & AS & $\mathrm{AC}$ & B & M & AS & $\mathrm{AC}$ \\
\hline S5V8 & 1,53 & 1,66 & 1,85 & 0,03 & 1,76 & 1,91 & 2,12 & 2,75 & 1,87 & 2,03 & 2,25 & 2,92 \\
\hline S5V9 & 2,94 & 3,19 & 3,54 & 4,60 & 3,38 & 3,67 & 4,07 & 5,29 & 3,58 & 3,89 & 4,32 & 5,61 \\
\hline S5V10 & - & - & - & - & - & - & - & - & - & - & - & - \\
\hline S5V11 & 1,23 & 1,32 & 1,42 & 1,85 & 1,38 & 1,47 & 1,59 & 2,07 & 1,47 & 1,57 & 1,69 & 2,21 \\
\hline S5V12 & - & - & - & - & - & - & - & - & - & - & - & - \\
\hline S5V13 & - & - & - & - & - & - & - & - & - & - & - & - \\
\hline S5V14 & 2,61 & 2,84 & 3,15 & 4,09 & 3,01 & 3,27 & 3,63 & 4,71 & 3,19 & 3,47 & 3,85 & 4,99 \\
\hline S5V15 & 4,00 & 4,34 & 4,82 & 6,26 & 4,60 & 5,00 & 5,55 & 7,19 & 4,88 & 5,30 & 5,88 & 7,63 \\
\hline S6V1 & - & - & - & - & - & - & - & - & - & - & - & - \\
\hline S6V2 & 2,12 & 2,31 & 2,56 & 3,32 & 2,44 & 2,66 & 2,95 & 3,82 & 2,59 & 2,82 & 3,13 & 4,06 \\
\hline S6V3 & 18,45 & 20,05 & 22,26 & 28,88 & 21,22 & 23,06 & 25,60 & 33,21 & 22,51 & 24,47 & 27,16 & 35,23 \\
\hline S6V4 & 1,45 & 1,57 & 1,73 & 2,24 & 1,66 & 1,79 & 1,97 & 2,56 & 1,76 & 1,90 & 0,31 & 2,72 \\
\hline S6V5 & 1,55 & 1,66 & 1,78 & 2,33 & 1,74 & 1,86 & 2,00 & 2,61 & 1,85 & 1,98 & 1,73 & 2,79 \\
\hline S6V6 & - & - & - & - & - & - & - & - & - & - & - & - \\
\hline S6V7 & 1,55 & 1,68 & 1,87 & 2,42 & 1,76 & 1,91 & 2,12 & 2,75 & 1,86 & 2,03 & 2,25 & 2,92 \\
\hline S6V8 & 1,47 & 1,57 & 1,69 & 2,21 & 1,64 & 1,75 & 1,89 & 2,47 & 1,75 & 1,87 & 2,01 & 2,63 \\
\hline S6V9 & 1,47 & 1,59 & 1,76 & 2,29 & 1,69 & 1,83 & 2,02 & 2,63 & 1,79 & 1,94 & 2,15 & 2,79 \\
\hline S6V10 & - & - & - & - & - & - & - & - & - & - & - & - \\
\hline S6V11 & 1,12 & 1,19 & 1,24 & 1,63 & 1,23 & 1,30 & 1,36 & 1,79 & 1,32 & 1,39 & 1,46 & 1,92 \\
\hline S6V12 & 0,96 & 1,04 & 1,16 & 1,50 & 1,10 & 1,20 & 1,33 & 1,72 & 1,17 & 1,27 & 1,41 & 1,83 \\
\hline S6V13 & - & - & - & - & - & - & - & - & - & - & - & - \\
\hline S6V14 & 1,77 & 1,92 & 2,13 & 2,76 & 2,00 & 2,18 & 2,42 & 3,13 & 2,13 & 2,31 & 2,57 & 3,33 \\
\hline S6V15 & - & - & - & - & - & - & - & - & - & - & - & - \\
\hline
\end{tabular}


Tabela 12: Valores de COS para pastagem (Continua).

\begin{tabular}{|c|c|c|c|c|}
\hline \multirow{3}{*}{ SVA } & \multicolumn{4}{|c|}{ Pastagem } \\
\hline & \multicolumn{2}{|c|}{ Melhorada } & \multirow{2}{*}{$\begin{array}{c}\text { Moderadamente } \\
\text { degradada }\end{array}$} & \multirow{2}{*}{$\begin{array}{c}\text { Severamente } \\
\text { degradada }\end{array}$} \\
\hline & Input médio de insumo & $\begin{array}{l}\text { Input alto de } \\
\text { insumo }\end{array}$ & & \\
\hline S1V1 & 5,9553 & 5,9553 & 4,9373 & 3,56 \\
\hline S1V2 & 3,766275788 & 4,180566124 & 3,122398847 & 2,25 \\
\hline S1V3 & 6,758268068 & 7,501677556 & 5,613212046 & 4,08 \\
\hline S1V4 & 5,408053317 & 6,002939182 & 4,492668878 & 3,27 \\
\hline S1V5 & 4,758345746 & 5,281763778 & 3,949330497 & 2,86 \\
\hline S1V6 & 11,37466921 & 12,62588282 & 9,460312806 & 6,92 \\
\hline S1V7 & 7,430691868 & 8,248067974 & 6,173594579 & 4,49 \\
\hline S1V8 & 5,616 & 6,23376 & 4,656 & 3,36 \\
\hline S1V9 & 2,847444796 & 3,136301149 & 2,339948265 & 1,71 \\
\hline S1V10 & 7,633406934 & 8,473081697 & 6,342937956 & 4,62 \\
\hline S1V11 & 2,8314 & 3,142854 & 2,3474 & 1,69 \\
\hline S1V12 & 3,9546 & 4,389606 & 3,2786 & 2,366 \\
\hline S1V13 & 3,988637853 & 4,368548062 & 3,294344502 & 2,39 \\
\hline S1V14 & 8,397572892 & 9,32130591 & 6,985381928 & 5,11 \\
\hline S1V15 & 5,9553 & 6,610383 & 4,9373 & 3,56 \\
\hline $\mathrm{S} 2 \mathrm{~V} 1$ & 5,5575 & 6,168825 & 4,6075 & 3,33 \\
\hline $\mathrm{S} 2 \mathrm{~V} 2$ & 6,072256173 & 6,740236784 & 5,034285391 & 3,63 \\
\hline $\mathrm{S} 2 \mathrm{~V} 3$ & 6,086868984 & 6,756424572 & 5,049961468 & 3,66 \\
\hline $\mathrm{S} 2 \mathrm{~V} 4$ & 3,59297625 & 3,988203638 & 2,977006374 & 2,16 \\
\hline S2V5 & 5,15363742 & 5,720537536 & 4,271016264 & 3,1 \\
\hline S2V6 & 11,82390252 & 13,12453179 & 9,830000588 & 7,18 \\
\hline $\mathrm{S} 2 \mathrm{~V} 7$ & 10,4770296 & 11,62950286 & 8,7117864 & 6,36 \\
\hline $\mathrm{S} 2 \mathrm{~V} 8$ & 2,311038672 & 2,571426 & 1,9206 & 1,39 \\
\hline S2V9 & 5,035333158 & 6,367744482 & 4,173960262 & 3,02 \\
\hline S2V10 & 5,4522 & 6,051942 & 4,5202 & 3,26 \\
\hline S2V11 & 3,017113929 & 3,348996461 & 2,501113929 & 1,81 \\
\hline $\mathrm{S} 2 \mathrm{~V} 12$ & - & - & - & - \\
\hline S2V13 & 5,874111772 & 6,520264067 & 4,867286 & 3,53 \\
\hline S2V14 & 4,8321 & 5,363631 & 4,0061 & 2,89 \\
\hline S2V15 & 5,4756 & 6,077916 & 4,5396 & 3,28 \\
\hline
\end{tabular}


Tabela 13: Valores de COS para pastagem (Continua).

\begin{tabular}{|c|c|c|c|c|}
\hline \multirow{3}{*}{ SVA } & \multicolumn{4}{|c|}{ Pastagem } \\
\hline & \multicolumn{2}{|c|}{ Melhorada } & \multirow{2}{*}{$\begin{array}{c}\text { Moderadamente } \\
\text { degradada }\end{array}$} & \multirow{2}{*}{$\begin{array}{c}\text { Severamente } \\
\text { degradada }\end{array}$} \\
\hline & Input médio de insumo & $\begin{array}{c}\text { Input alto de } \\
\text { insumo }\end{array}$ & & \\
\hline $\mathrm{S} 3 \mathrm{~V} 1$ & 5,721034443 & 6,349758694 & 4,742768885 & 3,42 \\
\hline $\mathrm{S} 3 \mathrm{~V} 2$ & 5,485784257 & 6,089220525 & 4,547784257 & 3,28 \\
\hline $\mathrm{S} 3 \mathrm{~V} 3$ & 4,988035323 & 5,536719208 & 4,139777222 & 3 \\
\hline S3V4 & 4,665251914 & 5,178429625 & 3,456524439 & 2,8 \\
\hline S3V5 & 4,356721587 & 4,835960962 & 3,61223642 & 2,62 \\
\hline S3V6 & 6,536722969 & 7,255762496 & 1,990543399 & 3,98 \\
\hline S3V7 & 5,95446564 & 6,60945686 & 4,95004376 & 3,61 \\
\hline S3V8 & 4,454826279 & 4,944857169 & 3,692826279 & 2,67 \\
\hline S3V9 & 4,203970566 & 4,666407328 & 3,484364243 & 2,52 \\
\hline S3V10 & 7,157599426 & 7,944935362 & 5,93453295 & 4,28 \\
\hline S3V11 & 3,063808744 & 3,400827706 & 2,539808744 & 1,83 \\
\hline S3V12 & 4,1184 & 4,571424 & 3,4144 & 2,46 \\
\hline S3V13 & 4,639370246 & 5,149700973 & 3,844121513 & 2,79 \\
\hline S3V14 & 3,870254166 & 4,295982124 & 3,209069444 & 2,32 \\
\hline S3V15 & 5,6277 & 6,246747 & 4,6657 & 3,37 \\
\hline S4V1 & 4,8087 & 5,337657 & 3,9867 & 2,88 \\
\hline S4V2 & 5,919883305 & 6,571070469 & 4,907883305 & 3,54 \\
\hline $\mathrm{S} 4 \mathrm{~V} 3$ & 7,399414765 & 8,213350389 & 6,135643177 & 4,43 \\
\hline S4V4 & 3,0303 & 3,363633 & 2,5123 & 1,81 \\
\hline S4V5 & 3,159 & 3,50649 & 2,619 & 1,89 \\
\hline S4V6 & - & - & - & - \\
\hline S4V7 & - & - & - & - \\
\hline S4V8 & 5,1129 & 5,675319 & 4,2389 & 3,06 \\
\hline S4V9 & 2,246313984 & 2,493408522 & 1,862313984 & 1,34 \\
\hline S4V10 & - & - & - & - \\
\hline S4V11 & 1,7667 & 1,961037 & 1,4647 & 1,06 \\
\hline S4V12 & - & - & - & - \\
\hline S4V13 & - & - & - & - \\
\hline S4V14 & 5,849869926 & 4,295982124 & 4,852813028 & 3,51 \\
\hline S4V15 & 7,217957418 & 8,011932734 & 5,983957418 & 4,32 \\
\hline
\end{tabular}


Tabela 14: Valores de COS para pastagem (Continuação).

\begin{tabular}{|c|c|c|c|c|}
\hline \multirow{3}{*}{ SVA } & \multicolumn{4}{|c|}{ Pastagem } \\
\hline & \multicolumn{2}{|c|}{ Melhorada } & \multirow{2}{*}{$\begin{array}{c}\text { Moderadamente } \\
\text { degradada }\end{array}$} & \multirow{2}{*}{$\begin{array}{c}\text { Severamente } \\
\text { degradada }\end{array}$} \\
\hline & Input médio de insumo & $\begin{array}{c}\text { Input alto de } \\
\text { insumo }\end{array}$ & & \\
\hline S5V1 & 5,1012 & 5,662332 & 4,2292 & 3,05 \\
\hline S5V2 & 6,1659 & 6,844149 & 5,1119 & 3,69 \\
\hline S5V3 & 4,18775425 & 4,648407217 & 3,47175425 & 2,51 \\
\hline S5V4 & 3,8259 & 4,246749 & 3,1719 & 1,81 \\
\hline S5V5 & 6,2712 & 6,961032 & 5,1992 & 3,75 \\
\hline S5V6 & - & - & - & - \\
\hline S5V7 & - & - & - & - \\
\hline S5V8 & 4,0482 & 4,493502 & 3,3562 & 2,42 \\
\hline S5V9 & 7,7805 & 8,636355 & 6,4505 & 4,66 \\
\hline S5V10 & - & - & - & - \\
\hline S5V11 & 2,9367 & 3,259737 & 2,4347 & 1,46 \\
\hline S5V12 & - & - & - & - \\
\hline S5V13 & - & - & - & - \\
\hline S5V14 & 6,9264 & 7,688304 & 5,7424 & 4,14 \\
\hline S5V15 & 10,5885 & 11,753235 & 8,7785 & 6,34 \\
\hline S6V1 & - & - & - & - \\
\hline S6V2 & 5,6277 & 6,246747 & 4,6657 & 3,37 \\
\hline S6V3 & 48,8826 & 54,259686 & 40,5266 & 29,25 \\
\hline S6V4 & 3,7206 & 4,129866 & 3,0846 & 2,23 \\
\hline S6V5 & 3,6972 & 4,103892 & 3,0652 & 2,21 \\
\hline S6V6 & - & - & - & - \\
\hline S6V7 & 3,822392941 & 4,242856165 & 3,171461961 & 2,3 \\
\hline S6V8 & 3,393 & 3,76623 & 2,813 & 2,03 \\
\hline S6V9 & 3,8493 & 4,272723 & 3,1913 & 2,3 \\
\hline S6V10 & - & - & - & - \\
\hline S6V11 & 2,4453 & 2,714283 & 2,0273 & 1,46 \\
\hline S6V12 & 2,5389 & 2,818179 & 2,1049 & 1,52 \\
\hline S6V13 & - & - & - & - \\
\hline S6V14 & 4,333452626 & 4,810132415 & 3,595768417 & 2,6 \\
\hline S6V15 & - & - & - & - \\
\hline
\end{tabular}


Tabela 15: Valores de COS para a situação de referência, por estados.

\begin{tabular}{|c|c|}
\hline Estado / Região & \multirow[t]{2}{*}{$\mathrm{COS}_{\mathrm{PNV}}$ por estados } \\
\hline Região norte & \\
\hline Acre & 48,80 \\
\hline Amapá & 48,90 \\
\hline Amazonas & 47,80 \\
\hline Pará & 46,10 \\
\hline Rondônia & 45,30 \\
\hline Roraima & 46,00 \\
\hline Tocantins & 40,50 \\
\hline \multicolumn{2}{|l|}{ Região nordeste } \\
\hline Alagoas & 35,80 \\
\hline Bahia & 32,80 \\
\hline Ceará & 24,70 \\
\hline Maranhão & 39,10 \\
\hline Paraíba & 25,40 \\
\hline Pernambuco & 26,60 \\
\hline Piauí & 28,50 \\
\hline Rio Grande do Norte & 24,40 \\
\hline Sergipe & 29,30 \\
\hline \multicolumn{2}{|l|}{ Região Centro-Oeste } \\
\hline Distrito Federal & 41,30 \\
\hline Goiás & 41,1 \\
\hline Mato Grosso & 42,8 \\
\hline Mato Grosso do Sul & 35,9 \\
\hline \multicolumn{2}{|l|}{ Região sudeste } \\
\hline Espirito Santo & 47,4 \\
\hline Minas Gerais & 38,9 \\
\hline Rio de Janeiro & 53,5 \\
\hline São Paulo & 40,3 \\
\hline \multicolumn{2}{|l|}{ Região sul } \\
\hline Paraná & 58,3 \\
\hline Rio Grande do Sul & 61 \\
\hline Santa Catarina & 63,9 \\
\hline
\end{tabular}

Fonte: Bernoux et al. (2001) 
Tabela 16: Valores calculados para COS de culturas anuais, por estados.

\begin{tabular}{|c|c|c|c|c|c|c|c|c|c|c|c|c|}
\hline \multirow{3}{*}{$\begin{array}{c}\text { Estado / Região } \\
\text { Região norte }\end{array}$} & \multicolumn{12}{|c|}{ Culturas anuais } \\
\hline & \multicolumn{4}{|c|}{ Preparo convencional } & \multicolumn{4}{|c|}{ Preparo reduzido } & \multicolumn{4}{|c|}{ Plantio direto } \\
\hline & B & M & AS & $\mathrm{AC}$ & B & M & AS & $\mathrm{AC}$ & B & M & AS & $\mathrm{AC}$ \\
\hline Acre & 21,55 & 23,42 & 26,00 & 33,73 & 24,78 & 26,94 & 29,90 & 38,79 & 26,29 & 28,58 & 31,72 & 41,15 \\
\hline Amapá & 21,59 & 23,47 & 26,05 & 33,80 & 24,83 & 26,99 & 29,96 & 38,87 & 26,34 & 28,64 & 31,79 & 41,24 \\
\hline Amazonas & 21,11 & 22,94 & 25,47 & 33,04 & 24,27 & 26,39 & 29,29 & 38,00 & 25,75 & 27,99 & 31,07 & 40,31 \\
\hline Pará & 20,36 & 22,13 & 24,56 & 31,86 & 23,41 & 25,45 & 28,25 & 36,64 & 24,84 & 27,00 & 29,97 & 38,87 \\
\hline Rondônia & 20,00 & 21,74 & 24,14 & 31,31 & 23,01 & 25,01 & 27,76 & 36,01 & 24,41 & 26,53 & 29,45 & 38,20 \\
\hline Roraima & 20,31 & 22,08 & 24,51 & 31,80 & 23,36 & 25,39 & 28,19 & 36,56 & 24,78 & 26,94 & 29,90 & 38,79 \\
\hline Tocantins & 17,88 & 19,44 & 21,58 & 27,99 & 20,57 & 22,36 & 24,82 & 32,19 & 21,82 & 23,72 & 26,33 & 34,15 \\
\hline \multicolumn{13}{|l|}{ Região nordeste } \\
\hline Alagoas & 19,73 & 20,76 & 21,59 & 28,45 & 21,50 & 22,63 & 23,54 & 31,01 & 23,08 & 24,29 & 25,27 & 33,28 \\
\hline Bahia & 18,07 & 19,02 & 19,78 & 26,06 & 19,70 & 20,74 & 21,57 & 28,41 & 21,15 & 22,26 & 23,15 & 30,49 \\
\hline Ceará & 13,61 & 14,33 & 14,90 & 19,63 & 14,83 & 15,62 & 16,24 & 21,39 & 15,92 & 16,76 & 17,43 & 22,96 \\
\hline Maranhão & 17,27 & 18,77 & 20,83 & 27,03 & 19,86 & 21,58 & 23,96 & 31,08 & 21,07 & 22,90 & 25,42 & 32,97 \\
\hline Paraíba & 14,00 & 14,73 & 15,32 & 20,18 & 15,25 & 16,06 & 16,70 & 22,00 & 16,37 & 17,24 & 17,93 & 23,61 \\
\hline Pernambuco & 14,66 & 15,43 & 16,05 & 21,14 & 15,98 & 16,82 & 17,49 & 23,04 & 17,15 & 18,05 & 18,77 & 24,73 \\
\hline Piauí & 15,70 & 16,53 & 17,19 & 22,65 & 17,12 & 18,02 & 18,74 & 24,68 & 18,37 & 19,34 & 20,11 & 26,50 \\
\hline $\begin{array}{c}\text { Rio Grande do } \\
\text { Norte }\end{array}$ & 13,44 & 14,15 & 14,72 & 19,39 & 14,65 & 15,43 & 16,04 & 21,13 & 15,73 & 16,56 & 17,22 & 22,68 \\
\hline Sergipe & 16,14 & 16,99 & 17,67 & 23,28 & 17,60 & 18,52 & 19,26 & 25,38 & 18,89 & 19,88 & 20,68 & 27,24 \\
\hline \multicolumn{13}{|c|}{ Região Centro-Oeste } \\
\hline Distrito Federal & 18,24 & 19,82 & 22,00 & 28,55 & 20,97 & 22,80 & 25,31 & 32,83 & 22,25 & 24,19 & 26,85 & 34,83 \\
\hline Goiás & 18,15 & 19,73 & 21,90 & 28,41 & 20,87 & 22,69 & 25,18 & 32,67 & 22,14 & 24,07 & 26,72 & 34,66 \\
\hline Mato Grosso & 18,90 & 20,54 & 22,80 & 29,58 & 21,74 & 23,63 & 26,22 & 34,02 & 23,06 & 25,06 & 27,82 & 36,09 \\
\hline $\begin{array}{c}\text { Mato Grosso do } \\
\text { Sul }\end{array}$ & 15,85 & 17,23 & 19,13 & 24,81 & 18,23 & 19,82 & 22,00 & 28,54 & 19,34 & 21,02 & 23,34 & 30,27 \\
\hline \multicolumn{13}{|l|}{ Região sudeste } \\
\hline Espirito Santo & 20,93 & 22,75 & 25,25 & 32,76 & 24,07 & 26,16 & 29,04 & 37,68 & 25,54 & 27,76 & 30,81 & 39,97 \\
\hline Minas Gerais & 21,43 & 22,56 & 23,46 & 30,91 & 23,36 & 24,59 & 25,58 & 33,69 & 25,08 & 26,40 & 27,45 & 36,16 \\
\hline Rio de Janeiro & 29,48 & 31,03 & 32,27 & 42,51 & 32,13 & 33,82 & 35,18 & 46,34 & 34,49 & 36,31 & 37,76 & 49,74 \\
\hline São Paulo & 17,80 & 19,34 & 21,47 & 27,86 & 20,47 & 22,25 & 24,69 & 32,03 & 21,71 & 23,60 & 26,20 & 33,98 \\
\hline \multicolumn{13}{|l|}{ Região sul } \\
\hline Paraná & 25,75 & 27,98 & 31,06 & 40,30 & 29,61 & 32,18 & 35,72 & 46,34 & 31,41 & 34,14 & 37,90 & 49,16 \\
\hline $\begin{array}{c}\text { Rio Grande do } \\
\text { Sul }\end{array}$ & 26,94 & 29,28 & 32,50 & 42,16 & 30,98 & 33,67 & 37,38 & 48,49 & 32,86 & 35,72 & 39,65 & 51,44 \\
\hline Santa Catarina & 28,22 & 30,67 & 34,05 & 44,17 & 32,45 & 35,27 & 39,15 & 50,79 & 34,43 & 37,42 & 41,54 & 53,88 \\
\hline
\end{tabular}


Tabela 17: Valores calculados de COS para culturas perenes, por estados

\begin{tabular}{|c|c|c|c|c|c|c|c|c|c|c|c|c|}
\hline \multirow{3}{*}{$\begin{array}{c}\begin{array}{c}\text { Estado / } \\
\text { Região }\end{array} \\
\begin{array}{c}\text { Região } \\
\text { norte }\end{array}\end{array}$} & \multicolumn{11}{|c|}{ Culturas perenes } & \multirow{3}{*}{ Pousio } \\
\hline & \multicolumn{3}{|c|}{ Preparo convencional } & \multicolumn{4}{|c|}{ Preparo reduzido } & \multicolumn{4}{|c|}{ Plantio direto } & \\
\hline & B & AS & $\mathrm{AC}$ & B & M & AS & $\mathrm{AC}$ & B & M & AS & $\mathrm{AC}$ & \\
\hline Acre & 44,896 & 48,8 & 54,168 & 70,272 & 51,6304 & 56,12 & 62,2932 & 80,8128 & 54,77312 & 59,536 & 66,08496 & 45,384 \\
\hline Amapá & 44,988 & 48,9 & 54,279 & 70,416 & 51,7362 & 56,235 & 62,42085 & 80,9784 & 54,88536 & 59,658 & 66,22038 & 40,098 \\
\hline Amazonas & 43,976 & 47,8 & 53,058 & 68,832 & 50,5724 & 54,97 & 61,0167 & 79,1568 & 53,65072 & 58,316 & 64,73076 & 44,454 \\
\hline Pará & 42,412 & 46,1 & 51,171 & 66,384 & 48,7738 & 53,015 & 58,84665 & 76,3416 & 51,74264 & 56,242 & 62,42862 & 42,873 \\
\hline Rondônia & 41,676 & 45,3 & 50,283 & 65,232 & 47,9274 & 52,095 & 57,82545 & 75,0168 & 50,84472 & 55,266 & 61,34526 & 42,129 \\
\hline Roraima & 42,32 & 46 & 51,06 & 66,24 & 48,668 & 52,9 & 58,719 & 76,176 & 51,6304 & 56,12 & 62,2932 & 42,78 \\
\hline Tocantins & 37,26 & 40,5 & 44,955 & 58,32 & 42,849 & 46,575 & 51,69825 & 67,068 & 45,4572 & 49,41 & 54,8451 & 37,665 \\
\hline \multicolumn{13}{|c|}{ Região nordeste } \\
\hline Alagoas & 34,01 & 35,8 & 37,232 & 51,552 & 37,0709 & 39,022 & 40,58288 & 53,46014 & 39,7917 & 41,886 & 43,56144 & 33,294 \\
\hline Bahia & 31,16 & 32,8 & 34,112 & 47,232 & 33,9644 & 35,752 & 37,18208 & 48,98024 & 36,4572 & 38,376 & 39,91104 & 30,504 \\
\hline Ceará & 23,465 & 24,7 & 25,688 & 35,568 & 25,57685 & 26,923 & 27,99992 & 36,88451 & 27,45405 & 28,899 & 30,05496 & 22,971 \\
\hline Maranhão & 35,972 & 39,1 & 43,401 & 56,304 & 41,3678 & 44,965 & 49,91115 & 64,7496 & 43,88584 & 47,702 & 52,94922 & 36,363 \\
\hline Paraíba & 24,13 & 25,4 & 26,416 & 36,576 & 26,3017 & 27,686 & 28,79344 & 37,92982 & 28,2321 & 29,718 & 30,90672 & 23,622 \\
\hline Pernambuco & 25,27 & 26,6 & 27,664 & 38,304 & 27,5443 & 28,994 & 30,15376 & 39,72178 & 29,5659 & 31,122 & 32,36688 & 24,738 \\
\hline Piauí & 27,075 & 28,5 & 29,64 & 41,04 & 29,51175 & 31,065 & 32,3076 & 42,55905 & 31,67775 & 33,345 & 34,6788 & 26,505 \\
\hline $\begin{array}{l}\text { Rio Grande } \\
\text { do Norte }\end{array}$ & 23,18 & 24,4 & 25,376 & 35,136 & 25,2662 & 26,596 & 27,65984 & 36,43652 & 27,1206 & 28,548 & 29,68992 & 22,692 \\
\hline Sergipe & 27,835 & 29,3 & 30,472 & 42,192 & 30,34015 & 31,937 & 33,21448 & 43,75369 & 32,56695 & 34,281 & 35,65224 & 27,249 \\
\hline \multicolumn{13}{|c|}{ Região Centro-Oeste } \\
\hline $\begin{array}{l}\text { Distrito } \\
\text { Federal }\end{array}$ & 37,996 & 41,3 & 45,843 & 59,472 & 43,6954 & 47,495 & 52,71945 & 68,3928 & 46,35512 & 50,386 & 55,92846 & 38,409 \\
\hline Goiás & 37,812 & 41,1 & 45,621 & 59,184 & 43,4838 & 47,265 & 52,46415 & 68,0616 & 46,13064 & 50,142 & 55,65762 & 38,223 \\
\hline $\begin{array}{c}\text { Mato } \\
\text { Grosso }\end{array}$ & 39,376 & 42,8 & 47,508 & 61,632 & 45,2824 & 49,22 & 54,6342 & 70,8768 & 48,03872 & 52,216 & 57,95976 & 39,804 \\
\hline $\begin{array}{c}\text { Mato } \\
\text { Grosso do } \\
\text { Sul }\end{array}$ & 33,028 & 35,9 & 39,849 & 51,696 & 37,9822 & 41,285 & 45,82635 & 59,4504 & 40,29416 & 43,798 & 48,61578 & 33,387 \\
\hline \multicolumn{13}{|c|}{ Região sudeste } \\
\hline $\begin{array}{c}\text { Espirito } \\
\text { Santo }\end{array}$ & 43,608 & 47,4 & 52,614 & 68,256 & 50,1492 & 54,51 & 60,5061 & 78,4944 & 53,20176 & 57,828 & 64,18908 & 44,082 \\
\hline $\begin{array}{l}\text { Minas } \\
\text { Gerais }\end{array}$ & 36,955 & 38,9 & 40,456 & 56,016 & 40,28095 & 42,401 & 44,09704 & 58,08937 & 43,23735 & 45,513 & 47,33352 & 36,177 \\
\hline $\begin{array}{l}\text { Rio de } \\
\text { Janeiro }\end{array}$ & 50,825 & 53,5 & 55,64 & 77,04 & 55,39925 & 58,315 & 60,6476 & 79,89155 & 59,46525 & 62,595 & 65,0988 & 49,755 \\
\hline São Paulo & 37,076 & 40,3 & 44,733 & 58,032 & 42,6374 & 46,345 & 51,44295 & 66,7368 & 45,23272 & 49,166 & 54,57426 & 37,479 \\
\hline \multicolumn{13}{|l|}{ Região sul } \\
\hline Paraná & 53,636 & 58,3 & 64,713 & 83,952 & 61,6814 & 67,045 & 74,41995 & 96,5448 & 65,43592 & 71,126 & 78,94986 & 54,219 \\
\hline $\begin{array}{c}\text { Rio Grande } \\
\text { do Sul }\end{array}$ & 56,12 & 61 & 67,71 & 87,84 & 64,538 & 70,15 & 77,8665 & 101,016 & 68,4664 & 74,42 & 82,6062 & 56,73 \\
\hline $\begin{array}{c}\text { Santa } \\
\text { Catarina }\end{array}$ & 58,788 & 63,9 & 70,929 & 92,016 & 67,6062 & 73,485 & 81,56835 & 105,8184 & 71,72136 & 77,958 & 86,53338 & 59,427 \\
\hline
\end{tabular}


Tabela 18: Valores calculados para COS para pastagens, por estado.

\begin{tabular}{|c|c|c|c|c|}
\hline \multirow{3}{*}{$\begin{array}{c}\text { Estado / Região } \\
\text { Região norte }\end{array}$} & \multicolumn{4}{|c|}{ Pastagem } \\
\hline & \multicolumn{2}{|c|}{ Melhorada } & \multirow{2}{*}{$\begin{array}{c}\text { Moderadamente } \\
\text { degradada }\end{array}$} & \multirow{2}{*}{$\begin{array}{c}\text { Severamente } \\
\text { degradada }\end{array}$} \\
\hline & $\begin{array}{l}\text { Média entrada de } \\
\text { insumo }\end{array}$ & $\begin{array}{l}\text { Entrada alta de } \\
\text { insumo }\end{array}$ & & \\
\hline Acre & 57,10 & 63,38 & 48,80 & 47,34 \\
\hline Amapá & 57,21 & 63,51 & 48,90 & 47,43 \\
\hline Amazonas & 55,93 & 62,08 & 47,80 & 46,37 \\
\hline Pará & 53,94 & 59,87 & 46,10 & 44,72 \\
\hline Rondônia & 53,00 & 58,83 & 45,30 & 43,94 \\
\hline Roraima & 53,82 & 59,74 & 46,00 & 44,62 \\
\hline Tocantins & 47,39 & 52,60 & 40,50 & 39,29 \\
\hline \multicolumn{5}{|l|}{ Região nordeste } \\
\hline Alagoas & 41,89 & 46,49 & 35,80 & 34,73 \\
\hline Bahia & 38,38 & 42,60 & 32,80 & 31,82 \\
\hline Ceará & 28,90 & 32,08 & 24,70 & 23,96 \\
\hline Maranhão & 45,75 & 50,78 & 39,10 & 37,93 \\
\hline Paraíba & 29,72 & 32,99 & 25,40 & 24,64 \\
\hline Pernambuco & 31,12 & 34,55 & 26,60 & 25,80 \\
\hline Piauí & 33,35 & 37,01 & 28,50 & 27,65 \\
\hline Rio Grande do Norte & 28,55 & 31,69 & 24,40 & 23,67 \\
\hline Sergipe & 34,28 & 38,05 & 29,30 & 28,42 \\
\hline \multicolumn{5}{|l|}{ Região Centro-Oeste } \\
\hline Distrito Federal & 48,32 & 53,64 & 41,30 & 40,06 \\
\hline Goiás & 48,09 & 53,38 & 41,10 & 39,87 \\
\hline Mato Grosso & 50,08 & 55,58 & 42,80 & 41,52 \\
\hline Mato Grosso do Sul & 42,00 & 46,62 & 35,90 & 34,82 \\
\hline \multicolumn{5}{|l|}{ Região sudeste } \\
\hline Espirito Santo & 55,46 & 61,56 & 47,40 & 45,98 \\
\hline Minas Gerais & 45,51 & 50,52 & 38,90 & 37,73 \\
\hline Rio de Janeiro & 62,60 & 69,48 & 53,50 & 51,90 \\
\hline São Paulo & 47,15 & 52,34 & 40,30 & 39,09 \\
\hline \multicolumn{5}{|l|}{ Região sul } \\
\hline Paraná & 68,21 & 75,71 & 58,30 & 56,55 \\
\hline Rio Grande do Sul & 71,37 & 79,22 & 61,00 & 59,17 \\
\hline Santa Catarina & 74,76 & 82,99 & 63,90 & 61,98 \\
\hline
\end{tabular}

